\title{
Otimização de sistemas de faixas adicionais em aclives de rodovias de pista simples
}

Dissertação apresentada à Escola de Engenharia de São Carlos, da Universidade de São Paulo, como parte dos requisitos para a obtenção do título de Mestre em Ciências pelo Programa de Pós-Graduação em Engenharia de Transportes. Área de concentração: Planejamento e Operação de Sistemas de Transportes.

Orientador:

Prof. Dr. José Reynaldo Anselmo Setti 
AUTORIZO A REPRODUÇÃO E DIVULGAÇÃO TOTAL OU PARCIAL DESTE TRABALHO, POR QUALQUER MEIO CONVENCIONAL OU ELETRÔNICO, PARA FINS DE ESTUDO E PESQUISA, DESDE QUE CITADA A FONTE.

Ficha catalográfica preparada pela Seção de Tratamento da Informação do Serviço de Biblioteca - EESC/USP

Lima, Francisco Arcelino Araújo
Otimizaça de sistemas de faixas adicionais em aclives
de rodovias de pista simples / Francisco Arcelino Araújo
Lima ; orientador José Reynaldo Anselmo Setti. -- São
Carlos, 2010.
Dissertação (Mestrado-Programa de Pós-Graduação em
Engenharia de Transportes e Area de Concentração em
Planejamento e Operação de Sistema de Transportes) --
Escola de Engenharia de São Carlos da Universidade de São
Paulo, 2010.
1. Tráfego rodoviário - simulação. 2. Faixas
adicionais de subida. 3. Rodovias de pista simples.
4. Avaliação econômica. I. Título.


Candidato(a): Engenheiro FRANCISCO ARCELINO ARAUJO LIMA.

Dissertação defendida e julgada em 02/08/2010 perante a Comissão Julgadora:

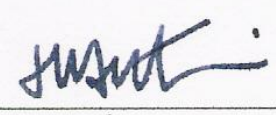

Prof. Associado JOSÉ REYNALDO ANSELMO SETTI - (Orientador)

(Escola de Engenharia de São Carlos/USP)

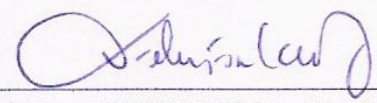

ApRoraOo

Prof. Dr. FELIPE ISSA KABACH JUNIOR

(Escola Politécnica/USP)

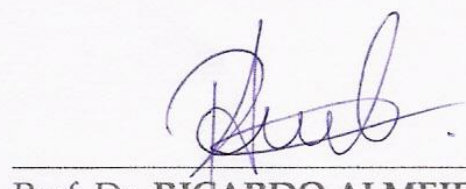

Prof. Dr. RICARDO ALMEIDA DE MELO

APROVADO

(Universidade Federal da Paraíba/UFPB)

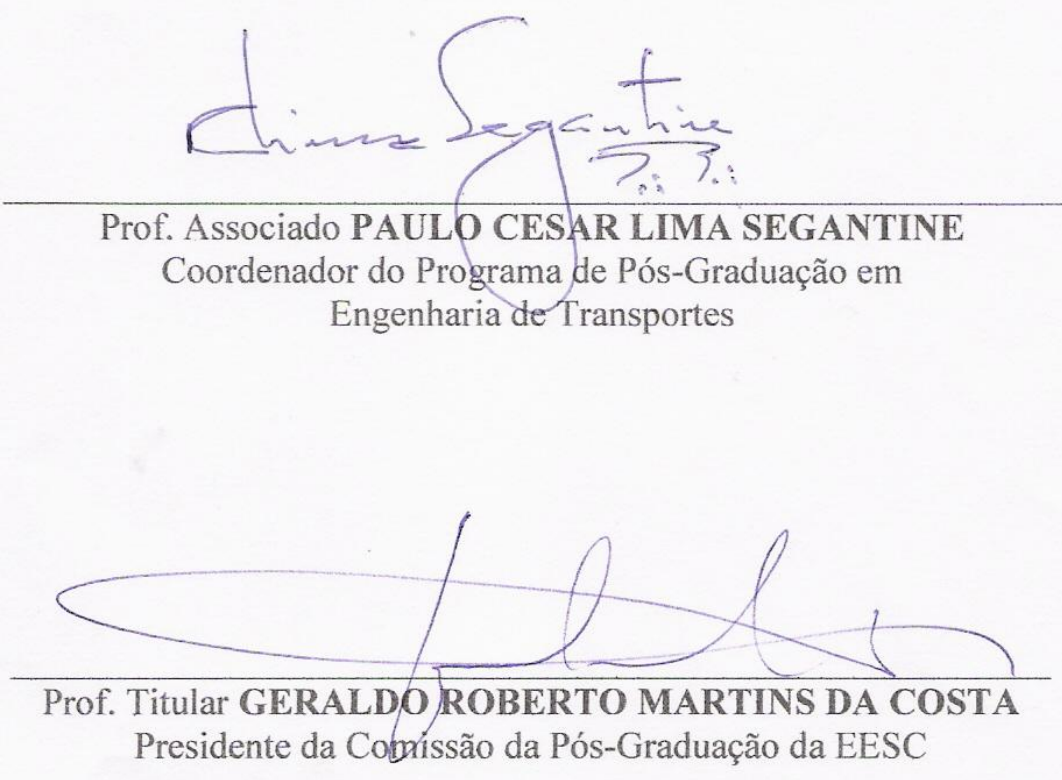


Aos meus pais, Ana e Arcelino, e aos meus irmãos, Caroline, Renata e Leo, pelo apoio e por compreenderem a minha ausência durante a realização deste trabalho.

À minha esposa, Nilra, com gratidão por sua compreensão, presença e incansável apoio ao longo do período de elaboração deste trabalho.

Dedico. 


\section{AGRADECIMENTOS}

Ao professor e orientador José Reynaldo Setti, pelos ensinamentos e compromisso em contribuir com esta pesquisa, dedicando-se inclusive à noite e nos finais de semana. Muito obrigado pelo seu apoio.

À CAPES, pela bolsa de estudos concedida.

Ao professor Felipe Loureiro, por me motivar a cursar a Pós-Graduação em São Carlos e pela confiança depositada ao me indicar para o Programa.

Ao casal Sofia e José Elievam, pelo apoio e companheirismo antes, durante e após a minha estadia em São Carlos. Serei eternamente grato a vocês.

Aos amigos do grupo de pesquisa, André Cunha e Diogo Colella, pela amizade e saudável convivência. Muito obrigado pela ajuda na coleta de dados.

A todos os professores e funcionários do Departamento de Transportes da EESC-USP, em especial à Heloísa, Beth e Toco, pelo apoio e suporte no desenvolvimento deste trabalho.

Agradeço também aos demais amigos e colegas de departamento, que de alguma forma ou outra, acabaram dividindo os bons e maus momentos vividos ao longo da minha pósgraduação. 


\section{RESUMO}

LIMA, F. A. A. Otimização de sistemas de faixas adicionais em aclives de rodovias de pista simples. 2010. 165p. Dissertação (Mestrado) - Escola de Engenharia de São Carlos, Universidade de São Paulo, São Carlos, 2010.

O objetivo desta pesquisa foi propor um método capaz de estabelecer a sequência de implantação de um conjunto de faixas adicionais que maximize os benefícios do investimento nos aclives das rodovias de pista simples. O método proposto consiste em: $(i)$ definir os aclives mais longos que o comprimento crítico; (ii) definir os aclives que satisfazem os critérios técnico-econômicos para implantação das faixas adicionais no horizonte de projeto; (iii) determinar as faixas adicionais que devem ser implantadas a cada ano do projeto, em função do crescimento do tráfego; e (iv) determinar a sequência ótima para implantação das faixas, em função do benefício global e do valor disponível para investimento a cada ano. Dentre os critérios técnicos que indicam a necessidade de faixa adicional, optou-se por utilizar a adaptação das diretrizes da AASHTO para as condições das rodovias brasileiras proposta por Melo e Setti (2003). Para quantificar os benefícios proporcionados pelas reduções dos custos operacionais e dos tempos de viagem, optou-se por utilizar modelos desenvolvidos por pesquisas nacionais; para quantificar os benefícios da redução dos acidentes, foi utilizado o modelo do HDM-4. Custos típicos de construção por quilômetro de faixa adicional (serviços de terraplenagem, pavimentação, drenagem e sinalização) foram obtidos da tabela do DERSP. Um estudo de caso demonstrou que a sequência de implantação estabelecida pelo método proposto é mais eficiente, pelos pontos de vista econômico e social, do que a sequência determinada usando-se os critérios atuais.

PALAVRAS-CHAVE: Faixas adicionais de subida; Rodovias de pista simples; Avaliação econômica; Simulação de tráfego. 


\section{ABSTRACT}

LIMA, F. A. A. Optimization of climbing lanes system on two-lane highways. 2010. 165p. Dissertação (Mestrado) - Escola de Engenharia de São Carlos, Universidade de São Paulo, São Carlos, 2010.

The objective of this research was to propose a methodology able to establish the sequence of deployment that would maximize the benefits from climbing lanes on two-lane highways. The proposed method consists of: ( $i$ ) find the set of grades that are longer than the critical length; (ii) choose, among these grades, those that satisfy the technical and economic criteria to warrant the construction of climbing lanes within the project service life; (iii) find which climbing lanes should be built in each year, given the traffic growth forecast; and (iv) find the best construction sequence, considering the global benefits from the climbing lanes and the annual budget. The criteria to justify climbing lanes adopted are the adaptation to Brazil of the AASHTO criteria proposed by Melo and Setti (2003). The quantification of benefits from the reduction of vehicle operating costs and travel time uses several models proposed in the literature in Portuguese; HDM-4 models were used to quantify the benefits from the reduction in accident number and severity. Typical construction costs for climbing lanes (including earth-moving, paving, drainage and signage) were derived from data published by DER-SP. A case study demonstrated that the application of the proposed method results in a more efficient use of the available resources (both from the economic and social viewpoints) than the results obtained by the use of the current criteria.

KEY WORDS: Climbing lanes; Two-lane highways; Economic evaluation; Traffic simulation. 


\section{SUMÁRIO}

1.1. JUSTIFICATIVA

1.2. META E OBJETIVOS

1.3. ESTRUTURA DO TEXTO

2.1. PELOTÕES E OS NÍVEIS DE SERVIÇO

2.2. PROCESSO DE FORMAÇÃ̃O DOS PELOTÕES

2.3. DISPERSÃO DOS PELOTÕES

2.3.1. Extensão ideal das faixas adicionais

2.4. ESPAÇAMENTO ENTRE FAIXAS ADICIONAIS E RECOMPOSIÇÃO DOS PELOTÕES

2.5. CRITÉRIOS PARA IMPLANTAÇÃO DAS FAIXAS ADICIONAIS EM ACLIVES

2.5.1. AASHTO

2.5.2. MTO

2.5.3. ATU

2.5.4. IMT

2.5.5. DNER

2.5.6. Kabbach Júnior

2.5.7. Melo

2.5.8. Outros estudos

2.6. ANÁLISE ECONÔMICA DE PROJETOS

2.6.1. Relações benefício-custo $\quad 30$

2.6.2. Relações benefício-custo incremental 31

2.6.3. Valor presente líquido (VPL) 32

2.7. SIMULAÇÃO DE TRÁFEGO EM RODOVIAS DE PISTA SIMPLES

2.7.1. TWOPAS 34

3.1. ETAPAS PARA DEFINIR A SEQUÊNCIA DE CONSTRUÇÃO DE FAIXAS ADICIONAIS

3.1.1. Rampas candidatas à implantação de faixa adicional

3.1.2. Obtenção do conjunto de faixas adicionais que devem ser implantadas 38

3.1.3. Obtenção da sequência ideal para construção das faixas adicionais 40

3.2. SELEÇÃO E COLETA DOS DADOS DE ENTRADA 42 
4.1. REDUÇÃO DOS CUSTOS OPERACIONAIS 46

4.1.1. Estimativas de redução de custos operacionais pelo HDM-4 46

4.1.2. Estimativas de redução de custos operacionais pelo ESTRADA 49

4.1.3. Estimativas de redução de custos operacionais pelos modelos nacionais $\quad 50$

4.2. REDUÇÃO DOS TEMPOS DE VIAGEM

4.2.1. Estimativas de redução dos tempos de viagem pelo HDM-4 54

4.2.2. Estimativas de redução dos tempos de viagem pelo ESTRADA 55

4.2.3. Estimativas de redução dos tempos de viagem pelos modelos nacionais $\quad 56$

4.3. REDUÇÃO DOS ACIDENTES

4.3.1. Estimativas de redução do número de acidentes pelo ESTRADA 58

4.3.2. Estimativas de redução do número de acidentes pelos modelos nacionais $\quad 59$

4.3.3. Estimativas de redução do número de acidentes pelo HDM -4 61

4.4. MÉTODOS DE CÁLCULO SELECIONADOS PARA APLICAÇÃO NA PRESENTE PESQUISA $\quad 62$

4.4.1. Considerações para o cálculo do benefício da redução do custo operacional (BRCO) 62

4.4.2. Considerações para o cálculo do benefício da redução do tempo de viagem (BRTV) 65

4.4.3. Considerações para o cálculo do benefício da redução dos acidentes (BRACID) 67

\section{CÁLCULO DOS CUSTOS}

5.1. CUSTOS DE CONSTRUÇÃO DAS OBRAS DE MELHORIA EM RODOVIAS 71

5.1.1. Estimativas dos custos de construção pelo HDM-4 71

5.1.2. Estimativas dos custos de construção pelo ESTRADA $\quad 72$

5.1.3. Estimativas dos custos de construção por pesquisas nacionais $\quad 74$

5.2. CUSTOS DA INFRAESTRUTURA VIÁRIA APÓS IMPLANTAÇÃO DAS MELHORIAS $\quad 75$

5.2.1. Estimativas dos custos de operação, conservação, manutenção e restauração pelo HDM$4 \quad 76$

5.2.2. Estimativas dos custos de operação, conservação, manutenção e restauração pelo ESTRADA

5.2.3. Estimativas dos custos de operação, conservação, manutenção e restauração pelas pesquisas nacionais

5.3. MÉTODO SELECIONADO PARA APLICAÇÃO NA PRESENTE PESQUISA 78

6.1. CARACTERÍSTICAS DO TRECHO ANALISADO

6.1.1. Alinhamento Horizontal 81

6.1.2. Alinhamento Vertical $\quad 82$

6.1.3. Características do Fluxo de Veículos 83

6.2. RESULTADOS DA RECALIBRAÇÃO 85

6.3. CURVAS DE DESEMPENHO

6.4. APLICAÇÃO DO MÉTODO PROPOSTO

6.4.1. Verificação dos aclives com redução excessiva de velocidade $\quad 88$

6.4.2. Faixas adicionais que devem ser implantadas $\quad 89$ 
6.4.3. Sequência ideal para construção das faixas adicionais 91

6.4.4. Estimativa dos benefícios ano a ano 92

6.5. BENEFÍCIOS DA REDUÇÃO DOS ACIDENTES 98

6.5.1. Primeiro modo de cálculo do BRACID 99

6.5.2. Segundo modo de cálculo do BRACID 99

6.6. PROGRAMAÇÃO DAS IMPLANTAÇÕES E EFICÁCIA DO MÉTODO 103

7. CONCLUSÕES E RECOMENDACÕES 110

7.1. CONCLUSÕES 110

7.2. RECOMENDAÇÕES 111

8. REFERÊNCIAS BIBLIOGRÁFICAS 114

APÊNDICE A - BENEFÍCIOS DA REDUCÃO DOS CUSTOS OPERACIONAIS 122

APÊNDICE B - BENEFÍCIOS DA REDUCÃ̃O DOS TEMPOS DE VIAGEM

APÊNDICE C - BENEFÍCIOS DA REDUCÃO DOS ACIDENTES 137

ANEXO A - NÚMEROS ALEATÓRIOS USADOS NA CALIBRACÃO DO TWOPAS 


\section{LISTA DE TABELAS}

Tabela 2.1 - Relação entre fluxo direcional e o tamanho ótimo de uma faixa adicional (Harwood et. al. 1998)

Tabela 2.2 - Relação volume de tráfego $\times$ espaçamento entre faixas adicionais de ultrapassagem

Tabela 2.3 - Fluxos mínimos que justificam a implantação de faixas adicionais (Melo e Setti, 2007b)

Tabela 5.1 - Características e serviços necessários para construção de um quilômetro de faixa adicional (DER/SP, 2006). 79

Tabela 6.1 - Caracterização do perfil horizontal do trecho 82

Tabela 6.2 - Estaqueamento do perfil vertical do trecho 83

Tabela 6.3 - Parâmetros de tráfego por hora de coleta (sentido ascendente) 84

Tabela 6.4 - Parâmetros de tráfego por hora de coleta (sentido descendente) 84

Tabela 6.5 - Divisão por categoria do volume de caminhões 85

Tabela 6.6 - Parâmetros comportamentais dos motoristas 86

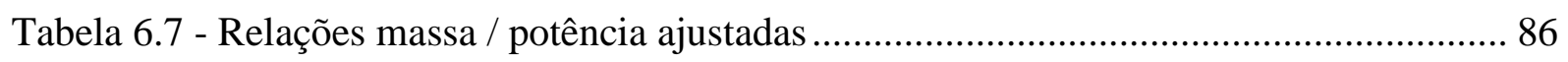

Tabela 6.8 - Velocidades médias desejadas por direção e tipo de veículo .............................. 86

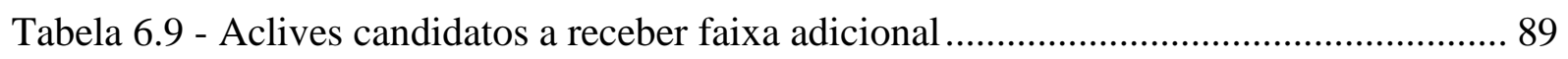

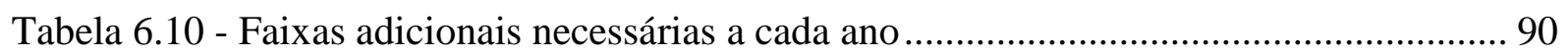

Tabela 6.11 - Valores utilizados para calcular CHu e R .................................................. 92

Tabela 6.12 - Conjuntos de faixas adicionais analisados no $1^{\circ}$ ano...................................... 93

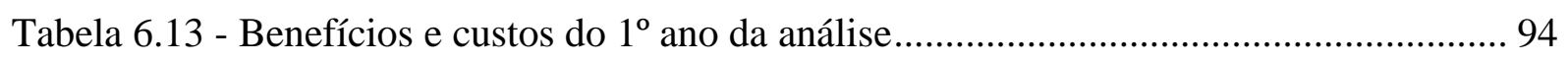

Tabela 6.14 - Conjuntos de faixas adicionais analisados no $2^{\circ}$ ano...................................... 95

Tabela 6.15 - Benefícios e custos do $2^{\circ}$ ano da análise ......................................................... 96

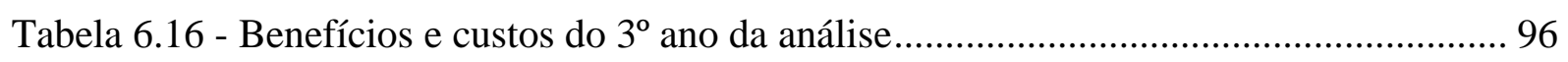

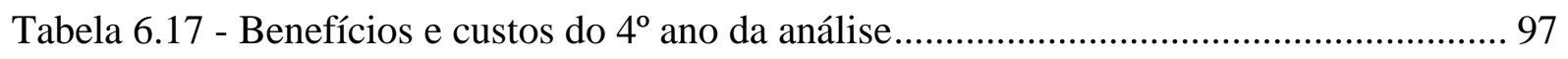

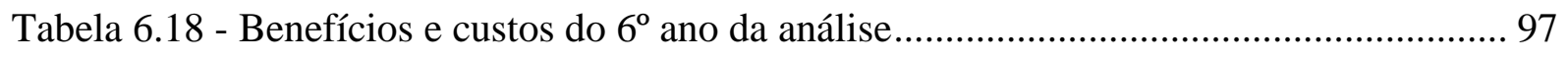

Tabela 6.19 - Programação de implantação das faixas adicionais .......................................... 98

Tabela 6.20 - Benefícios da redução de acidentes $\left(1^{\circ}\right.$ Modo $)$................................................ 101

Tabela 6.21 - Benefícios da redução de acidentes ( $2^{\circ}$ Modo) ............................................. 102

Tabela 6.22 - Benefício/custo incremental dos conjuntos de faixas adicionais ..................... 103 
Tabela 6.23 - Valores utilizados para mensurar os Níveis de Serviço ao longo do horizonte de projeto

Tabela 6.24 - Custos gerados pelo comparativo entre as alternativas1 e 0 106

Tabela 6.25 - Custos gerados pelo comparativo entre as alternativas 2 e 0 107

Tabela 6.26 - Somatório dos custos de implantação de ambos os comparativos para taxas de juros de 1 a $9 \%$ 108

Tabela A.1 - Composição dos benefícios da redução dos custos operacionais do 1o ano da análise

Tabela A.2 - Composição dos benefícios da redução dos custos operacionais (BRCO) do 2o ano da análise

Tabela A.3 - Composição dos benefícios da redução dos custos operacionais (BRCO) do $3^{\circ}$ ano da análise

Tabela A.4 - Composição dos benefícios da redução dos custos operacionais (BRCO) do $4^{\circ}$ ano da análise

Tabela A.5 - Composição dos benefícios da redução dos custos operacionais (BRCO) do 6o ano da análise

Tabela B.1 - Composição dos benefícios da redução dos tempos de viagem do $1^{\circ}$ ano da análise

Tabela B.2 - Composição dos benefícios da redução dos tempos de viagem do 20 ano da análise

Tabela B.2 - Composição dos benefícios da redução dos tempos de viagem do 20 ano da análise

Tabela B.3 - Composição dos benefícios da redução dos tempos de viagem do $3^{\circ}$ ano da análise

Tabela B.4 - Composição dos benefícios da redução dos tempos de viagem do $4^{\circ}$ ano da análise 135

Tabela B.5 - Composição dos benefícios da redução dos tempos de viagem do $6^{\circ}$ ano da análise

Tabela C.1 - Composição dos benefícios das reduções de acidentes $\left(1^{\circ}\right.$ modo $)$ 137

Tabela C. 2 - Composição dos benefícios das reduções de acidentes ( $2^{\circ}$ modo) 140

Tabela BB.1 - Conjunto de números aleatórios usados na calibração do TWOPAS 143 
Tabela AA.1 - Composição de custos operacionais para carros populares (Economia e Transporte, 2007) ........................................................................... 144

Tabela AA.2 - Composição de custos operacionais para ônibus rodoviários (Economia e Transporte, 2007) .......................................................................... 144

Tabela AA.3 - Composição de custos operacionais para caminhões semi-pesado (Economia e

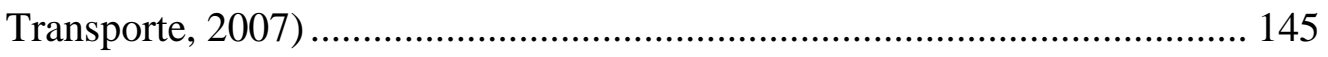




\section{LISTA DE FIGURAS}

Figura 2.1 - Curvas de oferta e demanda por oportunidades de ultrapassagens em rodovias de

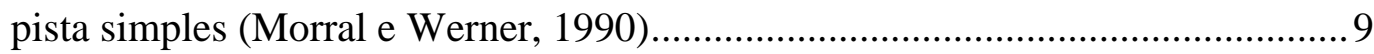

Figura 2.2 - Comprimento real e efetivo das faixas adicionais (Morral, 1986) 16

Figura 2.3 - Porcentagem de veículos em pelotões $\times$ fluxo direcional na faixa adicional (MonMa, 2002)

Figura 2.4 - Comprimento crítico do aclive para caminhões com $120 \mathrm{~kg} / \mathrm{kW}$ e velocidade de entrada de $110 \mathrm{~km} / \mathrm{h}$ (AASHTO, 2001) 19

Figura 3.1 - Resumo do método proposto 35

Figura 3.2 - Obtenção do conjunto de rampas candidatas a receber faixas adicionais. 37

Figura 3.3 - Processo para obtenção do conjunto de faixas que devem ser implantadas no trecho.

Figura 3.4 - Obtenção da sequência ideal de implantação das faixas adicionais 41

Figura 4.1 - Custo Operacional total (euro/100.veíc.km) (Macário et al. 2007)

Figura 4.2 - Relação de custos operacionais unitários para veículos de passeio em função da velocidade e declividade da rampa.

Figura 4.3 - Relação de custos operacionais unitários para ônibus em função da velocidade e declividade da rampa

Figura 4.4 - Relação de custos operacionais unitários para caminhões vazios em função da velocidade e declividade da rampa. 52

Figura 6.1 - Perfil horizontal do trecho hipotético estudado 82

Figura 6.2 - Perfil vertical do trecho estudado 83

Figura 6.3 - Curva de desaceleração da categoria Extra-Pesado $(205 \mathrm{~kg} / \mathrm{kW})$ 87

Figura 6.4 - Curva de desaceleração da categoria Pesado $(160 \mathrm{~kg} / \mathrm{kW})$ 87

Figura 6.5 - Curva de desaceleração da categoria Médio $(143 \mathrm{~kg} / \mathrm{kW})$................................ 88

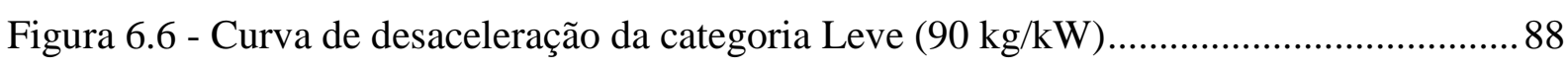

Figura 6.7 - Distribuição do tráfego numa praça de pedágio próxima ao trecho estudado .......91

Figura 6.8 - Diferença entre os somatórios dos custos dos comparativos $\times$ Taxa de juros .... 108 



\section{INTRODUÇÃO}

No Brasil a rede rodoviária pavimentada é constituída em sua maioria por rodovias de pista simples que, em 2007, eram quase $90 \%$ da extensão total da rede (CNT, 2007). É fato também que nas matrizes brasileiras do transporte de carga e de passageiros, os modos rodoviários são predominantes (GEIPOT, 2002).

Neste cenário, altos volumes de caminhões de variados pesos e dimensões são observados em rodovias brasileiras. Tendo-se em vista a redução de velocidade sofrida por estes veículos em aclives, torna-se necessário adotar medidas para mitigar os impactos dos caminhões na operação do tráfego, visando reduzir os custos dos deslocamentos.

Uma medida que tem se mostrado eficiente, principalmente pelo baixo custo de implantação, é a construção de faixas adicionais nos aclives onde ocorrem as maiores reduções de velocidade. Chamadas de faixas adicionais de subida, essas são faixas auxiliares, construídas ao lado direito da pista, no sentido do aclive, destinadas ao tráfego de veículos lentos (DNER, 1999).

Os benefícios proporcionados pela implantação das faixas adicionais em aclives são devidos, principalmente, à redução da porcentagem de veículos viajando em pelotões, do número de acidentes e do tempo de atraso experimentado pelos usuários. Sabe-se também que esses benefícios são função do comprimento da faixa adicional, da taxa de fluxo dos veículos, da composição do tráfego e das oportunidades de ultrapassagem depois da faixa (Harwood et al. 1988).

\subsection{JUSTIFICATIVA}

Dentre as medidas consideradas para o melhoramento de rodovias de pista simples, ressaltamse o realinhamento do perfil e a duplicação da rodovia. A eficiência dessas medidas é indiscutível, porém, o principal inconveniente delas é o alto investimento necessário, que somente é justificado se o volume de tráfego for suficientemente elevado (ATU, 1999; Hoban, 1984). Em países em desenvolvimento, onde os recursos financeiros costumam ser escassos, a adoção de melhorias de baixo custo de implantação, é uma opção atraente para a manutenção do nível de serviço da malha rodoviária. 
Nesse contexto, surgem as faixas adicionais, as quais são capazes de proporcionar uma significativa melhoria nas condições operacionais e de segurança, com um pequeno investimento de capital, possibilitando que sejam implantadas em trechos com baixos volumes diários médios (Mon-Ma, 2002).

Atualmente, o principal método empregado para projetos de implantação de faixas adicionais nas rodovias nacionais é o do Manual de Projeto Geométrico de Rodovias Rurais, publicado pelo Departamento Nacional de Estradas de Rodagem (DNER, 1999). Os critérios recomendados pelo DNER (1999) baseiam-se em parâmetros utilizados em outros países, especialmente nos Estados Unidos, sem que tenham sido feitas adaptações para as condições brasileiras. Existem ainda os critérios propostos por Kabbach Jr. (1992) e Melo (2002), que são variantes dos critérios do DNER, voltados exclusivamente para recomendação de construção de faixas adicionais em específicos trechos de subida das rodovias de pista simples.

Ressalta-se, portanto, a importância de estabelecer um método para determinar a sequência construtiva de sistemas de faixas adicionais de subida, o qual propicie ao usuário desse método a certificação da viabilidade financeira da implantação desses sistemas, através da análise econômica de projetos.

\subsection{META E OBJETIVOS}

A meta principal desta pesquisa de mestrado foi propor um método capaz de estabelecer a sequência de implantação de um conjunto de faixas adicionais que maximize os benefícios do investimento nas rodovias de pista simples. Para ser efetivo, o procedimento proposto é suficientemente simples e pode ser utilizado por engenheiros e planejadores após breve treinamento.

Com intuito de atingir tal meta, os seguintes objetivos específicos foram estabelecidos:

i. Seleção dos critérios técnicos mais adequados para identificação da necessidade de faixas adicionais, a partir dos dados de tráfego e da previsão de seu crescimento;

ii. Determinação de uma função que reflita o benefício associado a cada uma das faixas; 
iii. Definição de um método para calcular os custos de implantação das faixas adicionais; e

iv. Delineação de um método para analisar a sequência de implantação das faixas adicionais que maximize os benefícios, considerando as limitações de recursos em cada etapa do investimento.

\subsection{ESTRUTURA DO TEXTO}

O texto está dividido em sete capítulos, mais as referências bibliográficas. No Capítulo 1, fazse uma breve introdução da pesquisa em desenvolvimento, além de apresentar sua meta, justificativa e estrutura.

O Capítulo 2 contém uma revisão bibliográfica sobre os pelotões e níveis de serviço das rodovias de pista simples; o processo de formação dos pelotões; o efeito das faixas adicionais na dispersão dos pelotões; o espaçamento entre faixas adicionais e a recomposição dos pelotões; critérios para implantação das faixas adicionais; a análise econômica de projetos; e simulação do tráfego em rodovias de pista simples.

No Capítulo 3 é explicado o método usado para atingir os objetivos da pesquisa. Nos Capítulos 4 e 5 estão apresentados os principais métodos disponíveis para o cálculo dos benefícios e custos das faixas adicionais, respectivamente. Optou-se por apresentar esses métodos fora da revisão bibliográfica, devido à necessidade de comentar cada um dos modelos e escolher os mais apropriados para aplicação na presente pesquisa.

No Capítulo 6 é apresentado um estudo de caso com aplicação do método aqui defendido. Finalmente, o Capítulo 7 apresenta as conclusões e recomendações. 


\section{REVISÃO BIBLIOGRÁFICA}

Este capítulo apresenta os conceitos e métodos que serviram como base para a presente pesquisa. Assim, estão aqui discutidos os principais trabalhos publicados sobre:

- Os pelotões e níveis de serviço das rodovias de pista simples;

- $\quad$ O processo de formação dos pelotões;

- O efeito das faixas adicionais na dispersão dos pelotões;

- O espaçamento entre faixas adicionais e a recomposição dos pelotões;

- Critérios para implantação das faixas adicionais;

- A análise econômica de projetos; e

- A simulação de tráfego em rodovias de pista simples.

\subsection{PELOTÕES E OS NÍVEIS DE SERVIÇO}

As rodovias de pista simples são vias sem barreira física entre as faixas de tráfego por onde trafegam fluxos de direções opostas. Nessas rodovias, para ultrapassar os veículos lentos, os motoristas que viajam mais rápido têm que utilizar a faixa do fluxo oposto quando houver uma combinação de distância de visibilidade e gap que permita a realização da manobra com segurança. Consequentemente, com o aumento do volume do fluxo de tráfego e das restrições geométricas da via, as condições favoráveis para ultrapassar diminuem, resultando na formação de pelotões na corrente de tráfego e na degradação do nível de serviço percebido pelos usuários (TRB, 2000).

Várias já foram as medidas propostas para definir o nível de serviço das rodovias de pista simples: velocidade média de viagem, tempo de atraso, porcentagem de tempo viajando em pelotões, densidade e taxa de ultrapassagem estão entre as mais comuns (Morral e Werner, 1990; Hoban, 1984; DeArazoza e McLean, 1989; Botha et al. 1994). Embora não haja um consenso sobre uma medida específica devido à complexidade do fluxo de tráfego neste tipo de rodovia, numa pesquisa realizada com os usuários do HCM para decidir a medida mais apropriada para mensurar o nível de serviço das rodovias de pista simples, elegeu-se uma combinação da porcentagem de tempo viajando em pelotões com a velocidade média de 
viagem, as quais acabaram sendo utilizadas no desenvolvimento do HCM 2000 (Harwood et al. 1999).

Para Harwood et al. (1999), a importância dessas duas medidas (porcentagem do tempo viajando em pelotões e velocidade média de viagem) se deve ao fato de que as rodovias de pista simples classificadas na Classe II, vias coletoras ou locais, são geralmente implantadas onde não se espera e nem desejam altas velocidades de operação, mas que ao mesmo tempo devem comportar um tráfego de veículos sem interrupções e atrasos. Visto que a porcentagem do tempo viajando em pelotões (PTSF) é definida como a porcentagem média do tempo de viagem na qual o veículo foi obrigado a viajar em pelotões devido à impossibilidade de realizar a ultrapassagem, esta medida representa a liberdade de manobrar, o conforto e a conveniência de viajar por esta classe das rodovias de pista simples (Morrall e Hoban, 1985). Já nas rodovias de Classe I, que são as vias arteriais, além da porcentagem do tempo viajando em pelotões, a velocidade média de viagem é utilizada para medir o nível de serviço, pois nessas são esperadas maiores velocidades de operação (Harwood et al. 1999).

No entanto, a porcentagem do tempo que os veículos viajam em pelotões não é uma medida possível de ser coletada em campo. Por isso, no Capítulo 20 do HCM 2000 são propostos procedimentos analíticos para a estimação do valor dessa medida em dois tipos de análise; análise direcional e análise nos dois sentidos. Para a análise direcional é proposto o modelo da seguinte equação:

$$
P T S F_{d}=B T S F_{d}+f_{n p}
$$

sendo: $\quad P T S F_{d}:$ porcentagem do tempo viajando em pelotões na direção analisada;

$B P T S F_{d}:$ porcentagem básica do tempo viajando em pelotões na direção analisada; $\mathrm{e}$ $f_{n p}:$ fator de ajuste para a porcentagem de zonas de ultrapassagem proibida.

São utilizados em tais procedimentos basicamente os valores da taxa de fluxo, da distribuição direcional do fluxo e da porcentagem de zonas com ultrapassagem proibida. Há também a proposta de estimar a porcentagem do tempo viajando em pelotões utilizando valores observados em campo, através da porcentagem de veículos viajando com headways inferiores a 3 segundos (TRB, 2000). 
Já para Al-Kaisy e Durbin (2007), o mais adequado seria substituir a PTSF medida em uma extensão específica de uma rodovia de pista simples por uma medida pontual na mesma rodovia, denominada percent following $(P F)$. Para estimar a $P F$, são propostos dois métodos: um método probabilístico e um método da média ponderada. Ambos têm o objetivo de estratificar os veículos que estão viajando em pelotões entre aqueles que estão no pelotão espontaneamente e os que estão "presos" no pelotão pela falta da oportunidade de ultrapassar. Os autores alegam que o surgimento da necessidade dessa estratificação aconteceu após estudos apontarem para uma superestimação das porcentagens do tempo viajando em pelotões calculadas pelos procedimentos analíticos do HCM 2000, quando comparadas com as medidas da PTSF coletadas em campo.

Luttinen (2001) ressalta que uma medida para representar o nível de serviço das rodovias de pista simples com alto grau de confiança deve refletir a percepção do usuário, ser fácil de medir, ser compatível com as medidas do nível de serviço de outros tipos de rodovia, descrever as situações saturadas e não saturadas e ser útil nas análises de segurança, econômica e ambiental. No entanto, é inviável apenas uma medida reunir todas essas características. Assim, para a definição do nível de serviço, é ressaltada a importância de pelo menos ser observada a estrutura das relações entre o fluxo, a velocidade e as medidas de desempenho que possam ser coletadas através da simples observação do tráfego em campo e que sejam adequadas para caracterizar a qualidade de serviço.

Van As (2003) testou as seguintes medidas de desempenho para medir o nível de serviço: porcentagem de veículos viajando em pelotões, fluxo de veículos em pelotões, densidade de veículos em pelotões, velocidade, porcentagem de redução da velocidade devido ao tráfego (como uma porcentagem da velocidade de fluxo livre), densidade do tráfego e atraso total dos pelotões. O autor define a densidade de veículos em pelotões como sendo o número de veículos viajando em pelotões por faixa por quilômetro de rodovia, estando os veículos em pelotões quando o headway entre eles for menor que 3,5 segundos. $\mathrm{O}$ atraso total dos pelotões é o somatório do atraso sofrido por cada veículo que está viajando em pelotão, dividido pela extensão da rodovia em quilômetros. Já a diferença entre a porcentagem de veículos viajando em pelotões e o fluxo de veículos em pelotões, é que este é a quantidade de veículos viajando em pelotões por cada hora analisada, e aquele é a fração do número total de veículos que está viajando em pelotões. 
Algumas dessas variáveis (porcentagem de veículos viajando em pelotões, velocidade e porcentagem de redução da velocidade) foram descartadas já na fase inicial do projeto, por refletirem apenas o nível de serviço experimentado por um único usuário e não por todos que estão trafegando no trecho. Nesse sentido, as variáveis mais recomendadas pelo autor para medir o nível de serviço de uma rodovia são o fluxo de veículos em pelotões e a densidade de veículos em pelotões, pois cada uma dessas tem a vantagem de agrupar três outras medidas: porcentagem de veículos viajando em pelotões, fluxo de tráfego e velocidade.

\subsection{PROCESSO DE FORMAÇÃO DOS PELOTÕES}

É necessário ressaltar que não são em todos os pelotões que os veículos viajando atrás do líder desejam fazer manobras de ultrapassagem. Em relevo plano, carros, caminhões ou utilitários, viajando em pelotões homogêneos, geralmente estão numa mesma velocidade; assim, se entre estes veículos houver headways que possibilitem sensação de segurança aos motoristas, manobras de ultrapassagem não serão necessárias.

Por outro lado, a demanda por ultrapassagens aumenta em situações nas quais os desempenhos dos veículos diferenciam-se consideravelmente, como em regiões montanhosas, onde caminhões carregados impedem o desenvolvimento da velocidade dos que estão mais rápidos, reduzindo o nível de serviço percebido pelos usuários. Também é verificado que o aumento da demanda por ultrapassagem ocorre quando os headways entre os veículos são inferiores a 3 segundos e a velocidade média da corrente de tráfego é inferior a $80 \mathrm{~km} / \mathrm{h}$ (Gattis et al. 1997). Nos pelotões liderados por veículos longos, para que seja observado o aumento da demanda por ultrapassagens, os valores dos headways mínimos suportados pelos usuários são um pouco maiores, já que o headway entre veículos é considerado entre os párachoques dianteiros de veículos sucessivos. (Sadeghhosseinni e Benekohal, 1997).

Werner e Morrall (1984) defendem o uso de um critério baseado no equilíbrio entre a demanda e a oferta da oportunidade de ultrapassagem para mensurar o nível de serviço das rodovias de pista simples, afirmando que os motoristas são mais sensíveis à falta de oportunidades de ultrapassagem do que aos atrasos sofridos no tempo de viagem, pois foi observado que, com o aumento do volume de tráfego, a taxa de ultrapassagem diminui mais rapidamente do que o aumento na porcentagem de tempo viajando em pelotões. Dessa forma, 
a medida proposta pelos autores foi a taxa de ultrapassagem, definida como o número de ultrapassagens realizadas dividido pelo número total de ultrapassagens desejadas, sendo este último o número total de ultrapassagens que ocorreriam em uma rodovia de pista simples com faixas adicionais de ultrapassagem ao longo de toda a sua extensão.

Analisando-se o modelo desenvolvido por Morrall e Werner (1990), ilustrado na Figura 2.1, percebe-se que a demanda por ultrapassagens e o tamanho dos pelotões crescem rapidamente com o aumento do volume de tráfego e que a qualidade do serviço está diretamente relacionada à diferença entre o número de ultrapassagens desejado e as ultrapassagens efetivamente realizadas. Esta abordagem, ainda que alternativa, tem como desvantagem apoiar-se em parâmetros que não podem ser medidos e nem observados diretamente numa rodovia real, como a quantidade de ultrapassagens desejadas e as efetivamente realizadas.

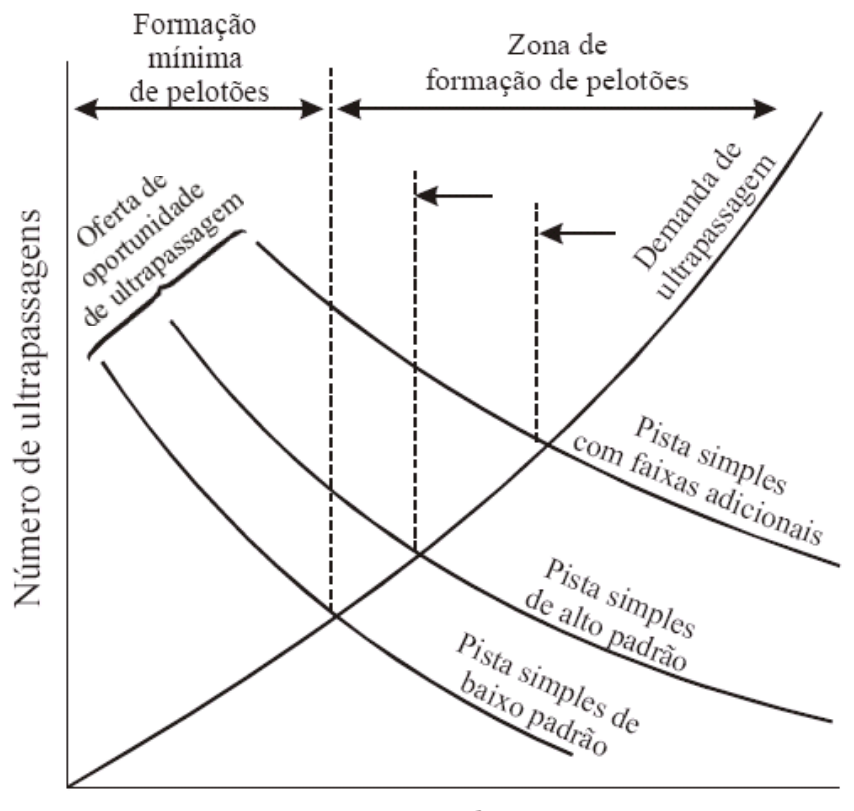

Volume

Figura 2.1 - Curvas de oferta e demanda por oportunidades de ultrapassagens em rodovias de pista simples (Morral e Werner, 1990)

\subsection{DISPERSÃO DOS PELOTÕES}

Através da Figura 2.1, pode-se concluir que a oferta de oportunidades de ultrapassagem diminui com o aumento do volume e que a demanda de ultrapassagens cresce com o aumento do volume. É correto afirmar, portanto, que a probabilidade de ocorrência de pelotões 
aumenta com o aumento do volume. Ou seja, em trechos onde há um aumento das oportunidades de ultrapassagem, como em locais com visibilidade adequada e com intervalos de gaps no fluxo oposto suficientes para a realização desse tipo de manobra, os pelotões tendem a se dispersar mais rapidamente (Gattis et al. 2006).

Dessa forma, para a dispersão dos pelotões, dentre outras medidas, têm que ser disponibilizados espaços suficientes para a realização da manobra de ultrapassagem com segurança, sendo para esses casos a solução mais adequada a construção de faixas adicionais, já que do ponto de vista econômico, em rodovias que ainda não tiveram a sua capacidade extrapolada, é quase sempre preferível fazer este tipo de melhoria nos trechos críticos do que duplicar a rodovia (Harwood e Hoban, 1987).

As faixas adicionais melhoram a qualidade de serviço da rodovia para um estágio intermediário entre as rodovias de pista simples e as de pista dupla. Elas são classificadas como faixas adicionais de subida e faixas de ultrapassagem, tanto em função da sua localização como dos motivos pelos quais foram implantadas (Mon-Ma, 2002). As faixas adicionais de subida são instaladas em aclives onde o desempenho dos veículos pesados interfere negativamente nas condições normais do tráfego. Já as faixas de ultrapassagem são implantadas em trechos menos íngremes onde a demanda por ultrapassagem é maior que a oferta de oportunidades de ultrapassagem. Ambas têm como objetivo suprir a demanda por ultrapassagem e permitir a dispersão de pelotões (Morrall e Hoban, 1985).

Portanto, para medir a eficiência das faixas adicionais no que se refere à dispersão dos pelotões, é necessário mensurar as variações proporcionadas por este tipo de melhoria na taxa de ultrapassagem e na porcentagem de veículos em pelotões (Harwood et al. 1985).

Definindo-se a taxa de ultrapassagem como sendo o número de ultrapassagens por hora, por milha em uma direção, esta medida passa a ser apropriada para medir a efetividade das faixas adicionais. Harwood et al. (1985), através de observações em campo, propuseram o modelo de regressão da Equação 2.2, pelo qual pode ser calculado que no sentido do tráfego com faixa adicional, a taxa de ultrapassagem varia de 0 a 219 ultrapassagens por hora por 1,6 km de rodovia, para um fluxo horário entre 50 e 400 veículos:

$$
P R=0,127 . F L O W-9,64 \cdot L+1,35 \cdot U P L, \text { para } 50 \text { veíc/h } \leq F L O W \leq 400 \text { veíc/h, }
$$


sendo: $\quad P R:$ taxa de ultrapassagem (ultrapassagens completas/hora/milhas);

FLOW : fluxo horário na direção do aclive (veíc/h);

$L:$ tamanho da faixa adicional (milhas); e

UPL: porcentagem de veículos em pelotões antes da faixa (\%).

Esse modelo mostra também que a taxa de ultrapassagem aumenta com o aumento do fluxo e da porcentagem de veículos em pelotões no início da faixa, mas diminui com o aumento da extensão da faixa adicional.

Já no fluxo oposto, que não dispõe de faixa adicional, foi observado que a taxa de ultrapassagem varia de 0 a 50 ultrapassagens por hora por 1,6 km de rodovia, sendo notada uma forte relação linear entre as taxas de ultrapassagem e do fluxo na direção sem a faixa adicional. $\mathrm{O}$ modelo proposto para essa relação está representado na equação:

$$
O P R=-6,97+0,13 . O F L O W, \text { para } O F L O W \geq 50 \text { veíc/h, }
$$

sendo: $\quad O P R$ : taxa de ultrapassagem na direção oposta (ultrapassagens completas/hora/milhas); e

OFLOW : fluxo horário na direção oposta (veíc/h).

Como pode ser notado, uma deficiência do modelo da Equação 2.3 é que, se o fluxo horário na direção oposta $(O F L O W)$ for menor ou igual a 53 veíc/h, a taxa de ultrapassagem na direção oposta $(O P R)$ será negativa.

Diversos estudos já se propuseram a medir a eficiência das faixas adicionais quanto à redução da porcentagem de veículos viajando em pelotões. Os mais discutidos até os dias de hoje são Messer (1983), Hoban (1984), Harwood et al. (1985), Enberg e Pursula (1997) e Morrall (1998). Com uma análise detalhada dessas pesquisas, verifica-se que as conclusões alcançadas foram diferentes, dependendo das características do fluxo de tráfego da região. Em comum, porém, permanece a conclusão de Messer (1983), de que a porcentagem de veículos em pelotões é mais sensível ao fluxo de tráfego, se comparada à velocidade média dos veículos.

Hoban (1984) realizou um estudo com o intuito de avaliar diferentes tipos de melhorias em rodovias de pista simples, utilizando o modelo de simulação TRARR e a porcentagem de 
veículos em pelotões como medida de desempenho. Nesse estudo, chegou-se a duas conclusões relevantes. Uma foi que o realinhamento do perfil (aumento da velocidade de projeto de $90 \mathrm{~km} / \mathrm{h}$ para $110 \mathrm{~km} / \mathrm{h}$ ) aparentemente não produz nenhum efeito na porcentagem de veículos em pelotões; a outra, que as faixas de ultrapassagem oferecem um nível de serviço intermediário entre as rodovias de pista simples e as rodovias de pista dupla.

Harwood et al. (1985) utilizaram os dados coletados em 12 estados norte-americanos para mostrar que as faixas de ultrapassagem reduzem a porcentagem de veículos em pelotões aproximadamente em $50 \%$, e que os efeitos destas faixas perduram por alguns quilômetros a frente, sendo esta extensão dependente das condições geométricas e das características do fluxo de tráfego. Foi observado também que essa redução na porcentagem de pelotões pode ser representada pelo modelo da Equação 2.4:

$$
\triangle P L=3,81+0,10 . U P L+3,99 . L
$$

sendo: $\quad \triangle P L:$ diferença entre a porcentagem de veículos em pelotões antes e após a faixa;

UPL: porcentagem de veículos em pelotões antes da faixa (\%); e

$L$ : tamanho da faixa adicional (milhas).

Mon-Ma (2002) verificou que, no Brasil, esse efeito das faixas adicionais de subida desaparece mais rapidamente e a porcentagem de veículos em pelotões volta ao patamar anterior muito mais depressa que nos EUA. Isso pode ser talvez explicado pela maior diferença de velocidade entre carros e caminhões no Brasil, em comparação à observada nos EUA.

No estudo de Enberg e Pursula (1997), foi feita uma comparação entre a situação antes e depois da implantação de uma terceira faixa em uma rodovia de pista simples finlandesa e foram desenvolvidos modelos a partir de dados empíricos e de simulação. Constatou-se que a maior porcentagem de veículos em pelotões ocorre imediatamente antes da faixa, havendo uma queda brusca desse valor no começo da faixa e, imediatamente antes do fim da mesma, a porcentagem de veículos em pelotões torna a crescer.

Para Morral (1998) não é aconselhável a simples utilização de técnicas de simulação para determinar o impacto de faixas de ultrapassagem na qualidade de serviço em rodovias de pista 
simples, por isso são propostos modelos matemáticos em que a porcentagem de veículos em pelotão está relacionada com a oportunidade de ultrapassagem assegurada (assured passing opportunity - APO). A variável \%APO é definida como a porcentagem de tempo que um veículo pode ultrapassar o veículo da frente com segurança, sem restrições devido à visibilidade ou ao tráfego oposto.

\subsubsection{Extensão ideal das faixas adicionais}

Várias foram as pesquisas que visaram estudar a extensão ideal de faixas adicionais, destacando-se: Morral e Hoban (1985), Morral (1986), Harwood e Hoban (1987), Harwood et al. (1988), May (1991), Khan et al. (1991), AustRoads (1993), Pursula e Siimes (1993), Mendoza e Mayoral (1994) e Gattis et al. (2006). Nessas, através de simulações e/ou observações em campo, foram verificadas as extensões que maximizam os efeitos das faixas quanto à redução da porcentagem de veículos em pelotões, quanto ao aumento da taxa de ultrapassagem, quanto à redução do atraso ou quanto a uma combinação desses efeitos.

Para Harwood et al. (1988), o tamanho ótimo de uma faixa adicional pode ser determinado através de análises custo-eficácia. A eficácia foi medida através do cálculo da diferença do tempo de atraso nos cenários com faixas adicionais e no cenário sem faixa adicional. Assim, foram encontrados tamanhos ótimos para diversos fluxos direcionais, que estão mostrados na Tabela 2.1.

Tabela 2.1 - Relação entre fluxo direcional e o tamanho ótimo de uma faixa adicional (Harwood et. al. 1998)

\begin{tabular}{lc}
\hline $\begin{array}{l}\text { Fluxo direcional } \\
\text { (veíc/h) }\end{array}$ & $\begin{array}{l}\text { Tamanho ótimo da } \\
\text { faixa adicional }(\mathrm{m})\end{array}$ \\
\hline$\leq 100$ & 800 \\
200 & $800-1200$ \\
400 & $1200-1600$ \\
700 & $1600-3200$ \\
\hline
\end{tabular}

May (1991) sugere que a eficiência das faixas adicionais depende da quantidade de oportunidades de ultrapassagem. Através de análises de sensibilidade com dados gerados pelo simulador TRARR para faixas adicionais em aclives, foi determinado que extensões entre 300 e 1200 m são mais eficientes, em termos da redução da porcentagem de atraso por metro de faixa adicional. Isso significa que, na maioria das vezes, os pelotões em aclives se dissiparam nos 1200 m iniciais da rampa, ocasionando, portanto, a redução do atraso também nessa extensão. 
Khan et al. (1991) encontraram que faixas adicionais longas têm um maior efeito na redução de pelotões do que faixas curtas. Em termos de benefícios em toda a rede (redução do tempo de viagem médio e aumento da velocidade média da corrente de tráfego), entretanto, faixas de 1000 a $2000 \mathrm{~m}$ são mais eficientes do que faixas de $3000 \mathrm{~m}$.

Em AustRoads (1993) também estão determinados tamanhos ideais de faixas adicionais. Para uma velocidade de projeto de $100 \mathrm{~km} / \mathrm{h}$, o comprimento deveria ser no mínimo de $600 \mathrm{~m}$ e no máximo de $1200 \mathrm{~m}$, sendo recomendada uma extensão de $800 \mathrm{~m}$. O estudo ressalta ainda que faixas com comprimentos menores que o mínimo devem ser usadas apenas em locais em que a velocidade de projeto é baixa, como em trechos montanhosos.

Pursula e Siimes (1993) analisaram, por simulações de tráfego, um par de faixas adicionais, em direções opostas, para verificar a influência do fluxo de tráfego em medidas como velocidade de viagem, número de ultrapassagens, porcentagem de pelotões e porcentagem do tempo viajando em pelotões. Considerando a medida de eficiência como sendo o número de ultrapassagens por quilômetro de faixa adicional, foi encontrado que essa medida depende do volume de tráfego. Comprimentos de $1000 \mathrm{~m}$ para fluxos baixos, $1500 \mathrm{~m}$ para fluxos médios e $2000 \mathrm{~m}$ para fluxos pesados foram os valores que proporcionam a maior eficiência, sendo a eficiência quase constante para faixas de comprimentos entre 1000 e 2500 m.

Mendoza e Mayoral (1994) observaram em rodovias mexicanas que faixas adicionais em aclives proporcionam consideráveis melhorias quando são maiores que $800 \mathrm{~m}$. Essa extensão possibilita oportunidades significativas para dispersar os pelotões. Foi notado que os motoristas de veículos pesados tendem a não trafegar por uma faixa adicional se ela for menor do que $800 \mathrm{~m}$, devido ao risco de não haver espaço suficiente para voltar ao fluxo no final da faixa. Os autores ressaltam que faixas maiores do que $5000 \mathrm{~m}$ também não são recomendadas por causa do decréscimo do número de ultrapassagens por metro linear de faixa.

Gattis et al. (2006) utilizou dados coletados no estado de Arkansas (EUA) para, através de análises de sensibilidade, verificar que uma redução significativa do tamanho dos pelotões ocorre nos primeiros $1500 \mathrm{~m}$ das faixas de ultrapassagem, para volumes de tráfego baixos. Para volumes elevados, foi observado que, mesmo com faixas longas, o tamanho dos pelotões não é reduzido significativamente. 


\subsection{ESPAÇAMENTO ENTRE FAIXAS ADICIONAIS E RECOMPOSIÇÃO DOS PELOTÕES}

Como visto anteriormente, em uma via com tráfego moderado, as características operacionais oscilam entre a formação de pelotões e a disponibilização de gaps para a realização de manobras de ultrapassagem. Se a oferta de gaps é maior do que a demanda, os pelotões tendem a se dispersar. Quando a demanda por ultrapassagem se tornar maior do que a oferta de gaps, haverá uma tendência rumo à formação de pelotões.

Portanto, quando uma faixa de ultrapassagem é implantada em uma rodovia de pista simples, a porcentagem de veículos em pelotões cai bruscamente e estabiliza-se em torno da metade do valor inicial, persistindo seus efeitos por uma determinada extensão após o término da faixa (Mon-Ma, 2008).

Os principais fatores que influenciam no espaçamento adequado entre as faixas adicionais são: a porcentagem de zonas de ultrapassagem proibida, a melhoria desejada para rodovia em termos de redução na porcentagem de veículos em pelotões, o volume e a composição do tráfego (Mon-Ma, 2002). Para determinar o espaçamento mínimo entre faixas adicionais, um dos métodos utilizados começa com a determinação do comprimento efetivo de uma faixa adicional (Morral, 1986). Esse comprimento é medido entre o ponto onde está a primeira placa de advertência à faixa adicional até o ponto onde os seus efeitos cessam, ou seja, onde os pelotões se recompõem. A Figura 2.2 representa uma comparação entre um trecho com e sem faixa adicional, indicando o comprimento real e o efetivo dessa faixa.

É ressaltado em Morral (1986) que, para o espaçamento mínimo entre faixas de ultrapassagem, valores menores do que o comprimento efetivo das faixas não são recomendados do ponto de vista econômico ou operacional. Porém, com o aumento do volume de tráfego e a consequente necessidade de melhoria da qualidade do tráfego, o espaçamento entre as faixas de ultrapassagem tende a diminuir.

A Tabela 2.2 mostra os espaçamentos entre faixas adicionais recomendados em outras duas pesquisas, Griffin (1988) e Harwood e Hoban (1987). Em ambas, foi estabelecida uma relação entre o espaçamento e o volume de tráfego. Para o cálculo dos espaçamentos, Griffin (1988) baseou-se no conceito de oportunidades de ultrapassagem asseguradas, enquanto Harwood e 
Hoban (1987) usaram o comprimento efetivo da faixa adicional e a redução na porcentagem de veículos em pelotões.

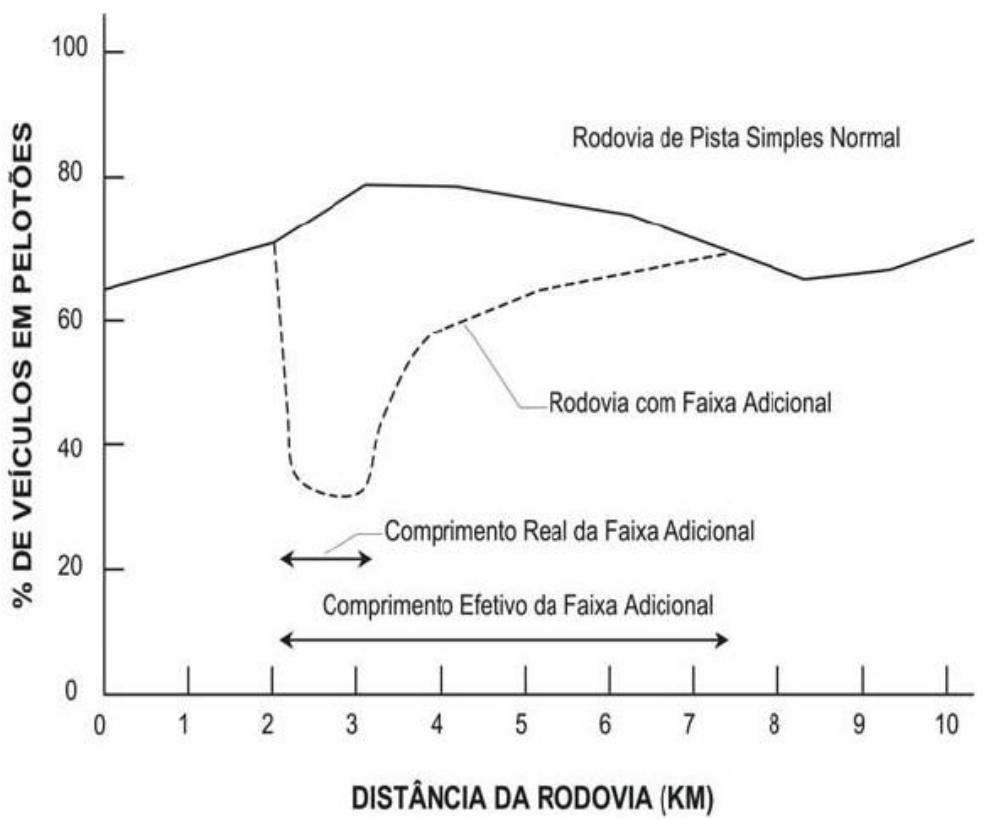

Figura 2.2 - Comprimento real e efetivo das faixas adicionais (Morral, 1986)

\begin{tabular}{lcc}
\multicolumn{3}{l}{ Tabela 2.2 - Relação volume de tráfego $\times$ espaçamento entre faixas adicionais de ultrapassagem } \\
\hline Autor & Volume de tráfego & Espaçamento sugerido \\
\hline Griffin (1988) & $1.000-3.000$ veíc/dia & $10 \mathrm{~km}$ \\
& $3.000-5.000$ veíc/dia & $8 \mathrm{~km}$ \\
Harwood e Hoban (1987) & $5.000-7.000$ veíc/dia & $6 \mathrm{~km}$ \\
& $\leq 700$ veíc $/ \mathrm{h}$ & $16-24 \mathrm{~km}$ \\
& $>700$ veíc $/ \mathrm{h}$ & $5-8 \mathrm{~km}$ \\
\hline
\end{tabular}

Enberg e Pursula (1997) encontraram que, nas rodovias finlandesas, a porcentagem de veículos em pelotões cerca de $1 \mathrm{~km}$ após o fim da faixa é quase a mesma da entrada da faixa, cessando totalmente os benefícios após $3,3 \mathrm{~km}$ do término da faixa, para todas as taxas de fluxo analisadas.

Para o Brasil, Mon-Ma (2002), numa tentativa de delinear o comprimento efetivo das faixas adicionais de subida quanto à redução na porcentagem de veículos em pelotões, encontrou que tais faixas reduzem o tamanho dos pelotões em cerca da metade do valor inicial, coincidindo com os resultados de outros estudos desenvolvidos nos Estados Unidos através de simulação (Harwood et al. 1988). No entanto, como pode ser verificado na Figura 2.3, para as diversas taxas de fluxo analisadas, no final da faixa o tamanho dos pelotões 
retorna para valores próximos aos encontrados no seu início. Entretanto, os pelotões que saem da faixa não são os mesmos que entram na faixa, ou seja, os veículos mais rápidos avançam de posição dentro do sistema e progridem para o pelotão da frente.

Através de observações em campo, Mon-Ma (2002) também verificou que o comprimento necessário para a dispersão dos pelotões varia de acordo com o número de veículos em fila. Considerando-se a condição mais comum, ou seja, o líder do pelotão utiliza corretamente o taper para entrar na faixa adicional e o veículo detrás espera o veículo líder completar a manobra antes de ultrapassá-lo, são necessários 1.300 metros para dispersar totalmente os pelotões compostos por cinco ou mais veículos. Apesar de Mon-Ma (2002) ter se concentrado nas faixas adicionais de subida, foi ressaltado que esse comprimento pode não ser suficiente para dispersar os pelotões em faixas de ultrapassagem, devido à provável maior velocidade do veículo líder, quando este estiver viajando em relevo menos íngreme.

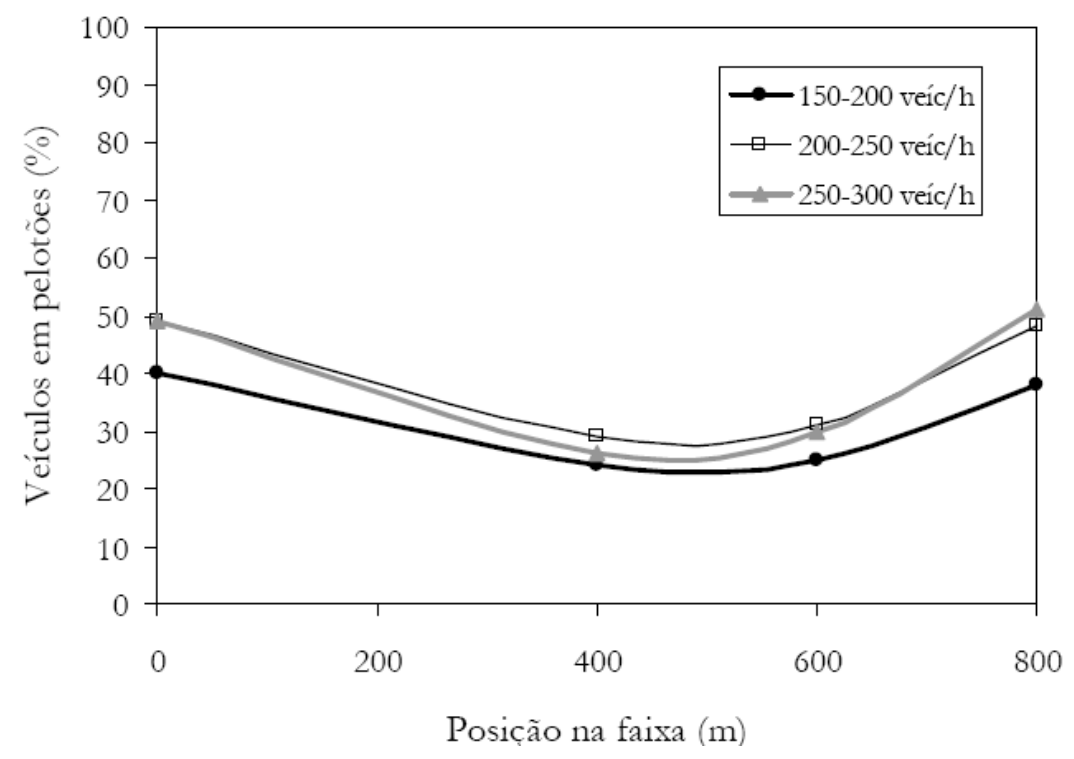

Figura 2.3 - Porcentagem de veículos em pelotões $\times$ fluxo direcional na faixa adicional (Mon-Ma, 2002)

\subsection{CRITÉRIOS PARA IMPLANTAÇÃO DAS FAIXAS ADICIONAIS EM ACLIVES}

Quando comparadas com as faixas de ultrapassagem, as faixas adicionais de subida são mais simples de serem especificadas, porque a maior parte dos critérios de implantação dessas é baseada no desempenho dos caminhões nos aclives das rodovias, o qual pode ser medido por observações em campo e pela caracterização da frota. 
Nesse contexto, há alguns grupos de critérios técnicos estabelecidos pelas agências de transporte e por pesquisadores da área, que contribuem para decisão quanto à necessidade da implantação de faixas adicionais em aclives.

A seguir, estão apresentadas características dos principais grupos de critérios de decisão existentes. É importante ressaltar que, por mais que a presente pesquisa tenha como meta delinear uma metodologia do planejamento das faixas adicionais em subidas, discutem-se também nesta revisão alguns critérios de implantação para faixas adicionais em trechos planos, nos casos em que esses estiverem relacionados à perda de velocidade de caminhões em rodovias de pista simples.

\subsubsection{AASHTO}

O Green Book da AASHTO adverte, antes de apresentar os critérios que devem ser observados para recomendar a construção de faixas adicionais de subida (climbing lanes), que na fase do desenvolvimento do projeto geométrico das rodovias de pista simples, as declividades das rampas devem ser, na medida do possível, compatibilizadas com a velocidade média de projeto da via.

Essa advertência é decorrente de estudos comprovarem que, independentemente da velocidade média da rodovia, quanto mais um veículo afasta-se dela, maior a sua chance de se envolver em um acidente. Assim, a redução da velocidade dos veículos pesados devido às subidas, aumenta exponencialmente a taxa de envolvimento desses em acidentes (AASHTO, 2001, p. 243).

É ressaltado ainda que a redução da velocidade dos veículos pesados nos aclives não depende só das declividades das rampas, mas também dos seus respectivos comprimentos. É então definido o termo "comprimento crítico" de um aclive, o qual é utilizado para indicar a distância máxima em uma subida pela qual um caminhão típico carregado pode trafegar sem reduzir a sua velocidade de entrada em $15 \mathrm{~km} / \mathrm{h}$ ou mais.

Para exemplificar, verifica-se através da análise da Figura 2.4 que os veículos carregados, com potência de $120 \mathrm{~kg} / \mathrm{kW}$ e entrando num aclive de $3 \%$ com $110 \mathrm{~km} / \mathrm{h}$, percorrem 500 
metros até atingirem uma velocidade de $95 \mathrm{~km} / \mathrm{h}$, ou seja, reduzindo sua velocidade inicial em $15 \mathrm{~km} / \mathrm{h}$. Nessas condições, o comprimento crítico do aclive é de 500 metros.

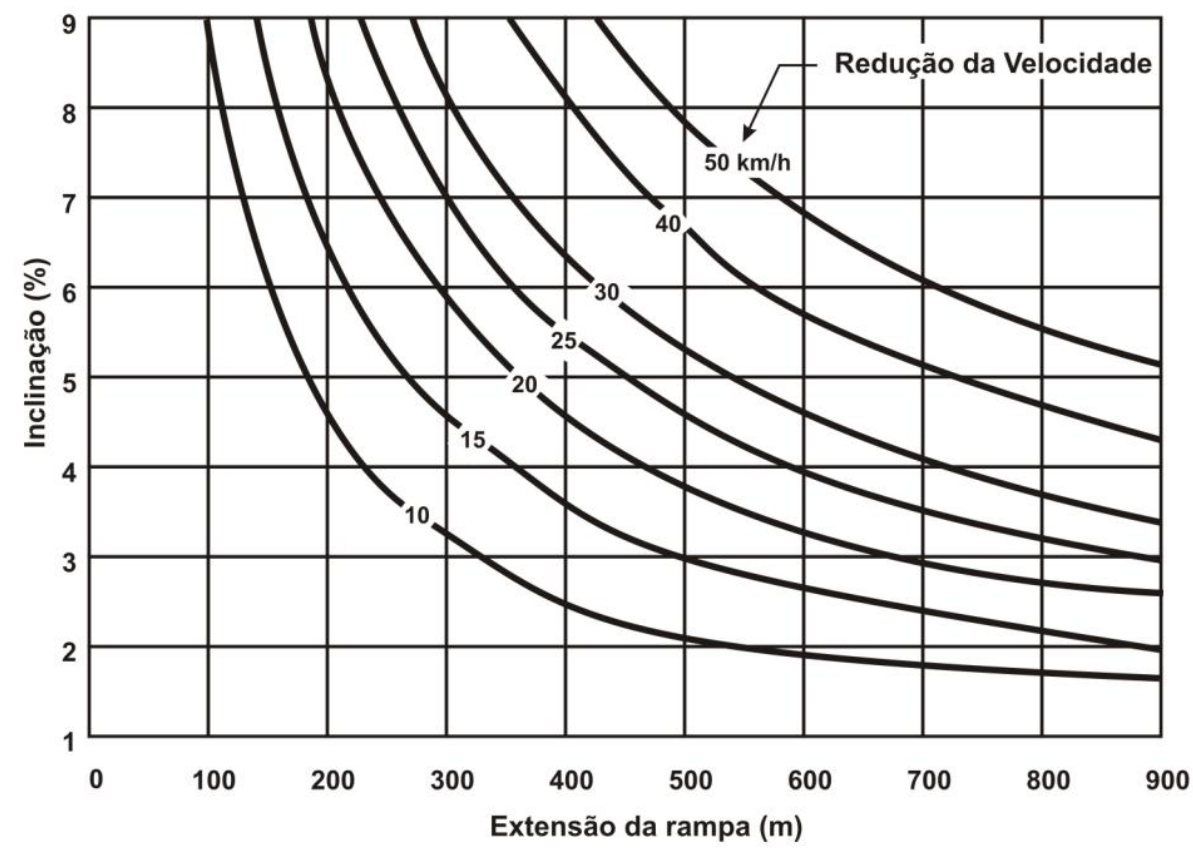

Figura 2.4 - Comprimento crítico do aclive para caminhões com $120 \mathrm{~kg} / \mathrm{kW}$ e velocidade de entrada de $110 \mathrm{~km} / \mathrm{h}$ (AASHTO, 2001)

Podem ser requeridas, portanto, a construção de faixas adicionais nos aclives com comprimentos maiores que o crítico, principalmente, nos locais onde o volume de veículos está próximo da capacidade e há uma considerável porcentagem de caminhões na corrente de tráfego, pois nessas condições, o fluxo de veículos carregados com baixas velocidades é constantemente observado.

Nesse contexto, são propostos critérios específicos para avaliar a necessidade da implantação de faixas adicionais em aclives mais longos que o comprimento crítico nas rodovias de pista simples. Uma sequência de três critérios, que envolvem a análise de variáveis como: o comprimento e a declividade da rampa, a curva massa $\times$ potência dos caminhões típicos, as diferenças de velocidade entre os veículos leves e pesados e os volumes de tráfego; devem ser atendidos para justificar a implantação de uma faixa adicional num determinado aclive: (AASHTO, 2001, p. 248 e 249)

1. A taxa do fluxo de tráfego excede 200 veículos por hora; e

2. A taxa do fluxo de caminhões excede 20 veículos por hora; e 
3. Uma das seguintes condições existe:

- Redução nos aclives de $15 \mathrm{~km} / \mathrm{h}$ ou mais das velocidades dos caminhões típicos; ou

- Nível de serviço na rampa igual a E ou F; ou

- A rodovia experimenta queda de dois ou mais níveis de serviço no trecho em subida.

Visto que há muitos locais onde mesmo com a desaceleração dos caminhões nos aclives, o volume de tráfego é muito pequeno e a construção de uma faixa adicional de subida não se justifica do ponto de vista econômico; os dois critérios iniciais estão ligados ao fluxo mínimo de veículos que garante uma relação benefício/custo adequada para indicar a necessidade de uma faixa adicional.

A verificação da redução de velocidade é possível através da análise das curvas de desempenho fornecidas pela AASHTO, para os caminhões típicos norte-americanos. Se não for observada a redução de $15 \mathrm{~km} / \mathrm{h}$, devem ser conferidos os critérios de nível de serviço. Para isso, é recomendada a utilização do HCM 2000.

É importante ressaltar que, se no aclive em estudo for observado uma grande quantidade de acidentes, o método da ASSHTO afirma que já é justificável a implantação da faixa, independente da observação dos critérios listados.

\subsubsection{MTO}

Os critérios para implantação de faixas adicionais de subida em Ontário são baseados na segurança dos usuários, na minimização dos atrasos dos veículos e nos custos de investimentos em obras de melhoria das rodovias (MTO, 1990).

Dentre os critérios recomendados pelo MTO para implantação da faixa adicional em aclive, o único acrescentado aos recomendados pela AASHTO é o de necessidade do desenvolvimento de análises benefício/custo. O MTO recomenda, contudo, 1,5 km como extensão mínima para as faixas adicionais em aclives instaladas no Canadá (MTO, 1990, p. $356)$. 
No método para o estudo da relação benefício/custo proporcionado pela construção das faixas adicionais, os benefícios considerados foram os gerados pelas reduções dos custos operacionais dos veículos, dos atrasos e dos acidentes após a implantação da faixa adicional. O investimento é economicamente viável quando a soma dos benefícios é maior que a dos custos de implantação (MTO, 1990).

Para quantificação dos benefícios, a velocidade média é utilizada para quantificar a redução no atraso devido às faixas adicionais em aclives.

É ressaltada a necessidade do conhecimento das curvas de redução das velocidades devido aos aclives, pois há a advertência que a taxa de acidentes aumenta rapidamente quando a redução da velocidade dos veículos pesados é superior a $15 \mathrm{~km} / \mathrm{h}$ ao longo da subida.

Nesse sentido, também foram desenvolvidas funções para quantificar as taxas de acidente em aclives das rodovias de pista simples. Duas equações de regressão foram propostas. Uma estima a taxa de ocorrência de acidentes em função do decréscimo da velocidade, entre 0 a 15 $\mathrm{km} / \mathrm{h}$, devido ao aclive. Enquanto a outra é recomendada para reduções maiores que $15 \mathrm{~km} / \mathrm{h}$.

Finalmente, outra contribuição do MTO foi a operacionalização de todo o método em um programa de computador, com intuito de auxiliar na análise de opções de projeto de faixas adicionais.

\subsubsection{ATU}

Em Alberta, Canadá, Alberta Transportation and Utilities (ATU, 1999) delineou critérios para verificar a necessidade de implantação de faixas adicionais em rodovias de pista simples. Esses critérios foram fundamentados, principalmente, nas seguintes diretrizes:

1. A redução de velocidade admissível é de $15 \mathrm{~km} / \mathrm{h}$, para caminhões com massa/potência de até $180 \mathrm{~kg} / \mathrm{kW}$. Quando a soma dos veículos de recreio mais os ônibus for maior que $85 \%$ da frota de veículos pesados, a redução de $15 \mathrm{~km} / \mathrm{h}$ admissível passa a ser para caminhões de até $120 \mathrm{~kg} / \mathrm{kW}$; 
2. São sugeridos volumes diários médios em função da porcentagem de ultrapassagem permitida, declividade e comprimento da rampa e, porcentagem de caminhões no tráfego. Este critério ainda está baseado em outras duas condições:

- O volume de veículos pesados for maior que 150 veíc/dia;

- O nível de serviço na hora de pico deve ser inferior a "A".

As razões que levaram o comitê canadense a sugerir um volume mínimo de veículos pesados foram motivadas pela observação que um critério baseado apenas no nível de serviço pode indicar a necessidade de faixas adicionais onde o volume de tráfego é baixo, ocasionando uma relação em que os benefícios são menores que os custos; além disto, houve a intenção de tornar o critério mais abrangente por assim também ser considerado a declividade, o comprimento da rampa e a composição de tráfego.

\subsubsection{IMT}

Com intuito de verificar quais aclives das rodovias de pista simples necessitam de faixas adicionais, o IMT (Instituto Mexicano del Transporte) propôs um método composto de 2 etapas, sendo a primeira a verificação de redução do nível de serviço nos aclives, e a segunda a verificação da viabilidade econômica da obra.

O HCM de 1985 foi adaptado para avaliar o nível de serviço em rampas específicas e adequá-lo às condições de tráfego e de geometria das rodovias do México. Para isso, foram feitas simulações de tráfego através do TRARR calibrado para as condições desse país. Os dados de entrada foram coletados em 10 greides específicos, com velocidades de projeto igual a $90 \mathrm{~km} / \mathrm{h}$, com faixas adicionais e boas condições do pavimento. A divisão modal, as velocidades na rampa e porcentagem de veículos viajando em pelotões foram notadas com as faixas adicionais liberadas e depois interditadas para o tráfego, consecutivamente em intervalos de 15 minutos, durante 16 horas em cada greide. Estabeleceu-se que o $95^{\circ}$ percentil da distribuição da relação massa-potência observada seria considerada a relação típica (210 $\mathrm{kg} / \mathrm{HP}$ ), surgindo assim, um contraste com o valor de $135 \mathrm{~kg} / \mathrm{HP}$, usado pelo HCM (1985). Os níveis de serviços, em função das velocidades, foram estimados e comparados com os valores do HCM. Entretanto, as velocidades para cada nível de serviço apresentaram valores menores no estudo do México. 
Dependendo do resultado verificado na melhora do nível de serviço da rodovia, é recomendada a execução de estudos de viabilidade econômica da implantação das faixas adicionais, através de análises benefício/custo. Os benefícios gerados pela construção de faixas adicionais são as reduções do custo operacional dos veículos e as dos tempos de viagem dos usuários. A redução de acidentes que em outros países é considerada como benefício, não foi observada no México. Por fim, compara-se o somatório dos benefícios aos custos de construção das faixas adicionais, para definir a recomendação, ou não, da construção das faixas. Em termos gerais, a implantação da faixa adicional está garantida se o volume diário médio estiver entre 3.000 e 6.000 veíc/dia e se a largura da plataforma da rodovia for suficiente para construir a melhoria.

\subsubsection{DNER}

Em 1999, o DNER publicou um conjunto de critérios para avaliar a necessidade de faixa adicional, em substituição às instruções publicadas em 1979. Basicamente, as diretrizes propostas foram fundamentadas no que estabelece a AASHTO (1994). Para implantar a faixa adicional deve ser verificado se:

1. O fluxo de tráfego no aclive é maior que 200 veíc/h; e

2. A taxa de fluxo de caminhões no aclive é maior que $10 \%$; e

3. Uma das seguintes condições existe:

- Uma redução de velocidade de $15 \mathrm{~km} / \mathrm{h}$ ou mais é esperada para um caminhão carregado típico; ou

- O nível de serviço calculado para a rampa é de E ou F; ou

- Redução de dois ou mais níveis de serviço quando se passa do segmento plano da aproximação para a rampa.

Nota-se, portanto, que os critérios recomendados pelo DNER são uma mera tradução, para a língua portuguesa, do método da AASHTO (1994), sem adaptações às condições de tráfego e às características de veículos das rodovias brasileiras (Melo, 2002). 


\subsubsection{Kabbach Júnior}

Entre os estudos realizados no Brasil, com objetivo de adaptar o manual americano HCM, o de Kabbach (1992) merece um destaque especial, porque sugere adaptações na variação admissível de velocidade, no nível de serviço e nos volumes mínimos de tráfego que refletem a necessidade de implantação de faixas adicionais em aclives.

Admitindo que a velocidade de entrada dos caminhões na rampa era de $80 \mathrm{~km} / \mathrm{h}$, foi estabelecido que, se a redução de velocidade do caminhão fosse de $25 \mathrm{~km} / \mathrm{h}$, a implantação da faixa adicional estaria garantida. Esse valor proposto é a média dos valores de redução de velocidades de $35 \mathrm{~km} / \mathrm{h}$, usado pelo DNER (1979) e $15 \mathrm{~km} / \mathrm{h}$, adotado pela AASHTO (1984).

Para a análise de capacidade e verificação do nível de serviço, Kabbach (1992) propõe o uso do HCM. Para a indicação da necessidade de faixas adicionais o nível de serviço calculado para a rampa deve ser $\mathrm{E}$ ou $\mathrm{F}$ e o volume de caminhões carregados deveria ser maior ou igual a 20 veíc/h na hora de pico. O autor ressalvou que a validade dos parâmetros estabelecidos no HCM 1985 para as condições brasileiras só poderia ser aferida com base em estudos criteriosos sobre o assunto.

Para a verificação da viabilidade econômica da obra, a relação entre benefícios gerados aos usuários e os custos de implantação da faixa deveria ser maior ou igual a um. Os benefícios considerados foram as reduções dos custos operacionais, dos tempos de viagem, do custo de manutenção viária, do custo de acidentes e de outros como a redução dos impactos ambientais. $\mathrm{O}$ benefício total é estimado através da seguinte expressão:

$$
B T=B R C O+B R T V+B R C M+B R A C I D+B R O U T
$$

sendo: $\quad B T$ : benefício total $(\mathrm{R} \$ / \mathrm{ano})$;

BRCO: benefício de redução dos custos operacionais ( $\mathrm{R}$ \$ano);

$B R T V$ : benefício de redução dos tempos de viagem (R $\$ / a n o)$;

BRCM: benefício de redução do custo de manutenção viária ( $\mathrm{R}$ /ano);

BRACID: benefício de redução dos custos de acidentes (R $\$ / a n o) ; \mathrm{e}$

BROUT: outros benefícios, como redução do impacto ambiental (R $\$ / a n o)$.

O custo operacional de um veículo foi considerado como sendo quanto um usuário tem que desembolsar para usar seu veículo na rodovia. São fornecidas expressões que caracterizaram 
as relações entre os custos operacionais unitários de cada tipo de veículo (automóvel, ônibus e caminhões) em função da velocidade e da declividade da rampa.

Para estimar os benefícios gerados pela redução do tempo de viagem, foi preciso definir o custo horário do usuário, que é estimado com o valor que o usuário estaria disposto a pagar se fosse reduzida uma hora no tempo de viagem. Esse custo depende do tipo e da finalidade da viagem, dos níveis de renda da população e do tempo gasto durante o deslocamento entre a origem e o destino. Kabbach (1992) utiliza os valores estabelecidos pela EBTU em 1981.

O aumento do custo de manutenção propiciado pela operação da faixa adicional é considerado como custo marginal, se comparado aos custos da rotina de manutenção estabelecida para toda a rodovia, e por isso o $B R C M$ foi desprezado na análise.

A carência de dados quanto aos acidentes ocorridos em ultrapassagens nas rampas, e à distribuição desses acidentes por nível de gravidade e custo, não possibilitou Kabbach (1992) calcular o BRACID para as condições brasileiras. Embora seja afirmado que, em muitos casos, é perceptível a contribuição do BRACID à viabilidade econômica da faixa adicional.

Os custos de implantação foram considerados serem dependentes de variáveis como: topografia e geotécnica do local, disponibilidade de materiais e respectivas distâncias de transportes, seção transversal adotada, volumes de cortes e de aterros, reforço ou demolição da estrutura do acostamento, drenagem, sinalização, defensas, desapropriações, provisões para contingências, custos de projeto e supervisão da obra.

\subsubsection{Melo}

Melo (2002) propôs uma adaptação das diretrizes da AASHTO para projetos de faixas adicionais em aclives, para as condições das rodovias brasileiras. Esta adaptação foi feita em três fases distintas: $(i)$ geração de curvas de desempenho para caminhões típicos brasileiros; (ii) determinação da redução admissível de velocidade e; (iii) estimativa do fluxo e da porcentagem de caminhões no tráfego que justifiquem economicamente a construção da faixa adicional. 
$\mathrm{Na}$ primeira fase, constatou-se que as relações massa/potência dos caminhões brasileiros variam de 100 a $380 \mathrm{~kg} / \mathrm{kW}$, e são significativamente maiores que a dos caminhões norteamericanos $(120 \mathrm{~kg} / \mathrm{kW})$. Através do modelo de locomoção desenvolvido por Demarchi (2000), devidamente calibrado e validado, foram geradas curvas de desempenho para sete categorias de caminhões da frota nacional (Melo e Setti, 2003).

$\mathrm{Na}$ segunda fase, foram obtidas as relações entre as diferenças de velocidade entre automóveis e caminhões e índices de envolvimento de caminhões em acidentes. Para atingir esse objetivo, foram coletados dados sobre acidentes envolvendo caminhões, velocidade de veículos em aclives e volume diário médio. Pela comparação das relações entre essas variáveis com a relação utilizada nas diretrizes da AASHTO, sugeriu-se que a redução admissível na velocidade dos caminhões brasileiros deve ser de $20 \mathrm{~km} / \mathrm{h}$, em rodovias de pista simples (Melo e Setti, 2007a).

$\mathrm{Na}$ terceira fase, foram analisadas relações benefício/custo para diversos cenários, visando estimar os fluxos de tráfego mínimos em que os benefícios fossem iguais aos custos. Os custos foram estimados a partir do investimento de capital necessário para a construção da faixa adicional, com base em projetos típicos do estado de São Paulo. Os benefícios estimados foram a redução do tempo de viagem e dos custos operacionais dos carros, ônibus e caminhões descarregados. O resultado desta fase está apresentado na Tabela 2.3.

Para a estimativa dos tempos de viagem, da porcentagem do tempo trafegando em pelotões e da porcentagem média de veículos em pelotões, foram feitas simulações, com e sem a faixa adicional, usando-se o modelo TRARR. Nessas simulações, os fluxos variaram entre 50 a 700 veíc/h e as porcentagens de caminhões de $10 \%$ a $40 \%$. Os resultados indicaram que os fluxos mínimos no aclive, que justificam economicamente a construção da faixa adicional, dependem da porcentagem de caminhões e da magnitude do aclive (Melo e Setti, 2007b), variando de 540 veíc/h (10\% de caminhões; aclives de até 2,5\%) a 230 veíc/h (30\% de caminhões; aclives de 8\%), conforme apresentado na Tabela 2.3. 
Tabela 2.3 - Fluxos mínimos que justificam a implantação de faixas adicionais (Melo e Setti, 2007b)

\begin{tabular}{|c|c|c|c|c|c|c|c|}
\hline \multirow{2}{*}{\multicolumn{2}{|c|}{ Rampa (\%) Comprimento (m) }} & \multicolumn{6}{|c|}{ Porcentagem de Caminhões } \\
\hline & & $10 \%$ & $20 \%$ & $25 \%$ & $30 \%$ & $35 \%$ & $40 \%$ \\
\hline \multirow{4}{*}{2,5} & 500 & 540 & 520 & 480 & 420 & 440 & 450 \\
\hline & 1000 & 530 & 500 & 460 & 400 & 420 & 435 \\
\hline & 1500 & 510 & 480 & 440 & 385 & 400 & 415 \\
\hline & 2000 & 490 & 460 & 420 & 370 & 390 & 405 \\
\hline \multirow{4}{*}{3} & 500 & 490 & 470 & 430 & 390 & 410 & 420 \\
\hline & 1000 & 480 & 450 & 410 & 375 & 395 & 405 \\
\hline & 1500 & 470 & 430 & 390 & 350 & 370 & 390 \\
\hline & 2000 & 450 & 410 & 370 & 340 & 360 & 375 \\
\hline \multirow{4}{*}{4} & 500 & 460 & 440 & 420 & 380 & 390 & 395 \\
\hline & 1000 & 440 & 420 & 400 & 365 & 375 & 380 \\
\hline & 1500 & 435 & 400 & 380 & 345 & 350 & 365 \\
\hline & 2000 & 400 & 380 & 360 & 330 & 340 & 350 \\
\hline \multirow{4}{*}{5} & 500 & 420 & 410 & 400 & 360 & 370 & 370 \\
\hline & 1000 & 400 & 375 & 350 & 340 & 345 & 350 \\
\hline & 1500 & 400 & 380 & 360 & 340 & 345 & 350 \\
\hline & 2000 & 360 & 340 & 320 & 300 & 305 & 310 \\
\hline \multirow{4}{*}{6} & 500 & 400 & 370 & 360 & 350 & 360 & 370 \\
\hline & 1000 & 370 & 340 & 340 & 320 & 330 & 350 \\
\hline & 1500 & 360 & 340 & 320 & 305 & 315 & 340 \\
\hline & 2000 & 330 & 310 & 300 & 290 & 300 & 330 \\
\hline \multirow{4}{*}{7} & 500 & 370 & 340 & 320 & 315 & 315 & 320 \\
\hline & 1000 & 340 & 300 & 290 & 280 & 290 & 300 \\
\hline & 1500 & 330 & 300 & 290 & 270 & 280 & 290 \\
\hline & 2000 & 300 & 275 & 265 & 260 & 275 & 280 \\
\hline \multirow{4}{*}{8} & 500 & 310 & 290 & 270 & 250 & 255 & 260 \\
\hline & 1000 & 300 & 280 & 260 & 250 & 255 & 260 \\
\hline & 1500 & 300 & 280 & 260 & 240 & 255 & 270 \\
\hline & 2000 & 280 & 265 & 250 & 230 & 235 & 245 \\
\hline
\end{tabular}

\subsubsection{Outros estudos}

Como podem ser notados, basicamente, os critérios para implantação das faixas adicionais em aclives são divididos nos seguintes grandes grupos: redução de velocidade dos caminhões, diferença de velocidade entre os caminhões e os veículos de passeio, qualquer um destes dois associados com o volume de tráfego, e redução do nível de serviço.

Nesse sentido, os grupos de critérios discutidos nesta seção foram considerados de menor importância para a presente pesquisa devido, principalmente, pelo fato de que uma parte deles analisa faixas de ultrapassagem em vez de faixas adicionais em aclives; e a outra parte recomendar apenas algumas adaptações nos grupos de critérios anteriormente discutidos. 
Kaub e Berg (1988) determinaram condições nas quais a construção de faixas adicionais em rodovias de pista simples é economicamente justificável. Atribuindo-se um custo por situações de conflito e ajustando-o para o tamanho disponível das zonas de ultrapassagem, os custos dos acidentes em ultrapassagem foram estimados. Uma versão anterior do TWOPAS (o simulador TWOWAF) foi utilizada para obter os atrasos a partir das velocidades de viagem dos carros e caminhões em segmentos de rodovias de pista simples com e sem faixa de ultrapassagem. Análises das relações benefício/custo foram usadas para determinar o nível do atraso diário do tráfego para o qual uma faixa de ultrapassagem seria economicamente justificável, em função da extensão do trecho, da porcentagem de zonas disponíveis para ultrapassagem, do custo por conflito, do custo de construção da faixa e dos benefícios advindos da operação da faixa (redução do atraso e dos acidentes e aumento da velocidade média).

Wolhuter e Polus (1988) usaram dados de fluxo, declividade das rampas e velocidade em rodovias da África do Sul para calibrar o simulador TRARR. Através de simulações, foram estabelecidas relações entre o atraso e os fluxos de veículos em várias declividades distintas. Visto que critérios baseados no atraso refletiriam tanto os benefícios dos usuários (redução do tempo de viagem, redução do custo de operação, redução do tempo de exposição aos acidentes e redução do stress), quanto da comunidade em geral (maiores níveis de serviço da rodovia e uma potencial redução dos custos de operação da rodovia), foram propostos critérios para recomendar faixas adicionais em aclives a partir da redução do atraso proporcionada pela implantação de faixas adicionais. A conclusão final é que esse critério, indica a necessidade de faixas adicionais para valores menores de fluxo em aclives suaves, comparado com os valores recomendados nos critérios da AASHTO.

Schulze e Lamm (2000) propuseram critérios para recomendar a implantação de faixas adicionais em rodovias de pista simples na Alemanha nas quais, além da redução de velocidade experimentada pelos caminhões devido aos aclives, é adicionada uma redução de velocidade devido às curvas horizontais, experimentadas pelos carros e caminhões. A relação massa/potência dos caminhões típico considerada foi de $130 \mathrm{~kg} / \mathrm{kW}$. Após gerar os perfis de velocidade dos caminhões e dos automóveis, a faixa adicional no aclive é justificada se o $15^{\circ}$ percentil das velocidades dos caminhões for menor do que o $85^{\circ}$ percentil das velocidades dos automóveis. Essa condição indica o ponto de início da faixa; já o ponto final da faixa fica 
onde o $15^{\circ}$ percentil das velocidades dos caminhões for maior que o $85^{\circ}$ percentil das velocidades dos automóveis. Além dessa comparação entre as velocidades dos automóveis e caminhões, mais duas características da rodovia têm que ser analisadas para a indicação da necessidade de faixa adicional, o comprimento mínimo do trecho sob análise deve ser de 500 metros; e havendo a necessidade da construção de mais de uma faixa adicional em rampas consecutivas em um trecho menor do que 800 metros, deve-se construir apena uma.

Jain e Taylor (1991), através do simulador TWOPAS, estimaram a redução dos tempos de viagem, nas rodovias com faixas de ultrapassagem, em função da composição do tráfego, geometria da via e características dos motoristas, com o objetivo principal de analisar os benefícios proporcionados pela redução de acidentes, proporcionados por faixas adicionais. As conclusões mostraram que faixas de ultrapassagens são eficientes na redução de acidentes em rodovias de pista simples. A redução do atraso dos veículos é maior em rampas suaves e médias do que em rampas íngremes e esses benefícios são maiores quando a porcentagem de caminhões no tráfego é baixa (entre 5\% e 10\%) do que quando existe grande porcentagem de caminhões $(\geq 20 \%)$. Os volumes mínimos de tráfego encontrados variam entre 300 e 500 veíc/h, para rampas com declividades de $2 \%$ e $4 \%$, e entre 800 e 1.500 veíc/h, para rampa com $6 \%$ de declividade.

\subsection{ANÁLISE ECONÔMICA DE PROJETOS}

Entende-se pelo termo projeto de investimento, ou simplesmente projeto, um empreendimento cujo principal objetivo é atender a uma necessidade de mercado. O projeto pode ser de cunho social, sendo subsidiado pelo Estado e não tendo como objetivo principal a geração de lucro. $\mathrm{Ou}$, com mais frequência, o projeto será notadamente capitalista, devendo pagar os recursos nele investidos e ainda gerar algum retorno aos acionistas (Kawamoto e Furtado, 1997).

Em ambos os casos, na maioria das vezes, há mais de uma opção de projeto a ser levado adiante, ou até diferentes formas de implantar um mesmo projeto. Contudo, a escassez de recursos dificilmente permitirá que todos os projetos possíveis sejam implementados, surgindo assim a necessidade da análise econômica de projetos, para facilitar a tomada de decisão, fazendo uso da matemática financeira e das ferramentas da área da engenharia denominada engenharia econômica. 
Dado que os projetos são normalmente irreversíveis e de longo prazo, o sucesso na tomada de decisão dependerá, dentre outras coisas, da análise inicial de viabilidade econômica destes projetos, provocando assim, a necessidade da aplicação de metodologias bastante complexas, que têm por objetivo identificar os benefícios sócioeconômicos.

Entre esses benefícios incluem-se, principalmente em projetos do Estado, variáveis ambientais, que fazem parte de um grupo de variáveis que irá determinar o fluxo de caixa do projeto e, consequentemente, a rentabilidade através de métodos de avaliação como: relação benefício-custo, relação benefício-custo incremental, taxa interna de retorno e valor presente líquido (Samuelson, 1954).

\subsubsection{Relações benefício-custo}

Dentro deste cenário, a análise da relação benefício-custo $(R B C)$ reveste-se de importância para a análise de viabilidade econômica de projetos a serem desenvolvidos com recursos públicos, já que o conceito dessa análise resume-se na comparação entre o somatório de todos os benefícios proporcionados pela implantação de um projeto com o somatório dos custos de implantação, em valores monetários. Custos e benefícios são reduzidos a uma sequência de fluxos líquidos de caixa e, posteriormente, a um simples número, o qual passa a representar uma medida de efetividade econômica do projeto. O cálculo dessa relação pode ser feito através da seguinte equação (Kawamoto e Furtado, 1997):

$$
R B C_{x}=\frac{\sum B_{x}}{\sum C_{x}}
$$

sendo: $\quad R B C_{x}$ : relação benefício-custo da alternativa $x$;

$$
\begin{aligned}
& B_{x} \text { : benefícios do projeto } x ; \mathrm{e} \\
& C_{x} \text { : custos do projeto } x .
\end{aligned}
$$

De acordo com esta medida de efetividade econômica, aceitam-se os projetos que apresentarem $R B C$ maior do que um, dado que revelam possibilidades de produzirem mais benefícios do que custos.

Os procedimentos da análise benefício/custo são bastante similares à metodologia empregada em análises marginais de input/output,ou seja, métodos relacionados que mostram 
como as partes de um sistema são afetadas pela mudança em uma porção, sendo o objetivo em ambos os casos:

- $\quad$ Obter o máximo output (benefício) dado um determinado nível de input (custo);

- Obter o máximo nível de output (benefício) empregando-se o mínimo possível de inputs (custo).

A diferença básica entre a análise da $R B C$ das outras está diretamente ligada à especificação dos custos e benefícios do projeto. Enquanto que, em análise marginal, a atenção é dirigida somente para alguns inputs e outputs, a $R B C$ considera todos os custos e retornos do projeto. A exclusão de elementos (inputs/outputs) afetará a sequência dos fluxos líquidos de caixa e, consequentemente, a validade dos resultados finais (Motta e Calôba, 2002).

\subsubsection{Relações benefício-custo incremental}

A técnica denominada de relação benefício-custo incremental ( $R B C I)$ é também comumente utilizada no setor público. O princípio básico constitui-se da utilização dos valores presentes de fluxos de benefícios e custos determinados na técnica de $R B C$. As alternativas são ordenadas de forma que a de menor custo inicial seja a primeira a ser analisada. Daí, em função do cálculo da $R B C$ sobre o valor incremental, determina-se qual é a melhor alternativa (Kawamoto e Furtado, 1997).

Dessa forma, para o cálculo da $R B C I$, seleciona-se a alternativa com menor custo inicial, verificando-se se a $R B C$ dessa alternativa é igual ou maior do que um. Se essa condição for atendida, a alternativa pode ser considerada como aceitável. Porém, se a $R B C$ for menor do que um, essa alternativa será rejeitada e será calculada a $R B C$ para a segunda alternativa de menor custo inicial. Esse processo é repetido até que seja encontrada a alternativa com $R B C$ maior ou igual a um. Entretanto, se todas as alternativas apresentarem $R B C$ menor do que um, todas devem ser rejeitadas do ponto de vista econômico.

Com isso, é determinado se uma alternativa $x$ é melhor ou não do que as alternativas com custos iniciais maiores que o de $x$, de forma a justificar qualquer incremento de custo. Para isso, é calculada a RBCI (Kawamoto e Furtado, 1997): 


$$
R B C I_{x+1, x}=\frac{\sum_{t=0}^{n} \frac{B_{x+1, t}}{(1+i)^{t}}-\sum_{t=0}^{n} \frac{B_{x, t}}{(1+i)^{t}}}{\sum_{t=0}^{n} \frac{C_{x+1, t}}{(1+i)^{t}}-\sum_{t=0}^{n} \frac{C_{x, t}}{(1+i)^{t}}}
$$

sendo: $R B C I_{x+1, x}$ : Relação benefício-custo incremental da alternativa $x+1$ sobre a $x$;

$B_{x+1, t}$ : Benefícios da alternativa $x+1$ na data $t$;

$B_{x, t}:$ Benefícios da alternativa $x$ na data $t$;

$C_{x+1, t}:$ Custos da alternativa $x+1$ na data $t$;

$C x, t$ : Custos da alternativa $\mathrm{x}$ na data $\mathrm{t}$;

$i$ : taxa de desconto; e

$t$ : período de anos.

Se $R B C I_{x+1, x}$ for menor que 1 , calcula-se $R B C I_{x+2, x}$, e assim por diante até encontrar uma alternativa cuja $R B C I$ em relação à alternativa $x$, a qual tem menor custo, seja maior ou igual a 1 (um). Caso não exista nenhuma alternativa com $R B C I$ maior que 1 (um) em relação a alternativa $x$, essa pode ser considerada a melhor do ponto de vista econômico.

\subsubsection{Valor presente líquido (VPL)}

Outra técnica bastante utilizada na análise de viabilidade financeira de projetos é o cálculo do Valor Presente Líquido (VPL), a qual é caracterizada pela transferência para a data inicial de todos os benefícios e custos do fluxo de caixa de uma alternativa de projeto, descontadas a uma taxa mínima de atratividade (TMA). Para qualquer alternativa $x$, o VPL dos fluxos em um período de $t$ anos, considerando-se a taxa de descontos $i$, é dado por:

$$
V P L_{x, n, i}=\sum_{t=0}^{n} \frac{B_{x, t}-C_{x, t}}{(1+i)^{t}}
$$

sendo: $\quad B_{x, t}:$ benefícios do projeto $x$ na data $t$; e

$C_{x, t}$ : custos do projeto $x$ na data $t$.

Um VPL nulo significa que, com a taxa considerada, o projeto não é desinteressante do ponto de vista econômico, pois produz um valor de retorno igual ao custo de oportunidade existente fora do âmbito dos projetos analisados. Para o caso em que o VPL é negativo, rejeita-se a alternativa, pois o valor dos benefícios sequer é suficiente para assegurar a 
recuperação do capital investido. Todas as alternativas que têm um VPL não negativo podem ser consideradas economicamente viáveis, sendo a melhor alternativa aquela que apresentar o maior valor dessa variável.

Contesta-se a utilização dessa técnica em projetos relacionados ao atendimento das necessidades básicas da população em geral, pois nesses devem ser envolvidos muito mais do que critérios técnicos e econômico-financeiros. Nesses casos, a taxa utilizada como parâmetro de mínima atratividade deve ser uma taxa social de descontos, ou uma melhor alternativa é a utilização da análise benefício/custo (B/C) (Kawamoto e Furtado, 1997).

\subsection{SIMULAÇÃO DE TRÁFEGO EM RODOVIAS DE PISTA SIMPLES}

O desenvolvimento de modelos de simulação surgiu na década de 50 com intuito de substituir os modelos analíticos, utilizando para isso técnicas numéricas capazes de representar o funcionamento real do tráfego de veículos de forma simplificada e idealizada. Portanto, assim como os antigos modelos analíticos, os simuladores agregam parâmetros da geometria da via, do comportamento dos motoristas, dos tipos de veículos e algumas interações entre esses parâmetros, em um programa computacional (Leiman e May, 1996).

Os simuladores têm a vantagem de serem capazes de refletir as reações do fluxo de tráfego frente a diversos cenários, sem a necessidade de uma intervenção direta na rede viária real sob análise (Demarchi, 2000). Portanto, possibilitam verificar o comportamento dos veículos em pelotões e na mudança de faixa, além de viabilizar o desenvolvimento das curvas de desempenho dos veículos, para posteriormente, medir o impacto da geometria da via sobre o desempenho dos veículos. Torna-se então necessário, o desenvolvimento de uma refinada calibração e validação dos parâmetros adotados nos modelos que os compõe, para garantir uma adequada representatividade das condições que estão sob análise.

O TWOPAS simula o fluxo de tráfego em rodovias de pista simples, e é amplamente utilizado pela comunidade técnico-científica. A seguir estão descritos mais detalhes sobre esse simulador. 


\subsubsection{TWOPAS}

O TWOPAS foi originalmente desenvolvido entre 1971 e 1983 pelo Federal Highway Administration norte-americana, e pode ser obtido sem custos para os interessados do website do IHSDM ${ }^{1}$.

Ele é um modelo estocástico e microscópico, capaz de simular o tráfego em rodovias de pista simples, com ou sem faixas adicionais. Ele funciona através da atualização, a cada segundo, da posição, velocidade e aceleração de cada veículo ao longo do trecho simulado. Os dados de saída podem ser lidos por um programa chamado TWOSIM, o qual produz um arquivo com uma pequena tabela sumário.

Esse programa foi utilizado no desenvolvimento do capítulo do Highway Capacity Manual (HCM) para avaliação de rodovias de pista simples. Desde então, vem passando por várias atualizações para representar com fidelidade a operação do tráfego nas rodovias de pista simples de diversos países, entre eles o Brasil.

Uma característica importante que diferencia o TWOPAS dos demais simuladores de rodovia de pista simples, é que nesse pode-se "alimentar" o modelo com dados das características geométricas por região ou zona (Leiman e May, 1996).

Em outras pesquisas recentes desenvolvidas na Escola de Engenharia de São Carlos da USP, foi examinada a capacidade do TWOPAS em simular as rodovias de pista simples no Estado de São Paulo, após calibrações de alguns parâmetros por algoritmos genéticos. Assim, os erros fornecidos pelo TWOPAS (2,27\% na calibração e 5,29\% na validação) podem ser considerados aceitáveis, podendo ser admitido que o TWOPAS é capaz de simular adequadamente o tráfego brasileiro (Egami, 2006; Mon-Ma, 2008). Por esses motivos, o TWOPAS foi o modelo de simulação escolhido para o desenvolvimento da presente pesquisa. A versão do TWOPAS usada foi calibrada pelo algoritmo genético desenvolvido em Bessa Jr. (2009) e lá podem ser encontrados mais detalhes.

\footnotetext{
${ }^{1}$ Disponível em: http://www.ihsdm.org (Acessado em fev. 2010)
} 


\section{MÉTODO}

O método proposto nesta pesquisa consiste em, a partir da determinação do conjunto de faixas adicionais necessárias dentro do horizonte de projeto, obter a sequência ótima de construção que maximize os benefícios advindos do investimento e atenda às restrições orçamentárias. A Figura 3.1 resume as principais etapas do processo.

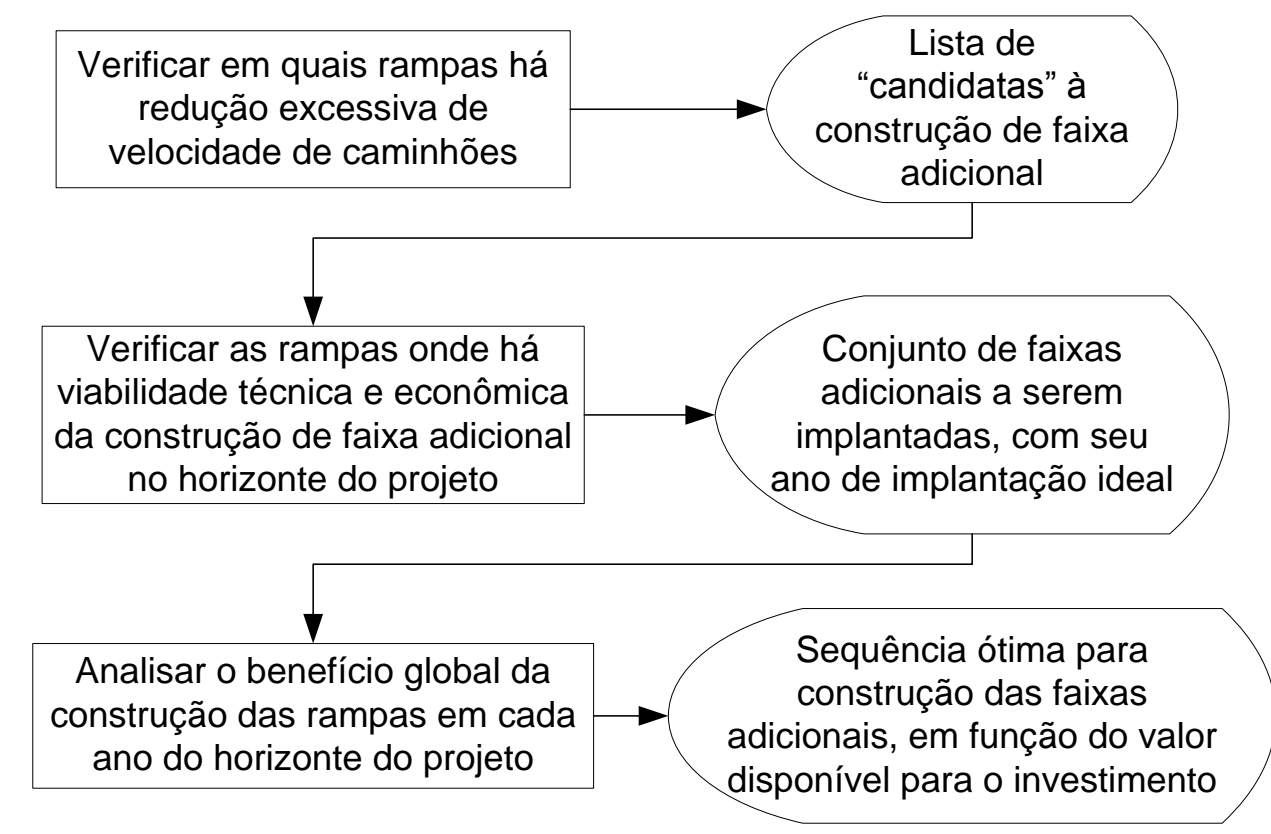

Figura 3.1 - Resumo do método proposto

$\mathrm{Na}$ primeira etapa, através das curvas de desempenho dos caminhões em aclives de rodovias de pista simples, verificam-se quais rampas do trecho tem comprimento maior do que o comprimento crítico, o qual está relacionado à magnitude da rampa, ao caminhão de projeto e à redução admissível de velocidade, sendo essas duas últimas definidas pelo usuário do método. Como resultado, obtém-se uma lista de todas as rampas em que pode haver a necessidade de construção de faixa adicional, que é chamada "lista de rampas candidatas à implantação de faixa adicional".

No entanto, a redução de velocidade dos caminhões, por si só, não garante a viabilidade econômica da faixa adicional; por isso, a segunda etapa do processo seleciona, entre as rampas identificadas na etapa anterior, aquelas nas quais a construção de faixa adicional é justificada através das diretrizes adotadas. Como resultado desta segunda etapa, obtém-se uma lista de rampas que necessitam de faixas adicionais e o ano em que tais faixas devem ser 
construídas. O número de rampas nesta lista é menor ou igual ao número de rampas da lista obtida na etapa anterior. Esta lista considera a construção de cada faixa de forma isolada, estimando sua relação benefício/custo individual, sem levar em conta o efeito da sua construção sobre a operação do trecho. A denominação dada para tal lista é "conjunto de faixas adicionais a serem implantadas".

Na etapa final, o objetivo é obter o sequenciamento ideal da implantação das faixas cuja construção é justificada pelas diretrizes adotadas. Para isso, faz-se uma análise do incremento na relação benefício/custo global do trecho que é trazido pela construção da faixa ou das faixas, no caso de serem necessárias mais de uma. As faixas que trouxerem os maiores incrementos na relação $B / C$ serão as construídas antes.

Nas seções a seguir estão apresentados mais detalhes de cada uma das etapas do método proposto nesta pesquisa.

\subsection{ETAPAS PARA DEFINIR A SEQUÊNCIA DE CONSTRUÇÃO DE FAIXAS ADICIONAIS}

Conforme mostrado na Figura 3.1, o método proposto tem três etapas principais:

1. Identificação das rampas em que há redução excessiva da velocidade dos caminhões de projeto;

2. Obtenção do conjunto de rampas nas quais a implantação de faixa adicional é justificada e o ano no qual a faixa deve ser implantada; e

3. Obtenção da sequência ótima de implantação das faixas adicionais, considerando as restrições orçamentárias para investimento de capital e o crescimento de tráfego.

\subsubsection{Rampas candidatas à implantação de faixa adicional}

Um dos indicadores que reflete a necessidade de implantação da faixa adicional é a redução excessiva das velocidades dos caminhões típicos nas rampas. AASHTO (2001), MTO (1990), ATU (1999), DNER (1999) e Stimpson e Glennon (1971) adotam uma redução da velocidade em $15 \mathrm{~km} / \mathrm{h}$, enquanto Polus (1981) e Melo (2002) sugeriram $20 \mathrm{~km} / \mathrm{h}$. Em todas as pesquisas 
citadas, há a recomendação de que o ponto de início da faixa deve ser onde se completa essa redução da velocidade e o ponto final, onde a velocidade volta a ser igual à de entrada na rampa.

Assim, através do conhecimento de que o desempenho dos veículos movimentando-se em uma rampa pode ser caracterizado por relações de velocidade $\times$ distância, o método defendido na presente pesquisa requer a utilização de curvas de desaceleração, com o intuito de verificar em quais aclives há a redução excessiva da velocidade dos caminhões críticos que possuem as maiores relações massa $\times$ potência. Tais curvas podem ser obtidas como o usuário desejar ou conseguir.

Para o completo entendimento desta etapa, foi elaborado o fluxograma representado na Figura 3.2. Inicialmente, é necessário conhecer as características de desempenho da frota de caminhões que trafega pelo trecho sob análise, para selecionar, dentre as curvas de desaceleração usadas, a do veículo de projeto, que será o caminhão com desempenho operacional crítico e participação razoável no fluxo total do trecho.

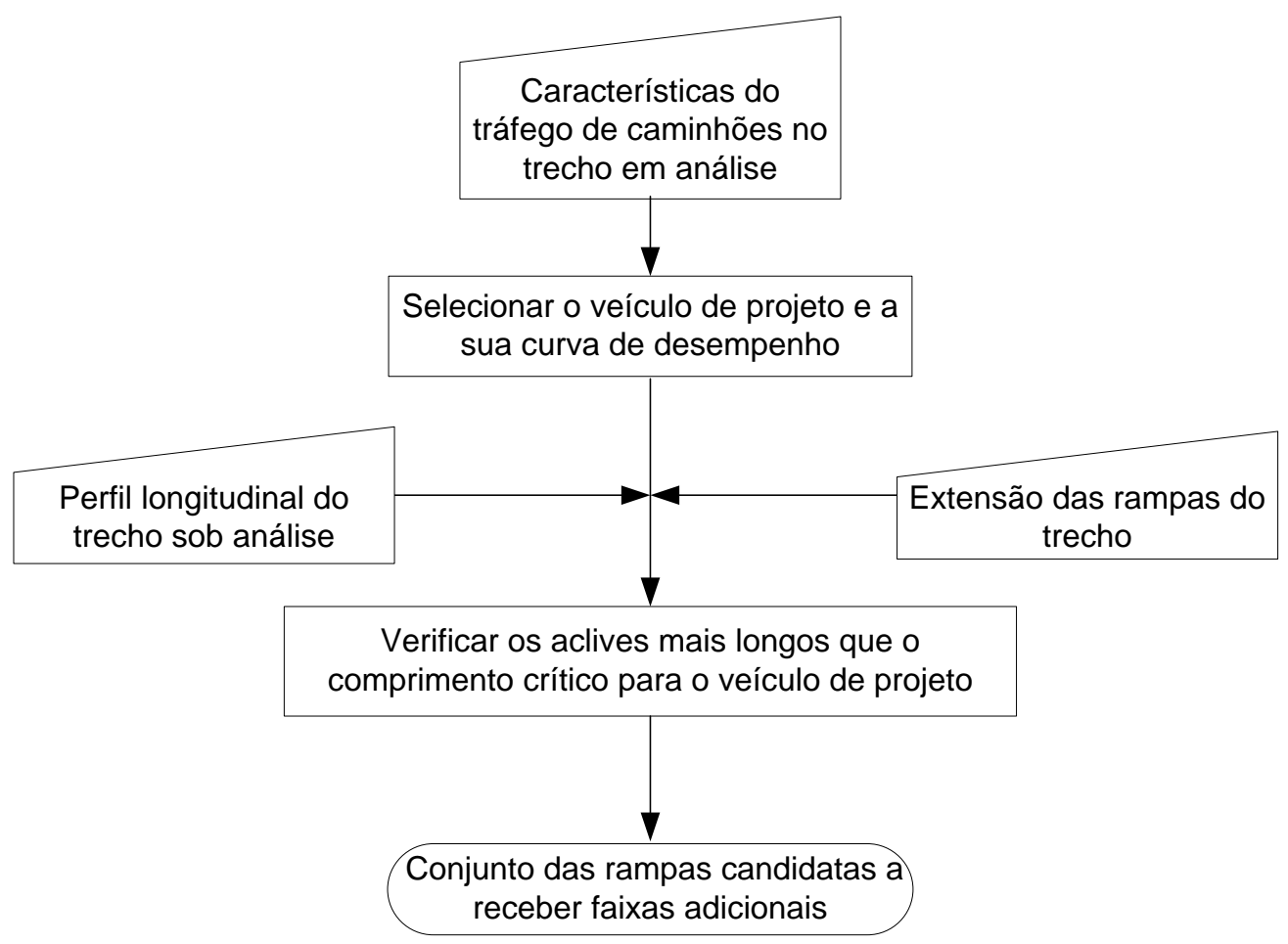

Figura 3.2 - Obtenção do conjunto de rampas candidatas a receber faixas adicionais 
A partir da declividade da rampa, da sua extensão, e da velocidade de entrada dos caminhões; verifica-se em quais rampas há redução de velocidade suficiente para garantir a necessidade de implantação de faixas adicionais. Para a definição do comprimento necessário dessas faixas, deve-se selecionar um dos métodos da bibliografia especializada listada no item 2.3.1.

\subsubsection{Obtenção do conjunto de faixas adicionais que devem ser implantadas}

A mera perda de velocidade dos veículos pesados não é suficiente para justificar a construção de faixas adicionais. Diretrizes de projeto consideram, além do efeito da perda da velocidade sobre a operação da rodovia, aspectos econômicos para verificar a necessidade de construção de uma faixa adicional de subida. Resumidamente, as diretrizes incluem três aspectos (AASHTO, 2001; Melo, 2002): (1) fluxo total de veículos na rampa; (2) porcentagem de caminhões no tráfego; e (3) impacto na operação da rodovia, medido em termos da perda de velocidade dos caminhões ou do nível de serviço na rampa. Por isso, a abordagem proposta usa uma previsão de tráfego ao longo do horizonte de projeto para verificar a necessidade de construção de faixas adicionais nas rampas candidatas.

Após o delineamento do conjunto das rampas que necessitam de faixas adicionais e da estimação dos fluxos das categorias veiculares consideradas em cada ano do horizonte de projeto, tem-se que conhecer o ano em que as melhorias serão necessárias. Para isso, são verificados os fluxos mínimos, da hora de pico e no sentido ascendente, que justificam a implantação das faixas adicionais em aclives. Esses fluxos mínimos são os estabelecidos por Melo e Setti (2007b) através da utilização do microsimulador TRARR e do cálculo das relações benefício/custo (Tabela 2.3, Pág. 26), nas quais os benefícios foram a redução do custo operacional e do tempo de viagem, e os custos foram os serviços de terraplenagem, pavimentação e drenagem.

Dessa forma, analisando-se o fluxograma da Figura 3.3, nota-se que esta etapa inicia-se com a especificação dos fluxos das horas de pico em todos os anos do horizonte de projeto. Tais fluxos são estimados a partir da multiplicação do volume diário médio (VDM) das categorias veiculares, pelas taxas de crescimento do tráfego observadas na região. 


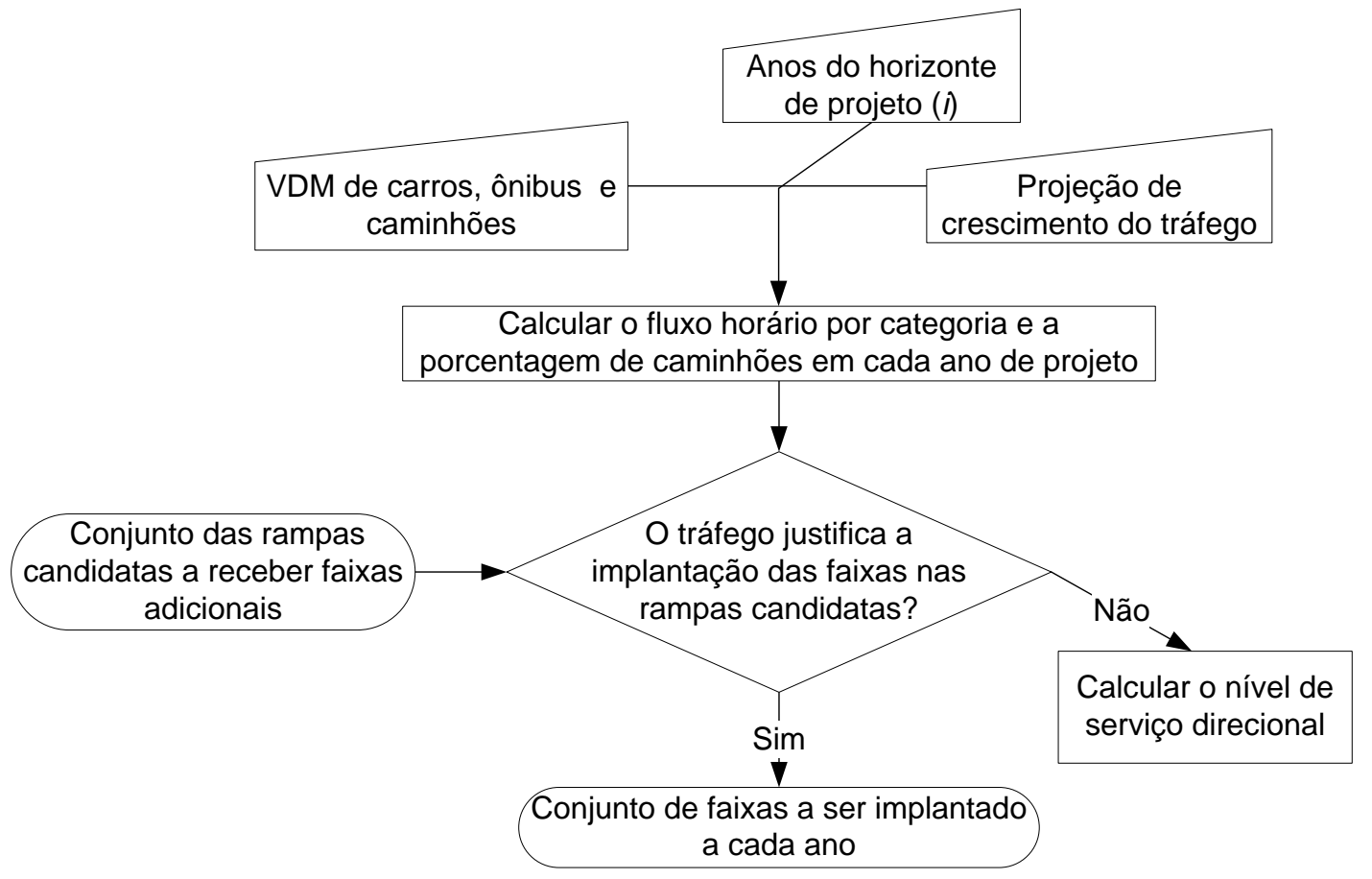

Figura 3.3 - Processo para obtenção do conjunto de faixas que devem ser implantadas no trecho

A partir daí, conhecendo-se as características geométricas do conjunto das rampas candidatas a receber as faixas adicionais e a porcentagem de caminhões na corrente de tráfego, a Tabela 2.3 (Pág. 26) é consultada para verificar o volume mínimo de tráfego que justifica economicamente a construção das faixas, verificando-se em quais anos pertencentes ao horizonte de projeto esses volumes são atingidos. Por exemplo, se em um determinado ano de projeto o fluxo horário direcional estimado for de 470 veíc/h, sendo $20 \%$ de caminhões, nas rampas com comprimento de $1000 \mathrm{~m}$ e declividade de até 2,5\% não há necessidade de faixa adicional. Porém, com esses mesmos valores de fluxo, porcentagem de caminhões e comprimento, nas rampas com declividade a partir de 3\% será necessário a implantação da faixa. A variável de saída dessa etapa será a lista das faixas adicionais que devem ser implantadas em cada ano de projeto, considerando a construção de cada faixa de forma isolada, sem avaliar o efeito da sua construção sobre a operação do trecho.

Nos anos da análise, em que nenhuma das rampas candidatas a receber faixas adicionais obtenha o fluxo mínimo que justifique a implantação da faixa, é recomendado um segundo critério de avaliação, baseado no nível de serviço direcional do trecho sob análise. Se o nível de serviço direcional, em um determinado ano $i$, for $\mathrm{D}$ ou pior, a primeira rampa do conjunto de candidatas que, nos anos posteriores ao $i$, atingir o fluxo mínimo que indica a necessidade 
de construção da faixa, deverá ter a faixa construída no ano $i$. Recomenda-se também esse critério de avaliação, visto que pela literatura, se o NS direcional do aclive estiver D, é mais uma indicação que há a necessidade de faixa adicional (ARTESP, 2005). Para o cálculo do NS deve-se utilizar o HCM (2000).

\subsubsection{Obtenção da sequência ideal para construção das faixas adicionais}

Uma vez obtido o conjunto de faixas adicionais que devem ser implementados a cada ano do projeto, a etapa seguinte do método proposto consiste em determinar a sequência de implantação que otimiza a utilização dos recursos disponíveis, a partir do efeito conjunto das faixas adicionais.

O método proposto está mostrado no fluxograma da Figura 3.4. O processo inicia-se pela verificação se o ano $i$ é maior do que o horizonte de projeto. A segunda verificação é se, para o mesmo ano $i$, há faixa adicional prevista. Se não houver, o algoritmo passa para o ano $i+1$ e o processo é reiniciado. Se houver, o algoritmo passa para a terceira e última verificação, que consiste em rastrear quantas faixas adicionais devem ser implantadas no ano $i$.

Sendo apenas uma faixa necessária, o usuário do método estipula um limite $k$ de anos, no qual a soma com $i$ não pode ser maior que o horizonte de projeto, e delineia-se um subconjunto de faixas cuja implantação deve ser feita entre o ano $i$ e o ano $i+k$.

Para cada uma das faixas desse subconjunto, são calculados os custos de implantação através da adoção de índices de reajuste econômico-financeiro para o ano $i$ sob análise. No cálculo dos benefícios, é utilizado o TWOPAS para simular o cenário atual e os cenários com adição de cada uma das faixas do subconjunto por vez. São calculadas as variações dos tempos de viagem, dos custos operacionais e dos acidentes observados apenas no aclive em que a faixa está sendo implantada. A partir daí, é feito um ranking das relações benefício/custo $(\mathrm{B} / \mathrm{C})$ individual das faixas adicionais que foram analisadas, sendo consequentemente implantada a faixa que obtiver o maior valor real dessa relação no ano $i$ sob análise.

Se forem duas ou mais faixas necessárias para um determinado ano, é definido também um limite $k$ de anos cuja soma com o ano $i$ não pode ser maior que o horizonte de projeto. A partir 
daí, tornam-se conhecidas todas as $p$ combinações de $j$ faixas necessárias do ano $i$ ao ano $i+$ $k$, sendo $j$ igual ao número de faixas necessárias no ano sob análise. Em todas as combinações analisadas, deve haver pelo menos uma das faixas necessárias no ano analisado.

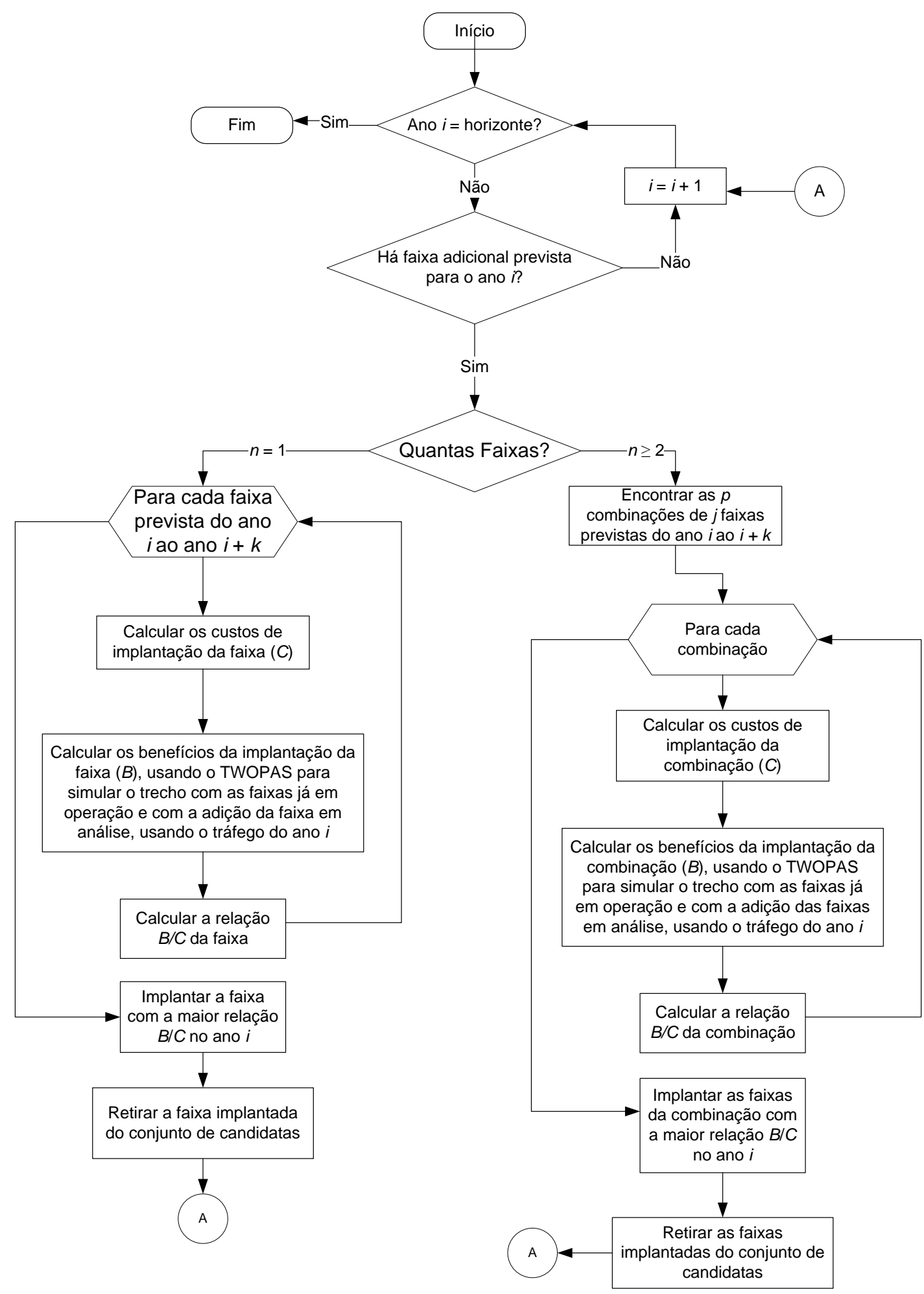

Figura 3.4 - Obtenção da sequência ideal de implantação das faixas adicionais 
O TWOPAS é usado para simular o cenário atual e os cenários com cada uma das combinações $C$ de $j$ faixas por vez para, a partir dos dados de saída (tempo de viagem, porcentagem do tráfego em pelotões e velocidade média no trecho), serem calculados os benefícios proporcionados por cada combinação em toda extensão do trecho analisado (benefício global).

Em seguida é criado o ranking das relações B/C global e são implantadas as faixas da combinação que obtiveram o maior valor. Em ambas as situações, é necessária a atualização do conjunto inicial de faixas a serem implantadas através da remoção das que já foram implantadas. Após a atualização do conjunto, o processo passa para o ano $i+1$ e é reiniciado, repetindo-se esse ciclo até o horizonte do projeto, ou até que todas as faixas do conjunto inicial tenham sido implantadas, se isso ocorrer antes do horizonte do projeto.

\subsection{SELEÇÃO E COLETA DOS DADOS DE ENTRADA}

Tanto na obtenção do conjunto de faixas adicionais necessárias, quanto no cálculo das relações benefício/custo global e individual, são necessários dados sobre o tráfego, características geométricas da via e custos de construção e de operação dos veículos.

Os dados de tráfego incluem a divisão da frota que passa pelo trecho analisado em classes veiculares e suas respectivas velocidades médias; a porcentagem do tráfego em pelotões; o tempo de viagem no trecho; o fluxo horário e volume diário médio; a média do número de passageiros nos carros e nos ônibus; e a velocidade de projeto do trecho.

A grande parte desses dados é facilmente coletada nas rodovias de pista simples. A divisão entre classes, o fluxo horário e o volume diário médio podem ser coletados através de simples observações em campo durante um intervalo de tempo predefinido.

Os dados necessários para a calibração do TWOPAS, as velocidades médias de cada classe, a porcentagem do tráfego em pelotões e o tempo de viagem no trecho podem ser coletados através de filmagens na entrada e na saída do trecho. Cada veículo é identificado pela placa, marca, modelo e cor. Posteriormente, o instante de passagem de cada veículo é extraído da imagem das filmadoras, que devem estar com o relógio interno sincronizados. Dessa forma, é possível identificar o tempo gasto pelo veículo para percorrer o trecho e, 
assim, estimar a velocidade média do veículo. A porcentagem de veículos em pelotões em cada ponto de filmagem é obtida pela computação da porcentagem do total de veículos que viajam com headways de até três segundos (HCM, 2000).

Devem ser também escolhidos os fatores de crescimento do tráfego baseados nas características da região. Por isso, é importante ter cuidado ao determinar o ano de horizonte de projeto, pois, já que todos esses fatores de crescimento são baseados em séries históricas, é recomendado que o limite seja de até 30 (trinta) anos. Caso contrário, os fluxos estimados podem desviar-se consideravelmente da realidade.

As variáveis das características geométricas necessárias são a largura das faixas de tráfego; a localização e extensão das faixas adicionais existentes e das que serão implantadas; o perfil longitudinal e a extensão do trecho analisado. Essas variáveis podem ser levantadas através dos projetos geométricos dos trechos e/ou levantamentos em campo.

As variáveis econômicas necessárias são: o valor do salário mínimo, os custos operacionais dos carros, ônibus rodoviários e caminhões (leve, médio, pesado e extra-pesado), além dos custos dos serviços necessários para obras de melhoria em rodovias (terraplenagem, drenagem, pavimentação e sinalização).

Os aspectos da estimativa dos benefícios e custos são discutidos, respectivamente, nos capítulos 4 e 5. O capítulo 6 traz um estudo de caso que demonstra a aplicação do método proposto. Um trecho hipotético serviu como modelo para a coleta de dados e desenvolvimento dos cenários que foram simulados. Optou-se por uma rodovia de pista simples, em um terreno ondulado, sem faixas adicionais. 


\section{CÁlCULO DOS BENEFÍCIOS}

Para garantir a aplicação de investimentos públicos em projetos que tragam os maiores benefícios à sociedade, é desejável estruturar análises de viabilidade econômica no desenvolvimento de qualquer projeto da infraestrutura rodoviária (Klein et. al., 2005). Nesse sentido, a correlação entre 3 dos principais componentes dos custos dos transportes rodoviários, os custos de construção; de conservação das vias e de operação dos veículos deve ser determinada através de modelos que representem o impacto de diversas variáveis sobre o custo de operação dos veículos (GEIPOT, 1982).

Button (1996) cita que os investimentos em melhoria de infraestrutura rodoviária também trazem "externalidades" positivas, como a redução do tempo de viagem para os usuários e/ou carga e a diminuição do número de acidentes.

A análise econômica do projeto deveria também incluir externalidades negativas, como a poluição, o aumento do ruído causado pelo tráfego, a poluição visual, a perda de áreas que poderiam ser usadas para equipamentos públicos para recreação ou parques, etc. No entanto, é difícil atribuir valor à degradação ambiental e modelos para isso ainda estão na fase inicial de desenvolvimento (Pedrozo, 2001).

Na prática, é verificado que todos esses benefícios interagem entre si. Porém, no presente trabalho, para a quantificação dos benefícios que são proporcionados pela implantação de faixas adicionais, buscou-se quantificar as reduções dos custos operacionais, dos tempos de viagem e dos acidentes.

A revisão da literatura mostrou que os modelos com maior capacidade de contribuir com os propósitos desta pesquisa seriam os do HDM-4 (Highway Development and Management System) (Kerali, 2000; Kerali et al. 2000; Odoki e Kerali, 2000) e do projeto ESTRADA (Estimação de Custos e Benefícios Reais para a Avaliação Econômica de Projetos de Investimento Rodoviário em Portugal) (Macário et al. 2007 e Rodrigues, 2007). Outros estudos importantes, desenvolvidos no Brasil, incluem GEIPOT (1982), DNER (1976, 1979), Kabbach (1992) e Melo (2002). 
Assim, as seções seguintes discutem como estimar os benefícios da construção de faixas adicionais em rodovias de pista simples, lembrando que esses benefícios são calculados através da diferença absoluta entre os somatórios dos custos operacionais, do tempo de viagem e do número de acidentes, para as condições depois e antes da implantação das melhorias.

\subsection{REDUÇÃO DOS CUSTOS OPERACIONAIS}

O cálculo da variação dos custos operacionais em relação às modificações geométricas das rodovias passou a ser importante a partir da década de 1970, devido principalmente ao aumento do preço dos combustíveis e, consequentemente, dos pneus e das peças de reposição (Klein et. al. 2005).

A economia e a segurança da operação dos veículos rodoviários são alcançadas quando se proporcionam condições para que as velocidades de percurso sejam as mais uniformes e contínuas possíveis. Na concepção dos projetos rodoviários atuais são buscadas as soluções que conduzem aos menores custos totais de transporte, relacionados tanto ao custo de construção da via como também aos custos operacionais do tráfego (Kabbach, 1992).

Assim, os custos operacionais dos veículos constituem-se no custo do usuário ou transportador da carga que estão relacionados à depreciação do veículo e às condições da rodovia e retratam o custo de utilizar determinada rodovia. Pedrozo (2001) notou que quanto mais alto o custo de construção, ou seja, quanto melhor o padrão da rodovia, menor será o custo operacional do usuário e da carga.

Diante disso, os custos operacionais veiculares têm a velocidade como o maior indicador da modificação; portanto tal parâmetro é primordial na variação dos custos de combustíveis e lubrificantes, pneus, manutenção, tripulação depreciação, tempo de passageiros e carga.

\subsubsection{Estimativas de redução de custos operacionais pelo HDM-4}

No modelo HDM-4, para uma dada seção viária e para cada ano de análise, os recursos consumidos são modelados considerando-se a operação de cada tipo de veículo sob as diferentes condições de intensidades do fluxo de tráfego, sendo os resultados agregados em 
totais anuais. O cálculo dos recursos consumidos por cada tipo de veículo considerado na análise inclui: 1) consumo de combustível, 2) consumo de lubrificantes, 3) desgaste dos pneus, 4) utilização do veículo, 5) consumo de peças de reposição, 6) horas da mão de obra de manutenção, 7) custos do capital investido, 8) horas da tripulação e, 9) despesas gerais. Visto a grande quantidade de equações e variáveis que compõe essa metodologia, é recomendada a consulta aos manuais do HDM-4 (Kerali, 2000; Kerali et al. 2000; Odoki e Kerali, 2000).

O modelo de consumo de combustível do HDM-4 é baseado no modelo mecanicista do ARFCOM (Biggs, 1988), o qual supõe que o consumo de combustível é proporcional à força necessária para mover o veículo, que é função da potência utilizada.

O modelo utilizado para o cálculo do consumo dos óleos de lubrificação é baseado no desenvolvido por Pienaar (1984). Esse modelo é dividido entre dois componentes: perda de óleo devido à contaminação e devido à operação. A perda devido à contaminação é em função das distâncias entre as trocas de óleo. Já a perda devido à operação é calculada em função do consumo de combustível.

O modelo de consumo de pneus do HDM é baseado na teoria da energia de escorregamento, sendo proporcional à energia requisitada pelo sistema. A taxa de consumo dos pneus é expressa em termos do número equivalente de pneus novos consumidos para percorrer $1000 \mathrm{~km}$, para cada roda do veículo. Essa taxa é calculada separadamente para segmentos em aclives e em declives. É feita uma média dos valores encontrados para representar o consumo de pneus em uma viagem de ida e volta num determinado segmento rodoviário.

A quantificação da utilização do veículo e o delineamento da sua vida útil são importantes por fazerem parte do cálculo do consumo de peças, do custo do capital e das despesas gerais (Odoki e Kerali, 2000).

A utilização do veículo é definida como a quilometragem total percorrida em um ano, durante o tempo de trabalho. O "tempo de trabalho" é definido por Kerali (2000) como o tempo gasto com a execução de um conjunto de tarefas necessárias para a realização de uma viagem de ida e volta. Ou seja, exclui o tempo que se gasta com repouso e alimentação, mas considera o tempo gasto com o carregamento, descarregamento, abastecimento e translado. 
São dois os métodos usados para o cálculo da vida útil dos veículos: o da depreciação constante e o da depreciação "otimizada". No primeiro, a partir da definição de um total de anos apropriado para o veículo virar sucata, é considerado que a perda de valor de mercado do veículo durante esses anos é constante e independe do seu estado de conservação. No método da depreciação "otimizada", é considerada uma quilometragem total como o limite para o veículo virar sucata, podendo ainda ser considerada na análise a rugosidade dos pavimentos pelos quais o veículo trafegou (Odoki e Kerali, 2000).

Os custos com peças sobressalentes constituem uma significante parcela dos custos de operação dos veículos. A necessidade de troca da maioria da peças é dependente da quilometragem percorrida pelo veículo e da rugosidade da superfície do pavimento. A variação da velocidade também afeta as taxas de uso e desgaste dos componentes veiculares (Kerali et al. 2000).

O método considera que as horas de trabalho de manutenção são as horas gastas com a montagem dos componentes e com a reposição de peças dos veículos. Para o cálculo dos custos de manutenção, é necessário, além de outras coisas, que o usuário forneça os valores das horas de trabalho. É necessário também o cálculo das horas gastas com os serviços de manutenção, o qual é feito em função do consumo de peças de reposição (Odoki e Kerali, 2000).

Os custos do capital compreendem o somatório entre a depreciação e os juros, sendo esses sensíveis à utilização do veículo e sua vida útil, as quais, por sua vez, dependem da velocidade do veículo e das condições viárias (Kerali et al. 2000).

Os custos com a tripulação estão incluídos na categoria de custos operacionais do veículo e não na dos custos do tempo de viagem. Esses custos com a tripulação são obtidos, basicamente, a partir do produto do número de membros da tripulação pelo valor do seu salário (Kerali et al. 2000).

As despesas gerais envolvem os recursos gastos com administração, seguro, estacionamento/garagem e, despesas gerais relacionadas com a tripulação (ex. treinamento, uniformes etc.). Esses custos são calculados em função da utilização anual do veículo e da velocidade média de funcionamento (Odoki e Kerali, 2000). 
Contudo, essa revisão torna evidente que os modelos propostos no HDM-4 para o cálculo dos benefícios devido às melhorias rodoviárias são atualmente os mais complexos. Isso se deve ao grande número de variáveis consideradas na análise e a maneira como elas interagem entre si. Apesar de as chances de gerar resultados mais precisos serem maiores, a utilização desses modelos requer a obtenção dos mais diversos tipos de informações, sendo necessária, portanto, a execução de várias coletas de dados e a estimação de valores médios.

\subsubsection{Estimativas de redução de custos operacionais pelo ESTRADA}

No ESTRADA os custos operacionais foram divididos entre aqueles relacionados ao consumo de combustível $\left(\mathrm{C}_{\mathrm{r}}\right)$ e os relacionados à utilização do veículo $\left(\mathrm{C}_{1}\right)$, tendo sido utilizado para $\mathrm{o}$ seu cálculo alguns modelos do COBA (2002), os quais foram adaptados e calibrados para a realidade de Portugal.

Nesse estudo, constatou-se que os custos relacionados com o combustível são proporcionais ao aumento da velocidade, ao passo que se verifica a situação inversa para os custos não relacionados com o combustível. O somatório das duas componentes do custo operacional, ou seja, o custo total é uma função decrescente até a velocidade de $50 \mathrm{~km} / \mathrm{h}$ e crescente a partir desse ponto, conforme ilustra a Figura 4.1. Nessa figura, TI são os veículos de passageiros, LGV são caminhonetes de até 3,5 toneladas, OGV1 são veículos de carga de 2 ou 3 eixos, OGV2 são veículos de 4 eixos ou mais e PSV são os ônibus rodoviários.

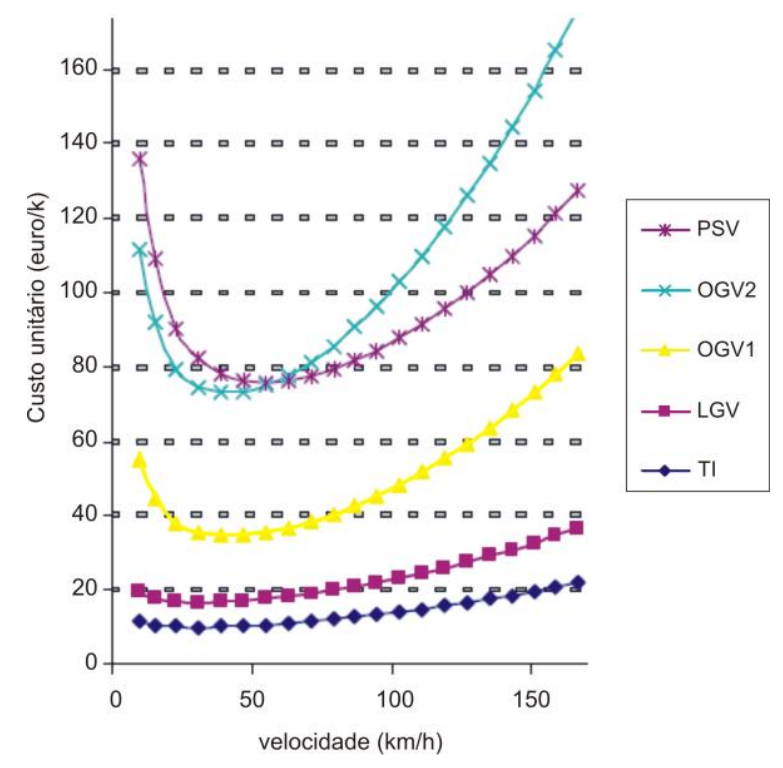

Figura 4.1 - Custo Operacional total (euro/100.veíc.km) (Macário et al. 2007) 
Nota-se que o ESTRADA, antes de tudo, é uma revisão dos métodos utilizados na União Européia para o cálculo dos benefícios e custos proporcionados pelas melhorias rodoviárias. Diferentemente do HDM-4, os modelos que calculam a redução dos custos operacionais não são compostos por muitas variáveis, e para serem aplicados em análises de cenários nacionais, torna-se necessária a calibração de diversos parâmetros, assim como no HDM-4.

\subsubsection{Estimativas de redução de custos operacionais pelos modelos nacionais}

Dentre os modelos nacionais que se propuseram a calcular a variação dos custos operacionais veiculares em função de melhorias geométricas, optou-se, para o desenvolvimento deste trabalho, pelos publicados inicialmente por DNER (1976 e 1979) e aperfeiçoados por Kabbach (1992) e Melo (2002). A escolha desses modelos foi feita por todos considerarem os efeitos das melhorias nos aclives.

Nessas quatro referências, é considerado que o benefício da redução dos custos operacionais $(B R C O)$ é igual ao somatório da redução desses custos para os automóveis (BRCOa), ônibus (BRCOo) e caminhões $(B R C O c)$.

Em um aclive que não tem faixa adicional e com reduzida possibilidade de ultrapassagem, os veículos "rápidos" (carros, ônibus e caminhões vazios) após alcançarem os veículos "lentos" (veículos carregados com baixo desempenho), são obrigados a trafegar à mesma velocidade dos veículos "lentos", o que acarreta no acréscimo dos custos operacionais dos veículos "rápidos", já que esses estão deixando de desenvolver sua velocidade padrão de operação, em função da extensão e declividade do greide (Kabbach, 1992).

A extensão em que os "rápidos" são obrigados a trafegar atrás dos "lentos" é denominada então de "distância média de acompanhamento" $\left(L_{m}\right)$. Portanto, a avaliação dessas distâncias torna-se necessária para cada combinação de declividade e extensão da rampa, e do volume e composição do tráfego. O valor dessa distância pode ser calculado pela equação (Kabbach, 1992):

$$
L_{m}=\frac{A_{d u}}{T_{1}-T_{2}}
$$

sendo: $\quad L_{m}$ : distância média de acompanhamento em que um veículo "rápido" 
acompanha um "lento" na rampa sob análise $(\mathrm{km})$;

$A_{d u}$ : atraso diário médio de cada veículo "rápido" na rampa sob análise (h);

$T_{1}$ : tempo gasto por um veículo "lento" para percorrer um segmento de 1 km da rampa com a velocidade de sustentação (h); e

$T_{2}$ : tempo gasto por um veículo "rápido" para percorrer um segmento de 1 $\mathrm{km}$ da rampa com a velocidade de $75 \mathrm{~km} / \mathrm{h}(\mathrm{h})$.

Os custos operacionais por quilômetro para os veículos brasileiros viajando em condições ideais nas rodovias de pista simples foram estabelecidos em DNER (1976) e DNER (1979). As condições ideais são: trecho em nível, pavimento em boas condições e velocidade mais econômica. Os acréscimos nos custos operacionais, quando as condições ideais alteram-se pelo fato do veículo estar trafegando em aclives, podem ser calculados em função de $L_{m}$.

As curvas das Figuras 4.2, 4.3 e 4.4 foram obtidas a partir dos custos operacionais unitários calculados pelo DNER para diferentes declividades e velocidade média de operação (Kabbach, 1992). Como pode ser notado, qualquer alteração nas condições "ideais" corresponde a um custo operacional superior, sendo a relação entre esses custos dada pela ordenada correspondente. Para todas as declividades analisadas, a velocidade do veículo de passeio é inversamente proporcional ao seu custo de operação, e no caso dos ônibus e caminhões a velocidade mais econômica é de, aproximadamente, $55 \mathrm{~km} / \mathrm{h}$.

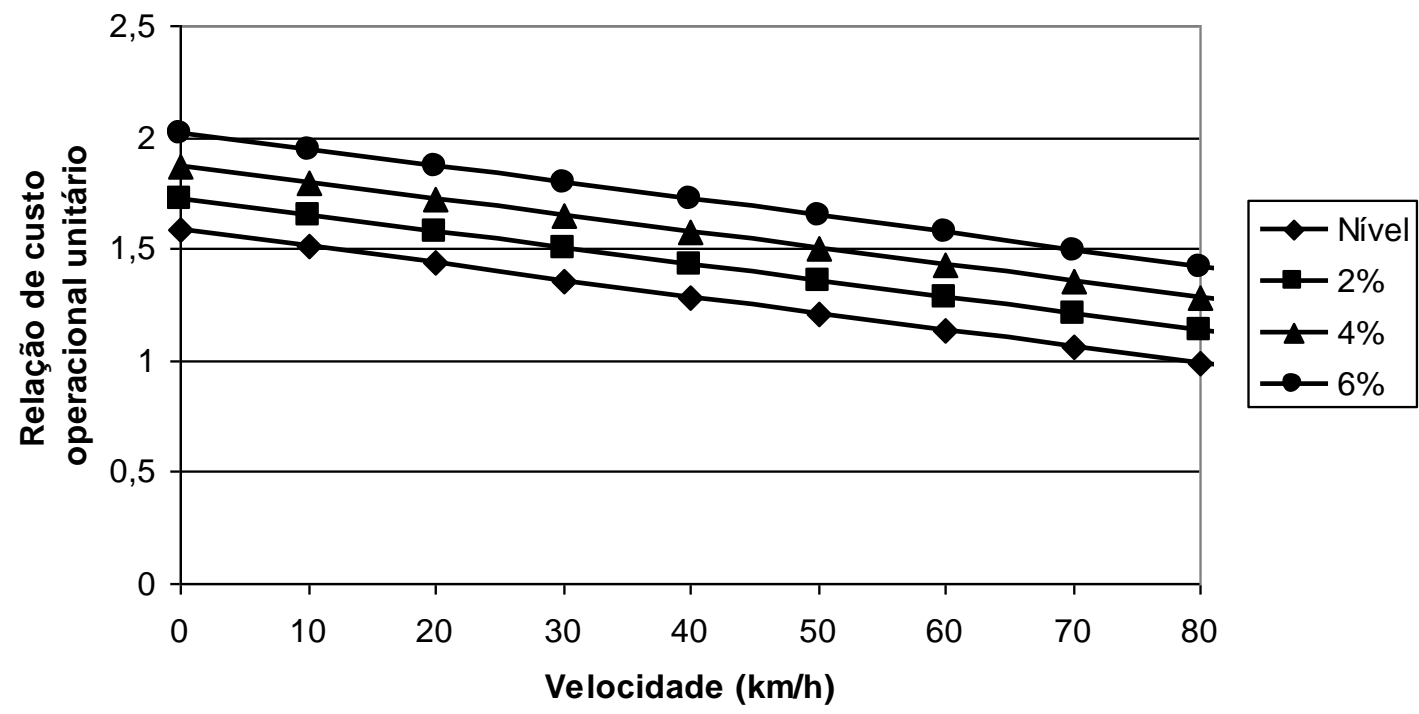

Figura 4.2 - Relação de custos operacionais unitários para veículos de passeio em função da velocidade e declividade da rampa 


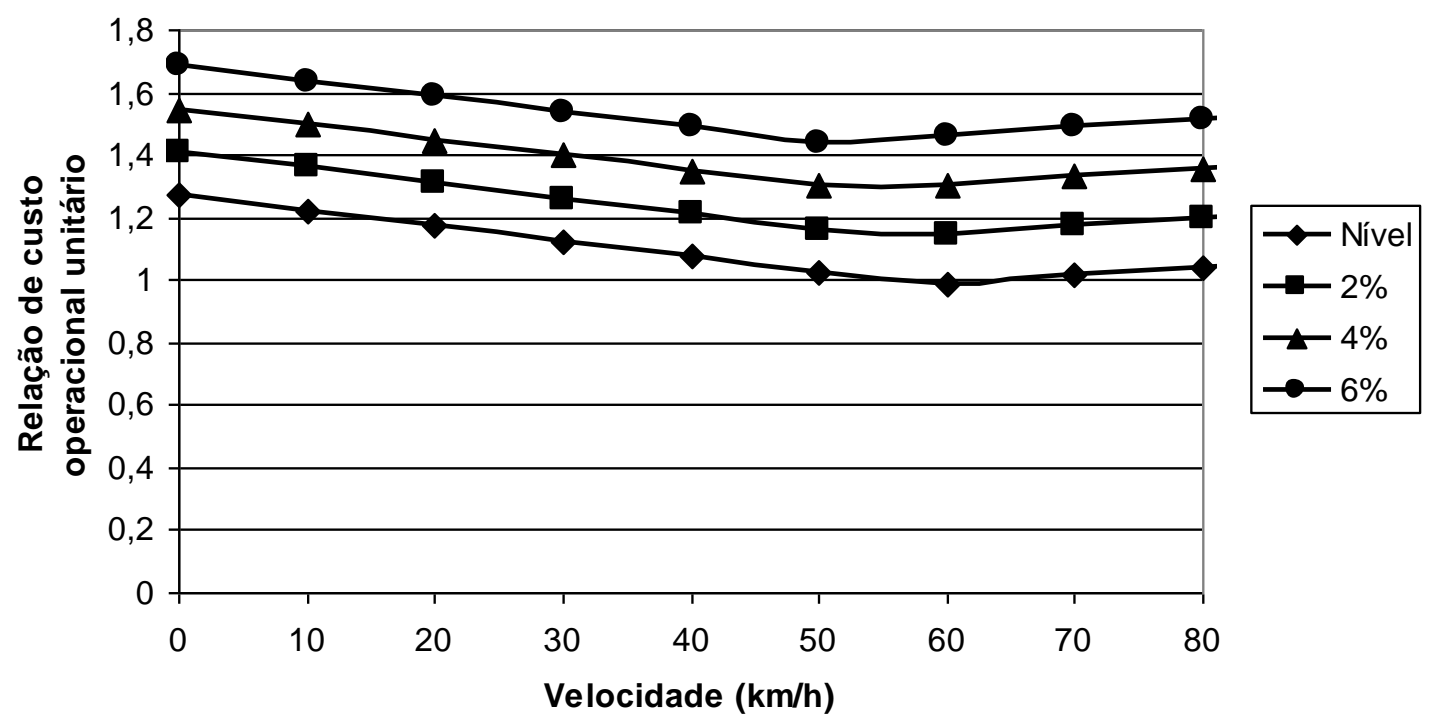

Figura 4.3 - Relação de custos operacionais unitários para ônibus em função da velocidade e declividade da rampa

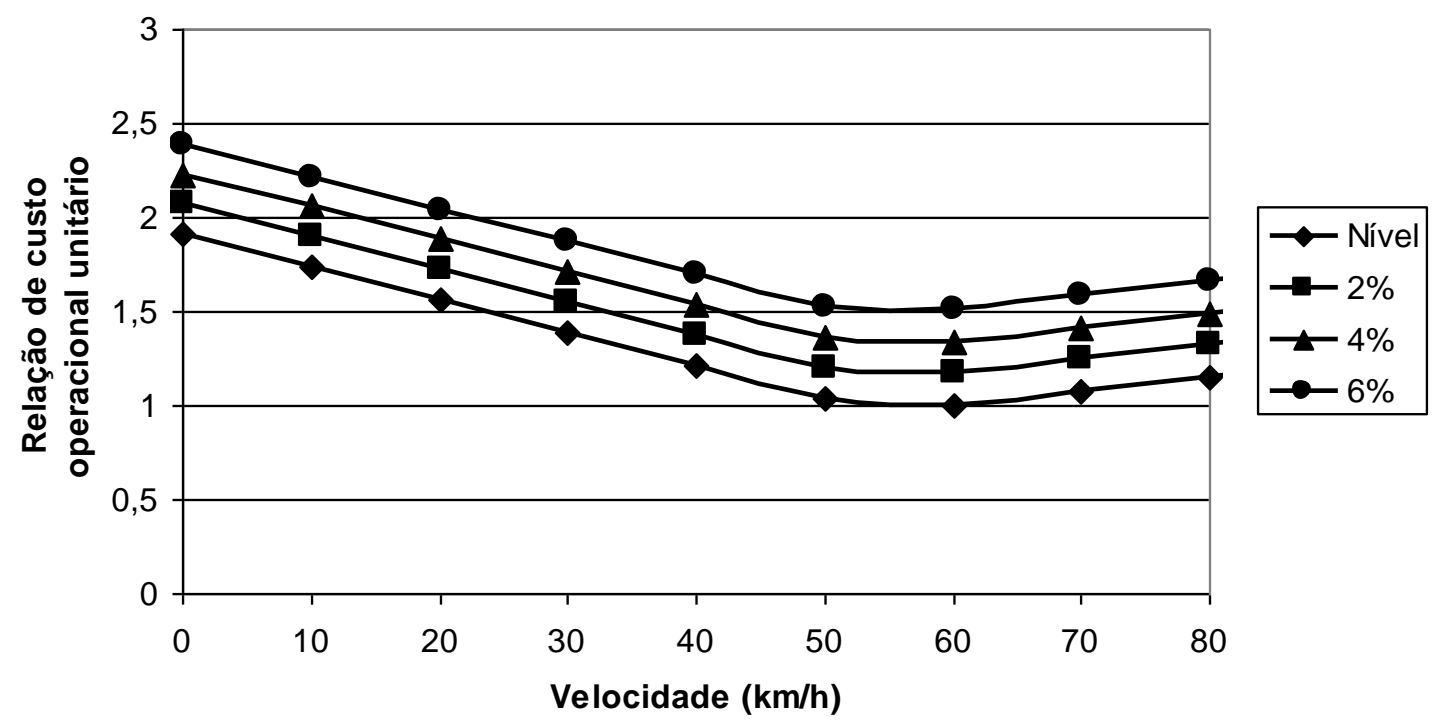

Figura 4.4 - Relação de custos operacionais unitários para caminhões vazios em função da velocidade e declividade da rampa

As relações entre os custos unitários, as velocidades e as declividades das rampas foram obtidas destas curvas, por regressão linear, e estão apresentadas a seguir nas Equações 4.2 a 4.6 (Kabbach, 1992).

* Para automóvel:

$$
R_{A}=1,5822+0,0721 \times i-0,0074 \times V_{A}
$$


* Para ônibus:

$$
\begin{gathered}
V_{O} \leq 55 \mathrm{~km} / \mathrm{h} \Rightarrow R_{O}=1,2705+0,069 \times i-0,0049 \times V_{O} \\
V_{O}>55 \mathrm{~km} / \mathrm{h} \Rightarrow R_{O}=0,8402+0,0788 \times i-0,0025 \times V_{O}
\end{gathered}
$$

* Para caminhão vazio:

$$
\begin{gathered}
V_{C V} \leq 55 \mathrm{~km} / \mathrm{h} \Rightarrow R_{C V}=1,9104+0,0801 \times i-0,0174 \times V_{C V} \\
V_{C V}>55 \mathrm{~km} / \mathrm{h} \Rightarrow R_{O}=0,54413+0,0844 \times i-0,00763 \times V_{C V}
\end{gathered}
$$

sendo: $\quad R_{A}$ : relação entre o custo operacional do automóvel, para a situação considerada e o custo operacional, para a situação ideal ( $V_{A}$ igual a 80 $\mathrm{km} / \mathrm{h}$, em trecho plano);

$R_{O}$ : relação entre o custo operacional do ônibus, para a situação considerada e o custo operacional, para a situação ideal ( $V_{O}$ igual a $55 \mathrm{~km} / \mathrm{h}$ em trecho plano);

$R_{C V}$ : relação entre o custo operacional do caminhão vazio, para a situação considerada e o custo operacional, para a situação ideal ( $\mathrm{V}_{\mathrm{CV}}$ igual a $55 \mathrm{~km} / \mathrm{h}$ em trecho plano);

$i$ : declividade do aclive (\%);

$V_{A}$ : velocidade do automóvel na rampa $(\mathrm{km} / \mathrm{h})$;

$V_{O}$ : velocidade do ônibus na rampa $(\mathrm{km} / \mathrm{h})$; e

$V_{C V}$ : velocidade do caminhão vazio na $\operatorname{rampa}(\mathrm{km} / \mathrm{h})$.

A partir dessas relações, Melo (2002) calculou os benefícios gerados pela redução dos custos operacionais. É importante ressaltar que na presente pesquisa serão seguidas as mesmas etapas propostas em Melo (2002), mas com as atualizações dos valores de algumas variáveis, conforme descrito na Seção 4.4.1.

\subsection{REDUÇÃO DOS TEMPOS DE VIAGEM}

Nas avaliações Benefício/Custo de projetos rodoviários, a redução do tempo de viagem pode representar até $80 \%$ do benefício total mensurado para o projeto (Romero et al. 2000). Para calcular o benefício proporcionado pela redução do tempo de viagem é necessário quantificar a economia do tempo total de viagem dos veículos rápidos, propiciada por investimentos em obras de melhorias rodoviárias. 
Após o cálculo dessa economia do tempo, é necessária a estimação do valor do tempo dos usuários. Além do uso nas análises econômicas de projetos, o valor atribuído ao tempo de viagem das pessoas é também utilizado em previsões de escolha modal ou de rotas. Essas duas aplicações são respectivamente definidas como (Ortúzar e Willumsen, 2001) valor social (ou para avaliação) e valor subjetivo (ou comportamental).

O valor subjetivo do tempo é normalmente referido como a disponibilidade de um indivíduo pagar a mais pela economia de tempo, ou seja, pode ser interpretado como a taxa marginal de substituição entre o tempo de viagem e o custo da viagem (Romero et. al. 2005). Na presente pesquisa, em que um dos objetivos é calcular a economia de tempo devido à implantação de faixas adicionais, a estimativa utilizada será a do valor social do tempo (ou para avaliação). Essa estimativa é, principalmente, uma questão empírica, apesar de alguns fortes fundamentos na microeconomia (Vilain e Bhandari, 2002). Nas próximas subseções serão apresentadas também algumas das principais metodologias utilizadas para o cálculo do valor social do tempo.

\subsubsection{Estimativas de redução dos tempos de viagem pelo HDM-4}

No HDM-4, o cálculo do número de horas como passageiro é feito em função da velocidade de operação do veículo, sendo esse número de horas calculado separadamente para as viagens com motivo trabalho e as com outros motivos que não trabalho. Isso torna possível o conhecimento dos atrasos associados às condições de operação particulares de cada período do fluxo de tráfego (Kerali et al. 2000).

Dessa forma, além de modelos específicos para calcular as horas de passageiro durante o período de trabalho e as horas de passageiro durante o período de não trabalho, há a recomendação de modelos para calcular o número de horas gasto em trânsito e os custos do tráfego em pavimentos deteriorados(Odoki e Kerali, 2000).

Ao analisar os modelos do HDM-4 que calculam o benefício da redução do tempo de viagem, nota-se novamente que, apesar da aparente precisão dos resultados gerados por esses, a sua utilização é impossibilitada se não forem conhecidos os valores de específicas variáveis, como a quantidade de horas gasta no trânsito por razões de trabalho e de não trabalho. 


\subsubsection{Estimativas de redução dos tempos de viagem pelo ESTRADA}

Para o projeto ESTRADA, o benefício da redução do tempo de viagem dá-se pela redução dos custos de congestionamento. Por isso, é necessária a quantificação do tempo perdido e do valor do tempo.

No cálculo do tempo perdido, são utilizadas as relações fluxo-velocidade do HCM, com intuito de comparar as condições reais do fluxo de tráfego com as condições de fluxo livre. Após calcular o acréscimo de tempo devido ao fluxo de tráfego no instante analisado, é determinado o custo total de congestionamento da corrente de tráfego.

O valor atribuído ao tempo é dependente de fatores como o motivo e a extensão da viagem, além do tipo de veículo. Representa-se, assim, o montante máximo que um determinado indivíduo está disposto a pagar para poupar tempo de viagem.

Também é ressaltado, que não existe um valor do tempo pré-definido para Portugal, nem um estudo detalhado sobre a intenção dos usuários em pagar mais pela economia de tempo. Assim, adota-se a recomendação do Bickel et al. (2006) acerca do tempo de viagem, ou seja, o tempo de viagem é uma composição do tempo no veiculo (in vehicle) e fora do veiculo (out of vehicle time).

No que diz respeito à desagregação recomenda-se três categorias em função do motivo da viagem: (i) passageiro em trabalho (passenger work); (ii) passageiro "não em trabalho" (non work); e (iii) tráfego de mercadorias (commercial goods traffic) (Rodrigues, 2007; pág. 63). Esta desagregação é recomendada por causa dos diferentes métodos de avaliação utilizados para calcular o valor dos efeitos da economia de tempo nas viagens (Bickel et al. 2006, pág. S4).

Bickel et al. (2006) ainda recomenda que diferentes métodos de avaliação da economia do tempo de viagem devem ser utilizados para analisar cada uma das três categorias citadas acima. É recomendada uma metodologia mínima aceitável para a avaliação da economia do tempo (cost saving), assim como uma metodologia mais complexa para tal, a de Hensher (1977). 
A abordagem cost saving não assume nenhum impacto sobre o usuário/motorista, apenas considera que todas as economias de tempo podem ser convertidas em aumento da produtividade. Já a abordagem mais sofisticada de Hensher (1977) não qualifica todos os tempos de viagem como improdutivos e nem todas as economias de tempo são empregadas no aumento da produtividade. Para o cálculo do valor do tempo, a abordagem a ser utilizada deve ser compatível com o nível de detalhe requerido no projeto em desenvolvimento.

Semelhante ao observado no HDM-4, o projeto português recomenda a desagregação do tempo em função do motivo da viagem, até para o método de avaliação mais simples (cost saving). Assim, a sua utilização torna-se inviável se não forem conhecidas as quantidades de horas gastas com atividades de trabalho, de não trabalho e de transporte de mercadorias.

\subsubsection{Estimativas de redução dos tempos de viagem pelos modelos nacionais}

$\mathrm{Na}$ presente pesquisa, para estimar os benefícios das reduções dos tempos de viagem, foram utilizados os modelos recomendados por EBTU (1981), Kabbach (1992) e Melo (2002).

Kabbach (1992) supôs que os benefícios anuais gerados pela redução do tempo de viagem (BRTV) podem ser estimados pela equação:

$$
B R T V=365 \times A_{d} \times C H_{u} \times R
$$

sendo: $\quad A_{d}$ : atraso diário real causado aos veículos rápidos que sobem a rampa (h); $\mathrm{CH}_{u}$ : valor médio ponderado da hora perdida por veículo $(\mathrm{R} \$)$, considerando motoristas de automóveis e passageiros de automóveis e de ônibus; e

$R$ : fator adimensional que exprime a participação dos veículos rápidos que geram benefícios de redução de atraso (automóveis e ônibus) na frota total de veículos rápidos (inclui os caminhões vazios).

Para o cálculo de $\mathrm{CH}_{u}$, foi adotado o modelo (EBTU, 1981):

$$
C H u=\frac{P_{A} \times\left(0,0352+0,0123 \times N_{p a}\right)+0,0123 \times P_{O} \times N_{p o}}{P_{A}+P_{O}} \times S M
$$

sendo: $\quad P_{A}$ : porcentagem de automóveis dentro da composição do tráfego (veíc/dia); $N_{p a}$ : Número médio de passageiros por automóvel; 
$P_{O}:$ porcentagem de ônibus dentro da composição do tráfego (veíc/dia);

$N_{p o}$ : Número médio de passageiros por ônibus; e

SM: valor do salário mínimo $(\mathrm{R} \$)$.

Já para o cálculo de $R$ foi proposto o modelo:

$$
R=\frac{P_{A}+P_{O}}{P_{A}+P_{O}+P_{C V}}
$$

sendo: $\quad P_{C V}:$ porcentagem de caminhões vazios dentro da composição do tráfego (veíc/dia).

Entretanto, Melo (2002) sugeriu que para o cálculo do BRTV, $A_{d}$ fosse substituído pela variável intitulada de redução do tempo de viagem ( $r t v)$, quando é possível utilizar um simulador de tráfego para obter a variação do tempo de viagem para as condições sem e com faixas adicionais. Assim, como foi feito para os custos operacionais, na presente pesquisa foi seguida a sequência de cálculo recomendada por Melo (2002), apresentada na Seção 4.4.2.

\subsection{REDUÇÃO DOS ACIDENTES}

Qualquer tipo de acidente rodoviário acarreta um grande ônus social, em decorrência dos prejuízos materiais e humanos.

Em aclives íngremes e extensos, nas rodovias de pista simples, a combinação da redução de velocidade imposta pelos veículos pesados aos veículos mais rápidos, com um alto fluxo de tráfego, conduz à formação de filas que geram impaciência e desconforto ao usuário. Essa situação aumenta a tendência dos veículos mais rápidos em assumir riscos crescentes para efetuar manobras de ultrapassagem inseguras, com alto potencial de gerar acidentes. Nestas condições, os acidentes tendem a ser graves, como colisões frontais.

Dentre as obras de melhoria capazes de diminuir a ocorrência da situação descrita acima, está a implantação de faixas adicionais. Por esses motivos, este método considera apenas as colisões frontais nas estimações das reduções de acidentes devido à implantação de faixas adicionais. 


\subsubsection{Estimativas de redução do número de acidentes pelo ESTRADA}

Para o ESTRADA, é importante a inclusão da redução do número de acidentes nas análises benefício/custo dos investimentos em infraestrutura rodoviária, pois assim é ressaltada a importância da redução dos custos associados às avarias, lesões e mortes.

A desagregação dos custos decorrentes dos acidentes rodoviários deve compreender três grupos:

- Custos econômicos diretos (custos médicos, dos danos materiais, administrativos e dos reparos no local do acidente);

- Custos econômicos indiretos (custo da perda de produção das vítimas); e

- Valor da vida.

Após uma revisão de diversos modelos de previsão de acidentes (Raeside, 2004; Cardoso, 2002; Ozbay et. al. 2001; Forkenbrock e Foster, 1997; etc.) verificou-se que todos utilizam algum tipo de variável explicativa, tais quais como: classificação da via, parâmetros de tráfego, parâmetros de qualidade do pavimento e ano de estudo.

No ESTRADA optou-se por utilizar o modelo de Cardoso (2002) por já ter sido utilizado para Portugal. O modelo (Equação 4.10) é baseado em duas variáveis (extensão da via e fluxo de tráfego médio diário por ano) e foi calibrado para cinco tipos de estradas portuguesas, em função do número de faixas e a largura dessas faixas.

$$
E(m)=a \times E X T \times T M D^{C}
$$

sendo: $\quad E(m)$ : frequência esperada de acidentes $\left(\mathrm{n}^{\circ}\right.$ de acidentes corporais $/ 10^{6}$ veíc. $\left.\mathrm{km}\right)$;

EXT: extensão do segmento $(\mathrm{km})$;

TMD: tráfego médio diário anual (veíc/dia); e

$a, c$ : parâmetros de calibração.

Para quantificação dos custos unitários, os acidentes foram desagregados por gravidade e tipo de veículo, e o cálculo do número de vitimas, por analogia com valores médios. Foi suposto ainda que, se for necessário obter uma desagregação dos acidentes por tipo de veículo, esta deve ser proporcional à composição do tráfego do segmento sob análise. 
Conhecendo-se o número previsto (ou real) dos acidentes por gravidade no segmento ou na rede em estudo, o custo total dos acidentes é o somatório dos custos unitários por nível de gravidade. Para tanto, somam-se os custos econômicos diretos, os indiretos e o valor da vida.

Nota-se, pela análise do modelo de previsão da frequência de acidentes utilizados por esse manual, que é necessária a calibração dos parâmetros $a$ e $c$ para sua correta utilização. Portanto, a utilização desse modelo pode ser inviável em casos com escassez de dados referentes ao tráfego anual de veículos por tipo de rodovia.

$\mathrm{Na}$ estratificação dos custos econômicos dos acidentes em diretos, indiretos e valor da vida, é recomendado um nível de detalhe elevado, como a monetarização da perda de produção do acidentado. No entanto, se os valores de algumas variáveis não estiverem disponíveis, a análise não é impossibilitada, apenas haverá uma menor precisão dos resultados.

\subsubsection{Estimativas de redução do número de acidentes pelos modelos nacionais}

No início, os estudos brasileiros que tiveram como objetivo a obtenção de dados para a quantificação dos benefícios da redução do número de acidentes devido às obras de melhorias, restringiram-se a uma tentativa de obtenção de indicadores básicos da influência dos acidentes e dos benefícios gerados por sua redução, quando se implanta um projeto de melhoria na rodovia.

Nesse sentido, Castro (1975), elaborou análises de dados de acidentes de tráfego das rodovias paulistas. Nesse trabalho, o autor apresentou um gráfico que correlaciona, através de uma função linear, os índices de acidentes $(I a)$ e os volumes diários médios anuais (VDM), ambos registrados em rodovias de pista simples com e sem faixas adicionais de subida. Para tal correlação, foi encontrado um coeficiente igual a 0,83 . Notou-se também neste estudo que, nos trechos com faixas adicionais em aclives, é observado uma maior fluidez do tráfego, além de uma menor taxa de ocorrência de acidentes, já que são evitadas tentativas arriscadas de manobras de ultrapassagem.

Em DNER (1979), foram compilados dados de acidentes ocorridos em um trecho rodoviário com $89 \mathrm{~km}$ de extensão, nos quais $32 \mathrm{~km}$ têm rampas superiores a $3 \%$ e não há 
faixas adicionais. Observou-se que $43 \%$ dos acidentes foram causados por ultrapassagens forçadas, os quais seriam potencialmente eliminados, caso fossem construídas faixas adicionais.

Já no início do século XXI, a importância do levantamento de custos de acidentes de trânsito em rodovias levou o DNIT, sucessor do DNER, a programar estudos com a finalidade de conhecer melhor as causas e variáveis que compõem estes custos e procurar um sistema de avaliação dos mesmos (DNIT, 2004).

O estudo desenvolveu metodologia para obtenção das seguintes componentes dos custos de acidentes: congestionamentos (retenção de tráfego causada pelo acidente); danos a veículos; elementos do sistema operacional de atendimento; perda de rendimentos futuros; gestão de seguros (custos de administração de seguros); danos ao patrimônio público; custos funerais; custos médico-hospitalares; custos subjetivos (pesar, dor e sofrimento); e custos administrativos de processos judiciais. Esses custos foram agregados ainda por região geográfica, tipo e gravidade dos acidentes, e classe de projeto da rodovia, a partir das informações registradas no boletim de ocorrências da Polícia Rodoviária Federal (PRF). Foram realizadas pesquisas amostrais para estimativa de estatísticas que não são passíveis de se obter no momento da ocorrência, como: a proporção de mortos e inválidos após a remoção e a evolução da gravidade das vítimas até 30 dias após a ocorrência; custos médico hospitalares; e perdas de rendimentos futuros, para mortos e inválidos. Outras pesquisas complementares foram feitas para estimar o valor do tempo perdido e o custo adicional de combustível causado pelas retenções, provocadas pelos acidentes.

A partir do banco de dados de acidentes da PRF e informações de tráfego, foi feita a estimação do tempo gasto em congestionamentos até a desobstrução da pista, por meio de um modelo matemático capaz de estimar o tempo de retenção para diferentes tipos de veículos, em situações de congestionamento parcial ou total, assim como os níveis de emissão de poluentes em razão da diminuição da velocidade de operação.

Foram criadas tabelas com valores dos componentes nacionais do custo de acidentes de trânsito ocorridos na malha rodoviária federal, apresentados por gravidade e tipo do acidente, e por classe de projeto de cada rodovia, tanto para os acidentes registrados no ano base do estudo (2000), quanto para a projeção para o ano de 2004. Nesse contexto, no ano de 2000, as 
colisões frontais em rodovias de pista simples tiveram o valor médio de R $\$ 97.640$ (DNIT, 2004, pág. 154).

Num outro estudo, é disponibilizado um método para quantificação de custos dos acidentes nas rodovias fundamentado na decomposição do acidente em componentes elementares, aditivos de custo, e da transferibilidade do custo médio padrão de um acidente (IPEA, 2006, pág. 19). A decomposição dos acidentes em componentes elementares não considerou o custo por tipo de acidente, e sim os custos associados às pessoas, aos veículos, à via/ambiente e às instituições. Foram quantificados custos para todos os acidentes ocorridos em todas as rodovias brasileiras entre julho de 2004 e junho de 2005 .

Nesse período, 4\% (3710 acidentes) de todos os acidentes em rodovias federais foram colisões frontais, das quais $81 \%$ (3005 acidentes) foram em rodovias de pista simples e $85 \%$ foram devidos às ultrapassagens indevidas (IPEA, 2006, pág. 37 e 38). Nesses 4\% de acidentes, estão quase $25 \%$ dos mortos em acidentes, sendo, portanto, o tipo de acidente que mais leva as vítimas ao óbito.

Ao analisar as pesquisas desenvolvidas no Brasil que avaliaram os acidentes ocorridos em rodovias nacionais, percebe-se que é satisfatório o nível de decomposição dos custos econômicos unitários dos acidentes. No entanto, quanto aos modelos que medem a exposição aos acidentes em rodovias de pista simples, não foi encontrado nenhum que fosse adaptado ou desenvolvido para a nossa realidade.

\subsubsection{Estimativas de redução do número de acidentes pelo HDM -4}

Para o HDM, acidente é um evento envolvendo um ou mais veículos que resulta em morte, lesões pessoais ou danos à propriedade.

Na presente pesquisa, para a estimação dos benefícios proporcionados pelas reduções de acidentes, será utilizada a metodologia publicada no manual do HDM-4, principalmente, por sua objetividade e necessidade de variáveis de entrada possíveis de estimar. A sequência de aplicação dos modelos desse manual está apresentada na Seção 4.4.3. 


\subsection{MÉTOdOS DE CÁlCULO SELECIONAdOS PARA APLICAÇÃo NA PRESENTE PESQUISA}

$\mathrm{Na}$ presente pesquisa, recomenda-se aos usuários do método defendido a utilização dos modelos desenvolvidos para a realidade nacional, para a mensuração dos benefícios das reduções dos custos operacionais e dos tempos de viagem nos cenários sem e com faixas adicionais; para o benefício das reduções de acidentes, recomenda-se a utilização do método do HDM-4.

\subsubsection{Considerações para o cálculo do benefício da redução do custo operacional $(B R C O)$}

A seguir é apresentada a sequência metodológica recomendada por Melo (2002) para o cálculo dos benefícios da redução dos custos operacionais $(B R C O)$, a qual foi adotada pela presente pesquisa, sendo apenas atualizados os valores de algumas variáveis. Após apresentação de cada passo, estão descritas algumas recomendações para os usuários do método.

1' Passo: Calcular as relações dos custos operacionais unitários de cada categoria $i$ de veículo para condições sem $\left(R_{i, s e m}\right)$ e com faixa adicional $\left(R_{i, c o m}\right)$. Essas relações são calculadas pelas equações 4.2 a 4.6 .

Dessa forma, os dados necessários nesta etapa são:

- As velocidades médias geradas pelo simulador para automóveis $\left(V_{A}\right)$, ônibus $\left(V_{O}\right)$ e caminhões $\left(V_{C}\right)$, para os cenários sem e com faixas adicionais; e

- As declividades das rampas do trecho estudado.

$\mathbf{2}^{\mathbf{0}}$ Passo: Calcular o custo operacional, em reais por quilômetro, para cada categoria $i$ de veículo através de:

$$
C O U_{i}=\frac{C F_{i}}{30 \cdot x_{i}}+C V_{i}
$$

sendo: $\quad C O U_{i}:$ custo operacional unitário da categoria $i(\mathrm{R} \$ / \mathrm{km})$;

$C F_{i}$ : custos fixos mensais da categoria $i(\mathrm{R} \$)$;

$C V_{i}$ : custos variáveis por quilômetro da categoria $i(\mathrm{R} \$ / \mathrm{km})$; e 
$x_{i}$ : utilização média diária do veículo da categoria $i(\mathrm{~km})$.

Os custos operacionais dos veículos são formados por duas parcelas, custo fixo e custo variável. O custo variável descreve o valor gasto com o consumo de combustível, lubrificantes, pneus, peças e acessórios e pessoal de oficina. Já o custo fixo está relacionado com as despesas com pessoal, depreciação, remuneração do capital, seguro e licenciamento.

$3^{\circ}$ Passo: Calcular o custo operacional para cada categoria $i$ de veículo nas condições sem e com faixas adicionais, $\mathrm{CO}_{i, \text { sem }}$ e $C O_{i, c o m}$, respectivamente. Esses custos são iguais à simples multiplicação de cada $C O U_{i}$ pela sua respectiva relação dos custos operacionais unitários para condições sem $\left(R_{i, \text { sem }}\right)$ e com faixa adicional $\left(R_{i, \text { com }}\right)$.

$4^{0}$ Passo: Estimar a redução do custo operacional diário $(r c o)$. Essa redução é o somatório das reduções de custo operacional de cada categoria $i$ e é dependente do volume de hora pico (VHP). Portanto, se $V H P \leq 50$ veíc/h, a redução do custo operacional ( $r c o$ ) é calculada por uma única parcela correspondente às horas entre picos:

$$
r c o=\sum_{i} L m_{i} \times\left(C O_{i, s e m}-C O_{i, c o m}\right) \times V D M_{i} \times y
$$

Se $V H P>50$ veíc/h, a rco é calculada por um modelo constituído de duas parcelas, em que a primeira parcela corresponde às horas entre picos e a segunda às horas de pico:

$$
r c o=2 \times r c o^{\prime}+\sum_{i} L m_{i} \times\left(C O_{i, s e m}-C O_{i, c o m}\right) \times V H P_{i} \times q h p \times y
$$

sendo: $\quad L m_{i}$ : distância média de acompanhamento de cada categoria $i$;

$V D M_{i}:$ volume diário médio de cada categoria $i$ (sentido do aclive);

qhp: quantidade de horas de pico;

y: porcentagem de veículos rápidos (igual a 1 para automóveis e ônibus;

0,10 para caminhões, pois admiti-se $10 \%$ de caminhões vazios na corrente de tráfego);

rco': parcela de redução do custo operacional relacionada às horas entre picos $(\mathrm{R} \$) ; \mathrm{e}$

$V H P_{i}$ : volume da hora de pico de cada categoria $i$ (sentido do aclive). 
Para o cálculo de $L m_{i}$, Melo (2002) admitiu que esse parâmetro fosse igual à diferença entre as porcentagens de tempo viajando em pelotões (PTSF), obtidas das simulações, para as condições sem e com a existência de faixa adicional no aclive, conforme mostrado na Equação 4.14 .

$$
L m_{i}=\frac{P T S F_{\text {sem_faixa }}-P T S F_{\text {com_faixa }}}{100} \times L_{i}
$$

sendo: $\quad L m_{i}$ : distância média em que um veículo rápido da categoria $i$ acompanha um veículo lento na rampa estudada $(\mathrm{km})$;

$i$ : categoria do veículo rápido (automóvel, ônibus e caminhão vazio);

$P T S F_{\text {sem_fa }}$ porcentagem média do tempo em que os veículos rápidos da categoria $i$

ixa: acompanham veículos lentos, quando não existe faixa adicional (\%);

$P T S F_{\text {com_fa }}$ porcentagem média do tempo em que os veículos rápidos da categoria $i$

ixa: acompanham veículos lentos, quando existe faixa adicional (\%); e

$L_{i}$ : extensão da rampa sob análise $(\mathrm{km})$.

$5^{\circ}$ Passo: Calcular o benefício anual gerado pela redução dos custos operacionais dos veículos $(B R C O)$, o qual é o resultado da multiplicação do valor de rco por 365.

No $1^{\circ}$ Passo devem ser utilizadas as características do tráfego de cada ano do horizonte de projeto, para simular o cenário sem nenhuma das faixas inclusas nos conjuntos que devem ser testados no respectivo ano, obtendo-se as velocidades médias dos automóveis, ônibus e caminhões; e a porcentagem de tempo seguindo em pelotão (PTSF), para cada direção do tráfego.

Nos cenários com faixas adicionais e em uma determinada rampa, é possível observar que para cada conjunto testado haverá um valor diferente das relações entre custos operacionais $\left(R_{a, c o m}, R_{o, c o m}\right.$ e $\left.R_{c, c o m}\right)$. Pois para cada um desses conjuntos, existirão velocidades médias diferentes para cada categoria. Quanto ao PTSF, há valores distintos para cada conjunto de faixas testado, mas o valor dessa variável é igual para automóveis, ônibus e caminhões.

No $2^{\circ}$ Passo, o cálculo do custo operacional unitário dos carros, ônibus e caminhões deve ser feito a partir dos custos fixos mensais e custos variáveis por quilômetro referentes ao 
período da análise, os quais podem ser encontrados em publicações específicas da área de transportes, como a revista eletrônica Economia e Transporte.

No $4^{\circ}$ Passo, os valores dos $V D M_{i}$ e $V H P_{i}$ por direção devem ser calculados de acordo com a coleta realizada e através das estimativas adotadas, como a quantidade de horas pico e entre picos.

\subsubsection{Considerações para o cálculo do benefício da redução do tempo de viagem (BRTV)}

A seguir está a sequência recomendada por Melo (2002) para o cálculo dos benefícios da redução dos tempos de viagem (BRTV), adotada na presente pesquisa, sendo apenas atualizados os valores de algumas variáveis. Após apresentação de cada passo, estão descritas algumas recomendações para os usuários do método.

$1^{0}$ Passo: Estimar o custo de uma hora de viagem, $\mathrm{CH}_{u}$ (Equação 4.8) e a relação entre veículos que geram benefícios e os que não geram benefícios, $R$ (Equação 4.9);

$2^{\mathbf{0}}$ Passo: Simular, para cada ano analisado, os cenários sem e com as melhorias indicadas como necessárias nesse mesmo ano. Depois, extrair dos arquivos gerados, os tempos de viagem de cada categoria de veículo $i$ para as condições sem $\left(t v_{i, s e m}\right)$ e com as faixas adicionais $\left(t v_{i, c o m}\right)$;

$3^{\circ}$ Passo: Calcular a redução do tempo de viagem (rtv), a qual depende do VHP. Portanto, se $V H P \leq 50$ veíc/h, a redução do tempo de viagem ( $r t v)$ é calcula por uma única parcela correspondente às horas entre picos:

$$
r t v=\frac{r p}{3600} \times \sum_{i}\left(t v_{i, \text { sem }}-t v_{i, \text { com }}\right) \times\left(V D M_{i}\right)
$$

sendo: $\quad r t v$ : redução do tempo de viagem para automóveis e ônibus após a implantação da faixa adicional (h);

rp: redução da porcentagem de pelotões (diferença entre a porcentagem de pelotões, nas situações sem e com a faixa adicional);

VDMi: volumes diários médios de cada categoria $i$ (sentido do aclive); 


$$
\begin{aligned}
t v_{i, \text { sem }}: & \text { tempo de viagem de cada categoria de veículo } i \text { para as condições sem } \\
& \text { faixa adicional; e } \\
t v_{i, \text { com }}: & \text { tempo de viagem de cada categoria de veículo } i \text { para as condições com } \\
& \text { faixa adicional. }
\end{aligned}
$$

Se $V H P>50$ veíc/h, usa-se um modelo constituído de duas parcelas, a primeira correspondente às horas entre picos e a segunda, às horas de pico:

$$
r t v=2 \times r t v^{\prime}+\frac{q h p \times r p}{3600} \times \sum_{i}\left(t v_{i, s e m}-t v_{i, \text { com }}\right) \times\left(V H P_{i}\right)
$$

sendo: $\quad r t v^{\prime}:$ parcela da redução do tempo de viagem relacionada às horas de entrepico (h);

qhp: quantidade de horas de pico; e

$V H P_{i}$ : volumes na hora de pico de cada categoria $i$ (sentido do aclive).

$4^{\circ}$ Passo: Calcular o benefício da redução do tempo de viagem (BRTV) através da equação:

$$
B R T V=365 \times r t v \times C H u \times R
$$

Nesse modelo, BRTV corresponde aos benefícios anuais decorrentes da redução do atraso causado pelos veículos lentos aos motoristas e passageiros dos automóveis e aos passageiros dos ônibus. Os benefícios gerados para os ônibus e caminhões vazios estão diretamente incorporados aos benefícios da redução dos custos operacionais, conforme visto anteriormente.

Para todos os anos da análise posteriores ao ano 0 , o valor do salário mínimo deve ser ajustado pelo IPCA acumulado no período de um ano. A porcentagem de ônibus no fluxo de tráfego, assim como a de automóveis, deve ser observada durante a coleta no corredor analisado. A porcentagem de caminhões vazios deve ser buscada na literatura, sendo a coletada numa balança rodoviária por Melo (2002) uma adequada referência para as rodovias de pista simples.

Para o cálculo dos tempos de viagem sem $\left(t v_{i, s e m}\right)$ e com faixa adicional $\left(t v_{i, c o m}\right)$ de cada categoria $i$, deve ser feita a divisão da extensão do corredor analisado pelas respectivas velocidades médias de cada categoria em cada cenário analisado, geradas pelas simulações. 
Visto que o TWOPAS gera para cada estação de observação um valor de porcentagem de veículos em pelotão (\%FOLL), deve ser delineado um espaçamento de 100 metros entre as estações. Então, para medir a redução da porcentagem de pelotões ( $r p$ ) em cada aclive, devese selecionar uma estação localizada no meio e outra ao final da rampa, para calcular as médias dos valores de \%FOLL observados em cada uma dessas estações. Deve-se repetir esse procedimento tanto para os cenários com quanto para os sem faixas adicionais, sempre utilizando as mesmas estações de cada rampa.

Os valores dos $V D M_{i}$ e $V H P_{i}$ por direção devem ser calculados de acordo com a coleta realizada e através das estimativas adotadas, como a quantidade de horas pico e a parcela de redução do tempo de viagem relacionada às horas entre picos ( $\left.r t v^{\prime}\right)$.

\subsubsection{Considerações para o cálculo do benefício da redução dos acidentes (BRACID)}

O método recomendado no HDM-4 para o cálculo do custo anual dos acidentes foi adotado na presente pesquisa, atualizados os valores de algumas variáveis. Entretanto, nesta seção é proposto um modelo para calcular os benefícios da redução do número de acidentes (BRACID).

Inicialmente, a exposição anual a acidentes em seções viárias sob a opção de investimento $j$, deve ser calculada por:

$$
\operatorname{EXPOSSEC~}_{j}=\frac{365 \times V D M \times L}{10^{8}}
$$

sendo: $E X P O S S E C_{j}$ : exposição anual aos acidentes no cenário $j$ (100 milhões veíc-km);

VDM: volume diário médio na seção (veíc/dia); e

$L$ : extensão da seção viária em observação $(\mathrm{km})$.

O número de acidentes de cada tipo sob a opção de investimento em análise deve ser estimado por:

$$
\operatorname{ACCYR}_{i j}=\text { EXPOSSEC }_{j} \times \text { ACCRATE }_{i}
$$

sendo: $\quad A C C Y R_{i j}$ : quantidade anual de acidentes do tipo $i$ no cenário $j$; EXPOSSEC $j$ : exposição anual aos acidentes no cenário $j$; e 
ACCRATE $_{i}$ : taxa anual de acidentes do tipo $i$ em todo o corredor.

O custo anual dos acidentes do tipo $i$ para cada opção de investimento analisada deve ser estimado usando-se:

$$
A_{C C O S T}=A C C Y R_{i j} \times U N I T C O S T_{i}
$$

sendo: $\quad A C C O S T_{i j}$ : custo anual dos acidentes do tipo $i$ no cenário $j$; e

UNITCOST $T_{i}$ : custo unitário do tipo de acidente $i$.

Visto isso, a computação da redução ou acréscimo do número de acidentes, e a consequente verificação do ganho de benefício, devem ser dadas pela simples diferença aritmética entre o custo total dos acidentes em um ano no cenário sem as faixas adicionais $\left(A C C O S T_{\text {sem }}\right)$ e esses mesmos custos no cenário com as faixas adicionais $\left(A C C O S T_{\text {com }}\right)$, conforme o modelo a seguir:

$$
B R A C I D_{i}=A C C O S T_{S F}-A C C O S T_{C F}
$$

sendo: $\quad$ BRACID $_{\mathrm{i}}$ : benefício da redução de acidente proporcionado pela faixa adicional $i$;

$\operatorname{ACCOST}_{S F}$ : custo anual das colisões frontais no cenário sem a faixa adicional $i$; e $A C \operatorname{COS} T_{C F}$ : custo anual das colisões frontais no cenário com a faixa adicional $i$.

Dentre todos os tipos de acidentes que podem ocorrer em aclives rodoviários, é recomendado considerar somente as colisões frontais como o tipo que pode ser evitado com a implantação de uma faixa adicional. Diante disso, o benefício das reduções de acidentes (BRACID) pode ser calculado de duas maneiras. Pela primeira, deve-se considerar que a implantação das melhorias recomendadas reduz o ACCRATEi de todo o corredor analisado em uma porcentagem definida pelo usuário e a extensão da exposição à colisões frontais $(L)$ para ambas as condições, com e sem as melhorias, é igual a extensão das rampas. Pela segunda maneira, deve-se adotar que o ACCRATE $i$ de todo o corredor analisado permanece inalterado com a construção das faixas adicionais. No entanto, para os cenários sem as melhorias recomendadas, deve-se considerar que $L$ é a extensão da rampa; e para os cenários com as melhorias, deve-se considerar que $L$ é a diferença entre a extensão da rampa e a extensão da faixa adicional, portanto, diminuindo para essa condição a exposição às colisões frontais. 
Quanto ao custo unitário de uma colisão frontal, o valor deve ser buscado na literatura e devidamente atualizado para o ano 0 da análise. Esta pesquisa recomenda a utilização dos valores publicados pelo Departamento Nacional de Infraestrutura de Transportes (DNIT). Para cada ano analisado após o ano 0, deve-se corrigir o custo unitário de uma colisão frontal de acordo com o IPCA acumulado em um ano. 


\section{CÁlCULO DOS CUSTOS}

A análise das alternativas de investimento na infraestrutura do transporte rodoviário é dependente da estimativa dos custos das obras. Essa estimativa é a soma de diversas parcelas ou etapas de produção, onde cada etapa possui um custo total ou unitário. Há na literatura modelos que se propõe a calcular etapas como concepção e desenvolvimento do projeto; planejamento e gerenciamento dos serviços; além dos custos indiretos (Kerali, 2000).

Nesse contexto, a revisão da literatura mostrou que os modelos de custo mais adequados para os propósitos desta pesquisa seriam os do HDM-4 (Highway Development and Management System) (Kerali, 2000; Kerali et al. 2000; Odoki e Kerali, 2000) e do projeto ESTRADA (Estimação de Custos e Benefícios Reais para a Avaliação Econômica de Projetos de Investimento Rodoviário em Portugal) (Macário et al. 2007 e Rodrigues, 2007). O primeiro, por atualmente ser a principal referência mundial desse assunto, e o segundo devido, principalmente, conter uma detalhada revisão de diversos modelos utilizados em países europeus. Outros estudos importantes, desenvolvidos no Brasil, incluem Kabbach (1992), Pedrozo (2001) e SICRO (2003).

As seções seguintes discutem como calcular os custos da construção de melhorias em rodovias de pista simples, assim como os respectivos custos de manutenção e operação.

\subsection{CUSTOS DE CONSTRUÇÃO DAS OBRAS DE MELHORIA EM RODOVIAS}

Watanatada (1987a) menciona que a estimação dos custos de construção é uma das divisões mais fortes da Engenharia. Como é cada vez maior a gama de opções dos projetos de infraestrutura, os projetistas necessitam de métodos de previsão dos custos de construção, que produzam resultados sensíveis aos diversos padrões construtivos e às características do terreno, utilizando o mínimo de dados de entrada.

\subsubsection{Estimativas dos custos de construção pelo HDM-4}

Nas versões anteriores do HDM, havia a oportunidade de fornecer os custos de construção de diferentes alternativas, calculados exogenamente pelo usuário. $\mathrm{Na}$ versão atual ainda é 
oferecida essa possibilidade, mas existem também rotinas endógenas da estimação dos custos de construção (Kerali et al. 2000).

O modelo de construção de vias (Road Construction Submodel - RCS) do HDM-4 visa computar e alocar os custos de construção por componente (econômico, financeiro e cambial) em cada ano do período de obras. Esse modelo pode ser dividido entre os seguintes estágios (Kerali, 2000):

- Durante a construção: para cada ano do período de obras, os custos incorridos durante o ano são computados em termos financeiros, econômicos e cambiais; e

- No ano de abertura: para o ano seguinte do término efetivo das obras, as características físicas do link afetado são modificadas para aquelas da nova via.

Os custos de construção de melhorias rodoviárias são divididos entre 8 tipos de serviços: aquisição da faixa de domínio, preparação do terreno, terraplenagem, pavimentação, drenagem, pontes, outros custos, e despesas gerais. Com exceção dos “outros custos” e das “despesas gerais", esses tipos de serviços podem ainda ser desagregados em quantidades físicas e custos unitários. O HDM-4 oferta uma rotina flexível para o usuário fornecer os custos de construção em diferentes níveis, como: custo total do link; custo total por segmento; componentes dos custos (custo por km); e custos unitários e quantidades dos componentes (Odoki e Kerali, 2000).

Ressalta-se que, os custos de construção considerados pelo HDM-4, sejam eles custo total, custo dos componentes ou custo unitário, devem ser fornecidos pelo usuário em termos financeiros, econômicos e cambiais, embora o financeiro e o cambial sejam opcionais. Esses são distribuídos pelo o período construtivo de acordo com as porcentagens também especificadas pelo usuário (Kerali et al. 2000).

\subsubsection{Estimativas dos custos de construção pelo ESTRADA}

Nesse projeto, os custos da infraestrutura rodoviária são divididos entre custos diretos e indiretos. Os custos diretos são o investimento inicial e os custos de manutenção, operação e administração da infraestrutura a ser implantada. Os custos indiretos são ligados à perturbação devida aos trabalhos de construção. 
ESTRADA utiliza a abordagem para avaliação de infraestrutura rodoviária recomendada por Bickel et al. (2006), a qual é baseada no custo do ciclo de vida. Esses custos podem ser incorridos pelo órgão responsável, pelos usuários ou entidades afetadas pela existência de tal infraestrutura (Macário et al. 2007).

Para o cálculo dos custos de construção, ou custos do investimento inicial, consideram-se os seguintes componentes:

- Trabalhos de construção: material, mão de obra, equipamento e energia;

- Preparação e administração: terraplenagem, desenvolvimento e gestão do projeto, serviços de consultoria e fiscalização; e

- Aquisição do terreno: custo da compra, despesas legais, gestão da propriedade e compensações.

É enfatizado que na fase de estudo preliminar, dificilmente, dispõe-se de informação suficiente em relação às quantidades de trabalho para se realizar um orçamento preciso, resultando os valores dos custos de construção de estimativas baseadas em custos médios. Já na fase da execução do projeto, as quantidades dos materiais e dos processos construtivos são suficientemente detalhadas para o desenvolvimento de um minucioso orçamento.

É recomendada a utilização do HDM-4 e do ROCKS (Road Costs Knowledge System) para calcular os custos dos trabalhos de construção, pois ambos permitem estimar as quantidades da construção e associar-lhes um custo unitário. No caso de Portugal, recorrer-se a um manual no qual se encontram valores médios dos atualizados por Manso et al. (2004).

Quanto aos custos de "preparação e administração", geralmente, uma parte ocorre antes da decisão de realizar o projeto e, tratando-se de um custo não recuperável, não deve ser incluído na análise Benefício/Custo. O projeto ESTRADA recomenda ainda que o último custo de construção a ser considerado seja o custo de aquisição do terreno, o qual pode subdividir-se em: custos da compra, despesas legais, custos da gestão da propriedade e indenizações.

Verifica-se, portanto, que para o cálculo dos custos de construção a contribuição do projeto ESTRADA resumiu-se às recomendações quanto às subdivisões das componentes do custo total e à sequência de cálculo do custo de construção, já que como método é aconselhado utilizar o HDM-4 ou o ROCKS. 


\subsubsection{Estimativas dos custos de construção por pesquisas nacionais}

Dentre as pesquisas nacionais, inicialmente, destaca-se a de Kabbach (1992), que aprofunda o cálculo dos custos de construção de faixas adicionais, o que se alinha perfeitamente aos objetos a serem alcançados pela presente pesquisa.

É destacado que os custos de construção de uma faixa adicional variam em função de diversos fatores específicos para cada caso: topografia, característica do subleito, distâncias de transportes, seção transversal, drenagem, sinalização, desapropriações, etc. Dessa forma, na análise dos projetos de faixas adicionais nas rodovias em operação, podem ser consideradas soluções mais econômicas, as quais podem variar de um simples reforço do acostamento existente, até outras mais complexas, que envolvam a construção de uma nova faixa com acostamento e dispositivos laterais de drenagem.

São apresentados exemplos de esquemas alternativos de implantação de faixas adicionais, considerando situações de vias novas e de existentes com e sem acostamento. Os custos unitários foram retirados da "Tabela de Preços Unitários" do DER-SP, que é atualizada periodicamente.

Para os quantitativos de serviços e de materiais, foi adotado um pavimento tipo adequado para tráfego pesado, considerando $50 \%$ do volume de terraplenagem em aterro e $50 \%$ em corte. A altura média dos cortes e aterros adotada foi de 5 metros. As seções previstas foram de 3,5 metros para a faixa adicional e 1,5 metros para acostamento, drenagem e sinalização, totalizando em 5 metros a largura da faixa de segurança (Melo, 2002).

Não foram incluídos os custos de desenvolvimento do projeto e de gerenciamento das obras; no entanto, há a recomendação de que a sua soma é cerca de $8 \%$ do custo total da construção.

Kabbach (1992) salienta que os custos de construção da faixa adicional são dependentes da extensão total projetada para a mesma. A extensão total deverá incluir não só o comprimento relativo à rampa ascendente, mas também o situado na rampa descendente subsequente, ao longo do qual os veículos "lentos" possam acelerar e readquirir a velocidade mínima aceitável. 
Em outra pesquisa, Pedrozo (2001) usa os seguintes componentes dos custos unitários de construção das rodovias: equipamentos, mão-de-obra, materiais e seu transporte. São abordadas as características a serem adotadas em pesquisa de preços dos insumos, além de serem mensurados os parâmetros empregados, comparando-se os encargos sociais, as bonificações e as despesas indiretas utilizados no DAER/RS e em outros estados e órgãos brasileiros.

Dentre os orçamentos de construção de rodovias analisados, o fator preponderante dos custos unitários dos serviços de terraplenagem é o custo com os equipamentos acrescidos da mão-de-obra para sua operação, correspondendo a 52\% do custo total, enquanto que os materiais e seu transporte são $33 \%$ do mesmo total. Quanto aos custos unitários de pavimentação, verificou-se que o principal elemento a ser considerado é a despesa com materiais, que inclui o CBUQ e corresponde a 74\% dos custos de pavimentação. Nos custos unitários de drenagem, o componente que maior peso tem é também a despesa com materiais, que é $69 \%$. No entanto, este é um item de pouca relevância no custo total do orçamento.

Do estudo dos custos médios das obras, obteve-se também que o preço médio por quilômetro de construção de rodovia é de R \$393.737,27, com desvio padrão de R\$ $100.509,47$, e o preço médio por quilômetro de restauração de rodovia é de $\mathrm{R} \$ 96.656,36$, com desvio padrão de $\mathrm{R} \$ 36.691,56$, tendo esses valores Julho/99 como referência (Pedrozo, 2001).

Melo (2002) priorizou o cálculo da construção de faixas adicionais, sendo esse estimado em função da quantidade de materiais e serviços necessários, bem como os custos unitários a esses associados. Quanto aos custos unitários, foram utilizados os publicados pelo DER-SP. O procedimento de cálculo utilizado por ambos os autores está detalhadamente apresentado na Seção 5.4, pois foi o utilizado na presente pesquisa para calcular os custos de construção de faixas adicionais.

\subsection{CUSTOS DA INFRAESTRUTURA VIÁRIA APÓS IMPLANTAÇÃO DAS MELHORIAS}

Os custos de operação, conservação, manutenção e restauração ocorrem ao longo da vida útil da rodovia e aumentam com o decorrer dos anos, na medida em que o pavimento se deteriora. 
Como exemplo, tem-se a conservação rotineira e preventiva, tapa-buracos, selagens, recapeamentos e as restaurações tanto dos pavimentos, quanto das pontes, túneis, taludes e outros (Pedrozo, 2001).

Para DNER (1996), a conservação, ou manutenção, é o conjunto de operações destinadas a manter as características técnicas e operacionais da rodovia, podendo ser de dois tipos:

- Preventiva Periódica: conjunto de operações realizadas periodicamente, com objetivo de evitar o surgimento ou agravamento de defeitos, que inclui limpeza de sarjetas e meiosfios, limpeza e pintura de juntas, roçada, capina, etc.

- Corretiva Rotineira: conjunto de operações realizadas com objetivo de reparar ou sanar defeitos, incluindo a selagem de trincas, recomposição de elementos de drenagem, etc.

A restauração é o conjunto de operações destinadas a restabelecer o adequado funcionamento do pavimento. Quando há a necessidade de uma ação de restauração, como por exemplo, um recapeamento, considera-se exaurida a vida útil do revestimento.

Quanto aos custos de operação das praças de pedágio e aos adicionais de operação das vias, tais como guinchos, socorro mecânico e ambulâncias, esses não são significativamente alterados após as obras de melhoria, sendo computados no custo de operação total do sistema (Watanatada et al. 1987b).

\subsubsection{Estimativas dos custos de operação, conservação, manutenção e restauração pelo HDM-4}

No HDM, os custos de operação, manutenção, conservação e restauração das vias resumem-se à soma simples dos custos anuais das intituladas manutenções periódicas, rotineiras e especiais, compondo assim o custo total anual da preservação da via, conforme mostra a Tabela 5.1. É considerado que o tempo de duração de todos esses serviços não são superiores a um ano. Para cada opção ou alternativa de investimento, os custos anuais totais de preservação serão computados pelos tipos de serviços e categorias orçamentárias. 


\subsubsection{Estimativas dos custos de operação, conservação, manutenção e restauração pelo ESTRADA}

No projeto ESTRADA, o somatório dos custos de operação, conservação, manutenção e restauração juntamente com os do investimento inicial compõem a categoria dos custos diretos da infraestrutura das rodovias.

Essa categoria de custos inclui custos de melhorias, custos de renovação, custos de manutenção corrente e custos de operação e administração. Para a estimação dos custos associados a essas componentes é recomendada uma das estratégias de cálculo a seguir:

1. Ajustar um modelo econométrico, baseado em uma função translogarítmica de custo;

2. Ajustar uma função de vida útil do pavimento, baseada nos eixos que passam na estrada e na vida do pavimento;

3. Procurar ajustar funções simples às séries de custos por regressão linear simples ou múltipla;

4. Calibrar um algoritmo de cálculo como o do HDM; e

5. Adotar valores médios por quilômetro para a manutenção e operação (a partir dos dados das contas nacionais, alocando-os a cada tipo de veículo de acordo com algum critério relevante), ou admitir que estes custos representem uma percentagem fixa do custo direto de construção.

Dessa forma, são recomendados os modelos de Macário et al. (2001) para o desenvolvimento das estratégias de cálculos de 1 a 3 . No cálculo dos custos pela estratégia 4 é recomendado seguir o exemplo da aplicação do HDM-4, realizado em QUADRO (2004). Para o cálculo através da estratégia 5, são recomendados os conceitos desenvolvidos em Bickel et al. (2006).

\subsubsection{Estimativas dos custos de operação, conservação, manutenção e restauração pelas pesquisas nacionais}

Para DNER (1979), Kabbach (1992) e Melo (2002), os custos de operação, conservação, manutenção e restauração requeridos pela implantação das faixas adicionais, podem ser considerados como custos marginais, e não necessitam ser considerados na avaliação econômica. 


\subsection{MÉTODO SELECIONADO PARA APLICAÇÃO NA PRESENTE PESQUISA}

Após a análise dos diversos modelos e parâmetros apresentados neste capítulo, recomenda-se que o usuário do método defendido mensure os custos de construção das faixas adicionais, a partir das estimativas das quantidades físicas de trabalho e material necessário para execução dos serviços, sendo esses multiplicados pelos seus respectivos valores monetários. Após todas as multiplicações deve ser feito um somatório dos valores calculados, para assim conhecer o valor total orçado para as obras de construção das faixas adicionais.

Nesse contexto, esta pesquisa considera que para a construção das faixas é necessário apenas o reforço no acostamento existente, ou seja, poucas quantidades de serviços de terraplenagem foram incluídas.

Similar ao considerado em Kabbach (1992) e Melo (2002), pela presente pesquisa, as quantidades de serviços necessários para a construção de cada quilômetro de faixa adicional devem ser relacionadas às características das faixas. Porém, além dos serviços considerados naquelas pesquisas, devem ser computados também os custos com a sinalização, cujas quantidades necessárias a cada quilômetro de faixa adicional estão também apresentadas na Tabela 5.1. Ressalta-se que todas essas quantidades foram retiradas do Manual de Sinalização Rodoviária do DER (2006).

Quanto aos valores monetários de cada um dos serviços, devem ser utilizados os publicados pelo DER-SP na "tabela de preços unitários". Para os anos do horizonte de projeto posteriores à data base da "tabela de preços unitários", os valores unitários devem ser corrigidos de acordo com o IPCA acumulado em um ano.

No método proposto, os custos de manutenção e operação das melhorias não fazem parte da análise econômica, embora o usuário possa considerar essas parcelas do custo total, conforme demonstrado na Equação 5.1. Para isso, será necessário conhecer os valores de Co e $C m$, além da duração do ciclo de vida dos pavimentos $(t)$.

$$
C T=C_{i}+\left(C_{m}+C_{o}\right) \times t
$$

sendo: $\quad C T$ : custo total do investimento $(\mathrm{R} \$)$;

$\mathrm{Ci}$ : custo inicial do investimento e ao longo do horizonte de proj. (R\$); 
$\mathrm{Cm}$ : custo anual de manutenção da infraestrutura da rodovia ( $\mathrm{R} \$ / \mathrm{ano})$;

Co: custo anual de operação da infraestrutura (R/ano); e

$t$ : período considerado (anos).

Tabela 5.1 - Características e serviços necessários para construção de um quilômetro de faixa adicional (DER/SP, 2006)

\begin{tabular}{|c|c|}
\hline \multicolumn{2}{|l|}{ Características das Faixas } \\
\hline Extensão (m) & 1.000 \\
\hline Largura de escavação (m) & 5,70 \\
\hline Largura de sub-leito e base (m) & 5,70 \\
\hline Espessura de escavação (m) & 0,2 \\
\hline Espessura de base (m) & 0,15 \\
\hline Espessura de CBUQ (m) & 0,05 \\
\hline Canaleta (espesura 0,08 m; largura 1,5 m) - $\left(\mathrm{m}^{3}\right)$ & 0,12 \\
\hline Dreno do pavimento $(\mathrm{m})$ & 1.000 \\
\hline Serviços & Quantidade \\
\hline \multicolumn{2}{|l|}{ Terraplenagem } \\
\hline Limpeza do terreno sem destocamento de arvores $\left(\mathrm{m}^{2}\right)$ & 5.700 \\
\hline Escavação e carga de material de $1^{a}$ e $2^{a}$ categoria $\left(\mathrm{m}^{3}\right)$ & 1.140 \\
\hline Transporte de $1^{\mathrm{a}}$ e $2^{\mathrm{a}}$ categoria ate $1 \mathrm{~km}\left(\mathrm{~m}^{3} \mathrm{x} \mathrm{km}\right)$ & 1.140 \\
\hline \multicolumn{2}{|l|}{ Pavimentação } \\
\hline Remoção camada de rolamento $\left(\mathrm{m}^{3}\right)$ & 145 \\
\hline Preparo e melhoramento sub-leito $\left(\mathrm{m}^{2}\right)$ & 5.700 \\
\hline Sub-base ou base solo cimento $3 \%$ - usina $\left(\mathrm{m}^{3}\right)$ & 855 \\
\hline Imprimadura betuminosa impermeabilizante $\left(\mathrm{m}^{2}\right)$ & 5.700 \\
\hline Imprimadura betuminosa ligante $\left(\mathrm{m}^{2}\right)$ & 5.700 \\
\hline Concreto asfáltico usinado a quente $\left(\mathrm{m}^{3}\right)$ & 285 \\
\hline \multicolumn{2}{|l|}{ Drenagem } \\
\hline Canaleta concreto esp. $80 \mathrm{~cm}\left(\mathrm{~m}^{3}\right)$ & 120 \\
\hline Tubo de PVC perfurado ou não $\mathrm{d}=5 \mathrm{~cm}(\mathrm{~m})$ & 1.000 \\
\hline \multicolumn{2}{|l|}{ Sinalização } \\
\hline Sinalização horizontal com resina vinilica ou acrílica. $\left(\mathrm{m}^{2}\right)$ & 500 \\
\hline Tacha bidirecional com refletor de vidro (unidade) & 83 \\
\hline Fornecimento e transporte de placa de aço $\left(\mathrm{m}^{2}\right)$ & 6,88 \\
\hline Colocação de placa em suporte de madeira - solo $\left(\mathrm{m}^{2}\right)$ & 6,88 \\
\hline
\end{tabular}

O cálculo das relações Benefício/Custo deve ser feito a cada ano do horizonte de projeto, para uma situação presente, e sendo conhecida a soma dos custos de construção de cada faixa adicional $(C c)$, deve-se aplicar o método de fator de recuperação de capital (Equação 5.2) para 
calcular as parcelas correspondentes a um ano do investimento total da faixa adicional $(A)$, para só assim, relacionar essas parcelas com os respectivos benefícios proporcionados pelas mesmas faixas. A taxa nominal de juros a ser utilizada é a taxa de juros de longo prazo (TJLP) estabelecida pelo BNDES.

$$
A=C c \times\left[\frac{i \times(1+i)^{n}}{(1+i)^{n}-1}\right]
$$

sendo: $\quad A$ : valor de uma parcela anual $(\mathrm{R} \$)$;

$C c$ : custo de construção da faixa adicional $(\mathrm{R} \$)$;

$i$ : taxa nominal de juros; e

$n$ : período de vida útil da faixa adicional (10 anos). 


\section{ESTUDO DE CASO}

Neste capítulo é apresentado um estudo de caso que demonstra a metodologia proposta na pesquisa. O capítulo inicia-se mostrando as características geométricas do trecho que serviu de exemplo, assim como as variáveis de tráfego utilizadas na calibração do modelo. A seguir, são apresentadas as etapas do processo utilizado no desenvolvimento dos cenários que foram testados, como a confecção das curvas de desempenho, averiguação das rampas que necessitam de faixas adicionais e identificação dos anos em que os fluxos mínimos que justificam a implantação de melhorias são atingidos. O capítulo ainda apresenta os cálculos das relações benefício/custo e o ranking de tais relações, por faixa ou combinações entre elas, e encerra-se apresentando os valores gerados pela análise da viabilidade financeira do método.

\subsection{CARACTERÍSTICAS DO TRECHO ANALISADO}

Na delineação do traçado geométrico utilizado neste estudo de caso, foi utilizado o atual perfil horizontal e vertical de um trecho hipotético de rodovia de pista simples, em um terreno ondulado, onde não existe faixa adicional.

Os dados dos alinhamentos horizontal e vertical foram coletados através de um GPS numa rodovia do Estado de São Pulo e podem ser visualizados nos perfis apresentados nas Figuras 6.1 e 6.2. Para as simulações, o trecho foi modelado através da ferramenta de análise de tráfego IHSDM.

\subsubsection{Alinhamento Horizontal}

O alinhamento horizontal do trecho da estudado está representado na Figura 6.1. No sentido ascendente das estacas há quatro curvas para direita e quatro para esquerda.

No IHSDM, para a modelagem do perfil horizontal, há a necessidade de informar o tipo de elemento (tangente ou curva), os pontos de início e término de cada elemento, os raios e as direções das curvas. A Tabela 6.1 apresenta os valores inseridos no IHSDM. 


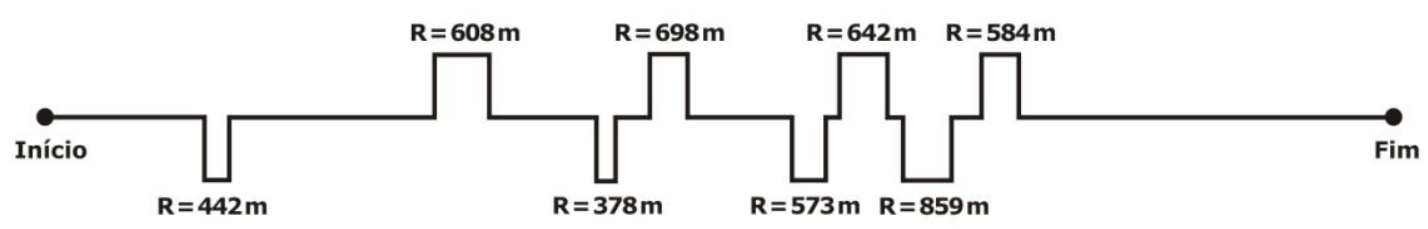

Figura 6.1 - Perfil horizontal do trecho hipotético estudado

Tabela 6.1 - Caracterização do perfil horizontal do trecho

\begin{tabular}{lllll}
\hline & \multicolumn{3}{c}{ Posição $(\mathrm{km})$} & \\
Tipo de Elemento & Inicial & Final & Raio da Curva $(\mathrm{m})$ & Direção da Curva \\
\hline Tangente & 0 & 2,476 & - & - \\
Curva & 2,476 & 2,846 & 442 & Direita \\
Tangente & 2,846 & 6,053 & - & - \\
Curva & 6,053 & 6,858 & 608 & Esquerda \\
Tangente & 6,858 & 8,557 & - & - \\
Curva & 8,557 & 8,834 & 378 & Direita \\
Tangente & 8,834 & 9,385 & - & - \\
Curva & 9,385 & 9,945 & 698 & Esquerda \\
Tangente & 9,945 & 11,566 & - & - \\
Curva & 11,566 & 12,106 & 573 & Direita \\
Tangente & 12,106 & 12,313 & - & - \\
Curva & 12,313 & 13,051 & 642 & Esquerda \\
Tangente & 13,051 & 13,321 & - & - \\
Curva & 13,321 & 14,025 & 859 & Direita \\
Tangente & 14,025 & 14,542 & - & - \\
Curva & 14,542 & 15,081 & 584 & Esquerda \\
Tangente & 15,081 & 21 & - & - \\
\hline
\end{tabular}

\subsubsection{Alinhamento Vertical}

Para a modelagem do alinhamento vertical, o IHSDM oferece a possibilidade de serem informados apenas os pontos de interseção vertical (PIV). No entanto, devido ao formato das coordenadas coletadas pelo GPS, esse perfil foi delineado através de tangentes com seus respectivos pontos de início e fim. Para o cálculo das declividades, foi encontrada a distância entre dois pontos e a diferença de altura. A Tabela 6.2 apresenta as declividades e as posições inicial e final de cada segmento.

A Figura 6.2 apresenta o perfil vertical do trecho rodoviário analisado. A numeração dada a cada rampa será a mesma utilizada para identificar a faixa adicional no lado direito do sentido do aclive dessa mesma rampa. Assim, a faixa adicional 2 será instalada na rampa 2, a faixa adicional 3 será instalada na rampa 3 , e assim sucessivamente. 


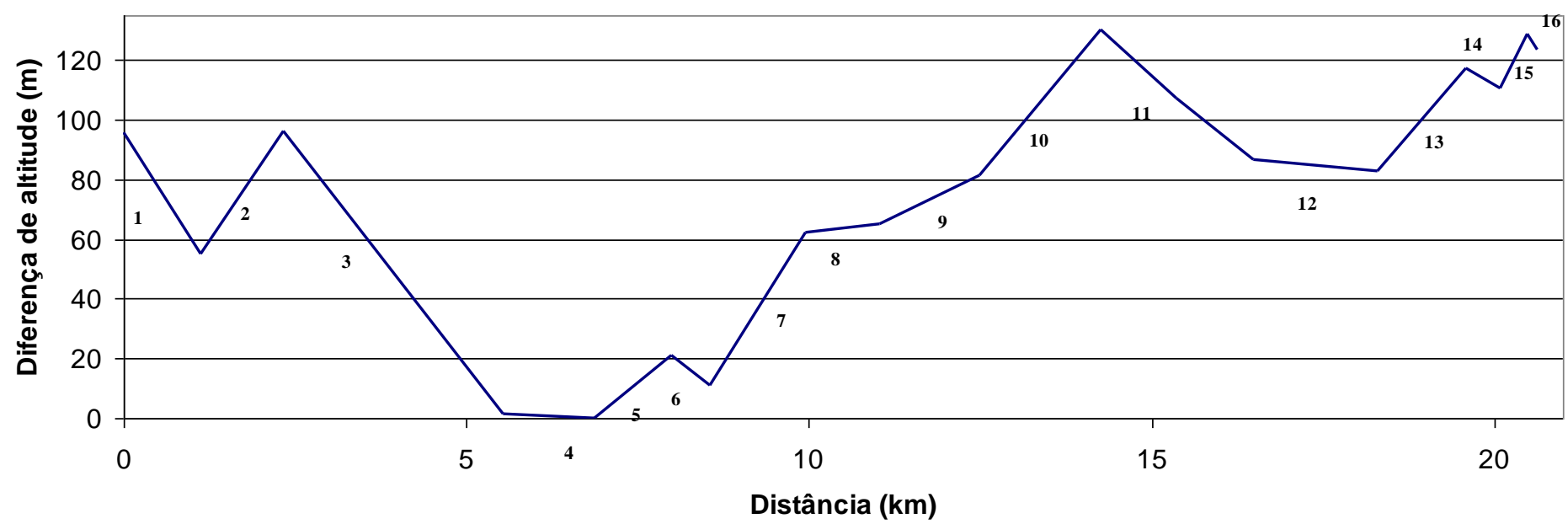

Figura 6.2 - Perfil vertical do trecho estudado

Tabela 6.2 - Estaqueamento do perfil vertical do trecho

\begin{tabular}{llll}
\hline & \multicolumn{2}{c}{ Posição $(\mathrm{km})$} \\
Segmento & Inicial & Final & Declividade (\%) \\
\hline 1 & 0 & 1,12 & -3.6 \\
2 & 1,12 & 2,327 & 3.41 \\
3 & 2,327 & 5,530 & -2.97 \\
4 & 5,530 & 6,858 & -0.09 \\
5 & 6,858 & 7,993 & 1.87 \\
6 & 7,993 & 8,557 & -1.77 \\
7 & 8,557 & 9,945 & 3.67 \\
8 & 9,945 & 11,037 & 0.28 \\
9 & 11,037 & 12,490 & 1.10 \\
10 & 12,490 & 14,254 & 2.78 \\
11 & 14,254 & 16,493 & -2.08 \\
12 & 16,493 & 18,291 & -0.21 \\
13 & 18,291 & 19,583 & 2.69 \\
14 & 19,583 & 20,077 & -1.36 \\
15 & 20,077 & 20,480 & 4.51 \\
16 & 20,480 & 21 & -3.97 \\
\hline
\end{tabular}

\subsubsection{Características do Fluxo de Veículos}

Os dados de tráfego coletados em um trecho hipotético foram utilizados também para calibrar o simulador. A coleta dos dados de tráfego consistiu no posicionamento de um pesquisador e uma câmera de vídeo em cada um dos quatro postos de observação. Esses postos foram divididos por sentido do fluxo de tráfego, sendo designados 2 postos para cada um dos sentidos, os quais foram distanciados 21 quilômetros um do outro. Antes de iniciar a coleta, ajustaram-se os relógios dos pesquisadores e das câmeras, para que todos igualassem até a 
casa dos segundos. Foram coletados, durante cinco horas (10:00 - 15:00h) de um dia típico da semana, o instante de passagem e o tipo de cada um dos veículos que passaram por cada um dos postos de observação. A partir daí, calcularam-se parâmetros como: porcentagem de veículo em pelotões, fluxo horário, porcentagem de caminhões na corrente de tráfego, as velocidades médias dos caminhões e carros, assim como o $15^{\circ}$ e o $85^{\circ}$ percentil das distribuições das velocidades dos automóveis e caminhões. Esses valores estão apresentados na Tabela 6.3, para o sentindo ascendente, e na Tabela 6.4, para o sentido descendente da quilometragem.

Tabela 6.3 - Parâmetros de tráfego por hora de coleta (sentido ascendente)

\begin{tabular}{llllll}
\hline Parâmetro & \multicolumn{5}{c}{ Horário $(\mathrm{h})$} \\
\cline { 2 - 5 } & 10 às 11 & 11 às 12 & 12 às 13 & 13 às 14 & 14 às 15 \\
\hline Início (\% de Veíc em Pelotões - headways $\leq 3 \mathrm{~s})$ & $26,8 \%$ & $23,7 \%$ & $31,6 \%$ & $26,6 \%$ & $32,8 \%$ \\
Fim (\% de Veíc em Pelotões - headways $\geq 3 \mathrm{~s})$ & $26,3 \%$ & $31,3 \%$ & $35,0 \%$ & $40,4 \%$ & $31,1 \%$ \\
Fluxo horário (veic/hora) & 97 & 143 & 120 & 120 & 140 \\
Porcentagem de caminhões & $28,8 \%$ & $37,0 \%$ & $25,0 \%$ & $27,5 \%$ & $22,8 \%$ \\
Velocidade média automóveis $(\mathrm{km} / \mathrm{h})$ & 73,8 & 62,4 & 77,1 & 77,1 & 71,9 \\
Velocidade média caminhões $(\mathrm{km} / \mathrm{h})$ & 61,9 & 54,5 & 61,7 & 68,5 & 59,1 \\
$\mathrm{~V}_{15}$ dos automóveis $(\mathrm{km} / \mathrm{h})$ & 65,0 & 34,8 & 69,6 & 65,1 & 63,6 \\
$\mathrm{~V}_{15}$ dos camihões $(\mathrm{km} / \mathrm{h})$ & 45,5 & 45,0 & 48,0 & 63,4 & 43,5 \\
$\mathrm{~V}_{85}$ dos automóveis $(\mathrm{km} / \mathrm{h})$ & 84,6 & 78,3 & 90,6 & 86,5 & 77,8 \\
$\mathrm{~V}_{85}$ dos camihões $(\mathrm{km} / \mathrm{h})$ & 74,7 & 66,4 & 76,0 & 75,6 & 73,0 \\
\hline
\end{tabular}

Tabela 6.4 - Parâmetros de tráfego por hora de coleta (sentido descendente)

\begin{tabular}{llllll}
\hline Parâmetro & \multicolumn{5}{c}{ Horário $(\mathrm{h})$} \\
\cline { 2 - 6 } & 10 às 11 & 11 às 12 & 12 às 13 & 13 às 14 & 14 às 15 \\
\hline Início (\% de Veíc em Pelotões - headways $\leq 3 \mathrm{~s})$ & $11,7 \%$ & $12,3 \%$ & $13,5 \%$ & $13,9 \%$ & $13,1 \%$ \\
Fim (\% de Veíc em Pelotões - headways $\geq 3 \mathrm{~s})$ & $22,2 \%$ & $23,8 \%$ & $25,6 \%$ & $30,0 \%$ & $27,5 \%$ \\
Fluxo horário (veic/hora) & 99 & 109 & 109 & 140 & 138 \\
Porcentagem de caminhões & $22,2 \%$ & $18,3 \%$ & $22,0 \%$ & $24,2 \%$ & $23,9 \%$ \\
Velocidade média automóveis $(\mathrm{km} / \mathrm{h})$ & 58,3 & 57,8 & 63,5 & 62,6 & 59,1 \\
Velocidade média caminhões $(\mathrm{km} / \mathrm{h})$ & 43,0 & 51,1 & 52,4 & 55,2 & 51,0 \\
$V_{15}$ dos automóveis $(\mathrm{km} / \mathrm{h})$ & 51,1 & 49,7 & 57,9 & 55,0 & 51,2 \\
$V_{15}$ dos camihões $(\mathrm{km} / \mathrm{h})$ & 32,5 & 41,7 & 45,2 & 46,7 & 45,4 \\
$V_{85}$ dos automóveis $(\mathrm{km} / \mathrm{h})$ & 71,1 & 70,3 & 69,5 & 70,6 & 67,2 \\
$\mathrm{~V}_{85}$ dos camihões $(\mathrm{km} / \mathrm{h})$ & 53,7 & 62,6 & 60,8 & 62,4 & 59,4 \\
\hline
\end{tabular}

O fator de hora-pico $(P H F)$ foi calculado para o período entre 14:00 e 15:00h (hora mais carregada), e o valor encontrado foi de 0,93, dentro do intervalo estimado por Mon-Ma (2008) para as rodovias de pista simples do estado de São Paulo. Foi verificado que a divisão direcional do fluxo de tráfego é $51 \%$ para o sentido ascendente e $49 \%$ para o sentido descendente da quilometragem. A porcentagem média de caminhões no fluxo de tráfego foi 
de $28 \%$ no sentido ascendente e de $22 \%$ no sentido descendente, valores que correspondem às médias aritméticas do que foi observado.

Como o TWOPAS é restrito a simular apenas quatro categorias de veículos pesados, a distribuição de caminhões também foi estratificada em 4 categorias, conforme descrito na Tabela 6.5, usando o esquema proposto por Cunha et al. (2008).

Tabela 6.5 - Divisão por categoria do volume de caminhões

\begin{tabular}{lll}
\hline Categoria & Número de Eixos & Porcentagem \\
\hline Leve & 2 & $40,0 \%$ \\
Médio & 3 & $37,0 \%$ \\
Pesado & 4 e 5 & $19,5 \%$ \\
Extra-Pesado & 6 ou mais & $3,5 \%$ \\
\hline
\end{tabular}

\subsection{RESULTADOS DA RECALIBRAÇÃO}

O TWOPAS foi calibrado através do algoritmo genético (AG) desenvolvido por Bessa Jr. (2009). O AG usado recalibra o TWOPAS modificando os valores dos seguintes parâmetros: probabilidade de ultrapassagem reconsiderada no período de revisão (PREC), fator de sensibilidade do modelo de car following (ZKCOR), parâmetros que descrevem os 10 tipos de motoristas $(B K P M)$ e desempenho dos veículos pesados (WOHP). O AG também busca o valor da velocidade desejada em cada direção. Mais detalhes do AG podem ser encontrados em Bessa Jr. (2009).

Ao todo, foram rodadas mais de 700 gerações, sendo o erro máximo (EMA) alcançado de aproximadamente 7\%. A recalibração alterou o PREC de 0,2 (default) para 0,1, pelo qual os motoristas reconsiderarão as oportunidades de ultrapassagem, em média, a cada 10 segundos. $\mathrm{O}$ valor do $Z K C O R$ reduziu de 0,8 para 0,7 .

Os valores dos BKPM estão na Tabela 6.6. É possível concluir que, comparado com os valores default do TWOPAS, todos os tipos de motoristas do trecho analisado aceitam mais riscos enquanto dirigem, já que quanto menor o valor do $B K P M$, mais agressivo é o motorista (FHWA, 2004). 
Tabela 6.6 - Parâmetros comportamentais dos motoristas

\begin{tabular}{lllllllllll}
\hline Tipo de Motorista & 1 & 2 & 3 & 4 & 5 & 6 & 7 & 8 & 9 & 10 \\
\hline BKPM (calibrado) & 0,26 & 0,34 & 0,40 & 0,48 & 0,59 & 0,74 & 0,96 & 1,17 & 1,41 & 1,95 \\
BKPM (default) & 0,43 & 0,51 & 0,57 & 0,65 & 0,76 & 0,91 & 1,13 & 1,34 & 1,58 & 2,12 \\
\hline
\end{tabular}

Os valores de WOHP, calibrados para o trecho estudado, estão na Tabela 6.7. Este parâmetro é relacionado ao desempenho dos veículos pesados, pois representa a relação entre a massa e a potência dos caminhões.

\begin{tabular}{lc}
\multicolumn{2}{l}{ Tabela 6.7 - Relações massa / potência ajustadas } \\
\hline Categoria & WOHP $(\mathrm{kg} / \mathrm{kW})$ \\
\hline LEVE & 90 \\
MÉDIO & 143 \\
PESADO & 160 \\
EXTRA-PESADO & 205 \\
\hline
\end{tabular}

Na Tabela 6.8 estão os valores das velocidades médias desejadas no trecho analisado que produzem o menor EMA. De acordo com Mon-Ma (2008), mais do que "desejadas", essas velocidades são as que os caminhões conseguem desenvolver devido as suas limitações de desempenho.

Tabela 6.8 - Velocidades médias desejadas por direção e tipo de veículo

\begin{tabular}{cll}
\hline Direção & Tipo de veículo & Velocidade desejada $(\mathrm{km} / \mathrm{h})$ \\
\hline \multirow{2}{*}{1} & Caminhões & 68 \\
& Automóveis & 88 \\
2 & Caminhões & 60 \\
& Automóveis & 77 \\
\hline
\end{tabular}

As menores velocidades obtidas para Direção 2 são explicadas pela maior extensão dos aclives nesse sentido. Mesmo sendo em um terreno ondulado, as velocidades da rodovia estudada são consideravelmente inferiores às velocidades default do TWOPAS: $99 \mathrm{~km} / \mathrm{h}$ para os automóveis e $96 \mathrm{~km} / \mathrm{h}$ para os caminhões. Nota-se a disparidade entre o desempenho dos caminhões norte-americanos e brasileiros, a qual pode ser também afetada pela inexistência de $3^{\text {a }}$ faixas na rodovia observada.

\subsection{CURVAS DE DESEMPENHO}

A partir do simulador calibrado, foi possível desenvolver curvas de desaceleração sofrida pelos caminhões em diversas declividades e comprimentos de rampa, para as relações massa/potência apresentadas na Tabela 6.7. 
A velocidade de entrada considerada foi de $90 \mathrm{~km} / \mathrm{h}$, que é, aproximadamente, a maior velocidade desejada pelos automóveis (Tabela 6.8), sendo então razoável admitir que essa velocidade é a de fluxo livre dos caminhões.

A versão recalibrada do TWOPAS foi usada para obter as curvas de desempenho. Foram feitas 10 replicações de cada um dos cenários, ou seja, 4 categorias $\times 7$ declividades $(0$ a $6 \%)$ $\times 10$ replicações, num total de 280 simulações. De cada conjunto de 10 resultados para cada replicação, foi calculado o desvio padrão entre as velocidades de cada estação de observação, que eram espaçadas de 100 em 100 m. O maior dos desvios padrão encontrados, $1,7 \mathrm{~km} / \mathrm{h}$, foi considerado como o desvio padrão das populações de todas as categorias sob análise.

Com a estimação do desvio padrão da população, considerando um erro amostral de 1 $\mathrm{km} / \mathrm{h}$, e considerando um grau de confiança de $95 \%$, foi calculado o tamanho da amostra. Assim, as curvas de desempenho (Figuras 6.3 a 6.6) foram geradas a partir da média das velocidades obtidas em 11 replicações simuladas com o TWOPAS.

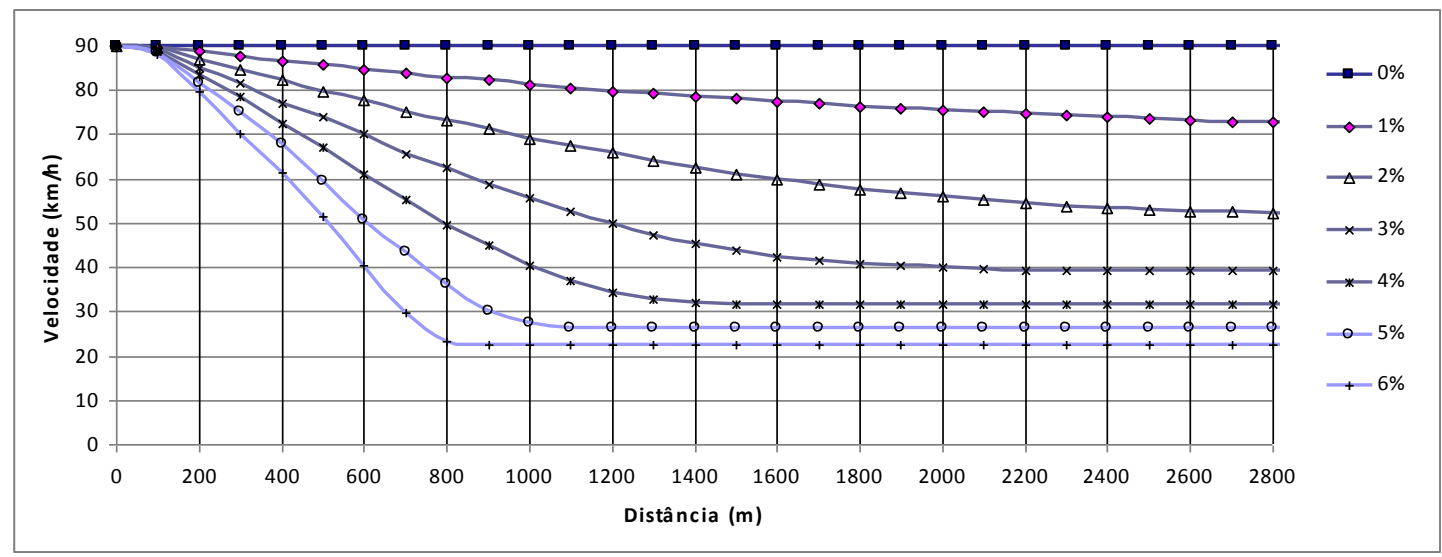

Figura 6.3 - Curva de desaceleração da categoria Extra-Pesado (205 kg/kW)

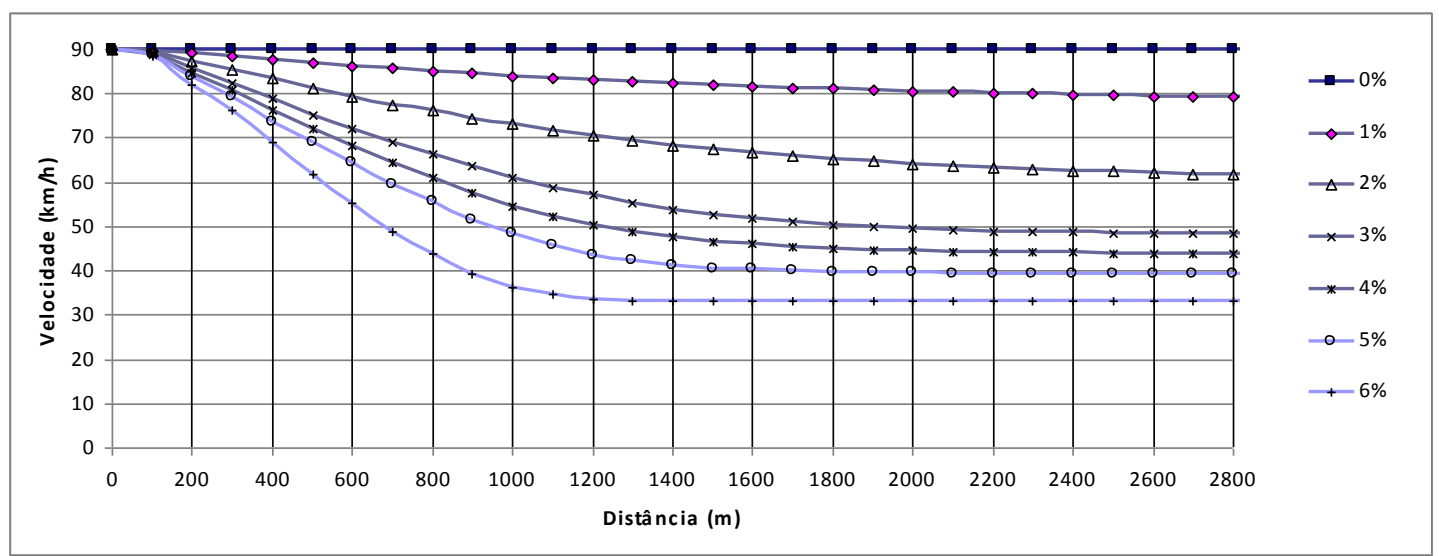

Figura 6.4 - Curva de desaceleração da categoria Pesado (160 kg/kW) 


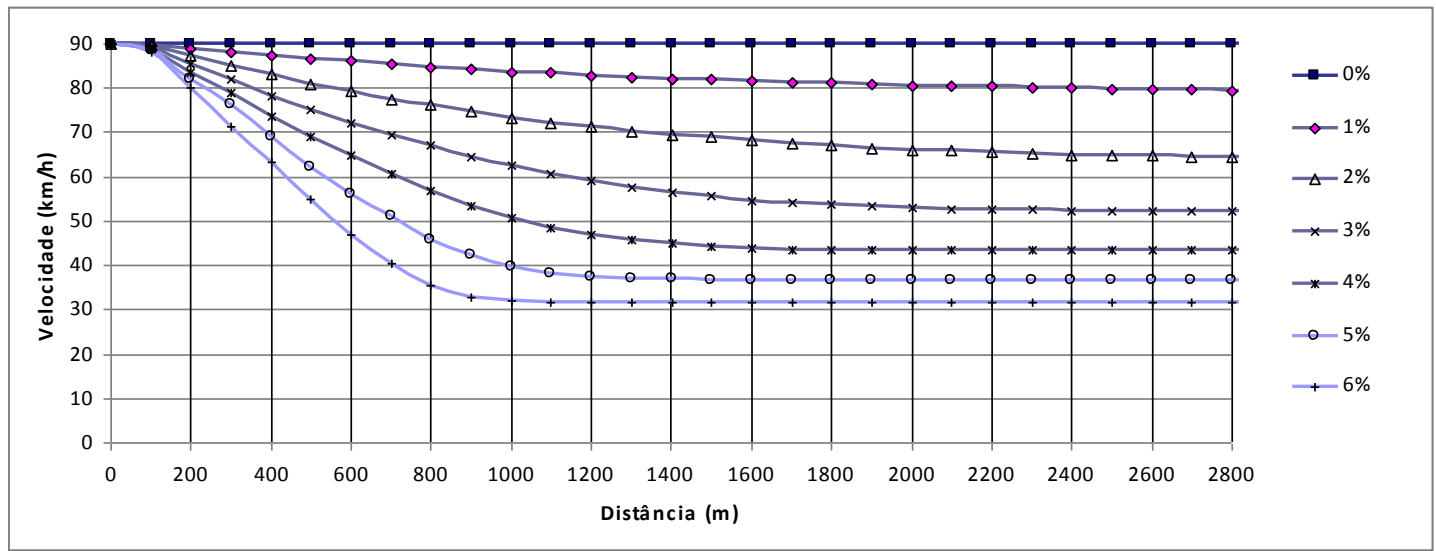

Figura 6.5 - Curva de desaceleração da categoria Médio (143 kg/kW)

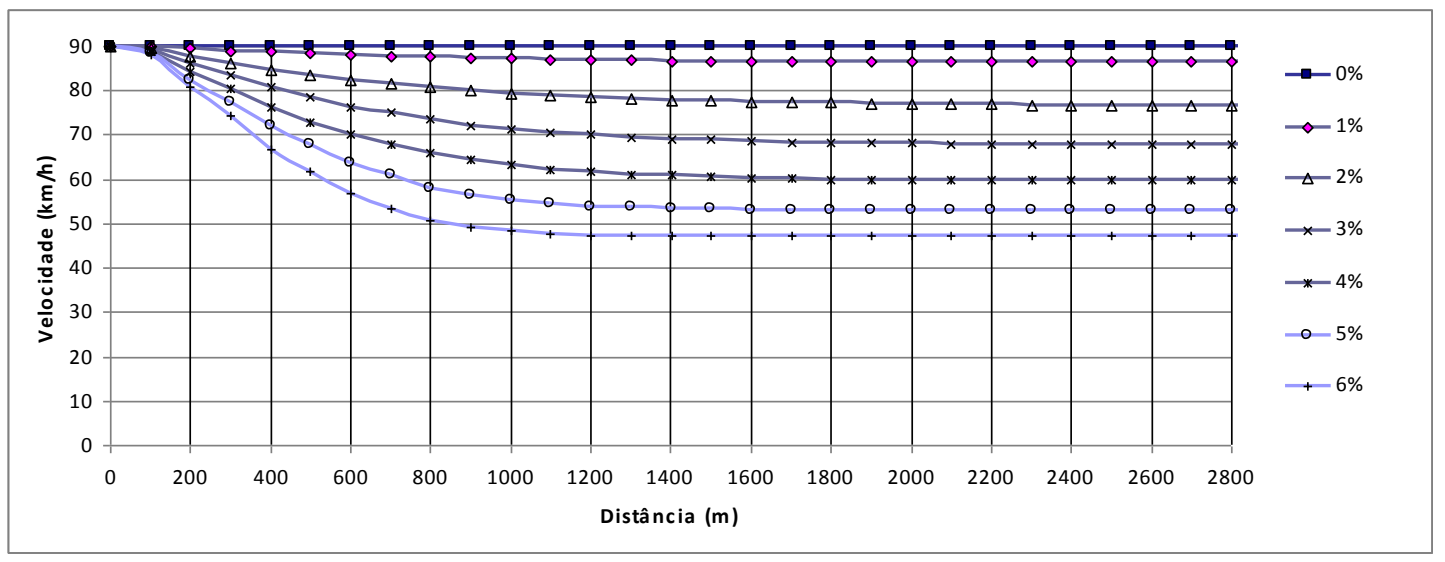

Figura 6.6 - Curva de desaceleração da categoria Leve $(90 \mathrm{~kg} / \mathrm{kW})$

\subsection{APLICAÇÃO DO MÉTODO PROPOSTO}

O método proposto estabelece uma sequência de implantação de um conjunto de faixas adicionais que maximiza os benefícios do investimento. Inicialmente, são verificadas as rampas onde há redução de velocidade que justifique a implantação de faixa adicional, através da curva de desaceleração do veículo de projeto, no caso, o de pior desempenho. Depois, são determinados os anos em que os fluxos mínimos de tráfego que justificam a implantação da faixa adicional são atingidos e, consequentemente, os cenários a serem testados. Por fim, é realizado o cálculo dos benefícios e custos do conjunto de faixas a serem implantadas a cada ano.

\subsubsection{Verificação dos aclives com redução excessiva de velocidade}

A Tabela 6.9 resume os aclives candidatos à implantação das faixas adicionais, em função do seu comprimento e declividade, do veículo de projeto $(205 \mathrm{~kg} / \mathrm{kW})$ e da máxima redução 
admitida de velocidade $(20 \mathrm{~km} / \mathrm{h})$. Nesta etapa, foi também determinada a extensão das faixas adicionais. Considerou-se que o início da faixa adicional coincide com o ponto em que se completa a perda de $20 \mathrm{~km} / \mathrm{h}$, e que o final da faixa adicional coincide com o final do aclive, salvo para um caso em que a diferença dessas estacas seja inferior a 300 metros, a qual é a extensão mínima recomendada na literatura para uma faixa adicional, incluindo os tapers de convergência e de divergência (Morral e Hoban, 1985). Sabe-se que numa aplicação real a consideração feita para definir a extensão das faixas não é suficiente, porém, visto a elevada quantidade de estimativas deste estudo de caso, essa consideração não deve interferir nos resultados.

Assim, conforme exibido na Tabela 6.9, para o aclive 15 foi determinada a extensão mínima das faixas adicionais. Ainda que, poderia ser questionada a necessidade de melhoria nesse aclive, como se pretendeu desenvolver um estudo de caso com o maior número de combinações de cenários, optou-se por incluir esta faixa na análise. O início da faixa adicional foi recuado, permanecendo o final da faixa coincidente com o final do aclive.

Tabela 6.9 - Aclives candidatos a receber faixa adicional

\begin{tabular}{llllll}
\hline $\begin{array}{l}\text { Sentido das } \\
\text { Estacas }\end{array}$ & Aclive & Declividade $(\%)$ & Extensão $(\mathrm{m})$ & $\begin{array}{l}\text { Há redução } \\
\text { de } 20 \mathrm{~km} / \mathrm{h} \text { ? }\end{array}$ & $\begin{array}{l}\text { Extensão da Faixa } \\
\text { Adicional }(\mathrm{m})\end{array}$ \\
\hline Ascendente & 2 & 3 & 1208 & Sim & 608 \\
Ascendente & 5 & 2 & 1134 & Sim & 334 \\
Ascendente & 7 & 4 & 1388 & Sim & 938 \\
Ascendente & 8 & 0,5 & 1092 & Não & - \\
Ascendente & 9 & 1 & 1453 & Não & - \\
Ascendente & 10 & 3 & 1764 & Sim & 1164 \\
Ascendente & 13 & 3 & 1293 & Sim & 693 \\
Ascendente & 15 & 5 & 403 & Sim & $300^{*}$ \\
Descendente & 16 & 4 & 140 & Não & - \\
Descendente & 14 & 1 & 494 & Não & - \\
Descendente & 12 & 0,5 & 1798 & Não & - \\
Descendente & 11 & 2 & 2239 & Sim & 1289 \\
Descendente & 6 & 2 & 564 & Não & - \\
Descendente & 4 & 0,5 & 1329 & Não & - \\
Descendente & 3 & 3 & 3202 & Sim & 2602 \\
Descendente & 1 & 4 & 120 & Não & - \\
\hline
\end{tabular}

* Adotada extensão mínima de $300 \mathrm{~m}$

\subsubsection{Faixas adicionais que devem ser implantadas}

Conhecido os aclives candidatos a receber faixas adicionais, é iniciada a etapa de verificação dos anos em que as faixas tornam-se justificáveis economicamente ao longo do horizonte de 
projeto. Para isso, foram utilizados os fluxos mínimos de tráfego propostos por Melo e Setti (2007), apresentados na Tabela 2.3.

Neste estudo de caso, o fluxo de tráfego direcional no $1^{\circ}$ ano foi admitido como sendo o que justifica a implantação da faixa adicional do caso mais crítico. Numa aplicação real o usuário deve utilizar o fluxo da hora pico em cada sentido. Os fluxos dos anos seguintes são estimados através de uma taxa média de crescimento do tráfego, que, neste caso, foi suposta como sendo de $5 \%$ ao ano. O horizonte de projeto considerado neste caso foi de 30 anos.

Em todos os anos analisados, as porcentagens de caminhões na corrente de tráfego foram mantidas constantes: $28 \%$ para o sentido ascendente das estacas e $22 \%$, para o descendente. Numa aplicação real, é possível que a fração de caminhões no tráfego não se mantenha inalterada ao longo do horizonte de projeto.

Através dos mesmos fluxos mínimos proposto em Melo e Setti (2007), foram verificados em quais anos da análise cada uma das faixas adicionais passam a ser justificáveis economicamente, sendo gerada a Tabela 6.10. Na subseção 6.4.3, há uma averiguação do critério dos fluxos mínimos através do cálculo dos Níveis de Serviço (NS).

Tabela 6.10 - Faixas adicionais necessárias a cada ano

\begin{tabular}{|c|c|c|c|c|c|c|}
\hline & $1^{\circ} \mathrm{ANO}$ & $2^{\circ} \mathrm{ANO}$ & $3^{\circ} \mathrm{ANO}$ & $4^{\circ} \mathrm{ANO}$ & $5^{\circ} \mathrm{ANO}$ & $6^{\circ} \mathrm{ANO}$ \\
\hline VHP & 345 veíc/h & 362 veíc/h & 380 veíc/h & 399 veíc/h & 419 veíc/h & 440 veíc/h \\
\hline VHP Descendente & 331 veíc/h & 348 veíc/h & 365 veíc/h & 383 veíc/h & 402 veíc/h & 423 veíc/h \\
\hline Faixas Necessárias & $7 \mathrm{e} 10$ & $15,13,2$ & 3 & 5 & - & 11 \\
\hline
\end{tabular}

Consultou-se a distribuição da média dos volumes horários de um trecho com características similares às do trecho sob análise, para determinar a quantidade de horas de pico e entre picos. Essa distribuição foi obtida a partir de dados coletados ao longo de uma semana típica num posto de pedágio próximo ao trecho analisado, numa rodovia de pista simples. Considerou-se que a distribuição do tráfego ao longo do dia no trecho estudado segue o mesmo padrão, mostrado na Figura 6.7.

Nesse contexto, adotou-se como pico de tráfego de um dia típico desse corredor as horas com mais do que 6\% do volume diário médio (VDM). Portanto, a análise da Figura 6.7 mostrou que há 7 horas de pico e 17 horas entre picos. Foi admitido também que, no trecho estudado, metade do VDM trafega durante as horas de pico e metade fora dos picos. 


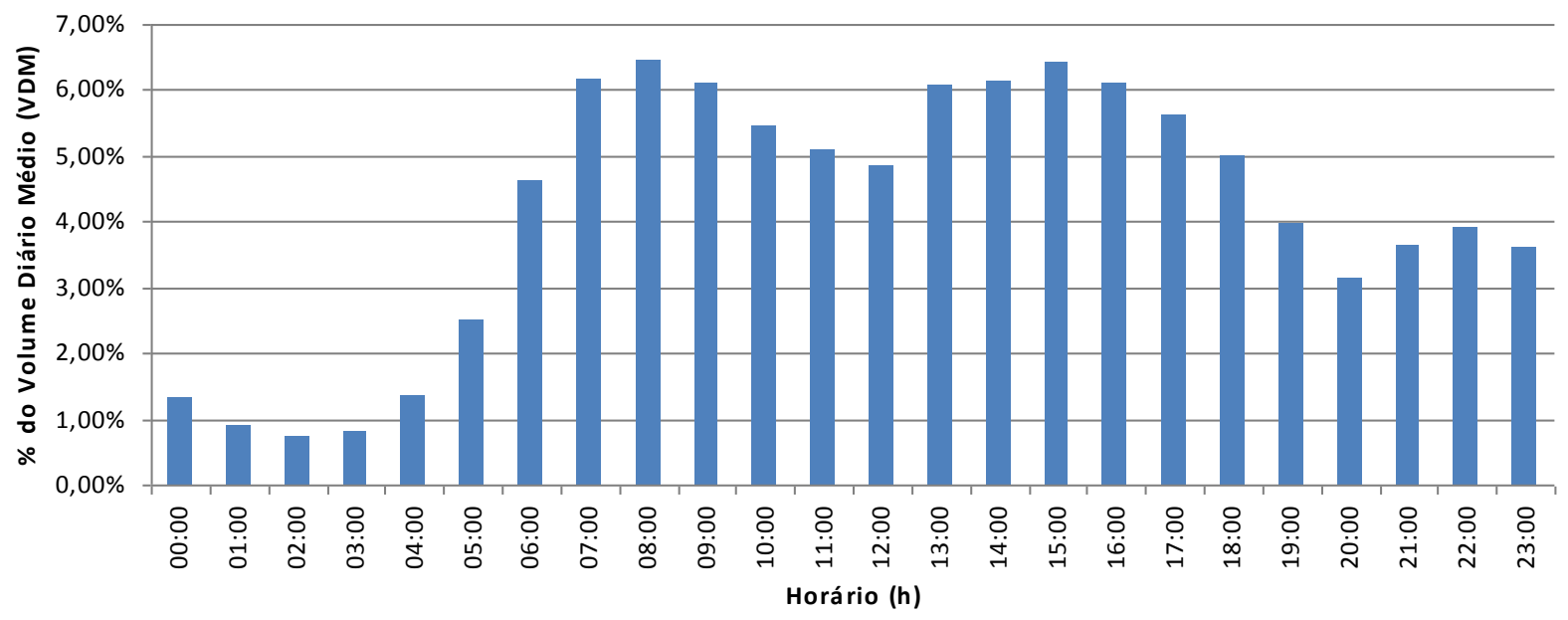

Figura 6.7 - Distribuição do tráfego numa praça de pedágio próxima ao trecho estudado

\subsubsection{Sequência ideal para construção das faixas adicionais}

Uma vez que se tenha o conjunto de faixas adicionais a serem implantadas, a etapa seguinte consiste em sequenciar a implantação das faixas adicionais, de forma a maximizar os benefícios do investimento.

Conforme explicado no Capítulo 3, a cada ano analisado foi considerado um intervalo de três anos para trás e para frente, com intuito de checar as combinações que proporcionam a maior relação benefício/custo. Se em um determinado ano $i$ houver $1+w$ faixas necessárias, com as características do tráfego desse mesmo ano $i$, serão testados todos os conjuntos de $1+$ $w$ faixas possíveis dentro do intervalo $(i-3 ; i+3)$. Só os conjuntos em que haja pelo menos uma das faixas necessárias no ano $i$ são considerados na análise.

Quanto ao número de replicações de cada cenário simulado, foi realizado um procedimento de cálculo do tamanho da amostra semelhante ao explicado no item 6.3. No entanto, foi calculado o desvio padrão da porcentagem de veículos em pelotões (\%FOLL) entre cada estaca, já que essa variável é a que faz parte do cálculo dos benefícios gerados pela redução do tempo de viagem. Foi considerado que o desvio padrão da população de \%FOLL é igual a $4 \%$, e o erro amostral admissível igual a $2 \%$. Com esses valores, e para um grau de confiança de $95 \%$, o tamanho da amostra foi igual a 15.

Assim, foram gerados 15 conjuntos de números aleatórios, que foram repetidos na simulação de cada cenário analisado, para permitir a comparação e escolha dos cenários mais 
eficientes. No Anexo A, estão os conjuntos de números aleatórios utilizados nas replicações de todos os cenários analisados nesta pesquisa, assim como a função no TWOPAS de cada elemento do conjunto.

\subsubsection{Estimativa dos benefícios ano a ano}

A seguir estão as análises ano a ano dos conjuntos de faixas adicionais. Os benefícios de cada conjunto analisado foram calculados usando-se os resultados das simulações e as estimativas apresentadas a seguir.

No cálculo do custo operacional unitário, foram considerados os custos fixos mensais e os custos variáveis por quilômetro referentes ao mês de novembro de 2007, publicados na revista eletrônica Economia e Transporte para cada categoria de veículo, cujas tabelas estão no Anexo B. Foi considerado que a utilização média diária dos automóveis, ônibus e caminhões são, respectivamente, 56, 250 e $292 \mathrm{~km}$. Assim, os valores de $C O U_{a}, C O U_{o}$ e $C O U_{c}$ foram, respectivamente, 0,64 R \$/km, 2,03 R \$/km e 1,30 R \$/km.

Para estimar o custos de uma hora de viagem $(\mathrm{CHu})$ e a relação entre veículos que geram benefícios e os que não geram benefícios $(R)$, foram utilizados os valores apresentados na Tabela 6.11. O valor do salário mínimo (SM) foi reajustado a cada ano da análise em 4,8\%, taxa essa correspondente ao IPCA acumulado no período de 01/07/2008 a 01/07/2009.

Tabela 6.11 - Valores utilizados para calcular CHu e R

\begin{tabular}{ll}
\hline Variável & Valor \\
\hline$P_{A}$ & Direção Ascendente $70,4 \%$ \\
& Direção Descendente $76,4 \%$ \\
\hline$P_{O}$ & Direção Ascendente 1,6\% \\
\hline$N_{p a}$ & Direção Descendente 1,6\% \\
$N_{p o}$ & 3 passageiros \\
$S M$ do ano 0 & 25 passageiros \\
$P C V$ & $R \$ 465$ (Jul/09) \\
\hline
\end{tabular}

Os valores de todas as variáveis que compões o cálculo do $B R C O$ e $B R T V$, para cada ano analisado e para cada categoria de veículo, estão apresentados, respectivamente, no Apêndice A e no Apêndice B.

Quanto aos valores monetários de cada um dos serviços de implantação das faixas adicionais (terraplenagem, drenagem, pavimentação e sinalização), foram utilizados os 
publicados pelo DER-SP na "tabelas de preços unitários" referente à data base de 31 de março de 2009 (DER, 2009). Para os anos do horizonte de projeto, esses valores unitários foram corrigidos em 4,8\% ao ano, sendo essa taxa o IPCA acumulado no período entre 01/07/2008 e 01/07/2009.

No cálculo das parcelas correspondentes a um ano do investimento total da faixa adicional (A), a taxa nominal de juros utilizada foi de $6,25 \%$, a qual é igual à taxa de juros de longo prazo (TJLP) concedida pelo BNDES como custo básico dos financiamentos de abril a junho de 2009 (BNDES, 2010). Nas Tabelas 6.13, 6.15, 6.16, 6.17 e 6.18 estão apresentadas as parcelas $(A)$ anuais dos custos de construção $(C c)$ das faixas necessárias nos anos do horizonte de projeto deste estudo de caso.

\section{$\underline{1^{o} \text { ano da análise }}$}

Com as características de tráfego que justificam as melhorias nos casos mais críticos, faixas 7 e 10, foram testados os conjuntos de cenários com 2 faixas adicionais. As faixas que compuseram esses conjuntos foram as que se mostraram necessárias do $1^{\circ}$ ao $4^{\circ}$ ano da análise, como mostrado na Tabela 6.12.

Não houve a necessidade de verificar o critério do nível de serviço (NS) da operação do tráfego deste ano da análise, já que pelo critério de fluxos mínimos a implantação das faixas estava justificada.

Tabela 6.12 - Conjuntos de faixas adicionais analisados no $1^{\circ}$ ano

Conjuntos analisados

(7 e 10); (7 e 15); (7 e 13); (7 e 2); (7 e 3); (7 e 5); $(10$ e 15$) ;(10$ e 13$) ;(10$ e 2$) ;(10$ e 3$) ;(10$ e 5$)$

Foram calculados os benefícios e os custos referentes à implantação das faixas adicionais, conforme os métodos indicados nos Capítulos 4 e 5 . Todos os valores das variáveis de entrada, ou seja, as características do tráfego do $1^{\circ}$ ano da análise estão apresentadas nos Apêndices A e B.

O valor presente dos benefícios das reduções do custo operacional $(B R C O)$ e do tempo de viagem $(B R T V)$, proporcionados por cada faixa, em cada combinação analisada, estão dados na Tabela 6.13. As parcelas anuais dos custos de implantação de cada faixa no $1^{\circ}$ ano da análise, também estão mostradas nessa tabela, na coluna "Custos". 
Tabela 6.13 - Benefícios e custos do $1^{\circ}$ ano da análise

\begin{tabular}{|c|c|c|c|c|c|}
\hline Conjunto & $\begin{array}{l}\text { Faixas } \\
\text { adicionais }\end{array}$ & $\begin{array}{l}\text { BRCO da faixa } \\
\text { adicional }\end{array}$ & $\begin{array}{l}\text { BRTV da faixa } \\
\text { adicional }\end{array}$ & Custos & $\begin{array}{l}\text { Relação } B / C \\
\text { do conjunto }\end{array}$ \\
\hline \multirow{2}{*}{1} & 7 & $\mathrm{R} \$ 3.586,45$ & $\mathrm{R} \$ 363.165,22$ & $\mathrm{R} \$ 37.263,17$ & 10,6 \\
\hline & 10 & $R \$ 3.586,45$ & $R \$ 522.050,00$ & $\mathrm{R} \$ 46.912,92$ & \\
\hline \multirow{2}{*}{2} & 10 & $\mathrm{R} \$ 1.778,96$ & $\mathrm{R} \$ 282.851,86$ & $\mathrm{R} \$ 46.912,92$ & 7,9 \\
\hline & 13 & $\mathrm{R} \$ 1.778,96$ & $R \$ 305.182,27$ & $\mathrm{R} \$ 27.613,42$ & \\
\hline \multirow[b]{2}{*}{3} & 7 & $\mathrm{R} \$ 1.369,80$ & $\mathrm{R} \$ 242.173,50$ & $\mathrm{R} \$ 37.263,17$ & 7,3 \\
\hline & 13 & $\mathrm{R} \$ 1.369,80$ & $\mathrm{R} \$ 228.615,53$ & $\mathrm{R} \$ 27.613,42$ & \\
\hline \multirow{2}{*}{4} & 7 & $\mathrm{R} \$ 910,85$ & $\mathrm{R} \$ 212.205,92$ & $\mathrm{R} \$ 37.263,17$ & 7,3 \\
\hline & 15 & $\mathrm{R} \$ 910,85$ & $R \$ 146.598,54$ & $\mathrm{R} \$ 12.173,82$ & \\
\hline \multirow{2}{*}{5} & 7 & $\mathrm{R} \$ 1.124,46$ & $\mathrm{R} \$ 237.817,81$ & $\mathrm{R} \$ 37.263,17$ & 6,4 \\
\hline & 5 & $R \$ 1.124,46$ & $\mathrm{R} \$ 89.181,68$ & $\mathrm{R} \$ 14.103,77$ & \\
\hline \multirow{2}{*}{6} & 10 & $\mathrm{R} \$ 643,75$ & $\mathrm{R} \$ 188.028,84$ & $\mathrm{R} \$ 46.912,92$ & 5,8 \\
\hline & 15 & $\mathrm{R} \$ 643,75$ & $\mathrm{R} \$ 152.982,95$ & $\mathrm{R} \$ 12.173,82$ & \\
\hline \multirow{2}{*}{7} & 7 & $\mathrm{R} \$ 1.426,97$ & $\mathrm{R} \$ 264.533,14$ & $\mathrm{R} \$ 37.263,17$ & 5,6 \\
\hline & 2 & $\mathrm{R} \$ 1.426,97$ & $\mathrm{R} \$ 75.070,22$ & $\mathrm{R} \$ 23.753,52$ & \\
\hline \multirow{2}{*}{8} & 10 & $\mathrm{R} \$ 226,76$ & $\mathrm{R} \$ 110.538,37$ & $\mathrm{R} \$ 46.912,92$ & 3,2 \\
\hline & 3 & $\mathrm{R} \$ 2.612,96$ & $R \$ 354.624,50$ & $\mathrm{R} \$ 101.028,72$ & \\
\hline \multirow{2}{*}{9} & 10 & $R \$ 380,24$ & $\mathrm{R} \$ 89.062,19$ & $\mathrm{R} \$ 46.912,92$ & 2,3 \\
\hline & 5 & $R \$ 380,24$ & $\mathrm{R} \$ 49.478,99$ & $\mathrm{R} \$ 14.103,77$ & \\
\hline \multirow{2}{*}{10} & 10 & $R \$ 544,43$ & $\mathrm{R} \$ 120.108,80$ & $\mathrm{R} \$ 46.912,92$ & 2,1 \\
\hline & 2 & $R \$ 544,43$ & $\mathrm{R} \$ 28.348,66$ & $R \$ 23.753,52$ & \\
\hline \multirow{2}{*}{11} & 7 & $\mathrm{R} \$ 737,99$ & $\mathrm{R} \$ 221.135,22$ & $\mathrm{R} \$ 37.263,17$ & 1,7 \\
\hline & 3 & $\mathrm{R} \$ 116,94$ & $\mathrm{R} \$ 19.041,30$ & $\mathrm{R} \$ 101.028,72$ & \\
\hline
\end{tabular}

Como pode ser notado pela análise da Tabela 6.13, tanto o $B R C O$ quanto o $B R T V$ de uma mesma faixa é variável de acordo com o conjunto que ela esteja inserida, porque o arranjo entre as faixas proporciona variação na velocidade média de operação e na PTSF.

Em um mesmo conjunto, a variação do valor do $B R C O$ é devida, principalmente, à forte correlação desse benefício com a velocidade média direcional da corrente de tráfego. Por isso, no $1^{\circ}$ ano da análise observou-se a maior variação desse benefício apenas nos conjuntos em que o aclive 3 estava presente, pois esse é o único que está na direção descendente das estacas.

Já a variação em um mesmo conjunto do $B R T V$ é devida, principalmente, à forte correlação desse benefício com \%FOLL, que normalmente varia com a distância entre as faixas adicionais de um trecho.

\section{$\underline{2^{\circ} \text { ano da análise }}$}

De acordo com o apresentado, o conjunto de faixas que proporcionaram a maior relação $\mathrm{B} / \mathrm{C}$ no $1^{\circ}$ ano foi o formado pelas faixas 7 e 10 . Essas duas faixas foram retiradas da análise do $2^{\circ}$ ano, uma vez que devem ser implantadas no $1^{\circ}$ ano. Por isso, para a confecção dos 
cenários pertencentes aos anos posteriores é necessário calcular os somatórios dos benefícios e dos custos de todos os cenários possíveis no ano anterior ao analisado, pois só assim foi possível conhecer as faixas que ainda não foram implantadas, podendo compor então, os conjuntos do ano sob análise. Na Tabela 6.14 estão descritos os conjuntos de faixas simulados com as características do tráfego do $2^{\circ}$ ano da análise. Não foi verificado o critério do nível de serviço (NS) da operação do tráfego, pois pelo critério de fluxos mínimos a implantação das faixas estava justificada.

Tabela 6.14 - Conjuntos de faixas adicionais analisados no $2^{\circ}$ ano

$\begin{array}{ll} & (15,13 \text { e } 2) ;(15,13 \text { e } 3) ;(15,13 \text { e } 5) ;(15,2 \text { e } 3) \\ \text { Conjuntos Analisados } & (15,2 \text { e } 5) ;(15,3 \text { e } 5) ;(13,2 \text { e } 3) ;(13,2 \text { e } 5) ; \\ & (13,3 \text { e } 5) ;(2,3 \text { e } 5)\end{array}$

As estimativas dos valores dos benefícios da redução do custo operacional $(B R C O)$ e do tempo de viagem $(B R T V)$ proporcionados por cada faixa em cada combinação analisada estão na Tabela 6.15. As parcelas anuais dos custos de implantação de cada faixa no $2^{\circ}$ ano da análise estão mostradas nessa tabela na coluna "Custos".

É possível observar as mesmas características da variação do $B R C O$ e do $B R T V$ que foram notadas no final da análise do ano anterior. Observa-se também o menor valor das relações benefício total/custo total devido ao início da operação das faixas implantadas no $1^{\circ}$ ano da análise. Aqui o conjunto que proporcionou mais benefício foi o formado pelas faixas $15,2 \mathrm{e}$ 3.

\section{$\underline{3^{\circ} \text { ano da análise }}$}

Neste ano, foram calculados os benefícios individuais proporcionados pelas faixas $5,13 \mathrm{e}$ 11, as únicas restantes do conjunto de faixas necessárias dentre os anos $1^{\circ}$ e $6^{\circ}$ (Tabela 6.16). O critério do nível de serviço (NS) da operação do tráfego não foi verificado, porque a implantação de uma faixa adicional estava garantida pelo critério de fluxos mínimos.

Observa-se que, com o volume de tráfego previsto para o $3^{\circ}$ ano, a única faixa com a relação B/C maior do que 1 foi a 11 . Então, no $3^{\circ}$ ano, a faixa 11 foi implantada, ressaltandose a superioridade dos benefícios gerados por essa faixa, quando comparados com os benefícios gerados pelas faixas 13 e 5 . Essa diferença deve-se, provavelmente, ao fato da 
faixa 11 ser a única do conjunto testado que está no sentido descendente da quilometragem, e esse sentido ainda não ter sido contemplado com nenhuma faixa adicional.

Tabela 6.15 - Benefícios e custos do $2^{\circ}$ ano da análise

\begin{tabular}{|c|c|c|c|c|c|}
\hline Conjunto & $\begin{array}{l}\text { Faixas } \\
\text { adicionais }\end{array}$ & $\begin{array}{l}\text { BRCO da faixa } \\
\text { adicional }\end{array}$ & $\begin{array}{l}\text { BRTV da faixa } \\
\text { adicional }\end{array}$ & Custos & $\begin{array}{l}\text { Relação B/C } \\
\text { do conjunto }\end{array}$ \\
\hline \multirow{3}{*}{1} & 15 & $\mathrm{R} \$ 134,29$ & $\mathrm{R} \$ 24.292,76$ & $\mathrm{R} \$ 12.758,16$ & $\overline{3,1}$ \\
\hline & 2 & $\mathrm{R} \$ 134,29$ & $\mathrm{R} \$ 5.872,62$ & $\mathrm{R} \$ 24.893,69$ & \\
\hline & 3 & $\mathrm{R} \$ 4.196,41$ & $\mathrm{R} \$ 416.052,07$ & $\mathrm{R} \$ 105.878,10$ & \\
\hline \multirow{3}{*}{2} & 13 & $\mathrm{R} \$ 231,92$ & $\mathrm{R} \$ 42.686,95$ & $\mathrm{R} \$ 28.938,87$ & 2,0 \\
\hline & 2 & $\mathrm{R} \$ 231,92$ & $\mathrm{R} \$ 9.409,02$ & $\mathrm{R} \$ 24.893,69$ & \\
\hline & 3 & $\mathrm{R} \$ 1.173,41$ & $\mathrm{R} \$ 267.144,89$ & $\mathrm{R} \$ 105.878,10$ & \\
\hline \multirow{3}{*}{3} & 15 & $\mathrm{R} \$ 91,08$ & $\mathrm{R} \$ 16.196,72$ & $\mathrm{R} \$ 12.758,16$ & 1,8 \\
\hline & 13 & $\mathrm{R} \$ 91,08$ & $\mathrm{R} \$ 10.937,77$ & $\mathrm{R} \$ 28.938,87$ & \\
\hline & 3 & $\mathrm{R} \$ 1.136,61$ & $\mathrm{R} \$ 242.780,64$ & $\mathrm{R} \$ 105.878,10$ & \\
\hline \multirow{3}{*}{4} & 13 & $\mathrm{R} \$ 84,15$ & $\mathrm{R} \$ 19.840,79$ & $\mathrm{R} \$ 28.938,87$ & 1,8 \\
\hline & 3 & $\mathrm{R} \$ 1.140,31$ & $\mathrm{R} \$ 241.724,89$ & $\mathrm{R} \$ 105.878,10$ & \\
\hline & 5 & $\mathrm{R} \$ 84,15$ & $R \$ 9.235,44$ & $\mathrm{R} \$ 14.780,75$ & \\
\hline \multirow{3}{*}{5} & 15 & $\mathrm{R} \$ 22,08$ & $\mathrm{R} \$ 9.316,91$ & $\mathrm{R} \$ 12.758,16$ & 1,8 \\
\hline & 3 & $\mathrm{R} \$ 1.071,30$ & $\mathrm{R} \$ 219.743,34$ & $\mathrm{R} \$ 105.878,10$ & \\
\hline & 5 & $\mathrm{R} \$ 22,08$ & $\mathrm{R} \$ 4.395,19$ & $\mathrm{R} \$ 14.780,75$ & \\
\hline \multirow{3}{*}{6} & 2 & $\mathrm{R} \$ 90,61$ & $\mathrm{R} \$ 5.734,89$ & $\mathrm{R} \$ 24.893,69$ & 1,7 \\
\hline & 3 & $\mathrm{R} \$ 1.079,00$ & $\mathrm{R} \$ 232.424,34$ & $R \$ 105.878,10$ & \\
\hline & 5 & $\mathrm{R} \$ 90,61$ & $\mathrm{R} \$ 14.476,11$ & $\mathrm{R} \$ 14.780,75$ & \\
\hline \multirow{3}{*}{7} & 15 & $\mathrm{R} \$ 251,94$ & $\mathrm{R} \$ 41.465,32$ & $\mathrm{R} \$ 12.758,16$ & 1,2 \\
\hline & 13 & $\mathrm{R} \$ 251,94$ & $\mathrm{R} \$ 26.093,70$ & $\mathrm{R} \$ 28.938,87$ & \\
\hline & 2 & $\mathrm{R} \$ 251,94$ & $\mathrm{R} \$ 12.062,34$ & $\mathrm{R} \$ 24.893,69$ & \\
\hline \multirow{3}{*}{8} & 15 & $\mathrm{R} \$ 138,15$ & $\mathrm{R} \$ 33.778,31$ & $\mathrm{R} \$ 12.758,16$ & 1,2 \\
\hline & 2 & $\mathrm{R} \$ 138,15$ & $\mathrm{R} \$ 15.080,66$ & $\mathrm{R} \$ 24.893,69$ & \\
\hline & 5 & $\mathrm{R} \$ 138,15$ & $\mathrm{R} \$ 14.250,53$ & $\mathrm{R} \$ 14.780,75$ & \\
\hline \multirow{3}{*}{9} & 13 & $\mathrm{R} \$ 286,14$ & $\mathrm{R} \$ 44.544,12$ & $\mathrm{R} \$ 28.938,87$ & 1,3 \\
\hline & 2 & $\mathrm{R} \$ 286,14$ & $\mathrm{R} \$ 19.257,90$ & $\mathrm{R} \$ 24.893,69$ & \\
\hline & 5 & $\mathrm{R} \$ 286,14$ & $\mathrm{R} \$ 23.649,57$ & $\mathrm{R} \$ 14.780,75$ & \\
\hline \multirow{3}{*}{10} & 15 & $\mathrm{R} \$ 106,62$ & $\mathrm{R} \$ 19.455,24$ & $\mathrm{R} \$ 12.758,16$ & 0,7 \\
\hline & 13 & $R \$ 106,62$ & $\mathrm{R} \$ 13.447,25$ & $\mathrm{R} \$ 28.938,87$ & \\
\hline & 5 & $\mathrm{R} \$ 106,62$ & $\mathrm{R} \$ 5.519,46$ & $\mathrm{R} \$ 14.780,75$ & \\
\hline
\end{tabular}

Tabela 6.16 - Benefícios e custos do $3^{\circ}$ ano da análise

\begin{tabular}{llllll}
\hline Conjunto & $\begin{array}{l}\text { Faixas } \\
\text { adicionais }\end{array}$ & $\begin{array}{l}\text { BRCO da faixa } \\
\text { adicional }\end{array}$ & $\begin{array}{l}\text { BRTV da faixa } \\
\text { adicional }\end{array}$ & Custos & $\begin{array}{l}\text { Relação } B / C \\
\text { do conjunto }\end{array}$ \\
\hline 1 & 11 & $\mathrm{R} \$ 1.326,56$ & $\mathrm{R} \$ 206.679,91$ & $\mathrm{R} \$ 51.811,68$ & $\mathbf{4 , 0}$ \\
\hline 2 & 13 & $\mathrm{R} \$ 78,34$ & $\mathrm{R} \$ 28.376,33$ & $\mathrm{R} \$ 30.327,93$ & $\mathbf{0 , 9}$ \\
\hline 3 & 5 & $\mathrm{R} \$ 13,19$ & $\mathrm{R} \$ 9.286,34$ & $\mathrm{R} \$ 15.490,23$ & $\mathbf{0 , 6}$ \\
\hline
\end{tabular}

\section{$\underline{4^{\circ} \text { ano da análise }}$}

Neste ano, considerou-se que as faixas $7,10,15,2,3$ e 11 estavam em operação. Foram calculados os benefícios individuais das faixas 5 e 13, as únicas que restaram no conjunto de 
necessárias entre o $1^{\circ}$ e o $7^{\circ}$ ano. O critério do nível de serviço (NS) não foi verificado, porque a implantação de uma faixa adicional estava garantida pelo critério de fluxos mínimos.

Os valores do $B R C O$ e do $B R T V$ proporcionados por cada faixa estão na Tabela 6.17. As parcelas anuais dos custos de implantação de cada faixa no $4^{\circ}$ ano da análise também estão nessa tabela na coluna "Custos".

Tabela 6.17 - Benefícios e custos do $4^{\circ}$ ano da análise

\begin{tabular}{llllll}
\hline Conjunto & $\begin{array}{l}\text { Faixas } \\
\text { adicionais }\end{array}$ & $\begin{array}{l}\text { BRRCO da faixa } \\
\text { adicional }\end{array}$ & $\begin{array}{l}\text { BRTV da faixa } \\
\text { adicional }\end{array}$ & Custos & $\begin{array}{l}\text { Relação B/C } \\
\text { do conjunto }\end{array}$ \\
\hline 1 & 5 & $\mathrm{R} \$ 96,97$ & $\mathrm{R} \$ 26.051,90$ & $\mathrm{R} \$ 16.233,76$ & $\mathbf{1 , 6}$ \\
2 & 13 & $\mathrm{R} \$ 54,84$ & $\mathrm{R} \$ 50.695,59$ & $\mathrm{R} \$ 31.783,67$ & $\mathbf{1 , 5}$ \\
\hline
\end{tabular}

Neste ano, é possível observar que as faixas 5 e 13 obtiveram valores de $B R C O$ e $B R T V$ pequenos, devido, provavelmente, ao fato da operação de mais uma faixa adicional gerar um aumento quase desprezível da velocidade média de operação, e uma pequena redução da PTSF. Assim, a faixa a ser implantado neste ano é a 5.

\section{$\underline{5^{\circ} \text { ano da análise }}$}

No $5^{\circ}$ ano, não houve necessidade de faixas adicionais, segundo o critério de fluxos mínimos. Ademais, com o fluxo de tráfego do $5^{\circ}$ ano e com as faixas $7,10,15,2,3,11$ e 13 em operação, o nível de serviço de ambos os sentidos de tráfego é $\mathrm{C}$, confirmando a falta de necessidade de faixas adicionais neste ano.

\section{$\underline{6^{\circ} \text { ano da análise }}$}

No $6^{\circ}$ ano, pelo critério de fluxos mínimos, apenas uma faixa era prevista. No entanto, tal faixa já foi implantada no $3^{\circ}$ ano. Assim, a única faixa testada foi a 13 , sendo calculada a soma dos benefícios individuais e dos custos gerados pela implantação dessa faixa, exclusivamente, para verificar se tal conjunto é viável economicamente. Os resultados estão na tabela a seguir.

Tabela 6.18 - Benefícios e custos do $6^{\circ}$ ano da análise

\begin{tabular}{llllll}
\hline Conjunto & $\begin{array}{l}\text { Faixa } \\
\text { Adicional }\end{array}$ & $\begin{array}{l}\text { BRRCO da faixa } \\
\text { adicional }\end{array}$ & $\begin{array}{l}\text { BRTV da faixa } \\
\text { adicional }\end{array}$ & Custos & $\begin{array}{l}\text { Relação B/C } \\
\text { do conjunto }\end{array}$ \\
\hline 1 & 13 & $\mathrm{R} \$ 126,19$ & $\mathrm{R} \$ 63.286,57$ & $\mathrm{R} \$ 34.908,13$ & $\mathbf{1 , 8}$ \\
\hline
\end{tabular}


Como pode ser notada, a relação B/C da faixa 13 é maior do que um, comprovando, portanto, a viabilidade da sua implantação no $6^{\circ}$ ano da análise.

Neste ponto da aplicação do método, é possível determinar a sequência ótima de implantação das faixas adicionais, considerando o $B R C O$ e $B R T V$, e os custos de implantação dos conjuntos de faixas necessárias. (Tabela 6.19).

Tabela 6.19 - Programação de implantação das faixas adicionais

\begin{tabular}{clll}
\hline $\begin{array}{c}\text { Ano da } \\
\text { análise }\end{array}$ & $\begin{array}{l}\text { Faixas a serem } \\
\text { implantadas }\end{array}$ & $\begin{array}{l}\text { Extensão } \\
\text { da Faixa }\end{array}$ & $\begin{array}{l}\text { Declividade } \\
\text { da rampa }\end{array}$ \\
\hline \multirow{2}{*}{$1^{\circ}$} & 7 & $938 \mathrm{~m}$ & $4 \%$ \\
& 10 & $1164 \mathrm{~m}$ & $3 \%$ \\
\hline \multirow{2}{*}{$2^{\circ}$} & 15 & $300 \mathrm{~m}$ & $5 \%$ \\
& 2 & $608 \mathrm{~m}$ & $3 \%$ \\
\hline $3^{\circ}$ & 3 & $2602 \mathrm{~m}$ & $3 \%$ \\
\hline $4^{\circ}$ & 5 & $1289 \mathrm{~m}$ & $2 \%$ \\
\hline $6^{\circ}$ & 13 & $334 \mathrm{~m}$ & $2 \%$ \\
\hline
\end{tabular}

Verifica-se que as duas faixas adicionais mais extensas (3 e 11) estão no sentido descendente das estacas, e ambas não estão no conjunto a ser implantado no primeiro ano da análise. Isso pode ter sido ocasionado pelo fato de o volume de tráfego ser menor nesse sentido, justificando a implantação dessas faixas somente em anos mais avançados da análise; ou pode ser um indicativo de que faixas curtas, além de mais baratas, são mais eficientes do ponto de vista operacional.

Pode ser constatado também que o benefício da redução dos custos operacionais é inversamente proporcional ao fluxo de tráfego. Esse fenômeno pode ser explicado a partir da verificação dos valores das velocidades médias nos Apêndices A e B, as quais aumentam consideravelmente nos primeiros anos da análise e depois ficam praticamente estáveis.

\subsection{BENEFÍCIOS DA REDUÇÃO DOS ACIDENTES}

O cálculo dos benefícios da redução de acidentes (BRACID) foi desenvolvido em separado, pois, conforme estabelecido no Capítulo 4, avaliaram-se dois modos diferentes de determinar a exposição aos acidentes por ano (Expossec), consequentemente, chegando-se a dois valores distintos para BRACID. As equações utilizadas em ambos os modos foram a 4.18, 4.19, $4.20 \mathrm{e}$ 4.21 . 
Foi considerado que as faixas adicionais são capazes de diminuir exclusivamente o número de colisões frontais. Para o primeiro ano da análise, o valor considerado do custo unitário de uma colisão frontal foi de $\mathrm{R} \$ 179.423,26$. Esse valor foi obtido a partir da correção do valor publicado em DNIT (2004), o qual tinha a data base Julho de 2000. Portanto, para essa correção utilizou-se o IPCA acumulado entre 01/07/2000 a 01/07/2009, que foi de 83,76\%. Para todos os anos da análise após o primeiro, corrigiu-se o custo unitário de uma colisão frontal pelo IPCA acumulado entre 01/07/2008 e 01/07/2009, que foi de 4,8\%.

No Apêndice C podem ser conferidos todos os valores encontrados para cada uma das variáveis que compõe o cálculo do BRACID, estando na Tabela C.1 os valores calculados pelo primeiro modo e na Tabela C.2 os calculados pelo segundo.

\subsubsection{Primeiro modo de cálculo do BRACID}

No primeiro modo, considerou-se que a implantação de cada faixa dos conjuntos analisados reduz o $A_{C C R A T E}$ de todo o corredor analisado em $30 \%$, e a extensão da exposição à colisões frontais $\left(L_{i}\right)$ para ambas as condições, com e sem as melhorias, é igual a extensão das rampas.

Assim, foram alterados a cada ano somente o VDM e o custo unitário de uma colisão. Para a estimativa de aumento do $V D M$ foi utilizada a mesma taxa de $5 \%$ ao ano. A Tabela 6.20 resume a estimativa de custos e benefícios para cada ano do projeto.

Através da análise da Tabela 6.20, nota-se que não há alteração no valor do benefício gerado por uma determinada faixa entre os conjuntos de faixas analisados em um ano. Os maiores benefícios são gerados pelas faixas mais extensas, por causa do modelo adotado, no qual há uma forte correlação entre a extensão das faixas e a redução de acidentes.

\subsubsection{Segundo modo de cálculo do BRACID}

No segundo modo, supôs-se que o $A C C R A T E_{i}$ de todo o corredor analisado permanece inalterado com a construção das faixas adicionais. No entanto, para os cenários sem as melhorias recomendadas, considerou-se que o $L_{i}$ é igual a extensão da rampa e, para os cenários com as melhorias, considerou-se que o $L_{i}$ é igual a diferença entre a extensão da 
rampa e a extensão da faixa adicional, portanto, diminuindo a exposição à colisões frontais para essa condição.

Os demais dados de entrada foram iguais ao do modo anterior. Os valores de BRACID encontrados, assim como os novos valores das relações $\sum$ B / $\sum$ C obtidas, estão apresentados na Tabela 6.21. As características dos resultados do $2^{\circ}$ modo de cálculo do BRACID são semelhantes às observadas no modo anterior, com suaves variações dos valores desse benefício e no ranking das relações $\sum \mathrm{B} / \sum \mathrm{C}$ do $2^{\circ}$ e $3^{\circ}$ ano.

Dessa forma, recomenda-se a adoção do $2^{\circ}$ modo para o cálculo do BRACID, pois além dos benefícios dos dois modos serem praticamente equivalentes, a consideração feita no $1^{\circ}$ modo, que todas as faixas adicionais necessárias têm a mesma capacidade de reduzir as colisões frontais, pode não representar a realidade, já que assim, desconsideram-se a declividade do aclive, as distâncias de visibilidade, as condições da sinalização, etc.

Ressalta-se que, apesar do aumento do valor do somatório dos benefícios e a não alteração do somatório dos custos, a computação da redução de colisões frontais como benefício proporcionado pelas faixas adicionais não alterou a programação de implantação verificada apenas com $B R C O$ e $B R T V$. Os conjuntos eleitos anteriormente são os mesmos que devem ser implantados considerando também BRACID. 
Tabela 6.20 - Benefícios da redução de acidentes ( $1^{\circ}$ Modo)

\begin{tabular}{|c|c|c|c|c|c|c|c|}
\hline Ano & Conjunto & $\begin{array}{l}\text { Faixa } \\
\text { Adicional }\end{array}$ & $\begin{array}{l}\text { BRCO da faixa } \\
\text { adicional }\end{array}$ & $\begin{array}{l}\text { BRTV da faixa } \\
\text { adicional }\end{array}$ & $\begin{array}{l}\text { BRACID da faixa } \\
\text { adicional }\end{array}$ & Custos & $\begin{array}{l}\sum_{(C / \text { Modo 1) }} B / \sum C \\
\text { (C) }\end{array}$ \\
\hline \multirow{22}{*}{$1^{0}$} & \multirow{2}{*}{1} & 7 & $\mathrm{R} \$ 3.586,45$ & $\mathrm{R} \$ 363.165,22$ & $\mathrm{R} \$ 27.036,39$ & $\mathrm{R} \$ 37.263,17$ & 11,3 \\
\hline & & 10 & $\mathrm{R} \$ 3.586,45$ & $\mathrm{R} \$ 522.050,00$ & $\mathrm{R} \$ 34.361,72$ & $\mathrm{R} \$ 46.912,92$ & \\
\hline & \multirow{2}{*}{2} & 10 & $\mathrm{R} \$ 1.778,96$ & $\mathrm{R} \$ 282.851,86$ & $\mathrm{R} \$ 34.361,72$ & $\mathrm{R} \$ 46.912,92$ & 8,7 \\
\hline & & 13 & $R \$ 1.778,96$ & $\mathrm{R} \$ 305.182,27$ & $\mathrm{R} \$ 25.178,31$ & $\mathrm{R} \$ 27.613,42$ & \\
\hline & \multirow{2}{*}{3} & 7 & $\mathrm{R} \$ 1.369,80$ & $\mathrm{R} \$ 242.173,50$ & $\mathrm{R} \$ 27.036,39$ & $\mathrm{R} \$ 37.263,17$ & 8,1 \\
\hline & & 13 & $R \$ 1.369,80$ & $\mathrm{R} \$ 228.615,53$ & $\mathrm{R} \$ 25.178,31$ & $\mathrm{R} \$ 27.613,42$ & \\
\hline & \multirow{2}{*}{4} & 7 & $\mathrm{R} \$ 910,85$ & $\mathrm{R} \$ 212.205,92$ & $\mathrm{R} \$ 27.036,39$ & $\mathrm{R} \$ 37.263,17$ & 8,0 \\
\hline & & 15 & $\mathrm{R} \$ 910,85$ & $\mathrm{R} \$ 146.598,54$ & $\mathrm{R} \$ 7.845,34$ & $\mathrm{R} \$ 12.173,82$ & \\
\hline & \multirow{2}{*}{5} & 7 & $\mathrm{R} \$ 1.124,46$ & $\mathrm{R} \$ 237.817,81$ & $\mathrm{R} \$ 27.036,39$ & $\mathrm{R} \$ 37.263,17$ & 7,3 \\
\hline & & 5 & $\mathrm{R} \$ 1.124,46$ & $\mathrm{R} \$ 89.181,68$ & $\mathrm{R} \$ 22.092,97$ & $R \$ 14.103,77$ & \\
\hline & \multirow[b]{2}{*}{6} & 10 & $\mathrm{R} \$ 1.426,97$ & $\mathrm{R} \$ 264.533,14$ & $\mathrm{R} \$ 34.361,72$ & $\mathrm{R} \$ 37.263,17$ & 6,5 \\
\hline & & 15 & $\mathrm{R} \$ 1.426,97$ & $\mathrm{R} \$ 75.070,22$ & $\mathrm{R} \$ 7.845,34$ & $\mathrm{R} \$ 23.753,52$ & \\
\hline & \multirow{2}{*}{7} & 7 & $\mathrm{R} \$ 643,75$ & $\mathrm{R} \$ 188.028,84$ & $\mathrm{R} \$ 27.036,39$ & $\mathrm{R} \$ 46.912,92$ & 6,4 \\
\hline & & 2 & $\mathrm{R} \$ 643,75$ & $\mathrm{R} \$ 152.982,95$ & $\mathrm{R} \$ 23.526,75$ & $\mathrm{R} \$ 12.173,82$ & \\
\hline & \multirow{2}{*}{8} & 10 & $\mathrm{R} \$ 226,76$ & $\mathrm{R} \$ 110.538,37$ & $\mathrm{R} \$ 34.361,72$ & $\mathrm{R} \$ 46.912,92$ & 3,8 \\
\hline & & 3 & $R \$ 2.612,96$ & $\mathrm{R} \$ 354.624,50$ & $\mathrm{R} \$ 62.374,04$ & $\mathrm{R} \$ 101.028,72$ & \\
\hline & \multirow{2}{*}{9} & 10 & $\mathrm{R} \$ 380,24$ & $\mathrm{R} \$ 89.062,19$ & $\mathrm{R} \$ 34.361,72$ & $\mathrm{R} \$ 46.912,92$ & 3,2 \\
\hline & & 5 & $\mathrm{R} \$ 380,24$ & $\mathrm{R} \$ 49.478,99$ & $\mathrm{R} \$ 22.092,97$ & $\mathrm{R} \$ 14.103,77$ & \\
\hline & \multirow{2}{*}{10} & 10 & $\mathrm{R} \$ 544,43$ & $\mathrm{R} \$ 120.108,80$ & $\mathrm{R} \$ 34.361,72$ & $\mathrm{R} \$ 46.912,92$ & 2,9 \\
\hline & & 2 & $\mathrm{R} \$ 544,43$ & $\mathrm{R} \$ 28.348,66$ & $\mathrm{R} \$ 23.526,75$ & $R \$ 23.753,52$ & \\
\hline & \multirow{2}{*}{11} & 7 & $\mathrm{R} \$ 737,99$ & $\mathrm{R} \$ 221.135,22$ & $\mathrm{R} \$ 27.036,39$ & $\mathrm{R} \$ 37.263,17$ & 2,4 \\
\hline & & 3 & $\mathrm{R} \$ 116,94$ & $\mathrm{R} \$ 19.041,30$ & $\mathrm{R} \$ 62.374,04$ & $\mathrm{R} \$ 101.028,72$ & \\
\hline \multirow{30}{*}{$2^{\circ}$} & \multirow{3}{*}{1} & 15 & $\mathrm{R} \$ 134,29$ & $\mathrm{R} \$ 24.292,76$ & $\mathrm{R} \$ 8.633,01$ & $\mathrm{R} \$ 12.758,16$ & 3,9 \\
\hline & & 2 & $\mathrm{R} \$ 134,29$ & $R \$ 5.872,62$ & $\mathrm{R} \$ 25.888,83$ & $\mathrm{R} \$ 24.893,69$ & \\
\hline & & 3 & $\mathrm{R} \$ 4.196,41$ & $\mathrm{R} \$ 416.052,07$ & $\mathrm{R} \$ 68.636,39$ & $R \$ 105.878,10$ & \\
\hline & \multirow{3}{*}{2} & 13 & $\mathrm{R} \$ 231,92$ & $\mathrm{R} \$ 42.686,95$ & $\mathrm{R} \$ 27.706,21$ & $\mathrm{R} \$ 28.938,87$ & 2,8 \\
\hline & & 2 & $\mathrm{R} \$ 231,92$ & $\mathrm{R} \$ 9.409,02$ & $\mathrm{R} \$ 25.888,83$ & $R \$ 24.893,69$ & \\
\hline & & 3 & $\mathrm{R} \$ 1.173,41$ & $\mathrm{R} \$ 267.144,89$ & $\mathrm{R} \$ 68.636,39$ & $\mathrm{R} \$ 105.878,10$ & \\
\hline & \multirow{3}{*}{3} & 2 & $\mathrm{R} \$ 90,61$ & $\mathrm{R} \$ 5.734,89$ & $\mathrm{R} \$ 25.888,83$ & $\mathrm{R} \$ 24.893,69$ & 2,6 \\
\hline & & 3 & $\mathrm{R} \$ 1.079,00$ & $\mathrm{R} \$ 232.424,34$ & $\mathrm{R} \$ 68.636,39$ & $\mathrm{R} \$ 105.878,10$ & \\
\hline & & 5 & $\mathrm{R} \$ 90,61$ & $\mathrm{R} \$ 14.476,11$ & $\mathrm{R} \$ 24.311,10$ & $\mathrm{R} \$ 14.780,75$ & \\
\hline & & 13 & $\mathrm{R} \$ 84,15$ & $\mathrm{R} \$ 19.840,79$ & $\mathrm{R} \$ 27.706,21$ & $\mathrm{R} \$ 28.938,87$ & 2,6 \\
\hline & 4 & 3 & $R \$ 1.140,31$ & $\mathrm{R} \$ 241.724,89$ & $\mathrm{R} \$ 68.636,39$ & $\mathrm{R} \$ 105.878,10$ & \\
\hline & & 5 & $\mathrm{R} \$ 84,15$ & $R \$ 9.235,44$ & $\mathrm{R} \$ 24.311,10$ & $\mathrm{R} \$ 14.780,75$ & \\
\hline & & 15 & $\mathrm{R} \$ 22,08$ & $\mathrm{R} \$ 9.316,91$ & $\mathrm{R} \$ 8.633,01$ & $\mathrm{R} \$ 12.758,16$ & 2,5 \\
\hline & 5 & 3 & $R \$ 1.071,30$ & $\mathrm{R} \$ 219.743,34$ & $\mathrm{R} \$ 68.636,39$ & $\mathrm{R} \$ 105.878,10$ & \\
\hline & & 5 & $\mathrm{R} \$ 22,08$ & $R \$ 4.395,19$ & $\mathrm{R} \$ 24.311,10$ & $\mathrm{R} \$ 14.780,75$ & \\
\hline & & 15 & $\mathrm{R} \$ 91,08$ & $\mathrm{R} \$ 16.196,72$ & $\mathrm{R} \$ 8.633,01$ & $\mathrm{R} \$ 12.758,16$ & 2,5 \\
\hline & 6 & 13 & $\mathrm{R} \$ 91,08$ & $\mathrm{R} \$ 10.937,77$ & $\mathrm{R} \$ 27.706,21$ & $\mathrm{R} \$ 28.938,87$ & \\
\hline & & 3 & $\mathrm{R} \$ 1.136,61$ & $\mathrm{R} \$ 242.780,64$ & $\mathrm{R} \$ 68.636,39$ & $\mathrm{R} \$ 105.878,10$ & \\
\hline & & 13 & $\mathrm{R} \$ 286,14$ & $\mathrm{R} \$ 44.544,12$ & $\mathrm{R} \$ 27.706,21$ & $\mathrm{R} \$ 28.938,87$ & 2,4 \\
\hline & 7 & 2 & $\mathrm{R} \$ 286,14$ & $\mathrm{R} \$ 19.257,90$ & $\mathrm{R} \$ 25.888,83$ & $R \$ 24.893,69$ & \\
\hline & & 5 & $\mathrm{R} \$ 286,14$ & $\mathrm{R} \$ 23.649,57$ & $\mathrm{R} \$ 24.311,10$ & $\mathrm{R} \$ 14.780,75$ & \\
\hline & & 15 & $\mathrm{R} \$ 138,15$ & $\mathrm{R} \$ 33.778,31$ & $\mathrm{R} \$ 8.633,01$ & $\mathrm{R} \$ 12.758,16$ & 2,3 \\
\hline & 8 & 2 & $\mathrm{R} \$ 138,15$ & $\mathrm{R} \$ 15.080,66$ & $\mathrm{R} \$ 25.888,83$ & $\mathrm{R} \$ 24.893,69$ & \\
\hline & & 5 & $\mathrm{R} \$ 138,15$ & $\mathrm{R} \$ 14.250,53$ & $\mathrm{R} \$ 24.311,10$ & $\mathrm{R} \$ 14.780,75$ & \\
\hline & & 15 & $\mathrm{R} \$ 251,94$ & $\mathrm{R} \$ 41.465,32$ & $\mathrm{R} \$ 8.633,01$ & $\mathrm{R} \$ 12.758,16$ & 2,1 \\
\hline & 9 & 13 & $\mathrm{R} \$ 251,94$ & $\mathrm{R} \$ 26.093,70$ & $\mathrm{R} \$ 27.706,21$ & $\mathrm{R} \$ 28.938,87$ & \\
\hline & & 2 & $\mathrm{R} \$ 251,94$ & $\mathrm{R} \$ 12.062,34$ & $\mathrm{R} \$ 25.888,83$ & $R \$ 24.893,69$ & \\
\hline & & 15 & $\mathrm{R} \$ 106,62$ & $\mathrm{R} \$ 19.455,24$ & $\mathrm{R} \$ 8.633,01$ & $\mathrm{R} \$ 12.758,16$ & 1,8 \\
\hline & 10 & 13 & $\mathrm{R} \$ 106,62$ & $\mathrm{R} \$ 13.447,25$ & $\mathrm{R} \$ 27.706,21$ & $\mathrm{R} \$ 28.938,87$ & \\
\hline & & 5 & $\mathrm{R} \$ 106,62$ & $R \$ 5.519,46$ & $\mathrm{R} \$ 24.311,10$ & $\mathrm{R} \$ 14.780,75$ & \\
\hline & 1 & 11 & $\mathrm{R} \$ 1.326,56$ & $\mathrm{R} \$ 206.679,91$ & $\mathrm{R} \$ 52.809,87$ & $\mathrm{R} \$ 51.811,68$ & 5,0 \\
\hline $3^{\circ}$ & 2 & 5 & $\mathrm{R} \$ 13,19$ & $\mathrm{R} \$ 9.286,34$ & $\mathrm{R} \$ 30.488,93$ & $\mathrm{R} \$ 15.490,23$ & 2,3 \\
\hline & 3 & 13 & $\mathrm{R} \$ 78,34$ & $\mathrm{R} \$ 28.376,33$ & $\mathrm{R} \$ 26.752,84$ & $\mathrm{R} \$ 30.327,93$ & 1,9 \\
\hline 10 & 1 & 5 & $\mathrm{R} \$ 96,67$ & $\mathrm{R} \$ 26.051,90$ & $\mathrm{R} \$ 29.440,16$ & $\mathrm{R} \$ 16.233,76$ & 3,4 \\
\hline $4=$ & 2 & 13 & $\mathrm{R} \$ 54,84$ & $R \$ 50.695,59$ & $\mathrm{R} \$ 33.551,55$ & $\mathrm{R} \$ 31.783,67$ & 2,6 \\
\hline $6^{\circ}$ & 1 & 13 & $\mathrm{R} \$ 126,19$ & $\mathrm{R} \$ 63.286,57$ & $\mathrm{R} \$ 40.624,96$ & $\mathrm{R} \$ 34.908,13$ & 2,9 \\
\hline
\end{tabular}


Tabela 6.21 - Benefícios da redução de acidentes ( $2^{\circ}$ Modo)

\begin{tabular}{|c|c|c|c|c|c|c|c|}
\hline$\overline{A n o}$ & Conjunto & $\begin{array}{l}\text { Faixa } \\
\text { Adicional }\end{array}$ & $\begin{array}{l}\text { BRCO da faixa } \\
\text { adicional }\end{array}$ & $\begin{array}{l}\text { BRTV da faixa } \\
\text { adicional }\end{array}$ & $\begin{array}{l}\text { BRACID da faixa } \\
\text { adicional }\end{array}$ & Custos & $\begin{array}{l}\sum B / \sum C \\
(c / \text { Modo 2) }\end{array}$ \\
\hline \multirow{22}{*}{$1^{0}$} & \multirow{2}{*}{1} & 7 & $\mathrm{R} \$ 3.586,45$ & $\mathrm{R} \$ 363.165,22$ & $\mathrm{R} \$ 30.450,67$ & $\mathrm{R} \$ 37.263,17$ & 11,4 \\
\hline & & 10 & $\mathrm{R} \$ 3.586,45$ & $\mathrm{R} \$ 522.050,00$ & $\mathrm{R} \$ 37.787,40$ & $\mathrm{R} \$ 46.912,92$ & \\
\hline & \multirow{2}{*}{2} & 10 & $\mathrm{R} \$ 1.778,96$ & $\mathrm{R} \$ 282.851,86$ & $\mathrm{R} \$ 37.787,40$ & $\mathrm{R} \$ 46.912,92$ & 8,7 \\
\hline & & 13 & $\mathrm{R} \$ 1.778,96$ & $\mathrm{R} \$ 305.182,27$ & $\mathrm{R} \$ 22.497,14$ & $\mathrm{R} \$ 27.613,42$ & \\
\hline & \multirow{2}{*}{3} & 7 & $\mathrm{R} \$ 1.369,80$ & $\mathrm{R} \$ 242.173,50$ & $\mathrm{R} \$ 30.450,67$ & $\mathrm{R} \$ 37.263,17$ & 8,1 \\
\hline & & 13 & $R \$ 1.369,80$ & $R \$ 228.615,53$ & $\mathrm{R} \$ 22.497,14$ & $\mathrm{R} \$ 27.613,42$ & \\
\hline & \multirow{2}{*}{4} & 7 & $\mathrm{R} \$ 910,85$ & $\mathrm{R} \$ 212.205,92$ & $\mathrm{R} \$ 30.450,67$ & $\mathrm{R} \$ 37.263,17$ & 8,1 \\
\hline & & 15 & $\mathrm{R} \$ 910,85$ & $\mathrm{R} \$ 146.598,54$ & $\mathrm{R} \$ 9.739,02$ & $\mathrm{R} \$ 12.173,82$ & \\
\hline & \multirow{2}{*}{5} & 7 & $\mathrm{R} \$ 1.124,46$ & $\mathrm{R} \$ 237.817,81$ & $\mathrm{R} \$ 30.450,67$ & $\mathrm{R} \$ 37.263,17$ & 7,2 \\
\hline & & 5 & $\mathrm{R} \$ 1.124,46$ & $\mathrm{R} \$ 89.181,68$ & $\mathrm{R} \$ 10.842,78$ & $\mathrm{R} \$ 14.103,77$ & \\
\hline & \multirow{2}{*}{6} & 10 & $\mathrm{R} \$ 1.426,97$ & $\mathrm{R} \$ 264.533,14$ & $\mathrm{R} \$ 37.787,40$ & $\mathrm{R} \$ 37.263,17$ & 6,6 \\
\hline & & 15 & $\mathrm{R} \$ 1.426,97$ & $\mathrm{R} \$ 75.070,22$ & $\mathrm{R} \$ 9.739,02$ & $\mathrm{R} \$ 23.753,52$ & \\
\hline & \multirow{2}{*}{7} & 7 & $\mathrm{R} \$ 643,75$ & $\mathrm{R} \$ 188.028,84$ & $\mathrm{R} \$ 30.450,67$ & $\mathrm{R} \$ 46.912,92$ & 6,4 \\
\hline & & 2 & $\mathrm{R} \$ 643,75$ & $\mathrm{R} \$ 152.982,95$ & $\mathrm{R} \$ 19.478,04$ & $\mathrm{R} \$ 12.173,82$ & \\
\hline & \multirow{2}{*}{8} & 10 & $\mathrm{R} \$ 226,76$ & $\mathrm{R} \$ 110.538,37$ & $\mathrm{R} \$ 37.787,40$ & $\mathrm{R} \$ 46.912,92$ & 4,0 \\
\hline & & 3 & $\mathrm{R} \$ 2.612,96$ & $\mathrm{R} \$ 354.624,50$ & $\mathrm{R} \$ 84.404,85$ & $\mathrm{R} \$ 101.028,72$ & \\
\hline & \multirow{2}{*}{9} & 10 & $\mathrm{R} \$ 380,24$ & $\mathrm{R} \$ 89.062,19$ & $\mathrm{R} \$ 37.787,40$ & $\mathrm{R} \$ 46.912,92$ & 3,1 \\
\hline & & 5 & $\mathrm{R} \$ 380,24$ & $\mathrm{R} \$ 49.478,99$ & $\mathrm{R} \$ 10.842,78$ & $\mathrm{R} \$ 14.103,77$ & \\
\hline & \multirow{2}{*}{10} & 10 & $\mathrm{R} \$ 544,43$ & $\mathrm{R} \$ 120.108,80$ & $\mathrm{R} \$ 37.787,40$ & $\mathrm{R} \$ 46.912,92$ & 2,9 \\
\hline & & 2 & $\mathrm{R} \$ 544,43$ & $\mathrm{R} \$ 28.348,66$ & $\mathrm{R} \$ 19.478,04$ & $\mathrm{R} \$ 23.753,52$ & \\
\hline & \multirow{2}{*}{11} & 7 & $\mathrm{R} \$ 737,99$ & $\mathrm{R} \$ 221.135,22$ & $\mathrm{R} \$ 30.450,67$ & $\mathrm{R} \$ 37.263,17$ & 2,6 \\
\hline & & 3 & $\mathrm{R} \$ 116,94$ & $\mathrm{R} \$ 19.041,30$ & $\mathrm{R} \$ 84.404,85$ & $\mathrm{R} \$ 101.028,72$ & \\
\hline \multirow{30}{*}{$2^{0}$} & \multirow{3}{*}{1} & 15 & $\mathrm{R} \$ 134,29$ & $\mathrm{R} \$ 24.292,76$ & $\mathrm{R} \$ 10.716,82$ & $\mathrm{R} \$ 12.758,16$ & 4,0 \\
\hline & & 2 & $\mathrm{R} \$ 134,29$ & $\mathrm{R} \$ 5.872,62$ & $\mathrm{R} \$ 21.433,64$ & $\mathrm{R} \$ 24.893,69$ & \\
\hline & & 3 & $\mathrm{R} \$ 4.196,41$ & $\mathrm{R} \$ 416.052,07$ & $\mathrm{R} \$ 92.879,09$ & $\mathrm{R} \$ 105.878,10$ & \\
\hline & \multirow{3}{*}{2} & 13 & $\mathrm{R} \$ 231,92$ & $\mathrm{R} \$ 42.686,95$ & $\mathrm{R} \$ 24.755,85$ & $\mathrm{R} \$ 28.938,87$ & 2,9 \\
\hline & & 2 & $\mathrm{R} \$ 231,92$ & $\mathrm{R} \$ 9.409,02$ & $\mathrm{R} \$ 21.433,64$ & $\mathrm{R} \$ 24.893,69$ & \\
\hline & & 3 & $\mathrm{R} \$ 1.173,41$ & $\mathrm{R} \$ 267.144,89$ & $\mathrm{R} \$ 92.879,09$ & $\mathrm{R} \$ 105.878,10$ & \\
\hline & \multirow{3}{*}{3} & 15 & $\mathrm{R} \$ 91,08$ & $\mathrm{R} \$ 16.196,72$ & $\mathrm{R} \$ 10.716,82$ & $\mathrm{R} \$ 12.758,16$ & 2,7 \\
\hline & & 13 & $\mathrm{R} \$ 91,08$ & $\mathrm{R} \$ 10.937,77$ & $\mathrm{R} \$ 24.755,85$ & $\mathrm{R} \$ 28.938,87$ & \\
\hline & & 3 & $\mathrm{R} \$ 1.136,61$ & $\mathrm{R} \$ 242.780,64$ & $\mathrm{R} \$ 92.879,09$ & $\mathrm{R} \$ 105.878,10$ & \\
\hline & & 13 & $\mathrm{R} \$ 84,15$ & $\mathrm{R} \$ 19.840,79$ & $\mathrm{R} \$ 24.755,85$ & $\mathrm{R} \$ 28.938,87$ & 2,7 \\
\hline & 4 & 3 & $\mathrm{R} \$ 1.140,31$ & $\mathrm{R} \$ 241.724,89$ & $\mathrm{R} \$ 92.879,09$ & $\mathrm{R} \$ 105.878,10$ & \\
\hline & & 5 & $\mathrm{R} \$ 84,15$ & $\mathrm{R} \$ 9.235,44$ & $\mathrm{R} \$ 11.931,39$ & $\mathrm{R} \$ 14.780,75$ & \\
\hline & & 15 & $\mathrm{R} \$ 22,08$ & $\mathrm{R} \$ 9.316,91$ & $\mathrm{R} \$ 10.716,82$ & $\mathrm{R} \$ 12.758,16$ & 2,6 \\
\hline & 5 & 3 & $\mathrm{R} \$ 1.071,30$ & $\mathrm{R} \$ 219.743,34$ & $\mathrm{R} \$ 92.879,09$ & $\mathrm{R} \$ 105.878,10$ & \\
\hline & & 5 & $R \$ 22,08$ & $\mathrm{R} \$ 4.395,19$ & $\mathrm{R} \$ 11.931,39$ & $\mathrm{R} \$ 14.780,75$ & \\
\hline & & 2 & $\mathrm{R} \$ 90,61$ & $\mathrm{R} \$ 5.734,89$ & $\mathrm{R} \$ 21.433,64$ & $\mathrm{R} \$ 24.893,69$ & 2,6 \\
\hline & 6 & 3 & $\mathrm{R} \$ 1.079,00$ & $\mathrm{R} \$ 232.424,34$ & $\mathrm{R} \$ 92.879,09$ & $\mathrm{R} \$ 105.878,10$ & \\
\hline & & 5 & $R \$ 90,61$ & $\mathrm{R} \$ 14.476,11$ & $\mathrm{R} \$ 11.931,39$ & $\mathrm{R} \$ 14.780,75$ & \\
\hline & & 13 & $\mathrm{R} \$ 286,14$ & $\mathrm{R} \$ 44.544,12$ & $\mathrm{R} \$ 24.755,85$ & $\mathrm{R} \$ 28.938,87$ & 2,1 \\
\hline & 7 & 2 & $\mathrm{R} \$ 286,14$ & $\mathrm{R} \$ 19.257,90$ & $\mathrm{R} \$ 21.433,64$ & $\mathrm{R} \$ 24.893,69$ & \\
\hline & & 5 & $\mathrm{R} \$ 286,14$ & $\mathrm{R} \$ 23.649,57$ & $\mathrm{R} \$ 11.931,39$ & $\mathrm{R} \$ 14.780,75$ & \\
\hline & & 15 & $\mathrm{R} \$ 138,15$ & $\mathrm{R} \$ 33.778,31$ & $\mathrm{R} \$ 10.716,82$ & $\mathrm{R} \$ 12.758,16$ & 2,1 \\
\hline & 8 & 2 & $\mathrm{R} \$ 138,15$ & $\mathrm{R} \$ 15.080,66$ & $\mathrm{R} \$ 21.433,64$ & $\mathrm{R} \$ 24.893,69$ & \\
\hline & & 5 & $\mathrm{R} \$ 138,15$ & $\mathrm{R} \$ 14.250,53$ & $\mathrm{R} \$ 11.931,39$ & $\mathrm{R} \$ 14.780,75$ & \\
\hline & & 15 & $\mathrm{R} \$ 251,94$ & $\mathrm{R} \$ 41.465,32$ & $\mathrm{R} \$ 10.716,82$ & $\mathrm{R} \$ 12.758,16$ & 2,1 \\
\hline & 9 & 13 & $\mathrm{R} \$ 251,94$ & $\mathrm{R} \$ 26.093,70$ & $\mathrm{R} \$ 24.755,85$ & $\mathrm{R} \$ 28.938,87$ & \\
\hline & & 2 & $\mathrm{R} \$ 251,94$ & $\mathrm{R} \$ 12.062,34$ & $\mathrm{R} \$ 21.433,64$ & $\mathrm{R} \$ 24.893,69$ & \\
\hline & & 15 & $\mathrm{R} \$ 106,62$ & $\mathrm{R} \$ 19.455,24$ & $\mathrm{R} \$ 10.716,82$ & $\mathrm{R} \$ 12.758,16$ & 1,5 \\
\hline & 10 & 13 & $\mathrm{R} \$ 106,62$ & $\mathrm{R} \$ 13.447,25$ & $\mathrm{R} \$ 24.755,85$ & $\mathrm{R} \$ 28.938,87$ & \\
\hline & & 5 & $R \$ 106,62$ & $\mathrm{R} \$ 5.519,46$ & $\mathrm{R} \$ 11.931,39$ & $\mathrm{R} \$ 14.780,75$ & \\
\hline & 1 & 11 & $\mathrm{R} \$ 1.326,56$ & $\mathrm{R} \$ 206.679,91$ & $\mathrm{R} \$ 50.671,38$ & $\mathrm{R} \$ 51.811,68$ & 5,0 \\
\hline $3^{\circ}$ & 2 & 13 & $\mathrm{R} \$ 78,34$ & $\mathrm{R} \$ 28.376,33$ & $\mathrm{R} \$ 27.242,25$ & $\mathrm{R} \$ 30.327,93$ & 1,8 \\
\hline & 3 & 5 & $\mathrm{R} \$ 13,19$ & $\mathrm{R} \$ 9.286,34$ & $\mathrm{R} \$ 13.129,74$ & $\mathrm{R} \$ 15.490,23$ & 1,4 \\
\hline & 1 & 5 & $\mathrm{R} \$ 96,67$ & $\mathrm{R} \$ 26.051,90$ & $\mathrm{R} \$ 14.448,63$ & $R \$ 16.233,76$ & 2,5 \\
\hline $4^{\circ}$ & 2 & 13 & $\mathrm{R} \$ 54,84$ & $\mathrm{R} \$ 50.695,59$ & $\mathrm{R} \$ 29.978,74$ & $\mathrm{R} \$ 31.783,67$ & 2,5 \\
\hline $6^{0}$ & 1 & 13 & $\mathrm{R} \$ 126,19$ & $\mathrm{R} \$ 63.286 .57$ & $\mathrm{R} \$ 36.298,92$ & $\mathrm{R} \$ 34.908,13$ & 2,8 \\
\hline
\end{tabular}


Por fim, foram calculadas as relações benefício/custo incrementais $(R B C I)$ dos conjuntos de faixas adicionais testados, para averiguar, a cada ano $i$ do horizonte de projeto, se a sequência de construção das faixas recomendada pelo método, fornece também as melhores relações incrementais. Através da análise da Tabela 6.22, constata-se a maior viabilidade financeira dos conjuntos eleitos pela metodologia proposta, em relação aos conjuntos com menor valor de custo inicial. Ressalta-se que, nos valores das relações B/C apresentadas na tabela a seguir, estão considerados os benefícios da redução dos acidentes (BRACID).

Tabela 6.22 - Benefício/custo incremental dos conjuntos de faixas adicionais

\begin{tabular}{llll}
\hline Ano & Faixas adicionais & $\sum B / \sum C$ do conjunto & $R B C l$ \\
\hline 1 o & 7 e 10 & 11,4 & 16,11 \\
2 o & 15,2 e 3 & 4,0 & 5,14 \\
$3^{\circ}$ & 11 & 5,0 & 6,5 \\
4 & 5 & 2,5 & 2,5 \\
6o & 13 & 2,8 & $*$ \\
\hline
\end{tabular}

\subsection{PROGRAMAÇÃO DAS IMPLANTAÇÕES E EFICÁCIA DO MÉTODO}

A partir da programação de implantação de faixas adicionais (Tabela 6.22), determinada através do ranking dos valores das relações B/C de cada conjunto examinado em cada ano do horizonte de projeto, desenvolveu-se a análise de viabilidade financeira apresentada a seguir. Essa análise teve como objetivo principal verificar se essa sequência de implantação é mais interessante, do ponto de vista financeiro, do que a implantação das faixas de acordo com os critérios estabelecidos por DNER (1999).

Três alternativas de investimento foram então delineadas. A alternativa 0 foi não fazer nenhuma obra de melhoria ao longo de todo horizonte de projeto; a alternativa 1 foi construir as faixas adicionais necessárias na sequência de implantação recomendada pelo método defendido; e a alternativa 2 foi construir as faixas adicionais necessárias de acordo com os critérios de DNER (1999). Calculou-se, portanto, a cada ano do horizonte de projeto, as parcelas dos custos anuais da alternativa 1 em relação à alternativa 0 e da alternativa 2 em relação à alternativa 0 , somando todas as parcelas de cada comparativo ao final da análise.

Fez-se então necessário conhecer a sequência de implantação estabelecida pelos critérios do DNER. Através da listagem de critérios da Seção 2.5.5, observou-se que: 
$1^{\circ}$ ) Como foi considerado que no primeiro ano da análise, há em todas as rampas do trecho, o fluxo mínimo direcional que justifica a implantação das faixas nos casos mais críticos (345 veíc/h), o $1^{\circ}$ critério do DNER é alcançado já a partir do primeiro ano do horizonte de projeto;

$2^{\circ}$ ) Devido à taxa de fluxo de caminhões ter sido considerada constante durante todos os anos da análise, sendo $28 \%$ para o sentido crescente e $22 \%$ para o sentido decrescente das estacas, a partir do primeiro ano do horizonte de projeto o $2^{\circ}$ critério do DNER também é atingido;

$3^{\circ}$ ) Quanto às condições do $3^{\circ}$ critério do DNER, verificou-se que:

- As rampas que provocam redução de $15 \mathrm{~km} / \mathrm{h}$ na velocidade de entrada dos caminhões típicos carregados, são as mesmas 8 rampas que provocam a redução de $20 \mathrm{~km} / \mathrm{h}$, já notadas pelo método proposto nesta pesquisa. Portanto, pela condição 3.1 não houve alteração no conjunto de faixas necessárias;

- No conjunto de rampas que não geram redução de $15 \mathrm{~km} / \mathrm{h}$ da velocidade, não há nenhuma que, ao longo de todo o horizonte de projeto, apresente nível de serviço E ou F. No mínimo essas rampas apresentam nível D, estando a maior parte com nível C (Tabela 6.23). Portanto, pela condição 3.2 não houve alteração no conjunto de faixas necessárias;

- Ao longo de todo o horizonte de projeto, no conjunto de rampas que não geram redução de $15 \mathrm{~km} / \mathrm{h}$ da velocidade, não há redução de dois ou mais níveis de serviço quando se passa do segmento plano da aproximação para tais rampas. Portanto, pela condição 3.3 também não houve alteração no conjunto de faixas necessárias.

A Tabela 6.23 apresenta os valores das variáveis PTSF (percent time spent following) e ATS (average travel speed), as quais são utilizadas para determinar os níveis de serviço citados acima. Ressalta-se que, esses valores foram gerados a partir de simulações de tráfego cujas variáveis de tráfego consideradas foram idênticas às adotadas nas simulações desenvolvidas para determinar a programação de implantação das faixas adicionais desta pesquisa, para um horizonte de projeto de 15 anos. 
Tabela 6.23 - Valores utilizados para mensurar os Níveis de Serviço ao longo do horizonte de projeto

\begin{tabular}{|c|c|c|c|c|c|c|c|c|c|c|c|c|c|c|c|c|c|}
\hline \multirow{2}{*}{\multicolumn{2}{|c|}{ Rampas }} & \multicolumn{8}{|c|}{ PTSF (\%) } & \multicolumn{8}{|c|}{$\operatorname{ATS}(\mathrm{km} / \mathrm{h})$} \\
\hline & & 8 & 9 & 16 & 14 & 12 & 6 & 4 & 1 & 8 & 9 & 16 & 14 & 12 & 6 & 4 & 1 \\
\hline \multirow{15}{*}{$\begin{array}{l}\frac{\pi}{0} \\
0 \\
0 \\
0 \\
0 \\
0 \\
0 \\
0 \\
0 \\
0 \\
0 \\
0 \\
0 \\
0 \\
0 \\
\frac{1}{4}\end{array}$} & $1^{0}$ & 46 & 47 & 62 & 45 & 46 & 48 & 47 & 63 & 78 & 70 & 65 & 63 & 75 & 61 & 76 & 65 \\
\hline & $2^{0}$ & 48 & 52 & 64 & 44 & 51 & 46 & 50 & 63 & 79 & 71 & 69 & 66 & 79 & 65 & 79 & 67 \\
\hline & $3^{\circ}$ & 48 & 58 & 63 & 53 & 59 & 55 & 57 & 65 & 76 & 75 & 67 & 70 & 77 & 69 & 78 & 68 \\
\hline & $4^{\circ}$ & 49 & 61 & 67 & 51 & 62 & 53 & 61 & 66 & 75 & 74 & 70 & 72 & 78 & 71 & 70 & 71 \\
\hline & $5^{\circ}$ & 48 & 62 & 65 & 47 & 61 & 50 & 60 & 64 & 77 & 76 & 69 & 69 & 79 & 68 & 76 & 70 \\
\hline & $6^{\circ}$ & 51 & 61 & 69 & 50 & 59 & 52 & 58 & 67 & 76 & 77 & 67 & 65 & 76 & 66 & 74 & 69 \\
\hline & $7^{0}$ & 50 & 60 & 61 & 51 & 62 & 54 & 63 & 60 & 75 & 74 & 66 & 72 & 72 & 70 & 75 & 70 \\
\hline & 8응 & 49 & 69 & 72 & 51 & 63 & 53 & 61 & 71 & 77 & 78 & 68 & 70 & 75 & 69 & 77 & 71 \\
\hline & $9^{\circ}$ & 50 & 62 & 73 & 49 & 60 & 52 & 59 & 73 & 74 & 73 & 67 & 69 & 73 & 68 & 75 & 69 \\
\hline & $10^{\circ}$ & 52 & 61 & 75 & 50 & 64 & 51 & 64 & 72 & 75 & 69 & 63 & 70 & 78 & 71 & 72 & 65 \\
\hline & $11^{\circ}$ & 54 & 63 & 74 & 52 & 63 & 53 & 62 & 70 & 78 & 67 & 65 & 72 & 70 & 67 & 73 & 65 \\
\hline & $12^{\circ}$ & 54 & 65 & 73 & 51 & 64 & 52 & 60 & 72 & 75 & 67 & 66 & 69 & 72 & 65 & 73 & 68 \\
\hline & $13^{\circ}$ & 58 & 64 & 72 & 50 & 63 & 56 & 62 & 70 & 73 & 70 & 68 & 65 & 75 & 66 & 74 & 68 \\
\hline & $14^{\circ}$ & 57 & 62 & 73 & 52 & 60 & 60 & 66 & 71 & 74 & 72 & 67 & 66 & 74 & 64 & 76 & 66 \\
\hline & $15^{\circ}$ & 57 & 62 & 75 & 50 & 62 & 58 & 68 & 76 & 75 & 71 & 64 & 68 & 70 & 66 & 74 & 68 \\
\hline
\end{tabular}

Nota-se, portanto, que de acordo com os critérios estabelecidos em DNER (1999), as faixas adicionais $7,10,15,2,3,5,11$ e 13 devem ser implantadas de uma só vez no início do horizonte de projeto. Pode ser considerado que, as rampas do trecho analisado, cuja redução de velocidade dos veículos típicos não excede $15 \mathrm{~km} / \mathrm{h}$, não atendem às condições relacionadas ao nível de serviço do $3^{\circ}$ critério do DNER, devido, provavelmente, as suas curtas extensões e pequenas declividades, as quais podem ser verificadas pela análise da Tabela 6.9. Assim, como mencionado anteriormente, para o desenvolvimento da análise financeira que será apresentada a seguir, denominou-se esse cenário de alternativa 2 de investimento.

As parcelas anuais, dos custos de construção das faixas adicionais, gerados pelos comparativos entre as alternativas 1 e 0 e entre as alternativas 2 e 0 , foram calculadas utilizando-se a Equação 5.4, sendo adotadas as mesmas estimativas utilizadas na composição da programação de implantação das faixas adicionais desta pesquisa. Com um horizonte de projeto de 15 anos, os valores encontrados para os comparativos entre a 1 e a 0 e entre a 2 e a 0 estão, respectivamente, nas Tabelas 6.24 e 6.25. Foi considerado que a faixa deveria ser reconstruída após 10 anos e por isso não foram inseridos os custos de manutenção das faixas adicionais. 
Tabela 6.24 - Custos gerados pelo comparativo entre as alternativas 1 e 0

\begin{tabular}{|c|c|c|c|c|c|}
\hline Ano & Faixas & Custos & Ano & Faixas & Custos \\
\hline \multirow{2}{*}{$1^{\circ}$} & 7 & $\mathrm{R} \$ 37.263,17$ & \multirow{8}{*}{$9^{\circ}$} & 7 & $\mathrm{R} \$ 37.263,17$ \\
\hline & 10 & $\mathrm{R} \$ 46.912,92$ & & 10 & $\mathrm{R} \$ 46.912,92$ \\
\hline \multirow{5}{*}{$2^{\circ}$} & 7 & $\mathrm{R} \$ 37.263,17$ & & 15 & $\mathrm{R} \$ 12.758,16$ \\
\hline & 10 & $\mathrm{R} \$ 46.912,92$ & & 2 & $\mathrm{R} \$ 24.893,69$ \\
\hline & 15 & $\mathrm{R} \$ 12.758,16$ & & 3 & $\mathrm{R} \$ 105.878,10$ \\
\hline & 2 & $\mathrm{R} \$ 24.893,69$ & & 11 & $\mathrm{R} \$ 51.811,68$ \\
\hline & 3 & $\mathrm{R} \$ 105.878,10$ & & 5 & $\mathrm{R} \$ 16.233,76$ \\
\hline \multirow{6}{*}{ 3은 } & 7 & $\mathrm{R} \$ 37.263,17$ & & 13 & $\mathrm{R} \$ 34.908,13$ \\
\hline & 10 & $\mathrm{R} \$ 46.912,92$ & \multirow{8}{*}{$10^{\circ}$} & 7 & $\mathrm{R} \$ 37.263,17$ \\
\hline & 15 & $\mathrm{R} \$ 12.758,16$ & & 10 & $\mathrm{R} \$ 46.912,92$ \\
\hline & 2 & $\mathrm{R} \$ 24.893,69$ & & 15 & $\mathrm{R} \$ 12.758,16$ \\
\hline & 3 & $\mathrm{R} \$ 105.878,10$ & & 2 & $\mathrm{R} \$ 24.893,69$ \\
\hline & 11 & $\mathrm{R} \$ 51.811,68$ & & 3 & $\mathrm{R} \$ 105.878,10$ \\
\hline \multirow{7}{*}{$4^{\circ}$} & 7 & $\mathrm{R} \$ 37.263,17$ & & 11 & $\mathrm{R} \$ 51.811,68$ \\
\hline & 10 & $\mathrm{R} \$ 46.912,92$ & & 5 & $\mathrm{R} \$ 16.233,76$ \\
\hline & 15 & $\mathrm{R} \$ 12.758,16$ & & 13 & $\mathrm{R} \$ 34.908,13$ \\
\hline & 2 & $\mathrm{R} \$ 24.893,69$ & \multirow{8}{*}{$11^{\circ}$} & 7 & $\mathrm{R} \$ 59.551,49$ \\
\hline & 3 & $\mathrm{R} \$ 105.878,10$ & & 10 & $\mathrm{R} \$ 74.973,07$ \\
\hline & 11 & $\mathrm{R} \$ 51.811,68$ & & 15 & $\mathrm{R} \$ 12.758,16$ \\
\hline & 5 & $\mathrm{R} \$ 16.233,76$ & & 2 & $\mathrm{R} \$ 24.893,69$ \\
\hline \multirow{7}{*}{$5^{\circ}$} & 7 & $\mathrm{R} \$ 37.263,17$ & & 3 & $\mathrm{R} \$ 105.878,10$ \\
\hline & 10 & $\mathrm{R} \$ 46.912,92$ & & 11 & $R \$ 51.811,68$ \\
\hline & 15 & $\mathrm{R} \$ 12.758,16$ & & 5 & $\mathrm{R} \$ 16.233,76$ \\
\hline & 2 & $\mathrm{R} \$ 24.893,69$ & & 13 & $\mathrm{R} \$ 34.908,13$ \\
\hline & 3 & $\mathrm{R} \$ 105.878,10$ & \multirow{8}{*}{$12^{\circ}$} & 7 & $\mathrm{R} \$ 59.551,49$ \\
\hline & 11 & $\mathrm{R} \$ 51.811,68$ & & 10 & $\mathrm{R} \$ 74.973,07$ \\
\hline & 5 & $\mathrm{R} \$ 16.233,76$ & & 15 & $R \$ 20.389,24$ \\
\hline \multirow{8}{*}{$6^{\circ}$} & 7 & $\mathrm{R} \$ 37.263,17$ & & 2 & $\mathrm{R} \$ 39.783,42$ \\
\hline & 10 & $\mathrm{R} \$ 46.912,92$ & & 3 & $\mathrm{R} \$ 169.207,25$ \\
\hline & 15 & $\mathrm{R} \$ 12.758,16$ & & 11 & $\mathrm{R} \$ 51.811,68$ \\
\hline & 2 & $\mathrm{R} \$ 24.893,69$ & & 5 & $\mathrm{R} \$ 16.233,76$ \\
\hline & 3 & $\mathrm{R} \$ 105.878,10$ & & 13 & $\mathrm{R} \$ 34.908,13$ \\
\hline & 11 & $\mathrm{R} \$ 51.811,68$ & \multirow{8}{*}{$13^{\circ}$} & 7 & $\mathrm{R} \$ 59.551,49$ \\
\hline & 5 & $\mathrm{R} \$ 16.233,76$ & & 10 & $\mathrm{R} \$ 74.973,07$ \\
\hline & 13 & $\mathrm{R} \$ 34.908,13$ & & 15 & $R \$ 20.389,24$ \\
\hline \multirow{8}{*}{$7^{0}$} & 7 & $\mathrm{R} \$ 37.263,17$ & & 2 & $\mathrm{R} \$ 39.783,42$ \\
\hline & 10 & $\mathrm{R} \$ 46.912,92$ & & 3 & $\mathrm{R} \$ 169.207,25$ \\
\hline & 15 & $\mathrm{R} \$ 12.758,16$ & & 11 & $\mathrm{R} \$ 88.440,76$ \\
\hline & 2 & $\mathrm{R} \$ 24.893,69$ & & 5 & $\mathrm{R} \$ 16.233,76$ \\
\hline & 3 & $\mathrm{R} \$ 105.878,10$ & & 13 & $\mathrm{R} \$ 34.908,13$ \\
\hline & 11 & $\mathrm{R} \$ 51.811,68$ & \multirow{8}{*}{$14^{\circ}$} & 7 & $\mathrm{R} \$ 59.551,49$ \\
\hline & 5 & $\mathrm{R} \$ 16.233,76$ & & 10 & $\mathrm{R} \$ 74.973,07$ \\
\hline & 13 & $\mathrm{R} \$ 34.908,13$ & & 15 & $\mathrm{R} \$ 20.389,24$ \\
\hline \multirow{9}{*}{$8^{\circ}$} & 7 & $\mathrm{R} \$ 37.263,17$ & & 2 & $\mathrm{R} \$ 39.783,42$ \\
\hline & 10 & $\mathrm{R} \$ 46.912,92$ & & 3 & $\mathrm{R} \$ 169.207,25$ \\
\hline & 15 & $\mathrm{R} \$ 12.758,16$ & & 11 & $\mathrm{R} \$ 88.440,76$ \\
\hline & 2 & $\mathrm{R} \$ 24.893,69$ & & 5 & $\mathrm{R} \$ 25.943,70$ \\
\hline & 3 & $\mathrm{R} \$ 105.878,10$ & & 13 & $\mathrm{R} \$ 34.908,13$ \\
\hline & 11 & $\mathrm{R} \$ 51.811,68$ & \multirow[b]{4}{*}{$15^{\circ}$} & 7 & $\mathrm{R} \$ 59.551,49$ \\
\hline & 5 & $\mathrm{R} \$ 16.233,76$ & & 10 & $\mathrm{R} \$ 74.973,07$ \\
\hline & 13 & $\mathrm{R} \$ 34.908,13$ & & 15 & $R \$ 20.389,24$ \\
\hline & & & & $\begin{array}{c}2 \\
3 \\
11 \\
5 \\
13\end{array}$ & $\begin{array}{r}\mathrm{R} \$ 39.783,42 \\
\mathrm{R} \$ 169.207,25 \\
\mathrm{R} \$ 88.440,76 \\
\mathrm{R} \$ 25.943,70 \\
\mathrm{R} \$ 34.908,13\end{array}$ \\
\hline
\end{tabular}


Tabela 6.25 - Custos gerados pelo comparativo entre as alternativas 2 e 0

\begin{tabular}{|c|c|c|c|c|c|c|c|c|}
\hline Ano & Faixas & Custos & Ano & Faixas & Custos & Ano & Faixas & Custos \\
\hline $1^{\circ}$ & $\begin{array}{c}7 \\
10 \\
15 \\
2 \\
3 \\
5 \\
11 \\
13 \\
\end{array}$ & $\begin{array}{c}\mathrm{R} \$ 37.263,17 \\
\mathrm{R} \$ 46.912,92 \\
\mathrm{R} \$ 12.173,82 \\
\mathrm{R} \$ 23.753,52 \\
\mathrm{R} \$ 101.028,72 \\
\mathrm{R} \$ 14.103,77 \\
\mathrm{R} \$ 50.386,83 \\
\mathrm{R} \$ 27.613,42 \\
\end{array}$ & $8^{\circ}$ & $\begin{array}{c}7 \\
10 \\
15 \\
2 \\
3 \\
5 \\
11 \\
13 \\
\end{array}$ & $\begin{array}{c}R \$ 37.263,17 \\
R \$ 46.912,92 \\
R \$ 12.173,82 \\
R \$ 23.753,52 \\
R \$ 101.028,72 \\
R \$ 14.103,77 \\
R \$ 50.386,83 \\
R \$ 27.613,42\end{array}$ & $15^{\circ}$ & $\begin{array}{c}7 \\
10 \\
15 \\
2 \\
3 \\
5 \\
11 \\
13 \\
\end{array}$ & $\begin{array}{c}\mathrm{R} \$ 59.551,49 \\
\mathrm{R} \$ 74.973,07 \\
\mathrm{R} \$ 19.455,38 \\
\mathrm{R} \$ 37.961,28 \\
\mathrm{R} \$ 161.457,30 \\
\mathrm{R} \$ 22.539,70 \\
\mathrm{R} \$ 80.524,84 \\
\mathrm{R} \$ 44.129,91\end{array}$ \\
\hline $2^{\circ}$ & $\begin{array}{c}7 \\
10 \\
15 \\
2 \\
3 \\
5 \\
11 \\
13\end{array}$ & $\begin{array}{c}R \$ 37.263,17 \\
R \$ 46.912,92 \\
R \$ 12.173,82 \\
R \$ 23.753,52 \\
R \$ 101.028,72 \\
R \$ 14.103,77 \\
R \$ 50.386,83 \\
R \$ 27.613,42\end{array}$ & $9^{\circ}$ & $\begin{array}{c}7 \\
10 \\
15 \\
2 \\
3 \\
5 \\
11 \\
13 \\
\end{array}$ & $\begin{array}{c}\mathrm{R} \$ 37.263,17 \\
\mathrm{R} \$ 46.912,92 \\
\mathrm{R} \$ 12.173,82 \\
\mathrm{R} \$ 23.753,52 \\
\mathrm{R} \$ 101.028,72 \\
\mathrm{R} \$ 14.103,77 \\
\mathrm{R} \$ 50.386,83 \\
\mathrm{R} \$ 27.613,42\end{array}$ & & & \\
\hline $3^{0}$ & $\begin{array}{c}7 \\
10 \\
15 \\
2 \\
3 \\
5 \\
11 \\
13 \\
\end{array}$ & $\begin{array}{c}\mathrm{R} \$ 37.263,17 \\
\mathrm{R} \$ 46.912,92 \\
\mathrm{R} \$ 12.173,82 \\
\mathrm{R} \$ 23.753,52 \\
\mathrm{R} \$ 101.028,72 \\
\mathrm{R} \$ 14.103,77 \\
\mathrm{R} \$ 50.386,83 \\
\mathrm{R} \$ 27.613,42\end{array}$ & $10^{\circ}$ & $\begin{array}{c}7 \\
10 \\
15 \\
2 \\
3 \\
5 \\
11 \\
13 \\
\end{array}$ & $\begin{array}{c}\mathrm{R} \$ 37.263,17 \\
\mathrm{R} \$ 46.912,92 \\
\mathrm{R} \$ 12.173,82 \\
\mathrm{R} \$ 23.753,52 \\
\mathrm{R} \$ 101.028,72 \\
\mathrm{R} \$ 14.103,77 \\
\mathrm{R} \$ 50.386,83 \\
\mathrm{R} \$ 27.613,42\end{array}$ & & & \\
\hline $4^{\circ}$ & $\begin{array}{c}7 \\
10 \\
15 \\
2 \\
3 \\
5 \\
11 \\
13\end{array}$ & $\begin{array}{c}R \$ 37.263,17 \\
R \$ 46.912,92 \\
R \$ 12.173,82 \\
R \$ 23.753,52 \\
R \$ 101.028,72 \\
R \$ 14.103,77 \\
R \$ 50.386,83 \\
R \$ 27.613,42\end{array}$ & $11^{\circ}$ & $\begin{array}{c}7 \\
10 \\
15 \\
2 \\
3 \\
5 \\
11 \\
13\end{array}$ & $\begin{array}{c}\mathrm{R} \$ 59.551,49 \\
\mathrm{R} \$ 74.973,07 \\
\mathrm{R} \$ 19.455,38 \\
\mathrm{R} \$ 37.961,28 \\
\mathrm{R} \$ 161.457,30 \\
\mathrm{R} \$ 22.539,70 \\
\mathrm{R} \$ 80.524,84 \\
\mathrm{R} \$ 44.129,91\end{array}$ & & & \\
\hline $5^{0}$ & $\begin{array}{c}7 \\
10 \\
15 \\
2 \\
3 \\
5 \\
11 \\
13\end{array}$ & $\begin{array}{c}\mathrm{R} \$ 37.263,17 \\
\mathrm{R} \$ 46.912,92 \\
\mathrm{R} \$ 12.173,82 \\
\mathrm{R} \$ 23.753,52 \\
\mathrm{R} \$ 101.028,72 \\
\mathrm{R} \$ 14.103,77 \\
\mathrm{R} \$ 50.386,83 \\
\mathrm{R} \$ 27.613,42\end{array}$ & $12^{\circ}$ & $\begin{array}{c}7 \\
10 \\
15 \\
2 \\
3 \\
5 \\
11 \\
13\end{array}$ & $\begin{array}{c}\mathrm{R} \$ 59.551,49 \\
\mathrm{R} \$ 74.973,07 \\
\mathrm{R} \$ 19.455,38 \\
\mathrm{R} \$ 37.961,28 \\
\mathrm{R} \$ 161.457,30 \\
\mathrm{R} \$ 22.539,70 \\
\mathrm{R} \$ 80.524,84 \\
\mathrm{R} \$ 44.129,91\end{array}$ & & & \\
\hline $6^{0}$ & $\begin{array}{c}7 \\
10 \\
15 \\
2 \\
3 \\
5 \\
11 \\
13\end{array}$ & $\begin{array}{c}\mathrm{R} \$ 37.263,17 \\
\mathrm{R} \$ 46.912,92 \\
\mathrm{R} \$ 12.173,82 \\
\mathrm{R} \$ 23.753,52 \\
\mathrm{R} \$ 101.028,72 \\
\mathrm{R} \$ 14.103,77 \\
\mathrm{R} \$ 50.386,83 \\
\mathrm{R} \$ 27.613,42\end{array}$ & $13^{\circ}$ & $\begin{array}{c}7 \\
10 \\
15 \\
2 \\
3 \\
5 \\
11 \\
13\end{array}$ & $\begin{array}{c}\mathrm{R} \$ 59.551,49 \\
\mathrm{R} \$ 74.973,07 \\
\mathrm{R} \$ 19.455,38 \\
\mathrm{R} \$ 37.961,28 \\
\mathrm{R} \$ 161.457,30 \\
\mathrm{R} \$ 22.539,70 \\
\mathrm{R} \$ 80.524,84 \\
\mathrm{R} \$ 44.129,91\end{array}$ & & & \\
\hline $7^{\circ}$ & $\begin{array}{c}7 \\
10 \\
15 \\
2 \\
3 \\
5 \\
11 \\
13\end{array}$ & $\begin{array}{c}\mathrm{R} \$ 37.263,17 \\
\mathrm{R} \$ 46.912,92 \\
\mathrm{R} \$ 12.173,82 \\
\mathrm{R} \$ 23.753,52 \\
\mathrm{R} \$ 101.028,72 \\
\mathrm{R} \$ 14.103,77 \\
\mathrm{R} \$ 50.386,83 \\
\mathrm{R} \$ 27.613,42\end{array}$ & $14^{\circ}$ & $\begin{array}{c}7 \\
10 \\
15 \\
2 \\
3 \\
5 \\
11 \\
13\end{array}$ & $\begin{array}{c}\mathrm{R} \$ 59.551,49 \\
\mathrm{R} \$ 74.973,07 \\
\mathrm{R} \$ 19.455,38 \\
\mathrm{R} \$ 37.961,28 \\
\mathrm{R} \$ 161.457,30 \\
\mathrm{R} \$ 22.539,70 \\
\mathrm{R} \$ 80.524,84 \\
\mathrm{R} \$ 44.129,91\end{array}$ & & & \\
\hline
\end{tabular}


Utilizou-se o modelo da Equação 6.2 para calcular o valor presente das parcelas anuais dos custos de implantação de todas as faixas. Em seguida, calcularam-se os somatórios dos valores investidos em cada um dos comparativos de alternativa de investimento.

$$
C P=\frac{C F}{(1+i)^{t}}
$$

sendo:

$C P$ : custo no presente;

$C F$ : custo no da data $t$;

$i$ : taxa de juros considerada para trazer o $C F$ para o presente; e

$t$ : período de anos até a data do $C F$.

Ao variar a taxa de juros, observou-se a alteração da diferença entre os somatórios dos custos gerados pela alternativa 1 e dos gerados pela alternativa 2 , esses valores podem ser conferidos na Tabela 6.26. O gráfico que representa essa variação está representado na Figura 6.8 .

Tabela 6.26 - Somatório dos custos de implantação de ambos os comparativos para taxas de juros de 1 a $9 \%$

\begin{tabular}{|c|c|c|c|}
\hline Taxa de juros & ¿Custos Comp. 1 e 0 & ¿Custos Comp. 2 e 0 & Diferença entre $\sum$ Custos \\
\hline $1 \%$ & $-R \$ 4.804 .702,64$ & $-R \$ 5,217,896.98$ & $-8.3 \%$ \\
\hline $2 \%$ & $-R \$ 4.438 .552,33$ & $-R \$ 4,844,288.77$ & $-8.8 \%$ \\
\hline $3 \%$ & $-R \$ 4.110 .261,22$ & $-R \$ 4,509,190.64$ & $-9.3 \%$ \\
\hline $4 \%$ & $-R \$ 3.815 .295,28$ & $-R \$ 4,208,001.42$ & $-9.8 \%$ \\
\hline $5 \%$ & $-R \$ 3.549 .720,90$ & $-R \$ 3,936,727.62$ & $-10.3 \%$ \\
\hline $6 \%$ & $-R \$ 3.310 .118,88$ & $-R \$ 3,691,896.58$ & $-10.9 \%$ \\
\hline $7 \%$ & $-R \$ 3.093 .511,64$ & $-R \$ 3,470,483.00$ & $-11.4 \%$ \\
\hline $8 \%$ & $-R \$ 2.897 .301,30$ & $-R \$ 3,269,846.41$ & $-12.0 \%$ \\
\hline $9 \%$ & $-R \$ 2.719 .217,20$ & $-R \$ 3,087,678.14$ & $-12.6 \%$ \\
\hline
\end{tabular}

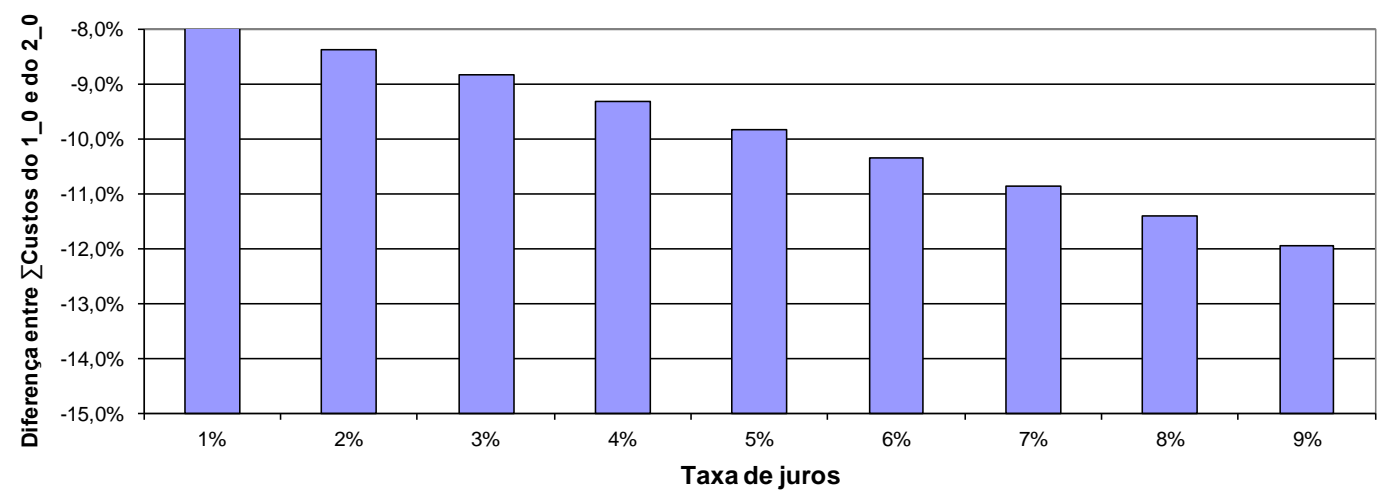

Figura 6.8 - Diferença entre os somatórios dos custos dos comparativos $\times$ Taxa de juros 
Assim, pela Figura 6.8, é possível concluir que, independentemente da taxa de juros utilizada, o somatório dos custos gerados pela programação de implantação de faixas adicionais, será inferior ao da construção simultânea, no início do horizonte de projeto, de todas as faixas adicionais necessárias.

Sabe-se que, numa comparação dos somatórios dos benefícios gerados por ambas alternativas de investimento, os valores dos benefícios proporcionados pela programação de implantação defendida seriam inferiores aos dos proporcionados pela construção simultânea das faixas no início do horizonte de projeto. Entretanto, optando-se pela construção simultânea, ou seja, utilizando os critérios atuais (DNER, 1999), os benefícios gerados a mais seriam experimentados apenas pelos usuários do trecho, enquanto que o montante economizado pela construção das faixas na programação apresentada poderia ser empregado em diversos projetos sociais, cujos benefícios favoreceriam toda a população.

Confirma-se assim que, em obras de melhoria em rodovias, como a construção de faixas adicionais, é mais interessante adotar uma rotina de investimento do que implantar planos de emergência, isso pelos aspectos financeiros e sociais. 


\section{CONCLUSÕES E RECOMENDAÇÕES}

Esta dissertação de mestrado descreveu as diversas etapas de uma pesquisa cuja meta principal foi propor um método capaz de estabelecer a sequência de implantação de um conjunto de faixas adicionais que maximize os benefícios do investimento nas rodovias de pista simples. Para atingir essa meta, foi necessário: (i) selecionar os critérios técnicos mais adequados para identificação da necessidade de faixas adicionais, a partir dos dados de tráfego e da previsão de seu crescimento; (ii) determinar funções que reflitam os benefícios associados a cada uma das faixas; (iii) definir um método para calcular os custos de implantação das faixas adicionais e; (iv) delinear um método para analisar a sequência de implantação das faixas adicionais que maximizasse os benefícios, considerando as limitações de recursos em cada etapa do investimento.

\subsection{CONCLUSÕES}

Tendo em vista os resultados do estudo de caso do Capítulo 6, pode-se considerar que os objetivos específicos foram atingidos, consequentemente, alcançando-se a meta principal desta pesquisa, visto que foi desenvolvido um método capaz de determinar uma sequência de implantação das faixas adicionais baseada no ranking dos valores das relações benefício/custo.

Em princípio, este método deve valer em qualquer situação, para qualquer projeto geométrico de rodovia de pista simples, fluxos, índices de correção, taxas de crescimento do tráfego e horizontes de projeto. Quando o tráfego e a as rampas (declividade e comprimento) indicarem a necessidade de construção de faixas adicionais, essas faixas devem ser implantadas seguindo a sequência estabelecida pelo método, para garantir a adequada aplicação dos recursos públicos.

Os benefícios gerados a mais pela construção das faixas adicionais numa data anterior a essas tornarem-se economicamente justificáveis, devem ser desprezados frente aos ganhos que o método defendido proporciona aos gestores da administração pública e à população em geral. Isso porque aqueles benefícios serão experimentados apenas pelos usuários de um determinado trecho, enquanto que os recursos economizados através da utilização do método podem ser aplicados em benefício de toda a sociedade. 
Para a aplicação do método na prática, os usuários devem obter, inicialmente, os fluxos direcionais das horas de pico nos aclives, a porcentagem de caminhões na corrente de tráfego, as curvas de desempenho desses caminhões, além do perfil vertical do trecho sob análise. Com esses dados e com a adoção de uma taxa de crescimento do fluxo, será conhecido a partir de qual ano torna-se justificável a construção das faixas adicionais. Se esses anos estiverem dentro do horizonte de projeto considerado pelo tomador de decisão, deve-se realizar uma coleta das demais variáveis do tráfego, para recalibrar o simulador. Com o simulador recalibrado e através da estimação dos custos operacionais dos veículos; do valor médio do tempo dos motoristas e passageiros; e do custo das colisões frontais; devem ser calculados os benefícios proporcionados pela implantação das faixas adicionais ano a ano, sendo esses comparados com os respectivos custos de construção dessas faixas.

Dentre as dificuldades potenciais para disseminar o método na comunidade técnica, destaca-se a necessidade de recalibrar o TWOPAS para todas as condições que serão testadas, pois somente após esse processo, os dados gerados podem ser utilizados com segurança. Por isso, na aplicação do método, não podem ser feitas apenas contagens do volume de veículos. Variáveis como velocidade média e porcentagem de veículos em pelotões devem ser coletadas para subsidiar a recalibração do modelo. Destaca-se que, após a obtenção desses dados, uma ferramenta eficiente para recalibrar os modelos de simulação são os algoritmos genéticos (AG), embora sejam requeridas habilidades específicas para desenvolvê-los.

Ressalta-se que, esta dissertação de mestrado foi mais um esforço no sentido de desenvolver procedimentos capazes de contribuir com a melhoria operacional das rodovias de pista simples, fazendo com que a duplicação de rodovias seja retardada ao máximo. No entanto, o método desenvolvido deve ser aperfeiçoado, e para isso algumas recomendações são apresentadas no próximo item.

\subsection{RECOMENDAÇÕES}

Neste trabalho está desenvolvido um método capaz de estabelecer a sequência de implantação de um conjunto de faixas adicionais, baseado na maximização dos benefícios. Os resultados encontrados atingiram completamente os objetivos propostos para a pesquisa e estimulam a 
possibilidade de novos estudos, com intuito de garantir que o método seja também viável quando aplicado em outros cenários.

A primeira recomendação que deve ser adotada nas próximas aplicações do método é desenvolver uma análise de sensibilidade do limite $k$ de anos, a fim de verificar a influência dele no delineamento da sequência ótima de construção das faixas adicionais.

Deve-se também estimar o benefício da redução do tempo de viagem na direção contrária à do aclive candidato a receber a faixa adicional, visto o aumento do número de gaps adequados para a dispersão dos pelotões no fluxo oposto, que as faixas adicionais proporcionam. Essa característica das faixas adicionais foi demonstrada por Mon-Ma (2002) e deve ser considerada, principalmente, nos aclives extensos, onde os custos de construção das faixas estejam equiparando-se aos benefícios.

Recomenda-se também que, nas próximas aplicações do método, sejam utilizados os modelos do HDM-4 e do ESTRADA para calcular os benefícios proporcionados pelas faixas adicionais quanto às reduções dos custos operacionais e dos tempos de viagem. Se houver dados suficientes, ou condições favoráveis para coletá-los, os modelos estrangeiros devem ser comparados com os desenvolvidos para a realidade nacional.

Quanto aos custos de manutenção das faixas adicionais, eles não fizeram parte da análise econômica desta pesquisa, entretanto, é recomendado que em aplicações posteriores o usuário considere essa parcela do custo total. Para isso, será necessário conhecer a duração do ciclo de vida dos pavimentos. Essa recomendação é decorrente de ser possível que a manutenção de um conjunto de faixas adicionais demande mais recursos do que o considerado em Kabbach (1992).

Esta pesquisa considerou também que para a construção das faixas é necessário um simples reforço no acostamento existente, ou seja, os custos de cortes e aterros não foram incluídos. No entanto, em um momento posterior, é recomendável que o usuário do método insira os valores de tais serviços no somatório do custo total das obras de construção.

Por fim, recomenda-se a compilação de todas as etapas do processo desenvolvido em um programa de computador, para automatizar o método proposto. Tal programa deve ser de fácil 
utilização para que os técnicos e tomadores de decisão utilizem-no após breve treinamento. A intenção principal, de transformar o método proposto em uma rotina computacional, deve ser a de possibilitar uma maior agilidade na análise da viabilidade econômica de projetos de sistemas de faixas adicionais. Para tanto, o programa deverá resolver as etapas do método e ser basicamente dividido nas seguintes fases:

- Inserção dos dados iniciais das variáveis de tráfego, de geometria e econômicas, assim como das taxas de crescimento da frota, dos índices de correção financeiros e do horizonte de projeto;

- Busca dentre as curvas de desempenho cadastradas por as dos caminhões típicos da região sob análise, para definição do conjunto de rampas candidatas a receber faixas adicionais;

- Análise da tabela de fluxos mínimos, para definição das implantações necessárias em cada ano do horizonte de projeto;

- Simulação de tráfego dos diversos cenários (com e sem as faixas adicionais), para geração dos dados que serão utilizados no cálculo das relações $\mathrm{B} / \mathrm{C}$;

- Cálculos das relações benefício/custo de todas as faixas do conjunto inicial de “necessárias", para definição da sequência ótima de construção; e

- Impressão dos resultados em planilha eletrônica.

A partir da ativação de botões de comando, sub-rotinas gravadas devem ser executadas para possibilitar as simulações no TWOPAS dos diversos cenários, as consequentes extrações dos dados gerados e a realização dos cálculos das relações B/C em planilhas eletrônicas. Deve ser viabiliza assim, a visualização dos resultados parciais à medida que os valores forem calculados para cada ano em estudo no projeto. 


\section{REFERÊNCIAS BIBLIOGRÁFICAS}

AASHTO (1994). A Policy on Geometric Design of Highways and Streets. American Association of State Highway and Transportation Officials. Chapter III: Elements of Design, p. 227-262. Washington, D. C..

AASHTO (2001). A Policy on Geometric Design of Highways and Streets. American Association of State Highway and Transportation Officials. Chapter III: Elements of Design, p. 235-254. Fourth Edition. Washington, D. C..

AL-KAISY, A.; DURBIN, C. (2007). Estimating percent time spent following on two-lane highways: field evaluation of new methodologies. Transportation Research Board 2007 Annual Meeting CD-ROM. TRB, National Research Council, Washington, D.C.

ARTESP (2005). Procedimento prático para implantação de faixas adicionais. Relatório Técnico. Agência de Transporte do Estado de São Paulo. Governo do Estado de São Paulo.

ATU (1999). Highway Geometric Design Guide. Alberta Infrastructure, Alberta Transportation and Utilities. Chapter B: Alignment Elements, p. B-55 to B-79. Alberta, Canada.

AUSTROADS (1993). Rural Road Design - Guide to the Geometric Design of Rural Roads. AustRoads, Sydney. Citado por Koorey e Tate (1999).

BESSA JR, J. E. (2009). Relações fluxo-velocidade e nível de serviço em rodovias de pista simples do Estado de São Paulo. São Carlos, 2009. Dissertação (Mestrado) - Escola de Engenharia de São Carlos, Universidade de São Paulo.

BICKEL P.; FRIEDERICH R.; BURGESS A.; FAGIANI P.; HUNT A.; DE JONG G.; LAIRD J.; LIEB C.; LINDBERG G.; MACKIE P.; NAVRUD S.; ODGAARD T.; RICCI A.; SHIRES J.; TAVASSZY L. (2006). Proposal for Harmonised Guidelines, HEATCO D5 (Harmonised European Approaches for Transport Costing and project assessment) Relatório 5. Disponível em: <http://heatco.ier.uni-stuttgart.de/HEATCO_D5.pdf/ http://heatco.ier.uni-stuttgart.de/HEATCO_D5_Annex.zip>. Acessado em 20/03/2009.

BIGGS D.C., (1988). ARFCOM - Models for Estimating Light to Heavy Vehicle Fuel Consumption. Research Report ARR 152, Australian Road Research Board, Nunawading, Australia. Citado por Watanatada et. al. (1987a).

BNDES (2010). Taxa de Juros de Longo Prazo. Banco nacional do desenvolvimento. Ministério do Desenvolvimento, Indústria e Comércio Exterior. Governo Federal do Brasil. Disponível em: <http://www.bndes.gov.br/bndes_pt/Institucional/Apoio_Financeiro/Custos_Financeiros/Ta xa_de_Juros_de_Longo_Prazo_TJLP/index.html>. Acessado em 05/02/2010.

BOTHA, J. L., SULLIVAN E. C., e ZENG X., (1994). Level of Service of Two-Lane Rural Highways with Low Design Speeds. Transportation Research Record 1457. Citado por Harwood (1999). 
BUTTON, K. (1996). Transport Economics. 2. ed. Cheltenham: Edward Elgar Publishing Ltd., 1996. Citado por Pedrozo (2001).

CARDOSO, J.L. (2002). Identificação de Zonas de Acumulação de Acidentes nas estradas da Rede Rodoviária Nacional. Comunicação ao 2. ${ }^{\circ}$ Congresso Rodoviário Português. CRP, Lisboa, 2002. Citado por Macário et al. (2007).

CASTRO J.N.R., (1975). Análise de dados de acidentes de tráfego nas rodovias paulistas. Relatório Preliminar. Série: Documentos básicos do DER/SP. Citado por Kabbach (1992).

CNT (2007). Pesquisa Rodoviária 2007. Confederação Nacional do Transporte. Disponível em: <http://www.cnt.org.br/>. Acessado em 09/06/08.

COBA (2002). Design Manual for Roads and Bridges: Volume 13 - Economic Assessment of Road Schemes. United Kingdom Department for Transport, Highways Agency. HRMSO, Londres, 2002.

CUNHA, A. L. B. N. ; Modotti, M. M. ; SETTI, J. R. (2008). Classificação de caminhões através de agrupamento por análise de cluster. In: XXII ANPET - Congresso de Pesquisa e Ensino em Transportes, 2008, Fortaleza. Anais XXII ANPET - Congresso de Pesquisa e Ensino em Transportes, 2008.

DEARAZOZA, R. D., and MCLEOD D. S. (1993). Methodology to Assess Level of Service on US-1 in the Florida Keys. Transportation Research Record 1398. Transportation Research Board. Citado por Harwood (1999).

DEMARCHI, S. H. (2000). Influência dos veículos pesados na capacidade e nível de serviço de rodovias de pista dupla. 166p. Tese (doutorado) - Escola de Engenharia de São Carlos, Universidade de São Paulo, São Carlos.

DER/SP (2006). Manual de Sinalização Rodoviária. Departamento de Estradas de Rodagem de São Paulo. Secretaria dos Transportes. Governo do Estado de São Paulo.

DER/SP (2009). Documentos e Informativos - Tabelas. Departamento de Estradas de Rodagem de São Paulo. Secretaria dos Transportes. Governo do Estado de São Paulo. Disponível em: <http://www.der.sp.gov.br/documentos/tabelas/tab_preco.aspx>. Acessado em 23/06/2009.

DNER (1976). Manual de custo de operação. Departamento Nacional de Estradas de Rodagem (DNER). Rio de Janeiro. Citado por Kabbach (1992).

DNER (1979). Instruções para implantação de terceiras faixas. Departamento Nacional de Estradas de Rodagem. Rio de Janeiro. Citado por Melo (2002).

DNER (1988). Um modelo de programa para aumento da segurança de trânsito nas Rodovias Federais. Departamento Nacional de Estradas de Rodagem (DNER). Rio de Janeiro. Citado por Kabbach (1992). 
DNER (1996). Manual de Pavimentação. Departamento Nacional de Estradas de Rodagem (DNER). Diretoria de Desenvolvimento Tecnológico. Rio de Janeiro.

DNER (1998). Guia de redução de acidentes com base em medidas de engenharia de baixo custo. Departamento Nacional de Estradas de Rodagem (DNER). Diretoria de Desenvolvimento Tecnológico. Rio de Janeiro.

DNER (1999). Manual de Projeto Geométrico de Rodovias Rurais. Capítulo 7: Terceira Faixa nas Rampas Ascendentes. Departamento Nacional de Estradas de Rodagem. Rio de Janeiro, p. 177-186.

DNIT (2004). Custos de Acidentes de Trânsito em Rodovias Federais. Relatório Final. Departamento Nacional de Infra-Estrutura de Transportes. Estudo desenvolvido pelo consórcio: Contécnica / ELSAMEX.

EGAMI, C. Y. (2006). Adaptação do HCM-2000 para a Determinação do Nível de Serviço em Rodovias de Pista Simples Sem Faixas Adicionais no Brasil. São Carlos, 2006. 233 p. Tese (Doutorado) - Escola de Engenharia de São Carlos, Universidade de São Paulo.

ENBERG, A. E PURSULA, M. (1997). Traffic Flow Characteristics on Three-Lane Rural Highway in Finland: Results from Empirical Studies and Simulations. Transportation Research Record 1572, p. 33-42.

FORKENBROCK D. J. e FOSTER N. S. J., (1997). Accident Cost Saving and Highway Attributes. Transportation n. 1, v. 24, p. 79-100. Fevereiro 1997. Citado por Macário et al. (2007).

FHWA (2004). Traffic Analysis Module Engineer's Manual - Interactive Highway Design Model (IHSDM). Federal Highway Administration, set 2004.

GATTIS, J.L.; ALGUIRE, M.S.; TOWNSEND, K. E RAO, S. (1997). Rural Two-Lane Passing Headways and Platooning. Transportation Research Record 1579, p. 27-34.

GATTIS, J.L.; BHAVE, R..; DUNCAN L.K. (2006). Alternating Passing Lane Lenghts. Transportation Research Record 1961, p. 16-23.

GEIPOT (1982). Pesquisa sobre o Inter-relacionamento dos Custos de Construção, Conservação e Utilização de Rodovias. Relatório Final (1981), v. 1, 5 e 9. Ministério dos Transportes. Empresa Brasileira de Planejamento de Transportes. Brasília, DF.

GEIPOT (2002). Anuário Estatístico de Transportes. Capítulo 5: Transporte Rodoviário (período 1996 a 2000). Empresa Brasileira de Planejamento de Transportes. Ministério dos Transportes do Brasil.

GRIFFIN, P.K. (1988). Mitigating Passing Restrictions. Division of Transportation Operations and Toll Bridges, California Department of Transportation, Sacramento, California. Citado por Morrall et al. (1995). 
HARWOOD, D.W.; ST JOHN, A.D. E WARREN, D.L. (1985). Operational and Safety Effectiveness of Passing Lanes on Two-Lane Highways. Transportation Research Record 1026, p.31-39.

HARWOOD, D.W. E HOBAN, C.J. (1987). Low-Cost for Improving Traffic Operations on Two-Lane Roads. U. S. Department of Transportation, Federal Highway Administration, Informational Guide, Report n. FHWA-IP-87-2.

HARWOOD, D.W.; HOBAN, C.J. E WARREN, D.L. (1988). Effective Use of Passing Lanes on Two-Lane Highways. Transportation Research Record 1195, p. 79-91.

HARWOOD, D.W.; MAY, A.D.; ANDERSON, I.B.; LEIMAN, L. E ARCHILLA, A.R. (1999). Capacity and Quality of Service of Two-Lane Highways. Final Report, Project 3, n. 55 v. 3. National Cooperative Highway Research Program, TRB, Washington, DC, EUA.

HENSHER, D.A. (1977), Value of Business Travel Time. Pergamon Press, Oxford. Citado por Bickel et al. (2006).

HOBAN, C. J. (1984). Traffic Operations and Level of Service on Two-Lane Roads. Proceedings of 12th Australian Road Research Board Conference, n. 5, v. 12, p. 117-131.

HOBAN C.J.; FAWCETT G.J. E ROBINSON G.K (1985). A model for simulating traffic on two-lane rural roads: user guide and manual for TRARR (version 3.0). Technical Manual ATM 10A. Australian Road Research Board, Nunawading. Victoria, 1985. Citado por Morral e Werner (1990).

IPEA e ANTP (2004). Impactos sociais e econômicos dos acidentes de trânsito nas aglomerações urbanas brasileiras. Pesquisa Acidentes de Trânsito - Cadastro RENAVAM. Instituto de pesquisa econômica aplicada (IPEA). Associação Nacional de Transportes Públicos (ANTP).

KABBACH, F. I. J. (1992). Contribuição para o estudo de implantação de faixas adicionais em rampas ascendentes de rodovias de pista simples. Tese (Doutorado). Escola Politécnica - Universidade de São Paulo. 333 p.

KAWAMOTO E. e FURTADO N., (1997). Avaliação de Projetos de Transporte. $1^{a}$ Edição. Departamento de Transporte. Escola de Engenharia de São Carlos. Universidade de São Paulo. São Carlos.

KERALI, H.G.R. (2000). The Highway Design and Maintenance Standards Model, v. 1: Overview of HDM-4. World Bank. Washington, D.C.

KERALI, H.G.R.; MCMULlEN, D. e ODOKI, J.B. (2000). The Highway Design and Maintenance Standards Model, v. 2: Applications Guide. World Bank. Washington, D.C.

KHAN, A.M. (1991). Cost-effectiveness of Passing lanes: Safety, Level of Service, and Cost Factors. Research and Development Branch, Ministry of Transportation, Ontario. Citado por Koorey e Tate (1999). 
KLEIN, F.C.; PARREIRA, A.B.; FERNANDES JR., J.L. (2005). Avaliação dos Custos de Operação dos Veículos e do Tempo de Viagem em Função da Geometria das Rodovias. Congresso de Pesquisa e Ensino em Transportes, XIX ANPET, Recife, v. 2, p. 1386-1397.

KOOREY, G. E TATE, F. (1999). Road infrastructure assessment model - Incorporation of passing-lane sections. The Institution of Professional Engineers New Zealand - IPENZ Transactions, n. 1/CIV, v. 26, p. 13-20.

LEIMAN, L. E MAY, A. D. (1996). User-Friendly Interface for Rural Highway Computer Simulation Models with Emphasis on the Incorporation of the TWOPAS Model. FHWA/CA/TO-96/25. NTIS - National Technical Information Service, U. S. Department of Commerce. University of California, Berkley Institute of Transportation Studies, CA.

LUTTINEN, R. T. (2001). Percent time spent following as performance measure for two-lane highways. TRB, National Research Council, Washington, D.C. Transportation Research Record 1776, p. 52-59.

MACÁRIO, R.; CARMONA, M.; CAIADO, G.; MARTINS P.; RODRIGUES, A.; LINK, H.; STEWART, L.; BICKEL, P.; DOLL, C. (2001). The Pilot Accounts for Portugal. UNITE D12 - A7. ITS, Universidade de Leeds, Leeds, 2001. http://www.its.leeds.ac.uk/projects/unite/downloads/D12_Annex7.doc. Acessado em 08/05/2009.

MACÁRIO R.; AFONSO I.T.; COSTA J.D.; RODRIGUES, M.J.; CARMONA M.J.; DIU F.C., (2007). Estimação de Custos e Benefícios Reais para a Avaliação Econômica de Projectos de Investimento Rodoviário em Portugal. Portugal.

MANSO, A.C.; FONSECA M.S.; ESPADA J.C., (2004). Informação sobre custos. Fichas de rendimentos, v. 1 e 2. Laboratório Nacional de Engenharia Civil, Lisboa. Citado por Macário et al. (2007).

MAY, A.D. (1991). Traffic performance and design of passing-lanes. Transportation Research Record 1303, p. 63-73.

MCLEAN, J. R. (1989). Two-Lane Highway Traffic Operations - Theory and Practice. New York, Gordon and Beach Science Publishers.

MELO, R. A. (2002). Faixas Adicionais para Aclives de Rodovias Brasileiras. São Carlos, 2002. 175 p. Tese (Doutorado) - Escola de Engenharia de São Carlos, Universidade de São Paulo.

MELO, R. A.; SETTI, J. R. (2003). Faixas adicionais para aclives em rodovias de pista simples brasileiras: uma adaptação dos critérios da AASHTO. Transportes (Rio de Janeiro), Rio de Janeiro, n. 2, v. 11, p. 41-48..

MELO, R. A.; SETTI, J. R. (2007a). Revising the AASHTO Curve: Accident Involvement Rates for Trucks and Speed Differentials on Highway Grades. Engenharia Civil UM (Braga), v. 29, p. 5-14, 2007. 
MELO, R. A.; SETTI, J. R. (2007b). Fluxos Mínimos de Veículos para Implantação de Faixas Adicionais em Aclives de Rodovias de Pista Simples. Transportes (Rio de Janeiro), v. 15, p. 16-23, 2007.

MENDONZA, A. E MAYORAL, E. (1994). Economic Feasibility Assessment Procedure for Climbing Lanes on Two-Lane Roads in Mexico. Transportation Research Record 1497, p. 26-34.

MESSER, C.J. (1983). Two-Lane, Two-Way Rural Highway Capacity. Final Report. Texas Transportation Institute. College Station, Texas. Citado por Morral e Werner (1990).

MON-MA, M. L. (2002). O Processo de Formação e Dispersão de Pelotões em Rodovias de Pista Simples. 103 p. Dissertação (Mestrado) - Escola de Engenharia de São Carlos, Universidade de São Paulo.

MON-MA, M. L. (2008). Adaptação do HCM2000 para Rodovias de Pista Simples com Faixas Adicionais Típicas do Estado de São Paulo. 162 p. Tese (Doutorado) - Escola de Engenharia de São Carlos, Universidade de São Paulo.

MORRALL, J.F. E HOBAN, C.J. (1985). A Comparison of Canadian and Australian Passing Lane Design Practice. Roads and Transportation Association of Canada, Vancouver. Transportation Forum, v. 2, 4, p. 9-21.

MORRALL, J.F. (1986). Design Guidelines for Passing Lanes in the Mountain Parks. Paper presented in the short course: Planning and Design of Passing Lanes - University of Calgary, Canada.

MORRALL, J.F. E WERNER, A. (1990). Measuring Level of Service of Two-Lane Highways by Overtakings. Transportation Research Record 1287, p. 62-69.

MORRALL, J.F. (1998). Impact of Passing Lanes on the Quality of Service on Two-Lane Highways. Proceedings of the Third International Symposium on Highway Capacity. Copenhagen, Denmark, v. 2.

MOTTA, R. R. E CALÔBA, G. M, (2002). Análise de Investimentos, Tomada de Decisão em Projetos Industriais. Editora Atlas.

MTO (1990). Cost-effectiveness of Climbing Lanes: Safety, Level of Service and Cost Factors. Documentation Page TDS-90-08. Ministry of Transportation Ontario.

ODOKI, J.B. e KERALI, H.G.R. (2000). The Highway Design and Maintenance Standards Model, v. 4: Analytical Framework and Model Descriptions. World Bank. Washington, D.C.

ORTÚZAR, J.D. e WILLUMSEN L.G. (2001). Modelling Transport. John Wiley e Sons, $3^{\mathrm{a}}$ ed, New York 
OZBAY K.; BARTIN B.; BERECHMAN J., (2001). Estimation and Evaluation of Full Marginal Costs of Highway Transportation in New Jersey. Journal of Transportation Statistics, n. 1, v. 4. Bureau of Transportation Statistics, U.S. Department of Transport. Disponível em:

<http://www.bts.gov/publications/journal_of_transportation_and_statistics/volume_04_nu mber_01/paper_06/>. Acessado em 05/04/2009.

PEDROZO, L.G. (2001). Custos da Infra-Estrutura Rodoviária - Análise e Sistematização. 171 p. Dissertação (Mestrado) - Universidade Federal do Rio Grande do Sul.

PIENAAR W.J., (1984). Olieverbruik van Padvoertuie in Suid-Afrika. NITRR Report RT/5, CSIR, Pretoria. Citado por Kerali (2000).

POLUS, A.; CRAUS, J. e GRINBERG, I. (1981). Applying the Level-of-Service Concept to Climbing Lanes. Transportation Research Record 806, p. 28-33.

PURSULA, M.; SIIMES, H. (1993). A Simulation Study of a High-Class Three-Lane Rural Road. Institute of Transportation Engineers 1993. Compendium of Technical Papers, Washington. Citado por Koorey e Tate (1999).

QUADRO (2004). Departamento de Transportes do Reino Unido. Design Manual for Roads and Bridges. v. 14: Economic Assessment of Road Maintenance. Section 1: The QUADRO Manual. Parte 2: The Valuation of Costs in Quadro. London. Disponível em: <http://www.dft.gov.uk/stellent/groups/dft_econappr/documents/page/dft_econappr_50488 4.pdf $>$. Acessado 05/05/2009.

RAESIDE R., (2004). Predicting and Monitoring Casualty Numbers in Great Britain. Journal of Transportation Statistics, n.1, v. 7. Disponível em: $<$ http://www.bts.gov/publications/journal_of_transportation_and_statistics/volume_07_nu mber_01/html/paper_04/index.html>. Acessado 05/05/2009.

RODRIGUES, M.J. (2007).Avaliação económica de projectos rodoviários- Estimação de custos e benefícios para os utentes. 91 p. Tese (Doutorado). Instituto Superior Técnico da Universidade Técnica de Lisboa.

ROMERO, J.; MORISUGI, H.; MORIGUCHI, T. (2005). Short Confidence Intervals for Value of Time. Transportation Research Board, National Research Council. Washington, D. C.

SADEGHHOSSEINI, S. E BENEKOHAL. R. F. (1997). Space Headway and Safety of Platooning Highway Traffic. Proceedings of the Conference on Traffic Congestion and Traffic Safety in the 21st Century - Challenges, Innovations, and Opportunities. ASCE, New York, p. 472-478.

SAMUELSON P.A. (1954). The pure theory of public expediture. Review of Economic and statiscs n. 4, v. 36, p. 387-389. 
SICRO (2003). Manual de Custos Rodoviários. Volume 1. Metodologia e Conceitos. $3^{\circ}$ Edição. Ministério dos Transportes. Departamento Nacional de Infra-Estrutura de Transportes - DNIT. Rio de Janeiro. 2003.

STIMPSON, W. A. e GLENNON, J. C. (1971). Critical Review of Climbing Lane Design Practices. Highway Research Board Bulletin n. 167, p. 1-11, Washington, D.C.

TRB (2000). Highway Capacity Manual 2000. Transportation Research Board. Washington D.C.

VAN AS, C. (2003). The development of an analysis method for the determination of level of service of two-lane undivided highways in South Africa. Project Summary. South African National Roads Agency Limited.

WATANATADA, T.; HARRAL, C.G.; PATERSON, W.D.O.; DHARESHWAR, A.M.; BHANDARI, A.; TSUNOKAWA, K. (1987a). The Highway Design and Maintenance Standards Model, v. 1: Description of the HDM - III Model. World Bank. The John Hopkins University Press. Baltimore, MD.

WATANATADA, T.; HARRAL, C.G.; PATERSON, W.D.O.; DHARESHWAR, A.M.; BHANDARI, A.; TSUNOKAWA, K. (1987b). The Highway Design and Maintenance Standards Model, v. 2: User's manual for the HDM - III Model. World Bank. The John Hopkins University Press. Baltimore, MD.

WERNER, A. E MORRALL, J.F. (1984). A Unified Traffic Flow Theory Model for TwoLane Rural Highways. Transportation Forum, v. 1-3, p. 79-87. Citado por Morrall (1998).

VILAIN, P. B.; BHANDARI N. (2002). Differences in the Subjective and Social Values of Time: Empirical Evidence from a Traffic Study in Croatia. Transportation Research Board, National Research Council. Washington, D. C. 


\section{APÊNDICE A - Benefícios da redução dos custos operacionais}

Tabela A.1 - Composição dos benefícios da redução dos custos operacionais do 10 ano da análise

\begin{tabular}{|c|c|c|c|c|c|c|c|c|c|c|c|c|}
\hline Aclive & 7 & 10 & 7 & 15 & 7 & 13 & 7 & 2 & 7 & 3 & 7 & 5 \\
\hline \multirow{3}{*}{$\begin{array}{c}\mathrm{i}(\%) \\
\mathrm{VHP} \\
\text { (veic/h) } \\
\text { Veic/h } \\
\text { (Entre } \\
\text { picos) }\end{array}$} & 4 & 3 & 4 & 5 & 4 & 3 & 4 & 3 & 4 & 3 & 4 & 2 \\
\hline & 676 & 676 & 676 & 676 & 676 & 676 & 676 & 676 & 676 & 676 & 676 & 676 \\
\hline & 278 & 278 & 278 & 278 & 278 & 278 & 278 & 278 & 278 & 278 & 278 & 278 \\
\hline \multirow{3}{*}{$\begin{array}{c}\text { Va }(\mathrm{km} / \mathrm{h}) \\
\mathrm{Ra} \\
\text { Custo }\end{array}$} & 58,38 & 58,38 & 58,38 & 58,38 & 58,38 & 58,38 & 58,38 & 58,38 & 58,38 & 53,491 & 58,38 & 58,38 \\
\hline & 1,439 & 1,366 & 1,439 & 1,511 & 1,439 & 1,366 & 1,439 & 1,366 & 1,439 & 1,403 & 1,439 & 1,294 \\
\hline & $\mathrm{R} \$ 0,58$ & $\mathrm{R} \$ 0,55$ & $\mathrm{R} \$ 0,58$ & $\mathrm{R} \$ 0,61$ & $\mathrm{R} \$ 0,58$ & $\mathrm{R} \$ 0,55$ & $\mathrm{R} \$ 0,58$ & $\mathrm{R} \$ 0,55$ & $\mathrm{R} \$ 0,58$ & $\mathrm{R} \$ 0,57$ & $\mathrm{R} \$ 0,58$ & $\mathrm{R} \$ 0,53$ \\
\hline $\begin{array}{c}\text { operacional } \\
\text { PTSF }\end{array}$ & 74,35 & 74,35 & 74,35 & 74,35 & 74,35 & 74,35 & 74,35 & 74,35 & 74,35 & 70,32 & 74,35 & 74,35 \\
\hline \multirow{3}{*}{$\begin{array}{c}\mathrm{Va}(\mathrm{km} / \mathrm{h}) \\
\mathrm{Ra} \\
\text { Custo }\end{array}$} & 67,29 & 67,29 & 63,66 & 63,66 & 64,13 & 64,13 & 64,37 & 64,37 & 63,21 & 53,92 & 63,99 & 63,99 \\
\hline & 1,373 & 1,301 & 1,400 & 1,472 & 1,396 & 1,324 & 1,394 & 1,322 & 1,403 & 1,399 & 1,397 & 1,253 \\
\hline & $\mathrm{R} \$ 0,56$ & $\mathrm{R} \$ 0,53$ & $\mathrm{R} \$ 0,57$ & $\mathrm{R} \$ 0,60$ & $\mathrm{R} \$ 0,57$ & $\mathrm{R} \$ 0,54$ & $\mathrm{R} \$ 0,57$ & $\mathrm{R} \$ 0,54$ & $\mathrm{R} \$ 0,57$ & $\mathrm{R} \$ 0,57$ & $\mathrm{R} \$ 0,57$ & $\mathrm{R} \$ 0,51$ \\
\hline $\begin{array}{c}\text { operacional } \\
\text { PTSF }\end{array}$ & 62,1 & 62,1 & 69,1 & 69,1 & 67,1 & 67,1 & 67,1 & 67,1 & 69,7 & 67 & 68,25 & 68,25 \\
\hline VDMa & 3300 & 3300 & 3300 & 3300 & 3300 & 3300 & 3300 & 3300 & 3300 & 3402 & 3300 & 3300 \\
\hline \multirow{5}{*}{$\begin{array}{c}\text { Lma }(\mathrm{km}) \\
\text { rco'a } \\
\text { VHPa } \\
\text { (aut/hora) } \\
\text { ya } \\
\text { rcoa } \\
\end{array}$} & 0,1225 & 0,1225 & 0,0525 & 0,0525 & 0,0725 & 0,0725 & 0,0725 & 0,0725 & 0,0465 & 0,0332 & 0,061 & 0,061 \\
\hline & $\mathrm{R} \$ 1,822$ & $\mathrm{R} \$ 1,822$ & $\mathrm{R} \$ 0,463$ & $\mathrm{R} \$ 0,463$ & $\mathrm{R} \$ 0,696$ & $\mathrm{R} \$ 0,696$ & $\mathrm{R} \$ 0,725$ & $\mathrm{R} \$ 0,725$ & $\mathrm{R} \$ 0,375$ & $\mathrm{R} \$ 0,024$ & $\mathrm{R} \$ 0,571$ & $\mathrm{R} \$ 0,571$ \\
\hline & 236 & 236 & 236 & 236 & 236 & 236 & 236 & 236 & 236 & 243 & 236 & 236 \\
\hline & 1 & 1 & 1 & 1 & 1 & 1 & 1 & 1 & 1 & 1 & 1 & 1 \\
\hline & $\mathrm{R} \$ 9,826$ & $\mathrm{R} \$ 9,826$ & $\mathrm{R} \$ 2,495$ & $\mathrm{R} \$ 2,495$ & $\mathrm{R} \$ 3,753$ & $\mathrm{R} \$ 3,753$ & $\mathrm{R} \$ 3,910$ & $\mathrm{R} \$ 3,910$ & $\mathrm{R} \$ 2,022$ & $\mathrm{R} \$ 0,131$ & $\mathrm{R} \$ 3,081$ & $\mathrm{R} \$ 3,081$ \\
\hline \multirow{3}{*}{$\begin{array}{c}\text { Vo }(\mathrm{km} / \mathrm{h}) \\
\text { Ro } \\
\text { Custo }\end{array}$} & 54,425 & 54,425 & 54,425 & 54,425 & 54,425 & 54,425 & 54,425 & 54,425 & 54,425 & 49,261 & 54,425 & 54,425 \\
\hline & 1,280 & 1,211 & 1,280 & 1,349 & 1,280 & 1,211 & 1,280 & 1,211 & 1,280 & 1,236 & 1,280 & 1,142 \\
\hline & $\mathrm{R} \$ 2,60$ & $\mathrm{R} \$ 2,46$ & $\mathrm{R} \$ 2,60$ & $\mathrm{R} \$ 2,74$ & $\mathrm{R} \$ 2,60$ & $\mathrm{R} \$ 2,46$ & $\mathrm{R} \$ 2,60$ & $\mathrm{R} \$ 2,46$ & $R \$ 2,60$ & $\mathrm{R} \$ 2,51$ & $\mathrm{R} \$ 2,60$ & $\mathrm{R} \$ 2,32$ \\
\hline $\begin{array}{c}\text { operacional } \\
\text { PTSF }\end{array}$ & 74,35 & 74,35 & 74,35 & 74,35 & 74,35 & 74,35 & 74,35 & 74,35 & 74,35 & 70,32 & 74,35 & 74,35 \\
\hline \multirow{4}{*}{$\begin{array}{c}\text { Vo }(\mathrm{km} / \mathrm{h}) \\
\text { Ro } \\
\text { Custo }\end{array}$} & 56,27 & 56,27 & 55,74 & 55,74 & 55,39 & 55,39 & 55,97 & 55,97 & 55,71 & 49,416 & 56,37 & 56,37 \\
\hline & 1,296 & 1,217 & 1,295 & 1,374 & 1,294 & 1,215 & 1,295 & 1,217 & 1,295 & 1,235 & 1,296 & 1,139 \\
\hline & & & & & & & & & & & & \\
\hline & $\mathrm{R} \$ 2,63$ & $\mathrm{R} \$ 2,47$ & $\mathrm{R} \$ 2,63$ & $\mathrm{R} \$ 2,79$ & $\mathrm{R} \$ 2,63$ & $\mathrm{R} \$ 2,47$ & $\mathrm{R} \$ 2,63$ & $\mathrm{R} \$ 2,47$ & $\mathrm{R} \$ 2,63$ & $\mathrm{R} \$ 2,51$ & $\mathrm{R} \$ 2,63$ & $\mathrm{R} \$ 2,31$ \\
\hline $\begin{array}{c}\text { operacional } \\
\text { PTSF }\end{array}$ & 62,1 & 62,1 & 69,1 & 69,1 & 67,1 & 67,1 & 67,1 & 67,1 & 69,7 & 67 & 68,25 & 68,25 \\
\hline \multirow{6}{*}{$\begin{array}{c}\text { VDMo } \\
\text { Lmo }(\mathrm{km}) \\
\text { rco'o } \\
\text { VHPo } \\
\text { (bus/hora) } \\
\text { yo } \\
\text { rcoo } \\
\end{array}$} & 77 & 77 & 77 & 77 & 77 & 77 & 77 & 77 & 77 & 74 & 77 & 77 \\
\hline & 0,1225 & 0,1225 & 0,0525 & 0,0525 & 0,0725 & 0,0725 & 0,0725 & 0,0725 & 0,0465 & 0,0332 & 0,061 & 0,061 \\
\hline & $-\mathrm{R} \$ 2,25$ & $-\mathrm{R} \$ 0,89$ & $-\mathrm{R} \$ 0,88$ & $-\mathrm{R} \$ 1,46$ & $-\mathrm{R} \$ 1,15$ & $-\mathrm{R} \$ 0,35$ & $-\mathrm{R} \$ 1,27$ & $-\mathrm{R} \$ 0,47$ & $-\mathrm{R} \$ 0,78$ & $\mathrm{R} \$ 0,03$ & $-\mathrm{R} \$ 1,14$ & $\mathrm{R} \$ 0,21$ \\
\hline & 6 & 6 & 6 & 6 & 6 & 6 & 6 & 6 & 6 & 5 & 6 & 6 \\
\hline & 1 & 1 & 1 & 1 & 1 & 1 & 1 & 1 & 1 & 1 & 1 & 1 \\
\hline & $-\mathrm{R} \$ 4,67$ & $-\mathrm{R} \$ 1,86$ & $-\mathrm{R} \$ 1,84$ & $-\mathrm{R} \$ 3,05$ & $-\mathrm{R} \$ 2,39$ & -R\$ 0,72 & $-R \$ 2,64$ & $-\mathrm{R} \$ 0,97$ & $-\mathrm{R} \$ 1,62$ & $\mathrm{R} \$ 0,06$ & $-\mathrm{R} \$ 2,36$ & $-\mathrm{R} \$ 2,36$ \\
\hline \multirow{3}{*}{$\begin{array}{c}\mathrm{Vcv}(\mathrm{km} / \mathrm{h}) \\
\text { Rcv } \\
\text { Custo }\end{array}$} & 54,425 & 54,425 & 54,425 & 54,425 & 54,425 & 54,425 & 54,425 & 54,425 & 54,425 & 49,261 & 54,425 & 54,425 \\
\hline & 1,284 & 1,204 & 1,284 & 1,364 & 1,284 & 1,204 & 1,284 & 1,204 & 1,284 & 1,294 & 1,284 & 1,124 \\
\hline & $\mathrm{R} \$ 1,67$ & $\mathrm{R} \$ 1,57$ & $\mathrm{R} \$ 1,67$ & $\mathrm{R} \$ 1,78$ & $\mathrm{R} \$ 1,67$ & $\mathrm{R} \$ 1,57$ & $\mathrm{R} \$ 1,67$ & $\mathrm{R} \$ 1,57$ & $\mathrm{R} \$ 1,67$ & $\mathrm{R} \$ 1,69$ & $\mathrm{R} \$ 1,67$ & $\mathrm{R} \$ 1,47$ \\
\hline $\begin{array}{c}\text { operacional } \\
\text { PTSF }\end{array}$ & 74,35 & 74,35 & 74,35 & 74,35 & 74,35 & 74,35 & 74,35 & 74,35 & 74,35 & 70,32 & 74,35 & 74,35 \\
\hline \multirow{3}{*}{$\begin{array}{c}\text { Vcv }(\mathrm{km} / \mathrm{h}) \\
\text { Rcv } \\
\text { Custo }\end{array}$} & 56,27 & 56,27 & 55,74 & 55,74 & 55,39 & 55,39 & 55,97 & 55,97 & 55,71 & 49,416 & 56,37 & 56,37 \\
\hline & 1,311 & 1,227 & 1,307 & 1,391 & 1,304 & 1,220 & 1,309 & 1,224 & 1,307 & 1,291 & 1,312 & 1,143 \\
\hline & $\mathrm{R} \$ 1,71$ & $\mathrm{R} \$ 1,60$ & $\mathrm{R} \$ 1,70$ & $\mathrm{R} \$ 1,81$ & $\mathrm{R} \$ 1,70$ & $\mathrm{R} \$ 1,59$ & $\mathrm{R} \$ 1,71$ & $\mathrm{R} \$ 1,60$ & $\mathrm{R} \$ 1,70$ & $\mathrm{R} \$ 1,68$ & $\mathrm{R} \$ 1,71$ & $\mathrm{R} \$ 1,49$ \\
\hline \multirow{2}{*}{$\begin{array}{c}\text { operacional } \\
\text { PTSF }\end{array}$} & & & & & & & & & & & & \\
\hline & 62,1 & 62,1 & 69,1 & 69,1 & 67,1 & 67,1 & 67,1 & 67,1 & 69,7 & 67 & 68,25 & 68,25 \\
\hline VDMcv & 145 & 145 & 145 & 145 & 145 & 145 & 145 & 145 & 145 & 116 & 145 & 145 \\
\hline $\operatorname{Lmcv}(\mathrm{km})$ & 0,1225 & 0,1225 & 0,0525 & 0,0525 & 0,0725 & 0,0725 & 0,0725 & 0,0725 & 0,0465 & 0,0332 & 0,061 & 0,061 \\
\hline rco'cr & $-\mathrm{R} \$ 2,42$ & $-\mathrm{R} \$ 2,04$ & $-\mathrm{R} \$ 0,88$ & $-\mathrm{R} \$ 1,05$ & $-\mathrm{R} \$ 1,08$ & $-\mathrm{R} \$ 0,85$ & $-\mathrm{R} \$ 1,31$ & $-\mathrm{R} \$ 1,09$ & $-\mathrm{R} \$ 0,78$ & $\mathrm{R} \$ 0,06$ & $-\mathrm{R} \$ 1,24$ & $-\mathrm{R} \$ 0,86$ \\
\hline $\begin{array}{c}\text { VHPcv } \\
\text { (cam/hora) }\end{array}$ & 10 & 10 & 10 & 10 & 10 & 10 & 10 & 10 & 10 & 8 & 10 & 10 \\
\hline $\mathrm{ycv}$ & 0,1 & 0,1 & 0,1 & 0,1 & 0,1 & 0,1 & 0,1 & 0,1 & 0,1 & 0,1 & 0,1 & 0,1 \\
\hline rcocv & $-\mathrm{R} \$ 4,88$ & $-\mathrm{R} \$ 4,11$ & $-\mathrm{R} \$ 1,78$ & $-\mathrm{R} \$ 2,11$ & $-\mathrm{R} \$ 2,18$ & $-\mathrm{R} \$ 1,72$ & $-\mathrm{R} \$ 2,64$ & $-\mathrm{R} \$ 2,19$ & $-\mathrm{R} \$ 1,56$ & $\mathrm{R} \$ 0,13$ & $-\mathrm{R} \$ 2,50$ & $-\mathrm{R} \$ 1,73$ \\
\hline$\sum \mathrm{rco}$ & $\mathrm{R} \$ 9,826$ & $\mathrm{R} \$ 9,826$ & $\mathrm{R} \$ 2,495$ & $\mathrm{R} \$ 2,495$ & $\mathrm{R} \$ 3,753$ & $\mathrm{R} \$ 3,753$ & $\mathrm{R} \$ 3,910$ & $\mathrm{R} \$ 3,910$ & $\mathrm{R} \$ 2,022$ & $\mathrm{R} \$ 0,320$ & $\mathrm{R} \$ 3,081$ & $\mathrm{R} \$ 3,081$ \\
\hline BRCO & $\mathrm{R} \$ 3.586,45$ & $\mathrm{R} \$ 3.586,45$ & $\mathrm{R} \$ 910,85$ & $\mathrm{R} \$ 910,85$ & $\mathrm{R} \$ 1.369,80$ & $\mathrm{R} \$ 1.369,80$ & $\mathrm{R} \$ 1.426,97$ & $\mathrm{R} \$ 1.426,97$ & $\mathrm{R} \$ 737,99$ & $\mathrm{R} \$ 116,94$ & $\mathrm{R} \$ 1.124,46$ & $\mathrm{R} \$ 1.124,46$ \\
\hline
\end{tabular}


Continuação Tabela A.1

\begin{tabular}{|c|c|c|c|c|c|c|c|c|c|c|}
\hline Aclive & 10 & 15 & 10 & 13 & 10 & 2 & 10 & 3 & 10 & 5 \\
\hline i (\%) & 3 & 5 & 3 & 3 & 3 & 3 & 3 & 3 & 3 & 2 \\
\hline $\begin{array}{c}\text { VHP } \\
\text { (veic/h) }\end{array}$ & 676 & 676 & 676 & 676 & 676 & 676 & 676 & 676 & 676 & 676 \\
\hline $\begin{array}{l}\text { Veic/h } \\
\text { (Entre } \\
\text { picos) }\end{array}$ & 278 & 278 & 278 & 278 & 278 & 278 & 278 & 278 & 278 & 278 \\
\hline $\mathrm{Va}(\mathrm{km} / \mathrm{h})$ & 58,38 & 58,38 & 58,38 & 58,38 & 58,38 & 58,38 & 58,38 & 53,491 & 58,38 & 58,38 \\
\hline $\begin{array}{c}\mathrm{Ra} \\
\text { Custo }\end{array}$ & 1,366 & 1,511 & 1,366 & 1,366 & 1,366 & 1,366 & 1,366 & 1,403 & 1,366 & 1,294 \\
\hline & $\mathrm{R} \$ 0,55$ & $\mathrm{R} \$ 0,61$ & $\mathrm{R} \$ 0,55$ & $\mathrm{R} \$ 0,55$ & $\mathrm{R} \$ 0,55$ & $\mathrm{R} \$ 0,55$ & $\mathrm{R} \$ 0,55$ & $\mathrm{R} \$ 0,57$ & $\mathrm{R} \$ 0,55$ & $\mathrm{R} \$ 0,53$ \\
\hline $\begin{array}{c}\text { operacional } \\
\text { PTSF }\end{array}$ & 74,35 & 74,35 & 74,35 & 74,35 & 74,35 & 74,35 & 74,35 & 70,32 & 74,35 & 74,35 \\
\hline $\mathrm{Va}(\mathrm{km} / \mathrm{h})$ & 61,91 & 61,91 & 65,19 & 65,19 & 61,52 & 61,52 & 60,44 & 58,88 & 60,28 & 60,28 \\
\hline $\begin{array}{c}\text { Ra } \\
\text { Custo }\end{array}$ & 1,340 & 1,485 & 1,316 & 1,316 & 1,343 & 1,343 & 1,351 & 1,363 & 1,352 & 1,280 \\
\hline operacional & $\mathrm{R} \$ 0,54$ & $\mathrm{R} \$ 0,60$ & $\mathrm{R} \$ 0,53$ & $\mathrm{R} \$ 0,53$ & $\mathrm{R} \$ 0,54$ & $\mathrm{R} \$ 0,54$ & $\mathrm{R} \$ 0,55$ & $\mathrm{R} \$ 0,55$ & $\mathrm{R} \$ 0,55$ & $\mathrm{R} \$ 0,52$ \\
\hline PTSF & 68,8 & 68,8 & 66,4 & 66,4 & 70,1 & 70,1 & 71 & 64,4 & 71,1 & 71,1 \\
\hline VDMa & 3300 & 3300 & 3300 & 3300 & 3300 & 3300 & 3300 & 3402 & 3300 & 3300 \\
\hline Lma (km) & 0,0555 & 0,0555 & 0,0795 & 0,0795 & 0,0425 & 0,0425 & 0,0335 & 0,0592 & 0,0325 & 0,0325 \\
\hline rco'a & $\mathrm{R} \$ 0,327$ & $\mathrm{R} \$ 0,327$ & $\mathrm{R} \$ 0,904$ & $\mathrm{R} \$ 0,904$ & $\mathrm{R} \$ 0,223$ & $\mathrm{R} \$ 0,223$ & $\mathrm{R} \$ 0,115$ & $\mathrm{R} \$ 0,533$ & $\mathrm{R} \$ 0,103$ & $\mathrm{R} \$ 0,103$ \\
\hline $\begin{array}{c}\text { VHPa } \\
\text { (aut/hora) }\end{array}$ & 236 & 236 & 236 & 236 & 236 & 236 & 236 & 243 & 236 & 236 \\
\hline ya & 1 & 1 & 1 & 1 & 1 & 1 & 1 & 1 & 1 & 1 \\
\hline rcoa & $\mathrm{R} \$ 1,764$ & $\mathrm{R} \$ 1,764$ & $\mathrm{R} \$ 4,874$ & $\mathrm{R} \$ 4,874$ & $\mathrm{R} \$ 1,201$ & $\mathrm{R} \$ 1,201$ & $\mathrm{R} \$ 0,621$ & $\mathrm{R} \$ 2,928$ & $\mathrm{R} \$ 0,556$ & $\mathrm{R} \$ 0,556$ \\
\hline Vo $(\mathrm{km} / \mathrm{h})$ & 54,425 & 54,425 & 54,425 & 54,425 & 54,425 & 54,425 & 54,425 & 49,261 & 54,425 & 54,425 \\
\hline $\begin{array}{l}\text { Ro } \\
\text { Custo }\end{array}$ & 1,211 & 1,349 & 1,211 & 1,211 & 1,211 & 1,211 & 1,211 & 1,236 & 1,211 & 1,142 \\
\hline & $\mathrm{R} \$ 2,46$ & $\mathrm{R} \$ 2,74$ & $\mathrm{R} \$ 2,46$ & $\mathrm{R} \$ 2,46$ & $\mathrm{R} \$ 2,46$ & $\mathrm{R} \$ 2,46$ & $\mathrm{R} \$ 2,46$ & $\mathrm{R} \$ 2,51$ & $\mathrm{R} \$ 2,46$ & $\mathrm{R} \$ 2,32$ \\
\hline $\begin{array}{c}\text { operacional } \\
\text { PTSF }\end{array}$ & 74,35 & 74,35 & 74,35 & 74,35 & 74,35 & 74,35 & 74,35 & 70,32 & 74,35 & 74,35 \\
\hline Vo $(\mathrm{km} / \mathrm{h})$ & 55,19 & 55,19 & 56,15 & 56,15 & 54,61 & 54,61 & 55,16 & 51,2 & 54,83 & 54,83 \\
\hline $\begin{array}{l}\text { Ro } \\
\text { Custo }\end{array}$ & 1,215 & 1,372 & 1,217 & 1,217 & 1,210 & 1,210 & 1,215 & 1,227 & 1,209 & 1,140 \\
\hline & $\mathrm{R} \$ 2,46$ & $\mathrm{R} \$ 2,78$ & $\mathrm{R} \$ 2,47$ & $\mathrm{R} \$ 2,47$ & $\mathrm{R} \$ 2,46$ & $\mathrm{R} \$ 2,46$ & $\mathrm{R} \$ 2,46$ & $\mathrm{R} \$ 2,49$ & $\mathrm{R} \$ 2,45$ & $\mathrm{R} \$ 2,31$ \\
\hline $\begin{array}{c}\text { operacional } \\
\text { PTSF }\end{array}$ & 68,8 & 68,8 & 66,4 & 66,4 & 70,1 & 70,1 & 71 & 64,4 & 71,1 & 71,1 \\
\hline VDMo & 77 & 77 & 77 & 77 & 77 & 77 & 77 & 74 & 77 & 77 \\
\hline $\operatorname{Lmo}(\mathrm{km})$ & 0,0555 & 0,0555 & 0,0795 & 0,0795 & 0,0425 & 0,0425 & 0,0335 & 0,0592 & 0,0325 & 0,0325 \\
\hline & $-\mathrm{R} \$ 0,24$ & $-\mathrm{R} \$ 1,46$ & $-\mathrm{R} \$ 0,55$ & $-\mathrm{R} \$ 0,55$ & $\mathrm{R} \$ 0,04$ & $\mathrm{R} \$ 0,04$ & $-\mathrm{R} \$ 0,14$ & $\mathrm{R} \$ 0,63$ & $\mathrm{R} \$ 0,07$ & $\mathrm{R} \$ 0,07$ \\
\hline $\begin{array}{c}\text { VHPo } \\
\text { (bus/hora) }\end{array}$ & 6 & 6 & 6 & 6 & 6 & 6 & 6 & 5 & 6 & 6 \\
\hline yo & 1 & 1 & 1 & 1 & 1 & 1 & 1 & 1 & 1 & 1 \\
\hline rcoo & $-\mathrm{R} \$ 0,49$ & $-\mathrm{R} \$ 3,04$ & $-\mathrm{R} \$ 1,15$ & $-\mathrm{R} \$ 1,15$ & $\mathrm{R} \$ 0,09$ & $\mathrm{R} \$ 0,09$ & $-\mathrm{R} \$ 0,29$ & $\mathrm{R} \$ 1,32$ & $\mathrm{R} \$ 0,15$ & $\mathrm{R} \$ 0,15$ \\
\hline $\operatorname{Vcv}(\mathrm{km} / \mathrm{h})$ & 54,425 & 54,425 & 54,425 & 54,425 & 54,425 & 54,425 & 54,425 & 49,261 & 54,425 & 54,425 \\
\hline $\begin{array}{l}\text { Rcv } \\
\text { Custo }\end{array}$ & 1,204 & 1,364 & 1,204 & 1,204 & 1,204 & 1,204 & 1,204 & 1,294 & 1,204 & 1,124 \\
\hline & $\mathrm{R} \$ 1,57$ & $\mathrm{R} \$ 1,78$ & $\mathrm{R} \$ 1,57$ & $\mathrm{R} \$ 1,57$ & $\mathrm{R} \$ 1,57$ & $\mathrm{R} \$ 1,57$ & $\mathrm{R} \$ 1,57$ & $\mathrm{R} \$ 1,69$ & $\mathrm{R} \$ 1,57$ & $\mathrm{R} \$ 1,47$ \\
\hline $\begin{array}{c}\text { operacional } \\
\text { PTSF }\end{array}$ & 74,35 & 74,35 & 74,35 & 74,35 & 74,35 & 74,35 & 74,35 & 70,32 & 74,35 & 74,35 \\
\hline $\operatorname{Vcv}(\mathrm{km} / \mathrm{h})$ & 55,19 & 55,19 & 56,15 & 56,15 & 54,61 & 54,61 & 55,16 & 51,2 & 54,83 & 54,83 \\
\hline $\begin{array}{l}\text { Rcv } \\
\text { Custo }\end{array}$ & 1,218 & 1,387 & 1,226 & 1,226 & 1,200 & 1,200 & 1,218 & 1,260 & 1,197 & 1,117 \\
\hline operacional & $\mathrm{R} \$ 1,59$ & $\mathrm{R} \$ 1,81$ & $\mathrm{R} \$ 1,60$ & $\mathrm{R} \$ 1,60$ & $\mathrm{R} \$ 1,57$ & $\mathrm{R} \$ 1,57$ & $\mathrm{R} \$ 1,59$ & $\mathrm{R} \$ 1,64$ & $\mathrm{R} \$ 1,56$ & $\mathrm{R} \$ 1,46$ \\
\hline PTSF & 68,8 & 68,8 & 66,4 & 66,4 & 70,1 & 70,1 & 71 & 64,4 & 71,1 & 71,1 \\
\hline VDMcr & 145 & 145 & 145 & 145 & 145 & 145 & 145 & 116 & 145 & 145 \\
\hline $\operatorname{Lmcv}(\mathrm{km})$ & 0,0555 & 0,0555 & 0,0795 & 0,0795 & 0,0425 & 0,0425 & 0,0335 & 0,0592 & 0,0325 & 0,0325 \\
\hline rco'cv & $-\mathrm{R} \$ 0,59$ & $-\mathrm{R} \$ 0,94$ & $-\mathrm{R} \$ 1,27$ & $-\mathrm{R} \$ 1,27$ & $\mathrm{R} \$ 0,10$ & $\mathrm{R} \$ 0,10$ & $-\mathrm{R} \$ 0,35$ & $\mathrm{R} \$ 1,45$ & $\mathrm{R} \$ 0,17$ & $\mathrm{R} \$ 0,17$ \\
\hline $\begin{array}{c}\text { VHPcv } \\
\text { (cam/hora) }\end{array}$ & 10 & 10 & 10 & 10 & 10 & 10 & 10 & 8 & 10 & 10 \\
\hline ycv & 0,1 & 0,1 & 0,1 & 0,1 & 0,1 & 0,1 & 0,1 & 0,1 & 0,1 & 0,1 \\
\hline rcocv & $-\mathrm{R} \$ 1,19$ & $-\mathrm{R} \$ 1,89$ & $-R \$ 2,56$ & $-\mathrm{R} \$ 2,56$ & $\mathrm{R} \$ 0,20$ & $\mathrm{R} \$ 0,20$ & $-\mathrm{R} \$ 0,71$ & $\mathrm{R} \$ 2,91$ & $\mathrm{R} \$ 0,33$ & $\mathrm{R} \$ 0,33$ \\
\hline$\sum \mathrm{rco}$ & $\mathrm{R} \$ 1,764$ & $\mathrm{R} \$ 1,764$ & $\mathrm{R} \$ 4,874$ & $\mathrm{R} \$ 4,874$ & $\mathrm{R} \$ 1,492$ & $\mathrm{R} \$ 1,492$ & $\mathrm{R} \$ 0,621$ & $\mathrm{R} \$ 7,159$ & $\mathrm{R} \$ 1,042$ & $\mathrm{R} \$ 1,042$ \\
\hline BRCO & $\mathrm{R} \$ 643,75$ & $\mathrm{R} \$ 643,75$ & $\mathrm{R} \$ 1.778,96$ & $\mathrm{R} \$ 1.778,96$ & $\mathrm{R} \$ 544,43$ & $\mathrm{R} \$ 544,43$ & $\mathrm{R} \$ 226,76$ & $\mathrm{R} \$ 2.612,96$ & $\mathrm{R} \$ 380,24$ & $\mathrm{R} \$ 380,24$ \\
\hline
\end{tabular}


Tabela A.2 - Composição dos benefícios da redução dos custos operacionais (BRCO) do 20 ano da análise

\begin{tabular}{|c|c|c|c|c|c|c|c|c|c|c|c|c|c|c|c|c|}
\hline & 15 & 13 & 2 & 15 & 13 & 3 & 15 & 13 & 5 & 15 & 2 & 3 & 15 & 2 & 5 \\
\hline \multirow{2}{*}{\multicolumn{2}{|c|}{$\begin{array}{c}\mathrm{i}(\%) \\
\mathrm{VHP} \\
(\mathrm{veic} / \mathrm{h})\end{array}$}} & 5 & 3 & 3 & 5 & 3 & 3 & 5 & 3 & 2 & 5 & 3 & 3 & 5 & 3 & 2 \\
\hline & & 710 & 710 & 710 & 710 & 710 & 710 & 710 & 710 & 710 & 710 & 710 & 710 & 710 & 710 & 710 \\
\hline \multicolumn{2}{|r|}{$\begin{array}{l}\text { Veic/h } \\
\text { (Entre } \\
\text { picos) }\end{array}$} & 292 & 292 & 292 & 292 & 292 & 292 & 292 & 292 & 292 & 292 & 292 & 292 & 292 & 292 & 292 \\
\hline \multirow{4}{*}{ 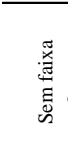 } & $\mathrm{Va}(\mathrm{km} / \mathrm{h})$ & 65,3 & $\begin{array}{l}65,3 \\
\end{array}$ & 65,3 & 65,3 & 65,3 & 52 & 65,3 & 65,3 & 65,3 & 65,3 & 65,3 & 52 & 65,3 & 65,3 & 65,3 \\
\hline & $\begin{array}{c}\mathrm{Ra} \\
\text { Custo }\end{array}$ & 1,459 & 1,315 & 1,315 & 1,459 & 1,315 & 1,414 & 1,459 & 1,315 & 1,243 & 1,459 & 1,315 & 1,414 & 1,459 & 1,315 & 1,243 \\
\hline & $\begin{array}{c}\text { operaciona } \\
1\end{array}$ & $\mathrm{R} \$ 0,59$ & $\mathrm{R} \$ 0,53$ & $\mathrm{R} \$ 0,53$ & $\mathrm{R} \$ 0,59$ & $\mathrm{R} \$ 0,53$ & $\mathrm{R} \$ 0,57$ & $\mathrm{R} \$ 0,59$ & $\mathrm{R} \$ 0,53$ & $\mathrm{R} \$ 0,50$ & $\mathrm{R} \$ 0,59$ & $\mathrm{R} \$ 0,53$ & $\mathrm{R} \$ 0,57$ & $\mathrm{R} \$ 0,59$ & $\mathrm{R} \$ 0,53$ & $\mathrm{R} \$ 0,50$ \\
\hline & PTSF & 65,16 & 65,16 & 65,16 & 65,16 & 65,16 & 73,34 & 65,16 & 65,16 & 65,16 & 65,16 & 65,16 & 73,34 & 65,16 & 65,16 & 65,16 \\
\hline \multirow{10}{*}{ 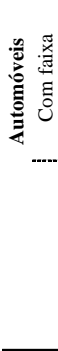 } & $\mathrm{Va}(\mathrm{km} / \mathrm{h})$ & 66,84 & 66,84 & 66,84 & 66,09 & 66,09 & 55,39 & 66,18 & 66,18 & 66,18 & 66,58 & 66,58 & 55,34 & 66,8 & 66,8 & 66,8 \\
\hline & $\begin{array}{c}\mathrm{Ra} \\
\text { Custo }\end{array}$ & 1,448 & 1,304 & 1,304 & 1,454 & 1,309 & 1,389 & 1,453 & 1,309 & 1,237 & 1,450 & 1,306 & 1,389 & 1,448 & 1,304 & 1,232 \\
\hline & $\begin{array}{c}\text { operaciona } \\
1\end{array}$ & $\mathrm{R} \$ 0,59$ & $\mathrm{R} \$ 0,53$ & $\mathrm{R} \$ 0,53$ & $\mathrm{R} \$ 0,59$ & $\mathrm{R} \$ 0,53$ & $\mathrm{R} \$ 0,56$ & $\mathrm{R} \$ 0,59$ & $\mathrm{R} \$ 0,53$ & $\mathrm{R} \$ 0,50$ & $\mathrm{R} \$ 0,59$ & $\mathrm{R} \$ 0,53$ & $\mathrm{R} \$ 0,56$ & $\mathrm{R} \$ 0,59$ & $\mathrm{R} \$ 0,53$ & $\mathrm{R} \$ 0,50$ \\
\hline & PTSF & 62,13 & 62,13 & 62,13 & 63,41 & 63,41 & 68,23 & 63,18 & 63,18 & 63,18 & 62,73 & 62,73 & 68,08 & 62,79 & 62,79 & 62,79 \\
\hline & VDMa & 3465 & 3465 & 3465 & 3465 & 3465 & 3573 & 3465 & 3465 & 3465 & 3465 & 3465 & 3573 & 3465 & 3465 & 3465 \\
\hline & Lma $(\mathrm{km})$ & 0,0303 & 0,0303 & 0,0303 & 0,0175 & 0,0175 & 0,0511 & 0,0198 & 0,0198 & 0,0198 & 0,0243 & 0,0243 & 0,0526 & 0,0237 & 0,0237 & 0,0237 \\
\hline & rco'a & $\mathrm{R} \$ 0,08$ & $\mathrm{R} \$ 0,08$ & $\mathrm{R} \$ 0,08$ & $\mathrm{R} \$ 0,02$ & $\mathrm{R} \$ 0,02$ & $\mathrm{R} \$ 0,30$ & $\mathrm{R} \$ 0,03$ & $\mathrm{R} \$ 0,03$ & $\mathrm{R} \$ 0,03$ & $\mathrm{R} \$ 0,05$ & $\mathrm{R} \$ 0,05$ & $\mathrm{R} \$ 0,31$ & $\mathrm{R} \$ 0,06$ & $\mathrm{R} \$ 0,06$ & $\mathrm{R} \$ 0,06$ \\
\hline & $\begin{array}{c}\text { VHPa } \\
\text { (aut/hora) }\end{array}$ & 248 & 248 & 248 & 248 & 248 & 255 & 248 & 248 & 248 & 248 & 248 & 255 & 248 & 248 & 248 \\
\hline & ya & 1 & 1 & 1 & 1 & 1 & 1 & 1 & 1 & 1 & 1 & 1 & 1 & 1 & 1 & 1 \\
\hline & rcoa & $\mathrm{R} \$ 0,44$ & $\mathrm{R} \$ 0,44$ & $\mathrm{R} \$ 0,44$ & $\mathrm{R} \$ 0,13$ & $\mathrm{R} \$ 0,13$ & $\mathrm{R} \$ 1,67$ & $\mathrm{R} \$ 0,16$ & $\mathrm{R} \$ 0,16$ & $\mathrm{R} \$ 0,16$ & $\mathrm{R} \$ 0,29$ & $\mathrm{R} \$ 0,29$ & $\mathrm{R} \$ 1,69$ & $\mathrm{R} \$ 0,34$ & $\mathrm{R} \$ 0,34$ & $\mathrm{R} \$ 0,34$ \\
\hline \multirow{14}{*}{ 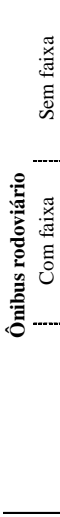 } & Vo $(\mathrm{km} / \mathrm{h})$ & 55,8 & 55,8 & 55,8 & 55,8 & 55,8 & 48,72 & 55,8 & 55,8 & 55,8 & 55,8 & 55,8 & 48,72 & 55,8 & 55,8 & 55,8 \\
\hline & $\begin{array}{c}\text { Ro } \\
\text { Custo }\end{array}$ & 1,374 & 1,216 & 1,216 & 1,374 & 1,216 & 1,239 & 1,374 & 1,216 & 1,137 & 1,374 & 1,216 & 1,239 & 1,374 & 1,216 & 1,137 \\
\hline & $\begin{array}{c}\text { operaciona } \\
1\end{array}$ & $\mathrm{R} \$ 2,79$ & $\mathrm{R} \$ 2,47$ & $\mathrm{R} \$ 2,47$ & $\mathrm{R} \$ 2,79$ & $\mathrm{R} \$ 2,47$ & $\mathrm{R} \$ 2,51$ & $\mathrm{R} \$ 2,79$ & $\mathrm{R} \$ 2,47$ & $\mathrm{R} \$ 2,31$ & $\mathrm{R} \$ 2,79$ & $\mathrm{R} \$ 2,47$ & $\mathrm{R} \$ 2,51$ & $\mathrm{R} \$ 2,79$ & $\mathrm{R} \$ 2,47$ & $\mathrm{R} \$ 2,31$ \\
\hline & PTSF & 65,16 & 65,16 & 65,16 & 65,16 & 65,16 & 73,34 & 65,16 & 65,16 & 65,16 & 65,16 & 65,16 & 73,34 & 65,16 & 65,16 & 65,16 \\
\hline & $V_{0}(\mathrm{~km} / \mathrm{h})$ & 55,34 & 55,34 & 55,34 & 55,42 & 55,42 & 49,45 & 55,44 & 55,44 & 55,44 & 55,63 & 55,63 & 55,34 & 55,7 & 55,7 & 55,7 \\
\hline & $\begin{array}{l}\text { Ro } \\
\text { Custo }\end{array}$ & 1,373 & 1,215 & 1,215 & 1,373 & 1,215 & 1,235 & 1,373 & 1,215 & 1,136 & 1,373 & 1,216 & 1,215 & 1,373 & 1,216 & 1,137 \\
\hline & $\begin{array}{c}\text { operaciona } \\
1\end{array}$ & $\mathrm{R} \$ 2,79$ & $\mathrm{R} \$ 2,47$ & $\mathrm{R} \$ 2,47$ & $\mathrm{R} \$ 2,79$ & $\mathrm{R} \$ 2,47$ & $\mathrm{R} \$ 2,51$ & $\mathrm{R} \$ 2,79$ & $\mathrm{R} \$ 2,47$ & $\mathrm{R} \$ 2,31$ & $\mathrm{R} \$ 2,79$ & $\mathrm{R} \$ 2,47$ & $\mathrm{R} \$ 2,47$ & $\mathrm{R} \$ 2,79$ & $\mathrm{R} \$ 2,47$ & $\mathrm{R} \$ 2,31$ \\
\hline & PTSF & 62,13 & 62,13 & 62,13 & 63,41 & 63,41 & 68,23 & 63,18 & 63,18 & 63,18 & 62,73 & 62,73 & 68,08 & 62,79 & 62,79 & 62,79 \\
\hline & VDMo & 81 & 81 & 81 & 81 & 81 & 78 & 81 & 81 & 81 & 81 & 81 & 78 & 81 & 81 & 81 \\
\hline & $\operatorname{Lmo}(\mathrm{km})$ & 0,0303 & 0,0303 & 0,0303 & 0,0175 & 0,0175 & 0,0511 & 0,0198 & 0,0198 & 0,0198 & 0,0243 & 0,0243 & 0,0526 & 0,0237 & 0,0237 & 0,0237 \\
\hline & rco'o & $\mathrm{R} \$ 0,04$ & $\mathrm{R} \$ 0,04$ & $\mathrm{R} \$ 0,04$ & $\mathrm{R} \$ 0,02$ & $\mathrm{R} \$ 0,02$ & $\mathrm{R} \$ 0,22$ & $\mathrm{R} \$ 0,02$ & $\mathrm{R} \$ 0,02$ & $\mathrm{R} \$ 0,02$ & $\mathrm{R} \$ 0,01$ & $\mathrm{R} \$ 0,01$ & $\mathrm{R} \$ 1,48$ & $\mathrm{R} \$ 0,01$ & $\mathrm{R} \$ 0,01$ & $\mathrm{R} \$ 0,01$ \\
\hline & $\begin{array}{c}\text { VHPo } \\
\text { (bus/hora) }\end{array}$ & 6 & 6 & 6 & 6 & 6 & 6 & 6 & 6 & 6 & 6 & 6 & 6 & 6 & 6 & 6 \\
\hline & yo & 1 & 1 & 1 & 1 & 1 & 1 & 1 & 1 & 1 & 1 & 1 & 1 & 1 & 1 & 1 \\
\hline & rcoo & $\mathrm{R} \$ 0,09$ & $\mathrm{R} \$ 0,09$ & $\mathrm{R} \$ 0,09$ & $\mathrm{R} \$ 0,04$ & $\mathrm{R} \$ 0,04$ & $\mathrm{R} \$ 0,45$ & $\mathrm{R} \$ 0,04$ & $\mathrm{R} \$ 0,04$ & $\mathrm{R} \$ 0,04$ & $\mathrm{R} \$ 0,03$ & $\mathrm{R} \$ 0,03$ & $\mathrm{R} \$ 3,08$ & $\mathrm{R} \$ 0,01$ & $\mathrm{R} \$ 0,01$ & $\mathrm{R} \$ 0,01$ \\
\hline \multirow{4}{*}{ 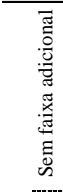 } & $\begin{array}{c}\begin{array}{c}\mathrm{Vcv} \\
(\mathrm{km} / \mathrm{h})\end{array}\end{array}$ & 55,8 & 55,8 & 55,8 & 55,8 & 55,8 & 48,72 & 55,8 & 55,8 & 55,8 & 55,8 & 55,8 & 48,72 & 55,8 & 55,8 & 55,8 \\
\hline & $\begin{array}{l}\text { Rev } \\
\text { Custo }\end{array}$ & 1,392 & 1,223 & 1,223 & 1,392 & 1,223 & 1,303 & 1,392 & 1,223 & 1,139 & 1,392 & 1,223 & 1,303 & 1,392 & 1,223 & 1,139 \\
\hline & $\begin{array}{c}\text { operaciona } \\
1\end{array}$ & $\mathrm{R} \$ 1,81$ & $\mathrm{R} \$ 1,59$ & $\mathrm{R} \$ 1,59$ & $\mathrm{R} \$ 1,81$ & $\mathrm{R} \$ 1,59$ & $\mathrm{R} \$ 1,70$ & $\mathrm{R} \$ 1,81$ & $\mathrm{R} \$ 1,59$ & $\mathrm{R} \$ 1,48$ & $\mathrm{R} \$ 1,81$ & $\mathrm{R} \$ 1,59$ & $\mathrm{R} \$ 1,70$ & $\mathrm{R} \$ 1,81$ & $\mathrm{R} \$ 1,59$ & $\mathrm{R} \$ 1,48$ \\
\hline & PTSF & 65,16 & 65,16 & 65,16 & 65,16 & 65,16 & $.73,34$ & 65,16 & 65,16 & 65,16 & 65,16 & 65,16 & 73,34 & 65,16 & 65,16 & 65,16 \\
\hline \multirow{12}{*}{ 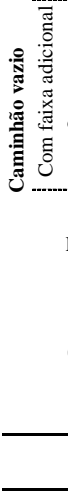 } & $\begin{array}{l}\mathrm{Vcv} \\
(\mathrm{km} / \mathrm{h})\end{array}$ & 55,34 & 55,34 & 55,34 & 55,42 & 55,42 & 49,45 & 55,44 & 55,44 & 55,44 & 55,63 & 55,63 & 55,34 & 55,7 & 55,7 & 55,7 \\
\hline & $\begin{array}{c}\text { Rcv } \\
\text { Custo }\end{array}$ & 1,388 & 1,220 & 1,220 & 1,389 & 1,220 & 1,290 & 1,389 & 1,220 & 1,136 & 1,391 & 1,222 & 1,220 & 1,391 & 1,222 & 1,138 \\
\hline & $\begin{array}{c}\text { operaciona } \\
1\end{array}$ & $\mathrm{R} \$ 1,81$ & $\mathrm{R} \$ 1,59$ & $\mathrm{R} \$ 1,59$ & $\mathrm{R} \$ 1,81$ & $\mathrm{R} \$ 1,59$ & $\mathrm{R} \$ 1,68$ & $\mathrm{R} \$ 1,81$ & $\mathrm{R} \$ 1,59$ & $\mathrm{R} \$ 1,48$ & $\mathrm{R} \$ 1,81$ & $\mathrm{R} \$ 1,59$ & $\mathrm{R} \$ 1,59$ & $\mathrm{R} \$ 1,81$ & $\mathrm{R} \$ 1,59$ & $\mathrm{R} \$ 1,48$ \\
\hline & PTSF & 62,13 & 62,13 & 62,13 & 63,41 & 63,41 & 68,23 & 63,18 & 63,18 & 63,18 & 62,73 & 62,73 & 68,08 & 62,79 & 62,79 & 62,79 \\
\hline & VDMcv & 152 & 152 & 152 & 152 & 152 & 122 & 152 & 152 & 152 & 152 & 152 & 122 & 152 & 152 & 152 \\
\hline & $\operatorname{Lmcv}(\mathrm{km})$ & 0,0303 & 0,0303 & 0,0303 & 0,0175 & 0,0175 & 0,0511 & 0,0198 & 0,0198 & 0,0198 & 0,0243 & 0,0243 & 0,0526 & 0,0237 & 0,0237 & 0,0237 \\
\hline & reo'cv & $\mathrm{R} \$ 0,08$ & $\mathrm{R} \$ 0,08$ & $\mathrm{R} \$ 0,08$ & $\mathrm{R} \$ 0,04$ & $\mathrm{R} \$ 0,04$ & $\mathrm{R} \$ 0,49$ & $\mathrm{R} \$ 0,04$ & $\mathrm{R} \$ 0,04$ & $\mathrm{R} \$ 0,04$ & $\mathrm{R} \$ 0,02$ & $\mathrm{R} \$ 0,02$ & $\mathrm{R} \$ 3,34$ & $\mathrm{R} \$ 0,01$ & $\mathrm{R} \$ 0,01$ & $\mathrm{R} \$ 0,01$ \\
\hline & $\begin{array}{c}\text { VHPcv } \\
\text { (cam/hora) }\end{array}$ & 11 & 11 & 11 & 11 & 11 & 9 & 11 & 11 & 11 & 11 & 11 & 9 & 11 & 11 & 11 \\
\hline & ycv & 0,1 & 0,1 & 0,1 & 0,1 & 0,1 & 0,1 & 0,1 & 0,1 & 0,1 & 0,1 & 0,1 & 0,1 & 0,1 & 0,1 & 0,1 \\
\hline & rcocv & $\mathrm{R} \$ 0,16$ & $\mathrm{R} \$ 0,16$ & $\mathrm{R} \$ 0,16$ & $\mathrm{R} \$ 0,08$ & $\mathrm{R} \$ 0,08$ & $\mathrm{R} \$ 0,99$ & $\mathrm{R} \$ 0,08$ & $\mathrm{R} \$ 0,08$ & $\mathrm{R} \$ 0,08$ & $\mathrm{R} \$ 0,05$ & $\mathrm{R} \$ 0,05$ & $\mathrm{R} \$ 6,72$ & $\mathrm{R} \$ 0,03$ & $\mathrm{R} \$ 0,03$ & $\mathrm{R} \$ 0,03$ \\
\hline & $\sum \mathrm{rco}$ & $\mathrm{R} \$ 0,69$ & $\mathrm{R} \$ 0,69$ & $\mathrm{R} \$ 0,69$ & $\mathrm{R} \$ 0,25$ & $\mathrm{R} \$ 0,25$ & $\mathrm{R} \$ 3,11$ & $\mathrm{R} \$ 0,29$ & $\mathrm{R} \$ 0,29$ & $\mathrm{R} \$ 0,29$ & $\mathrm{R} \$ 0,37$ & $\mathrm{R} \$ 0,37$ & $\mathrm{R} \$ 11,50$ & $\mathrm{R} \$ 0,38$ & $\mathrm{R} \$ 0,38$ & $\mathrm{R} \$ 0,38$ \\
\hline & BRCO & $\mathrm{R} \$ 251,94$ & $\mathrm{R} \$ 251,94$ & $\mathrm{R} \$ 251,94$ & $\mathrm{R} \$ 91,08$ & $\mathrm{R} \$ 91,08$ & $\mathrm{R} \$ 1.136,61$ & $\mathrm{R} \$ 106,62$ & $\mathrm{R} \$ 106,62$ & $\mathrm{R} \$ 106,62$ & $\mathrm{R} \$ 134,29$ & $\mathrm{R} \$ 134,29$ & $\mathrm{R} \$ 4.196,41$ & $\mathrm{R} \$ 138,15$ & $\mathrm{R} \$ 138,15$ & $\mathrm{R} \$ 138,15$ \\
\hline
\end{tabular}

Continua 
Continuação Tabela A.2

\begin{tabular}{|c|c|c|c|c|c|c|c|c|c|c|c|c|c|c|c|}
\hline \multirow{4}{*}{$\begin{array}{c}\text { Aclive } \\
\mathrm{i}(\%) \\
\mathrm{VHP} \\
\text { (veich) } \\
\text { Veic/h } \\
\text { (Entre } \\
\text { picos) } \\
\end{array}$} & 15 & 3 & 5 & 13 & 2 & 3 & 13 & 2 & 5 & 13 & 3 & 5 & 2 & 3 & 5 \\
\hline & 5 & 3 & 2 & 3 & 3 & 3 & 3 & 3 & 2 & 3 & 3 & 2 & 3 & 3 & 2 \\
\hline & 710 & 710 & 710 & 710 & 710 & 710 & 710 & 710 & 710 & 710 & 710 & 710 & 710 & 710 & 710 \\
\hline & 292 & 292 & 292 & 292 & 292 & 292 & 292 & 292 & 292 & 292 & 292 & 292 & 292 & 292 & 292 \\
\hline$\overline{\widetilde{J}} \tilde{0} \mathrm{Va}(\mathrm{km} / \mathrm{h})$ & 65,3 & 52 & 65,3 & 65,3 & 65,3 & 52 & 65,3 & 65,3 & 65,3 & 65,3 & 52 & 65,3 & 65,3 & 52 & 65,3 \\
\hline $\begin{array}{ll}0 \\
0\end{array}$ & 1,459 & 1,414 & 1,243 & 1,315 & 1,315 & 1,414 & 1,315 & 1,315 & 1,243 & 1,315 & 1,414 & 1,243 & 1,315 & 1,414 & 1,243 \\
\hline 递 operaciona & $\mathrm{R} \$ 0,59$ & $\mathrm{R} \$ 0,57$ & $\mathrm{R} \$ 0,50$ & $\mathrm{R} \$ 0,53$ & $\mathrm{R} \$ 0,53$ & $\mathrm{R} \$ 0,57$ & $\mathrm{R} \$ 0,53$ & $\mathrm{R} \$ 0,53$ & $\mathrm{R} \$ 0,50$ & $\mathrm{R} \$ 0,53$ & $\mathrm{R} \$ 0,57$ & $\mathrm{R} \$ 0,50$ & $\mathrm{R} \$ 0,53$ & $\mathrm{R} \$ 0,57$ & $\mathrm{R} \$ 0,50$ \\
\hline $\begin{array}{cc}1 \\
\stackrel{D}{0}\end{array}$ & 65,16 & 73,34 & 65,16 & 65,16 & 65,16 & 73,34 & 65,16 & 65,16 & 65,16 & 65,16 & 73,34 & 65,16 & 65,16 & 73,34 & 65,16 \\
\hline 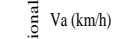 & 65,73 & 55,16 & 65,73 & 67,4 & 67,4 & 55,8 & 67,39 & 67,39 & 67,39 & 66,25 & 55,31 & 66,25 & 66,48 & 55,3 & 66,48 \\
\hline $\begin{array}{cc}\mathrm{Ra} \\
\mathrm{n}\end{array}$ & 1,456 & 1,390 & 1,240 & 1,300 & 1,300 & 1,386 & 1,300 & 1,300 & 1,228 & 1,308 & 1,389 & 1,236 & 1,307 & 1,389 & 1,234 \\
\hline operaciona & $\mathrm{R} \$ 0,59$ & $\mathrm{R} \$ 0,56$ & $\mathrm{R} \$ 0,50$ & $\mathrm{R} \$ 0,53$ & $\mathrm{R} \$ 0,53$ & $\mathrm{R} \$ 0,56$ & $\mathrm{R} \$ 0,53$ & $\mathrm{R} \$ 0,53$ & $\mathrm{R} \$ 0,50$ & $\mathrm{R} \$ 0,53$ & $\mathrm{R} \$ 0,56$ & $\mathrm{R} \$ 0,50$ & $\mathrm{R} \$ 0,53$ & $\mathrm{R} \$ 0,56$ & $\operatorname{R} \$ 0,50$ \\
\hline $\begin{array}{cc}\Xi \overline{0} & 1 \\
\text { PTSF }\end{array}$ & 63,94 & 68,1 & 63,94 & 61,96 & 61,96 & 68,17 & 61,65 & 61,65 & 61,65 & 63,27 & 68,08 & 63,27 & 62,97 & 68,08 & 62,97 \\
\hline VDMa & 3465 & 3573 & 3465 & 3465 & 3465 & 3573 & 3465 & 3465 & 3465 & 3465 & 3573 & 3465 & 3465 & 3573 & 3465 \\
\hline $\operatorname{Lma}(\mathrm{km})$ & 0,0122 & 0,0524 & 0,0122 & 0,032 & 0,032 & 0,0517 & 0,0351 & 0,0351 & 0,0351 & 0,0189 & 0,0526 & 0,0189 & 0,0219 & 0,0526 & 0,0219 \\
\hline rco'a & RS 0,01 & $\mathrm{R} \$ 0,29$ & $\mathrm{R} \$ 0,01$ & $\mathrm{R} \$ 0,12$ & $\mathrm{R} \$ 0,12$ & $\mathrm{R} \$ 0,34$ & $\mathrm{R} \$ 0,13$ & $\mathrm{R} \$ 0,13$ & $\mathrm{R} \$ 0,13$ & $\mathrm{R} \$ 0,03$ & $\mathrm{R} \$ 0,31$ & $\mathrm{R} \$ 0,03$ & $\mathrm{R} \$ 0,05$ & $\mathrm{R} \$ 0,30$ & RS 0,05 \\
\hline $\begin{array}{c}\text { VHPa } \\
\text { (authora) }\end{array}$ & 248 & 255 & 248 & 248 & 248 & 255 & 248 & 248 & 248 & 248 & 255 & 248 & 248 & 255 & 248 \\
\hline ya & 1 & 1 & 1 & 1 & 1 & 1 & 1 & 1 & 1 & 1 & 1 & 1 & 1 & 1 & 1 \\
\hline rcoa & $\mathrm{R} \$ 0,05$ & $\mathrm{R} \$ 1,60$ & $\mathrm{R} \$ 0,05$ & $\mathrm{R} \$ 0,64$ & $\mathrm{R} \$ 0,64$ & $\mathrm{R} \$ 1,89$ & $\mathrm{R} \$ 0,69$ & $\mathrm{R} \$ 0,69$ & $\mathrm{R} \$ 0,69$ & $\mathrm{R} \$ 0,17$ & $\mathrm{R} \$ 1,68$ & $\mathrm{R} \$ 0,17$ & $\mathrm{R} \$ 0,24$ & $\mathrm{R} \$ 1,67$ & $\operatorname{R} \$ 0,24$ \\
\hline$\underset{\mathrm{g}}{\bar{g}} \mathrm{O} \mathrm{V} 0(\mathrm{~km} / \mathrm{h})$ & 55,8 & 48,72 & 55,8 & 55,8 & 55,8 & 48,72 & 55,8 & 55,8 & 55,8 & 55,8 & 48,72 & 55,8 & 55,8 & 48,72 & 55,8 \\
\hline $\begin{array}{ll}0 \\
\frac{5}{5}\end{array}$ & 1,374 & 1,239 & 1,137 & 1,216 & 1,216 & 1,239 & 1,216 & 1,216 & 1,137 & 1,216 & 1,239 & 1,137 & 1,216 & 1,239 & 1,137 \\
\hline$\underset{\Xi}{\stackrel{x}{E}}$ operaciona & $\mathrm{R} \$ 2,79$ & $\mathrm{R} \$ 2,51$ & $\mathrm{R} \$ 2,31$ & $\mathrm{R} \$ 2,47$ & $\mathrm{R} \$ 2,47$ & $\mathrm{R} \$ 2,51$ & $\mathrm{R} \$ 2,47$ & $\mathrm{R} \$ 2,47$ & $\mathrm{R} \$ 2,31$ & $\mathrm{R} \$ 2,47$ & $\mathrm{R} \$ 2,51$ & $\mathrm{R} \$ 2,31$ & $\mathrm{R} \$ 2,47$ & $\mathrm{R} \$ 2,51$ & $\mathrm{R} \$ 2,31$ \\
\hline$\stackrel{1}{D}$ PTSF & 65,16 & 73,34 & 65,16 & 65,16 & 65,16 & 73,34 & 65,16 & 65,16 & 65,16 & 65,16 & 73,34 & 65,16 & 65,16 & 73,34 & 65,16 \\
\hline$\overline{\widetilde{J}} \mathrm{~g} \mathrm{~V}_{0}(\mathrm{~km} / \mathrm{h})$ & 55,75 & 49,38 & 55,75 & 55,8 & 55,8 & 49,38 & 55,66 & 55,66 & 55,66 & 55,62 & 49,43 & 55,62 & 55,79 & 49,35 & 55,79 \\
\hline 罚 Ro & 1,374 & 1,236 & 1,137 & 1,216 & 1,216 & 1,236 & 1,216 & 1,216 & 1,137 & 1,216 & 1,235 & 1,137 & 1,216 & 1,236 & 1,137 \\
\hline 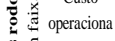 & $\mathrm{R} \$ 2,79$ & $\mathrm{R} \$ 2,51$ & $\mathrm{R} \$ 2,31$ & $\mathrm{R} \$ 2,47$ & $\mathrm{R} \$ 2,47$ & $\mathrm{R} \$ 2,51$ & $\mathrm{R} \$ 2,47$ & $\mathrm{R} \$ 2,47$ & $\mathrm{R} \$ 2,31$ & $\mathrm{R} \$ 2,47$ & $\mathrm{R} \$ 2,51$ & $\mathrm{R} \$ 2,31$ & $\mathrm{R} \$ 2,47$ & $\mathrm{R} \$ 2,51$ & $\mathrm{R} \$ 2,31$ \\
\hline 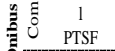 & 63,94 & 68,1 & 63,94 & 61,96 & 61,96 & 68,17 & 61,55 & 61,55 & 61,55 & 63,27 & 68,08 & 63,27 & 62,97 & 68,08 & 62,97 \\
\hline VDMo & 81 & 78 & 81 & 81 & 81 & 78 & 81 & 81 & 81 & 81 & 78 & 81 & 81 & 78 & 81 \\
\hline $\operatorname{Lmo}(\mathrm{km})$ & 0,0122 & 0,0524 & 0,0122 & 0,032 & 0,032 & 0,0517 & 0,0361 & 0,0361 & 0,0361 & 0,0189 & 0,0526 & 0,0189 & 0,0219 & 0,0526 & 0,0219 \\
\hline rco'o & $\mathrm{R} \$ 0,00$ & $\mathrm{R} \$ 0,20$ & $\mathrm{R} \$ 0,00$ & $\mathrm{R} \$ 0,00$ & $\mathrm{R} \$ 0,00$ & $\mathrm{R} \$ 0,20$ & $\mathrm{R} \$ 0,01$ & $\mathrm{R} \$ 0,01$ & $\mathrm{R} \$ 0,01$ & $\mathrm{R} \$ 0,01$ & $\mathrm{R} \$ 0,22$ & $\mathrm{R} \$ 0,01$ & $\mathrm{R} \$ 0,00$ & $\mathrm{R} \$ 0,19$ & $\operatorname{R} \$ 0,00$ \\
\hline $\begin{array}{c}\text { VHPo } \\
\text { (bus/hora) }\end{array}$ & 6 & 6 & 6 & 6 & 6 & 6 & 6 & 6 & 6 & 6 & 6 & 6 & 6 & 6 & 6 \\
\hline yo & 1 & 1 & 1 & 1 & 1 & 1 & 1 & 1 & 1 & 1 & 1 & 1 & 1 & 1 & 1 \\
\hline rcoo & $\mathrm{R} \$ 0,00$ & $\mathrm{R} \$ 0,42$ & $\mathrm{R} \$ 0,00$ & $\mathrm{R} \$ 0,00$ & $\mathrm{R} \$ 0,00$ & $\mathrm{R} \$ 0,41$ & $\mathrm{R} \$ 0,03$ & $\mathrm{R} \$ 0,03$ & $\mathrm{R} \$ 0,03$ & $\mathrm{R} \$ 0,02$ & $\mathrm{R} \$ 0,45$ & $\mathrm{R} \$ 0,02$ & $\mathrm{R} \$ 0,00$ & $\mathrm{R} \$ 0,40$ & RS 0,00 \\
\hline 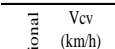 & 55,8 & 48,72 & 55,8 & 55,8 & 55,8 & 48,72 & 55,8 & 55,8 & 55,8 & 55,8 & 48,72 & 55,8 & 55,8 & 48,72 & 55,8 \\
\hline 总 $\mathrm{Rev}$ & 1,392 & 1,303 & 1,139 & 1,223 & 1,223 & 1,303 & 1,223 & 1,223 & 1,139 & 1,223 & 1,303 & 1,139 & 1,223 & 1,303 & 1,139 \\
\hline 造 operaciona & $\mathrm{R} \$ 1,81$ & $\mathrm{R} \$ 1,70$ & $\mathrm{R} \$ 1,48$ & $\mathrm{R} \$ 1,59$ & $\mathrm{R} \$ 1,59$ & $\mathrm{R} \$ 1,70$ & $\mathrm{R} \$ 1,59$ & $\mathrm{R} \$ 1,59$ & $\mathrm{R} \$ 1,48$ & $\mathrm{R} \$ 1,59$ & $\mathrm{R} \$ 1,70$ & $\mathrm{R} \$ 1,48$ & $\mathrm{R} \$ 1,59$ & $\mathrm{R} \$ 1,70$ & $\operatorname{R} \$ 1,48$ \\
\hline $\begin{array}{cc}\begin{array}{c}5 \\
0 \\
n\end{array} & 1 \\
\text { PTSF }\end{array}$ & 65,16 & 73,34 & 65,16 & 65,16 & 65,16 & 73,34 & 65,16 & 65,16 & 65,16 & 65,16 & 73,34 & 65,16 & 65,16 & 73,34 & 65,16 \\
\hline 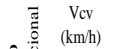 & 55,75 & 49,38 & 55,75 & 55,8 & 55,8 & 49,38 & 55,66 & 55,66 & 55,66 & 55,62 & 49,43 & 55,62 & 55,79 & 49,35 & 55,79 \\
\hline : & 1,392 & 1,291 & 1,138 & 1,223 & 1,223 & 1,291 & 1,222 & 1,222 & 1,138 & 1,222 & 1,291 & 1,137 & 1,223 & 1,292 & 1,139 \\
\hline 莡 operaciona & $\mathrm{R} \$ 1,81$ & $\mathrm{R} \$ 1,68$ & $\mathrm{R} \$ 1,48$ & $\mathrm{R} \$ 1,59$ & $\mathrm{R} \$ 1,59$ & $\mathrm{R} \$ 1,68$ & $\mathrm{R} \$ 1,59$ & $\mathrm{R} \$ 1,59$ & $\mathrm{R} \$ 1,48$ & $\mathrm{R} \$ 1,59$ & $\mathrm{R} \$ 1,68$ & $\mathrm{R} \$ 1,48$ & $\mathrm{R} \$ 1,59$ & $\mathrm{R} \$ 1,68$ & $\operatorname{R} \$ 1,48$ \\
\hline $\begin{array}{ll}E & 1\end{array}$ & & & & & & & & & & & & & & & \\
\hline U. PTSF & 63,94 & 68,1 & 63,94 & 61,96 & 61,96 & 68,17 & 61,55 & 61,55 & 61,55 & 63,27 & 68,08 & 63,27 & 62,97 & 68,08 & 62,97 \\
\hline VDMcv & 152 & 122 & 152 & 152 & 152 & 122 & 152 & 152 & 152 & 152 & 122 & 152 & 152 & 122 & 152 \\
\hline \multirow{2}{*}{$\begin{array}{c}\operatorname{Lmcv}(\mathrm{km}) \\
\text { rco'cv }\end{array}$} & 0,0122 & 0,0524 & 0,0122 & 0,032 & 0,032 & 0,0517 & 0,0361 & 0,0361 & 0,0361 & 0,0189 & 0,0526 & 0,0189 & 0,0219 & 0,0526 & 0,0219 \\
\hline & $\mathrm{R} \$ 0,00$ & $\mathrm{R} \$ 0,46$ & $\mathrm{R} \$ 0,00$ & $\mathrm{R} \$ 0,00$ & $\mathrm{R} \$ 0,00$ & $\mathrm{R} \$ 0,45$ & $\mathrm{R} \$ 0,03$ & $\mathrm{R} \$ 0,03$ & $\mathrm{R} \$ 0,03$ & $\mathrm{R} \$ 0,02$ & $\mathrm{R} \$ 0,49$ & $\mathrm{R} \$ 0,02$ & $\mathrm{R} \$ 0,00$ & $\mathrm{R} \$ 0,44$ & $\operatorname{R} \$ 0,00$ \\
\hline $\begin{array}{c}\text { VHPcv } \\
\text { (cam/hora) }\end{array}$ & 11 & 9 & 11 & 11 & 11 & 9 & 11 & 11 & 11 & 11 & 9 & 11 & 11 & 9 & 11 \\
\hline ycv & 0,1 & 0,1 & 0,1 & 0,1 & 0,1 & 0,1 & 0,1 & 0,1 & 0,1 & 0,1 & 0,1 & 0,1 & 0,1 & 0,1 & 0,1 \\
\hline reocv & RS 0,01 & $\mathrm{R} \$ 0,92$ & $\mathrm{R} \$ 0,01$ & $\mathrm{R} \$ 0,00$ & $\mathrm{R} \$ 0,00$ & $\mathrm{R} \$ 0,91$ & $\mathrm{R} \$ 0,06$ & $\mathrm{R} \$ 0,06$ & $\mathrm{R} \$ 0,06$ & $\mathrm{R} \$ 0,04$ & $\mathrm{R} \$ 1,00$ & $\mathrm{R} \$ 0,04$ & $\mathrm{R} \$ 0,00$ & $\mathrm{R} \$ 0,88$ & $\operatorname{R} \$ 0,00$ \\
\hline$\sum$ reo & $\mathrm{R} \$ 0,06$ & $\mathrm{R} \$ 2,94$ & $\mathrm{R} \$ 0,06$ & $\mathrm{R} \$ 0,64$ & $\mathrm{R} \$ 0,64$ & $\mathrm{R} \$ 3,21$ & $\mathrm{R} \$ 0,78$ & $\mathrm{R} \$ 0,78$ & $\mathrm{R} \$ 0,78$ & $\mathrm{R} \$ 0,23$ & $\mathrm{R} \$ 3,12$ & $\mathrm{R} \$ 0,23$ & $\mathrm{R} \$ 0,25$ & $\mathrm{R} \$ 2,96$ & $\operatorname{RS} 0,25$ \\
\hline BRCO & $\mathrm{R} \$ 22,08$ & $\mathrm{R} \$ 1.071,30$ & $\mathrm{R} S 22,08$ & $\mathrm{R} \$ 231,92$ & $\mathrm{R} \$ 231,92$ & $\mathrm{R} \$ 1.173,41$ & $\mathrm{R} \$ 286,14$ & $\mathrm{R} \$ 286,14$ & $\mathrm{R} \$ 286,14$ & $\mathrm{R} \$ 84,15$ & $\mathrm{R} \$ 1.140,31$ & $\mathrm{R} \$ 84,15$ & $\mathrm{R} \$ 90,61$ & $\mathrm{R} \$ 1.079,00$ & $\mathrm{R} \$ 90,61$ \\
\hline
\end{tabular}



Tabela A.3 - Composição dos benefícios da redução dos custos operacionais (BRCO) do $3^{\circ}$ ano da análise

\begin{tabular}{|c|c|c|c|c|c|}
\hline & & Aclive & 5 & 11 & 13 \\
\hline & & $\mathrm{i}(\%)$ & 2 & 2 & 3 \\
\hline & & $\begin{array}{c}\text { VHP } \\
\text { (veic/h) }\end{array}$ & 745 & 745 & 745 \\
\hline & & $\begin{array}{c}\text { Veic/h (Entre } \\
\text { picos) }\end{array}$ & 307 & 307 & 307 \\
\hline \multirow{14}{*}{ 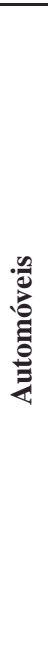 } & & $\mathrm{Va}(\mathrm{km} / \mathrm{h})$ & 65,7 & 55,37 & 65,7 \\
\hline & $\stackrel{\widetilde{ׁ}}{\exists}$ & $\mathrm{Ra}$ & 1,24022 & 1,316662 & 1,31232 \\
\hline & 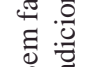 & Custo & $\mathrm{R} \$ 0,503$ & $\mathrm{R} \$ 0,534$ & $\mathrm{R} \$ 0,532$ \\
\hline & ڤ & $\begin{array}{c}\text { operacional } \\
\text { PTSF }\end{array}$ & 64,56 & 69,83 & 64,56 \\
\hline & & $\mathrm{Va}(\mathrm{km} / \mathrm{h})$ & 66,4 & 58,14 & 66,93 \\
\hline & 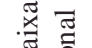 & $\mathrm{Ra}$ & 1,23504 & 1,296164 & 1,303218 \\
\hline & 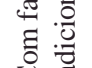 & Custo & 0,501 & 0,526 & 0,529 \\
\hline & U & PTSF & 64,04 & 64,03 & 62,88 \\
\hline & & VDMa & 3638 & 3496 & 3638 \\
\hline & & Lma (km) & 0,0052 & 0,058 & 0,0168 \\
\hline & & rco'a & $\mathrm{R} \$ 0,007$ & $\mathrm{R} \$ 0,296$ & $\mathrm{R} \$ 0,038$ \\
\hline & & $\begin{array}{c}\text { VHPa } \\
\text { (aut/hora) }\end{array}$ & 260 & 268 & 260 \\
\hline & & ya & 1 & 1 & 1 \\
\hline & & rcoa & $\mathrm{R} \$ 0,036$ & $\mathrm{R} \$ 1,626$ & $\mathrm{R} \$ 0,205$ \\
\hline \multirow{14}{*}{ 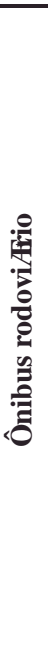 } & & Vo $(\mathrm{km} / \mathrm{h})$ & 55,05 & 49,43 & 55,05 \\
\hline & $\ddot{\varpi} \widetilde{\Xi}$ & Ro & 1,135 & 1,166 & 1,214 \\
\hline & 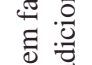 & Custo & $\mathrm{R} \$ 2,304$ & $\mathrm{R} \$ 2,367$ & $\mathrm{R} \$ 2,464$ \\
\hline & $\approx \approx$ & $\begin{array}{c}\text { operacional } \\
\text { PTSF }\end{array}$ & 64,56 & 69,83 & 64,56 \\
\hline & & Vo $(\mathrm{km} / \mathrm{h})$ & 55,17 & 50,28 & 55,02 \\
\hline & 永 & Ro & 1,136 & 1,162 & 1,214 \\
\hline & 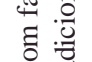 & Custo & $\mathrm{R} \$ 2,305$ & $\mathrm{R} \$ 2,358$ & $\mathrm{R} \$ 2,464$ \\
\hline & $\tilde{\Xi}$ & $\begin{array}{c}\text { operacional } \\
\text { PTSF }\end{array}$ & 64,04 & 64,03 & 62,88 \\
\hline & & VDMo & 85 & 82 & 85 \\
\hline & & Lmo (km) & 0,0052 & 0,058 & 0,0168 \\
\hline & & rco’o & $-\mathrm{R} \$ 0,002$ & $\mathrm{R} \$ 0,301$ & $\mathrm{R} \$ 0,002$ \\
\hline & & $\begin{array}{c}\text { VHPo } \\
\text { (bus/hora) }\end{array}$ & 6 & 6 & 6 \\
\hline & & yo & 1 & 1 & 1 \\
\hline & & rcoo & $-\mathrm{R} \$ 0,004$ & $\mathrm{R} \$ 0,625$ & $\mathrm{R} \$ 0,003$ \\
\hline \multirow{16}{*}{ 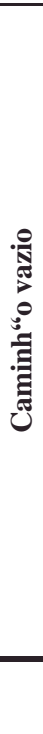 } & & $\mathrm{Vcv}(\mathrm{km} / \mathrm{h})$ & 55,05 & 49,43 & 55,05 \\
\hline & $\ddot{\widetilde{\varpi}}$ & $\mathrm{Rcv}$ & 1,133 & 1,211 & 1,217 \\
\hline & 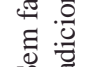 & Custo & $\mathrm{R} \$ 1,477$ & $\mathrm{R} \$ 1,578$ & $\mathrm{R} \$ 1,587$ \\
\hline & ڤ & $\begin{array}{c}\text { operacional } \\
\text { PTSF }\end{array}$ & 64,56 & 69,83 & 64,56 \\
\hline & & $\mathrm{Vcv}(\mathrm{km} / \mathrm{h})$ & 55,17 & 50,28 & 55,02 \\
\hline & $\mathscr{\dddot { \varkappa }}$ & $\mathrm{RcV}$ & 1,134 & 1,196 & 1,217 \\
\hline & 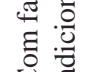 & Custo & $\mathrm{R} \$ 1,478$ & $\mathrm{R} \$ 1,559$ & $\mathrm{R} \$ 1,587$ \\
\hline & $U^{\approx}$ & $\begin{array}{l}\text { operacional } \\
\text { PTSF }\end{array}$ & 64,04 & 64,03 & 62,88 \\
\hline & & VDMcV & 160 & 128 & 160 \\
\hline & & Lmcv (km) & 0,0052 & 0,058 & 0,0168 \\
\hline & & rco'cv & $-\mathrm{R} \$ 0,004$ & $\mathrm{R} \$ 0,687$ & $\mathrm{R} \$ 0,003$ \\
\hline & & $\begin{array}{c}\text { VHPcv } \\
\text { (cam/hora) }\end{array}$ & 11 & 11 & 11 \\
\hline & & ycv & 0,1 & 0,1 & 0,1 \\
\hline & & reocv & $-0,008$ & 1,383 & 0,006 \\
\hline & & rco & $\mathrm{R} \$ 0,036$ & $\mathrm{R} \$ 3,634$ & $\mathrm{R} \$ 0,215$ \\
\hline & & $\mathrm{BRCO}$ & $\mathrm{R} \$ 13,19$ & $\mathrm{R} \$ 1.326,56$ & $\mathrm{R} \$ 78,34$ \\
\hline
\end{tabular}


Tabela A.4 - Composição dos benefícios da redução dos custos operacionais (BRCO) do $4^{0}$ ano da análise

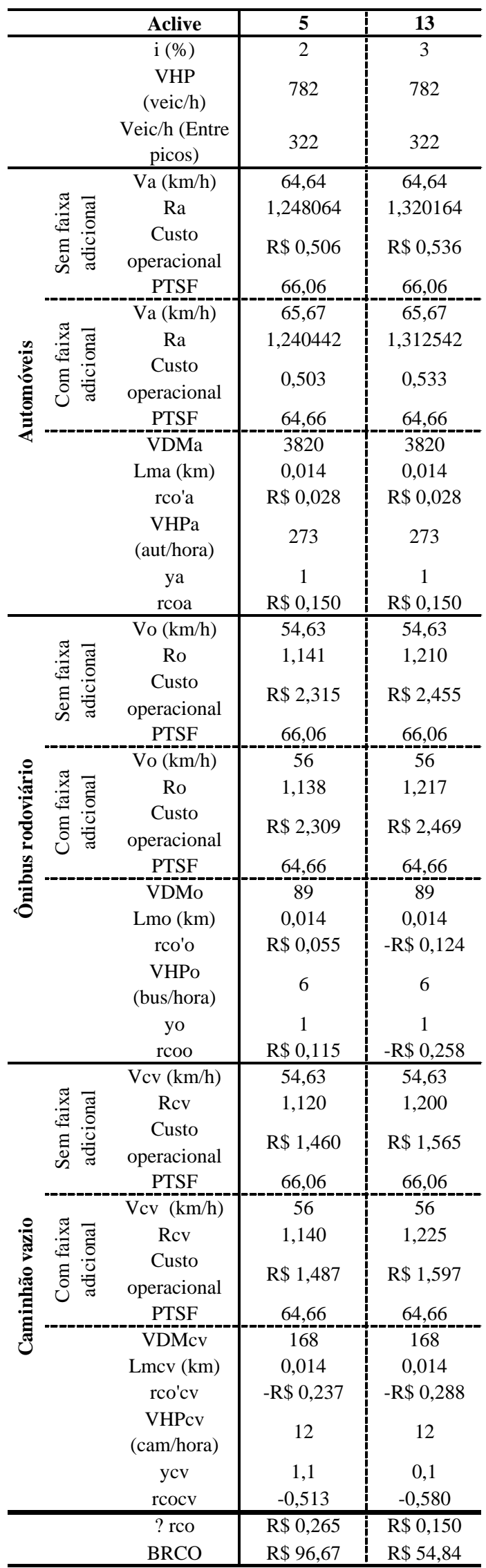


Tabela A.5 - Composição dos benefícios da redução dos custos operacionais (BRCO) do 60 ano da análise

\begin{tabular}{|c|c|c|c|}
\hline & & Aclive & 13 \\
\hline & & $\mathrm{i}(\%)$ & 3 \\
\hline & & $\begin{array}{c}\text { VHP } \\
\text { (veic/h) }\end{array}$ & 862 \\
\hline & & $\begin{array}{c}\text { Veic/h (Entre } \\
\text { picos) }\end{array}$ & 355 \\
\hline \multirow{14}{*}{ 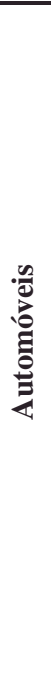 } & & $\mathrm{Va}(\mathrm{km} / \mathrm{h})$ & 63,6 \\
\hline & 焉 & $\mathrm{Ra}$ & 1,32786 \\
\hline & $\stackrel{\pi}{\tilde{0}}$ & Custo & $\mathrm{R} \$ 0,539$ \\
\hline & & PTSF & 68,81 \\
\hline & & $\mathrm{Va}(\mathrm{km} / \mathrm{h})$ & 65,39 \\
\hline & . & $\mathrm{Ra}$ & 1,314614 \\
\hline & $\stackrel{\widetilde{\Xi}}{\stackrel{\tilde{\Xi}}{0}}$ & Custo & 0,533 \\
\hline & $U \approx$ & PTSF & 67,6 \\
\hline & & VDMa & 4212 \\
\hline & & $\operatorname{Lma}(\mathrm{km})$ & 0,0121 \\
\hline & & rco'a & $\mathrm{R} \$ 0,046$ \\
\hline & & $\begin{array}{c}\text { VHPa } \\
\text { (aut/hora) }\end{array}$ & 301 \\
\hline & & ya & 1 \\
\hline & & rcoa & $\mathrm{R} \$ 0,249$ \\
\hline \multirow{14}{*}{ 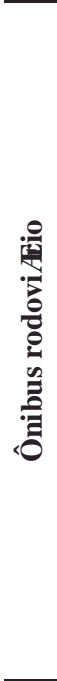 } & & Vo $(\mathrm{km} / \mathrm{h})$ & 54,21 \\
\hline & $\stackrel{\widetilde{\mathscr{Z}}}{\exists}$ & Ro & 1,212 \\
\hline & 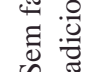 & $\begin{array}{c}\text { Custo } \\
\text { operacional }\end{array}$ & $\mathrm{R} \$ 2,459$ \\
\hline & & PTSF & 68,81 \\
\hline & & $\mathrm{Vo}(\mathrm{km} / \mathrm{h})$ & 54,38 \\
\hline & 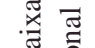 & Ro & 1,211 \\
\hline & 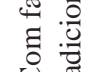 & $\begin{array}{c}\text { Custo } \\
\text { operacional }\end{array}$ & $\mathrm{R} \$ 2,457$ \\
\hline & & PTSF & 67,6 \\
\hline & & VDMo & 99 \\
\hline & & Lmo (km) & 0,0121 \\
\hline & & rco'o & $\mathrm{R} \$ 0,015$ \\
\hline & & $\begin{array}{c}\text { VHPo } \\
\text { (bus/hora) }\end{array}$ & 7 \\
\hline & & yo & 1 \\
\hline & & rcoo & $\mathrm{R} \$ 0,030$ \\
\hline \multirow{16}{*}{ 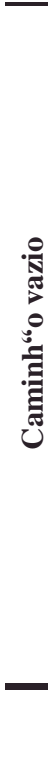 } & & $\mathrm{Vcv}(\mathrm{km} / \mathrm{h})$ & 54,21 \\
\hline & $\mathscr{\varpi} \Xi$ & Rcv & 1,207 \\
\hline & 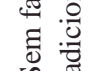 & $\begin{array}{c}\text { Custo } \\
\text { operacional }\end{array}$ & $\mathrm{R} \$ 1,574$ \\
\hline & $\infty \pi$ & PTSF & 68,81 \\
\hline & & $\mathrm{Vcv}(\mathrm{km} / \mathrm{h})$ & 54,38 \\
\hline &.$\widetilde{\Xi}$ & Rcv & 1,204 \\
\hline & 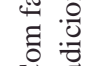 & Custo & $\mathrm{R} \$ 1,570$ \\
\hline & U & PTSF & \\
\hline & & VDMcv & 185 \\
\hline & & Lmcv (km) & 0,0121 \\
\hline & & rco'cv & $\mathrm{R} \$ 0,033$ \\
\hline & & $\begin{array}{c}\text { VHPcv } \\
\text { (cam/hora) }\end{array}$ & 13 \\
\hline & & $\mathrm{ycv}$ & 0,1 \\
\hline & & $\mathrm{rcocv}$ & 0,067 \\
\hline & & $\mathrm{rco}$ & $\mathrm{R} \$ 0,346$ \\
\hline & & $\mathrm{BRCO}$ & $\mathrm{R} \$ 126,19$ \\
\hline
\end{tabular}




\section{APÊNDICE B - Benefícios da redução dos tempos de viagem}

Tabela B.1 - Composição dos benefícios da redução dos tempos de viagem do 10 ano da análise

\begin{tabular}{|c|c|c|c|c|c|c|c|c|c|c|c|c|c|}
\hline & Aclive & 7 & 10 & 7 & 15 & 7 & 13 & 7 & 2 & 7 & 3 & 7 & 5 \\
\hline & $\mathrm{i}(\%)$ & 4 & 3 & 4 & 5 & 4 & & 4 & & 4 & 3 & 4 & 2 \\
\hline \multirow{21}{*}{ 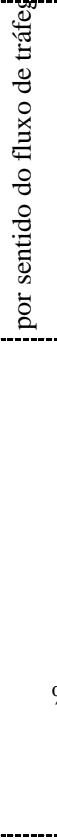 } & VHP (veic/h) & 345 & 345 & 345 & 345 & 345 & 345 & 345 & 345 & 345 & 331 & 345 & 345 \\
\hline & Veic/h (Entre_Pico) & 139 & 139 & 139 & 139 & 139 & 139 & 139 & 139 & 139 & 139 & 139 & 139 \\
\hline & VDM (p/ sent) & 4825 & 4825 & 4825 & 4825 & 4825 & 4825 & 4825 & 4825 & 4825 & 4635 & 4825 & 4825 \\
\hline & VDMa & 3300 & 3300 & 3300 & 3300 & 3300 & 3300 & 3300 & 3300 & 3300 & 3402 & 3300 & 3300 \\
\hline & VDMo & 77 & 77 & 77 & 77 & 77 & 77 & 77 & 77 & 77 & 74 & 77 & 77 \\
\hline & VDMc & 1447 & 1447 & 1447 & 1447 & 1447 & 1447 & 1447 & 1447 & 1447 & 1159 & 1447 & 1447 \\
\hline & $\mathrm{VHPa}$ & 236 & 236 & 236 & 236 & 236 & 236 & 236 & 236 & 236 & 243 & 236 & 236 \\
\hline & VHPo & 6 & 6 & 6 & 6 & 6 & 6 & 6 & 6 & 6 & 5 & 6 & 6 \\
\hline & VHPc & 103 & 103 & 103 & 103 & 103 & 103 & 103 & 103 & 103 & 83 & 103 & 103 \\
\hline & $\mathrm{Pa}(\%)$ & $70,40 \%$ & $70,40 \%$ & $70,40 \%$ & $70,40 \%$ & $70,40 \%$ & $70,40 \%$ & $70,40 \%$ & $70,40 \%$ & $70,40 \%$ & $76,40 \%$ & $70,40 \%$ & $70,40 \%$ \\
\hline & Po $(\%)$ & $1,60 \%$ & $1,60 \%$ & $1,60 \%$ & $1,60 \%$ & $1,60 \%$ & $1,60 \%$ & $1,60 \%$ & $1,60 \%$ & $1,60 \%$ & $1,60 \%$ & $1,60 \%$ & $1,60 \%$ \\
\hline & $\operatorname{Pc}(\%)$ & $28,00 \%$ & $28,00 \%$ & $28,00 \%$ & $28,00 \%$ & $28,00 \%$ & $28,00 \%$ & $28,00 \%$ & $28,00 \%$ & $28,00 \%$ & $22,00 \%$ & $28,00 \%$ & $28,00 \%$ \\
\hline & $\operatorname{Pcv}(\%)$ & $10,00 \%$ & $10,00 \%$ & $10,00 \%$ & $10,00 \%$ & $10,00 \%$ & $10,00 \%$ & $10,00 \%$ & $10,00 \%$ & $10,00 \%$ & $10,00 \%$ & $10,00 \%$ & $10,00 \%$ \\
\hline & $\mathrm{Na}$ & 3 & 3 & 3 & 3 & 3 & 3 & 3 & 3 & 3 & 3 & 3 & 3 \\
\hline & No & 25 & 25 & 25 & 25 & 25 & 25 & 25 & 25 & 25 & 25 & 25 & 25 \\
\hline & SM & $\mathrm{R} \$ 487,32$ & $\mathrm{R} \$ 487,32$ & $\mathrm{R} \$ 487,32$ & $\mathrm{R} \$ 487,32$ & $\mathrm{R} \$ 487,32$ & $\mathrm{R} \$ 487,32$ & $\mathrm{R} \$ 487,32$ & $\mathrm{R} \$ 487,32$ & $\mathrm{R} \$ 487,32$ & $\mathrm{R} \$ 487,32$ & $\mathrm{R} \$ 487,32$ & $\mathrm{R} \$ 487,32$ \\
\hline & $\mathrm{CHu}$ & $\mathrm{R} \$ 37,76$ & $\mathrm{R} \$ 37,76$ & $\mathrm{R} \$ 37,76$ & $\mathrm{R} \$ 37,76$ & $\mathrm{R} \$ 37,76$ & $\mathrm{R} \$ 37,76$ & $\mathrm{R} \$ 37,76$ & $\mathrm{R} \$ 37,76$ & $\mathrm{R} \$ 37,76$ & $\mathrm{R} \$ 37,58$ & $\mathrm{R} \$ 37,76$ & $\mathrm{R} \$ 37,76$ \\
\hline & $\mathrm{R}$ & 0,8750 & 0,8750 & 0,8750 & 0,8750 & 0,8750 & 0,8750 & 0,8750 & 0,8750 & 0,8750 & 0,8824 & 0,8750 & 0,8750 \\
\hline & $\%$ Pelotões Sem_Faixa & 72,85 & 83,55 & 72,85 & 81,6 & 72,85 & 81,8 & 72,85 & 49,9 & 72,85 & 68,3 & 72,85 & 66 \\
\hline & $\begin{array}{l}\text { \% Pelotões } \\
\text { Com_Faixa }\end{array}$ & 47,25 & 46,75 & 49,4 & 65,4 & 46,95 & 57,35 & 46,95 & 42,55 & 46,55 & 49,25 & 49,25 & 57,15 \\
\hline & rp & 0,256 & 0,368 & 0,2345 & 0,162 & 0,259 & 0,2445 & 0,259 & 0,0735 & 0,263 & 0,1905 & 0,236 & 0,0885 \\
\hline \multirow{11}{*}{ 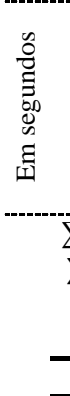 } & TVa Sem_Faixa & 1295 & 1295 & 1295 & 1295 & 1295 & 1295 & 1295 & 1295 & 1295 & 1413 & 1295 & 1295 \\
\hline & TVo Sem_Faixa & 1389 & 1389 & 1389 & 1389 & 1389 & 1389 & 1389 & 1389 & 1389 & 1535 & 1389 & 1389 \\
\hline & TVc Sem_Faixa & 1389 & 1389 & 1389 & 1389 & 1389 & 1389 & 1389 & 1389 & 1389 & 1535 & 1389 & 1389 \\
\hline & TVa Com_Faixa & 1123 & 1123 & 1188 & 1188 & 1179 & 1179 & 1174 & 1174 & 1196 & 1402 & 1181 & 1181 \\
\hline & TVo Com_Faixa & 1344 & 1344 & 1356 & 1356 & 1365 & 1365 & 1351 & 1351 & 1357 & 1530 & 1341 & 1341 \\
\hline & TVc Com_Faixa & 1344 & 1344 & 1356 & 1356 & 1365 & 1365 & 1351 & 1351 & 1357 & 1530 & 1341 & 1341 \\
\hline & $\sum\left(\mathrm{tv} \_\mathrm{sf}-\mathrm{tv} \_\mathrm{cf}\right) * \mathrm{VDMi}$ & 635288,31 & 635288,31 & 404400,67 & 404400,67 & 420056,39 & 420056,39 & 456124,11 & 456124,11 & 375387,48 & 44194,26 & 447720,82 & 447720,82 \\
\hline & $\sum$ (tv_sf-tv_cf)*VHPi & 45396,92 & 45396,92 & 28897,98 & 28897,98 & 30016,71 & 30016,71 & 32594,07 & 32594,07 & 26824,73 & 3158,07 & 31993,58 & 31993,58 \\
\hline & rtv` & 2,15 & 3,08 & 1,27 & 0,88 & 1,40 & 1,32 & 1,59 & 0,45 & 1,33 & 0,12 & 1,47 & 0,55 \\
\hline & rtv & 30,12 & 43,29 & 17,60 & 12,16 & 20,08 & 18,96 & 21,94 & 6,23 & 18,34 & 1,57 & 19,72 & 7,40 \\
\hline & BRTV & $\mathrm{R} \$ 363.165,22$ & $\mathrm{R} \$ 522.050,00$ & $\mathrm{R} \$ 212.205,92$ & $\mathrm{R} \$ 146.598,54$ & $\mathrm{R} \$ 242.173,50$ & $\mathrm{R} \$ 228.615,53$ & $\mathrm{R} \$ 264.533,14$ & $\mathrm{R} \$ 75.070,22$ & $\mathrm{R} \$ 221.135,22$ & $\mathrm{R} \$ 19.041,30$ & $\mathrm{R} \$ 237.817,81$ & $\mathrm{R} \$ 89.181,68$ \\
\hline
\end{tabular}


Continuação Tabela B.1

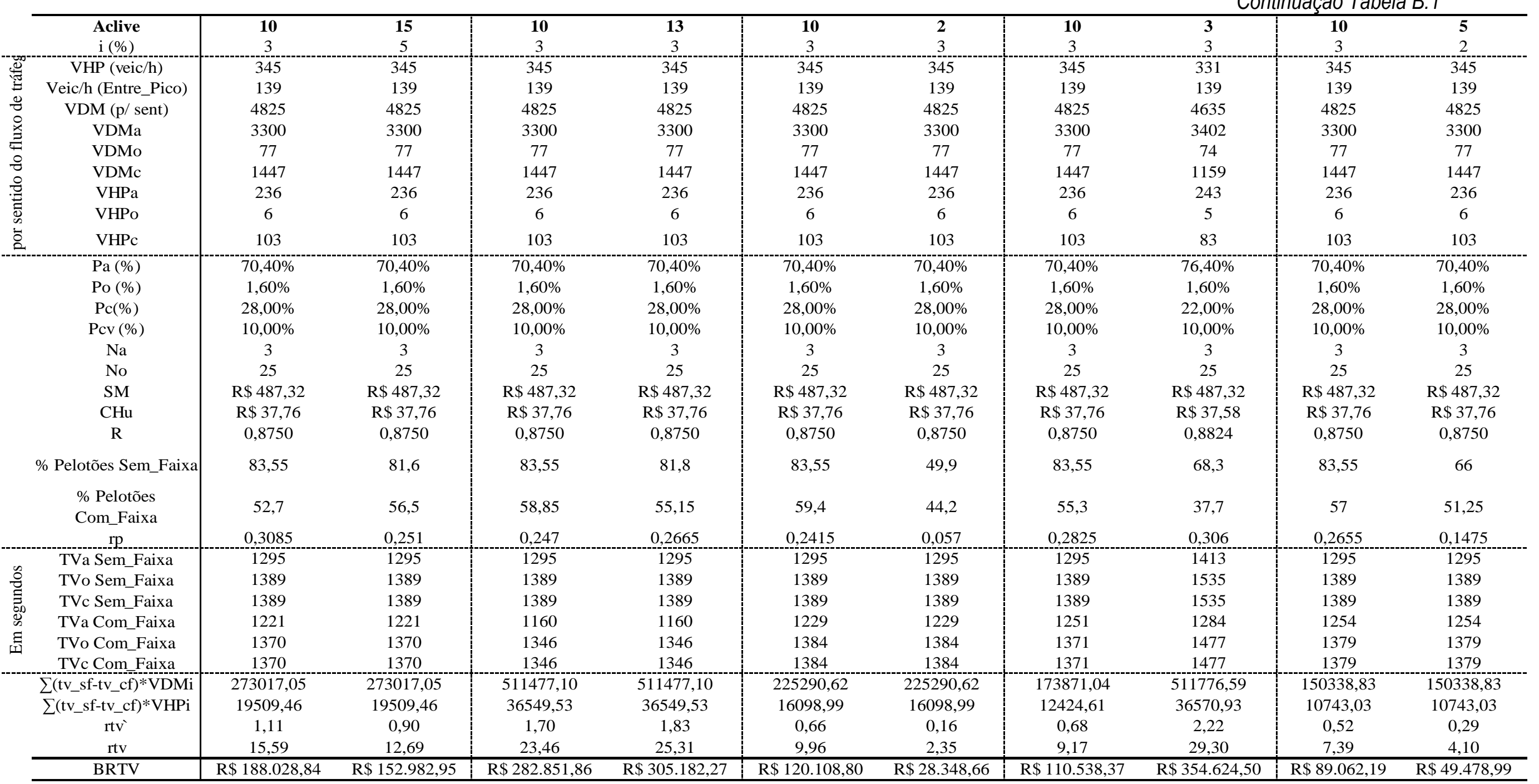


Tabela B.2 - Composição dos benefícios da redução dos tempos de viagem do 20 ano da análise

\begin{tabular}{|c|c|c|c|c|c|c|c|c|c|c|c|c|c|c|c|}
\hline Aclive & 15 & 13 & 2 & 15 & 13 & 3 & 15 & 13 & 5 & 15 & 2 & 3 & 15 & 2 & 5 \\
\hline $\mathrm{i}(\%)$ & 5 & 3 & 3 & 5 & 3 & 3 & 5 & 3 & 2 & 5 & 3 & 3 & 5 & 3 & 2 \\
\hline VHP (veic/h) & 362 & 362 & 362 & 362 & 362 & 348 & 362 & 362 & 362 & 362 & 362 & 348 & 362 & 362 & 362 \\
\hline Veic/h (Entre_Pico) & 149 & 149 & 149 & 149 & 149 & 143 & 149 & 149 & 149 & 149 & 149 & 143 & 149 & 149 & 149 \\
\hline VDM (p/sent) & 5066 & 5066 & 5066 & 5066 & 5066 & 4867 & 5066 & 5066 & 5066 & 5066 & 5066 & 4867 & 5066 & 5066 & 5066 \\
\hline VDMa & 3465 & 3465 & 3465 & 3465 & 3465 & 3573 & 3465 & 3465 & 3465 & 3465 & 3465 & 3573 & 3465 & 3465 & 3465 \\
\hline VDMo & 81 & 81 & 81 & 81 & 81 & 78 & 81 & 81 & 81 & 81 & 81 & 78 & 81 & 81 & 81 \\
\hline VDMc & 1520 & 1520 & 1520 & 1520 & 1520 & 1217 & 1520 & 1520 & 1520 & 1520 & 1520 & 1217 & 1520 & 1520 & 1520 \\
\hline VHPa & 248 & 248 & 248 & 248 & 248 & 255 & 248 & 248 & 248 & 248 & 248 & 255 & 248 & 248 & 248 \\
\hline VHPo & 6 & 6 & 6 & 6 & 6 & 6 & 6 & 6 & 6 & 6 & 6 & 6 & 6 & 6 & 6 \\
\hline VHPc & 109 & 109 & 109 & 109 & 109 & 87 & 109 & 109 & 109 & 109 & 109 & 87 & 109 & 109 & 109 \\
\hline $\mathrm{Pa}(\%)$ & $70,40 \%$ & $70,40 \%$ & $70,40 \%$ & $70,40 \%$ & $70,40 \%$ & $76,40 \%$ & $70,40 \%$ & $70,40 \%$ & $70,40 \%$ & $70,40 \%$ & $70,40 \%$ & $76,40 \%$ & $70,40 \%$ & $70,40 \%$ & $70,40 \%$ \\
\hline Po (\%) & $1,60 \%$ & $1,60 \%$ & $1,60 \%$ & $1,60 \%$ & $1,60 \%$ & $1,60 \%$ & $1,60 \%$ & $1,60 \%$ & $1,60 \%$ & $1,60 \%$ & $1,60 \%$ & $1,60 \%$ & $1,60 \%$ & $1,60 \%$ & $1,60 \%$ \\
\hline $\operatorname{Pc}(\%)$ & $28,00 \%$ & $28,00 \%$ & $28,00 \%$ & $28,00 \%$ & $28,00 \%$ & $22,00 \%$ & $28,00 \%$ & $28,00 \%$ & $28,00 \%$ & $28,00 \%$ & $28,00 \%$ & $22,00 \%$ & $28,00 \%$ & $28,00 \%$ & $28,00 \%$ \\
\hline $\operatorname{Pcv}(\%)$ & $10,00 \%$ & $10,00 \%$ & $10,00 \%$ & $10,00 \%$ & $10,00 \%$ & $10,00 \%$ & $10,00 \%$ & $10,00 \%$ & $10,00 \%$ & $10,00 \%$ & $10,00 \%$ & $10,00 \%$ & $10,00 \%$ & $10,00 \%$ & $10,00 \%$ \\
\hline $\mathrm{Na}$ & 3 & 3 & 3 & 3 & 3 & 3 & 3 & 3 & 3 & 3 & 3 & 3 & 3 & 3 & 3 \\
\hline No & 25 & 25 & 25 & 25 & 25 & 25 & 25 & 25 & 25 & 25 & 25 & 25 & 25 & 25 & 25 \\
\hline SM & $\mathrm{R} \$ 510,71$ & $\mathrm{R} \$ 510,71$ & $\mathrm{R} \$ 510,71$ & $\mathrm{R} \$ 510,71$ & $\mathrm{R} \$ 510,71$ & $\mathrm{R} \$ 510,71$ & $\mathrm{R} \$ 510,71$ & $\mathrm{R} \$ 510,71$ & $\mathrm{R} \$ 510,71$ & $\mathrm{R} \$ 510,71$ & $\mathrm{R} \$ 510,71$ & $\mathrm{R} \$ 510,71$ & $\mathrm{R} \$ 510,71$ & $\mathrm{R} \$ 510,71$ & $\mathrm{R} \$ 510,71$ \\
\hline $\mathrm{CHu}$ & $\mathrm{R} \$ 39,57$ & $\mathrm{R} \$ 39,57$ & $\mathrm{R} \$ 39,57$ & $\mathrm{R} \$ 39,57$ & $\mathrm{R} \$ 39,57$ & $\mathrm{R} \$ 39,39$ & $\mathrm{R} \$ 39,57$ & $\mathrm{R} \$ 39,57$ & $\mathrm{R} \$ 39,57$ & $\mathrm{R} \$ 39,57$ & $\mathrm{R} \$ 39,57$ & $\mathrm{R} \$ 39,39$ & $\mathrm{R} \$ 39,57$ & $\mathrm{R} \$ 39,57$ & $\mathrm{R} \$ 39,57$ \\
\hline $\mathrm{R}$ & 0,8750 & 0,8750 & 0,8750 & 0,8750 & 0,8750 & 0,8824 & 0,8750 & 0,8750 & 0,8750 & 0,8750 & 0,8750 & 0,8824 & 0,8750 & 0,8750 & 0,8750 \\
\hline \% Pelotões Sem_Faixa & 79,87 & 75,93 & 56,29 & 79,87 & 75,93 & 81,84 & 79,87 & 75,93 & 73,34 & 79,87 & 56,29 & 81,84 & 79,87 & 56,29 & 73,34 \\
\hline \% Pelotões Com_Faixa & 54,81 & 60,16 & 49 & 57,11 & 60,56 & 51,98 & 57,17 & 60,24 & 66,9 & 64,73 & 52,63 & 51,94 & 62,78 & 48,66 & 66,13 \\
\hline $\mathrm{rp}$ & 0,2506 & 0,1577 & 0,0729 & 0,2276 & 0,1537 & 0,2986 & 0,227 & 0,1569 & 0,0644 & 0,1514 & 0,0366 & 0,299 & 0,1709 & 0,0763 & 0,0721 \\
\hline TVa Sem_Faixa & 1158 & 1158 & 1158 & 1158 & 1158 & 1454 & 1158 & 1158 & 1158 & 1158 & 1158 & 1454 & 1158 & 1158 & 1158 \\
\hline TVo Sem_Faixa & 1355 & 1355 & 1355 & 1355 & 1355 & 1552 & 1355 & 1355 & 1355 & 1355 & 1355 & 1552 & 1355 & 1355 & 1355 \\
\hline TVc Sem_Faixa & 1355 & 1355 & 1355 & 1355 & 1355 & 1552 & 1355 & 1355 & 1355 & 1355 & 1355 & 1552 & 1355 & 1355 & 1355 \\
\hline TVa Com_Faixa & 1131 & 1131 & 1131 & 1144 & 1144 & 1365 & 1142 & 1142 & 1142 & 1135 & 1135 & 1366 & 1132 & 1132 & 1132 \\
\hline TVo Com_Faixa & 1366 & 1366 & 1366 & 1364 & 1364 & 1529 & 1364 & 1364 & 1364 & 1359 & 1359 & 1366 & 1357 & 1357 & 1357 \\
\hline TVc Com_Faixa & 1366 & 1366 & 1366 & 1364 & 1364 & 1529 & 1364 & 1364 & 1364 & 1359 & 1359 & 1366 & 1357 & 1357 & 1357 \\
\hline$\sum\left(\mathrm{tv} \_\mathrm{sf}-\mathrm{tv}\right.$ ccf) $*$ VDMi & 74399,31 & 74399,31 & 74399,31 & 33080,92 & 33080,92 & 347534,32 & 39258,93 & 39258,93 & 39258,93 & 70494,84 & 70494,84 & 553792,58 & 86186,59 & 86186,59 & 86186,59 \\
\hline$\sum$ (tv_sf-tv_cf) $* \mathrm{VHPi}$ & 5317,98 & 5317,98 & 5317,98 & 2364,59 & 2364,59 & 24841,37 & 2806,19 & 2806,19 & 2806,19 & 5038,89 & 5038,89 & 39584,49 & 6160,52 & 6160,52 & 6160,52 \\
\hline rtv' & 0,16 & 0,10 & 0,05 & 0,04 & 0,03 & 1,33 & 0,06 & 0,04 & 0,02 & 0,11 & 0,03 & 3,25 & 0,17 & 0,07 & 0,07 \\
\hline rtv & 3,28 & 2,06 & 0,95 & 1,28 & 0,87 & 19,14 & 1,54 & 1,06 & 0,44 & 1,92 & 0,46 & 32,80 & 2,67 & 1,19 & 1,13 \\
\hline BRTV & $\mathrm{R} \$ 41.465,32$ & $26.093,70$ & $2.062,34$ & $\mathrm{R} \$ 16.196,72$ & $10.937,77$ & $242.780,64$ & $\mathrm{R} \$ 19.455,24$ & 47,25 & 9,46 & $\$ 24.292,76$ & $\$ 5.872,62$ & 052,07 & 78,31 & 0,66 & R\$ 14.250,5 \\
\hline
\end{tabular}


Continuação Tabela B.2

\begin{tabular}{|c|c|c|c|c|c|c|c|c|c|c|c|c|c|c|c|c|}
\hline & $\begin{array}{c}\text { Aclive } \\
\text { i }(\%)\end{array}$ & $\begin{array}{c}15 \\
5\end{array}$ & $\begin{array}{l}3 \\
3\end{array}$ & $\begin{array}{l}\mathbf{5} \\
2\end{array}$ & $\begin{array}{c}\mathbf{1 3} \\
3\end{array}$ & $\begin{array}{l}2 \\
3\end{array}$ & $\begin{array}{l}\mathbf{3} \\
3\end{array}$ & $\begin{array}{c}13 \\
3\end{array}$ & $\begin{array}{l}2 \\
3\end{array}$ & $\begin{array}{l}5 \\
2\end{array}$ & $\begin{array}{c}13 \\
3\end{array}$ & $\begin{array}{l}3 \\
3\end{array}$ & $\begin{array}{l}5 \\
2\end{array}$ & $\begin{array}{l}2 \\
3\end{array}$ & $\begin{array}{l}3 \\
3\end{array}$ & $\begin{array}{l}5 \\
2\end{array}$ \\
\hline \multirow{21}{*}{ 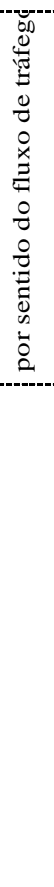 } & $\mathrm{VHP}$ (veic/h) & 362 & 348 & 362 & 362 & 362 & 348 & 362 & 362 & 362 & 362 & 348 & 362 & 362 & 348 & 362 \\
\hline & Veic/h (Entre_Pico) & 149 & 143 & 149 & 149 & 149 & 143 & 149 & 149 & 149 & 149 & 143 & 149 & 149 & 143 & 149 \\
\hline & $\mathrm{VDM}(\mathrm{p} /$ sent $)$ & 5066 & 4867 & 5066 & 5066 & 5066 & 4867 & 5066 & 5066 & 5066 & 5066 & 4867 & 5066 & 5066 & 4867 & 5066 \\
\hline & VDMa & 3465 & 3573 & 3465 & 3465 & 3465 & 3573 & 3465 & 3465 & 3465 & 3465 & 3573 & 3465 & 3465 & 3573 & 3465 \\
\hline & VDMo & 81 & 78 & 81 & 81 & 81 & 78 & 81 & 81 & 81 & 81 & 78 & 81 & 81 & 78 & 81 \\
\hline & VDMc & 1520 & 1217 & 1520 & 1520 & 1520 & 1217 & 1520 & 1520 & 1520 & 1520 & 1217 & 1520 & 1520 & 1217 & 1520 \\
\hline & VHPa & 248 & 255 & 248 & 248 & 248 & 255 & 248 & 248 & 248 & 248 & 255 & 248 & 248 & 255 & 248 \\
\hline & VHPo & 6 & 6 & 6 & 6 & 6 & 6 & 6 & 6 & 6 & 6 & 6 & 6 & 6 & 6 & 6 \\
\hline & VHPc & 109 & 87 & 109 & 109 & 109 & 87 & 109 & 109 & 109 & 109 & 87 & 109 & 109 & 87 & 109 \\
\hline & $\mathrm{Pa}(\%)$ & $70,40 \%$ & $76,40 \%$ & $70,40 \%$ & $70,40 \%$ & $70,40 \%$ & $76,40 \%$ & $70,40 \%$ & $70,40 \%$ & $70,40 \%$ & $70,40 \%$ & $76,40 \%$ & $70,40 \%$ & $70,40 \%$ & $76,40 \%$ & $70,40 \%$ \\
\hline & Po $(\%)$ & $1,60 \%$ & $1,60 \%$ & $1,60 \%$ & $1,60 \%$ & $1,60 \%$ & $1,60 \%$ & $1,60 \%$ & $1,60 \%$ & $1,60 \%$ & $1,60 \%$ & $1,60 \%$ & $1,60 \%$ & $1,60 \%$ & $1,60 \%$ & $1,60 \%$ \\
\hline & $\operatorname{Pc}(\%)$ & $28,00 \%$ & $22,00 \%$ & $28,00 \%$ & $28,00 \%$ & $28,00 \%$ & $22,00 \%$ & $28,00 \%$ & $28,00 \%$ & $28,00 \%$ & $28,00 \%$ & $22,00 \%$ & $28,00 \%$ & $28,00 \%$ & $22,00 \%$ & $28,00 \%$ \\
\hline & $\operatorname{Pcv}(\%)$ & $10,00 \%$ & $10,00 \%$ & $10,00 \%$ & $10,00 \%$ & $10,00 \%$ & $10,00 \%$ & $10,00 \%$ & $10,00 \%$ & $10,00 \%$ & $10,00 \%$ & $10,00 \%$ & $10,00 \%$ & $10,00 \%$ & $10,00 \%$ & $10,00 \%$ \\
\hline & $\mathrm{Na}$ & 3 & 3 & 3 & 3 & 3 & 3 & 3 & 3 & 3 & 3 & 3 & 3 & 3 & 3 & 3 \\
\hline & No & 25 & 25 & 25 & 25 & 25 & 25 & 25 & 25 & 25 & 25 & 25 & 25 & 25 & 25 & 25 \\
\hline & SM & $\mathrm{R} \$ 510,71$ & $\mathrm{R} \$ 510,71$ & $\mathrm{R} \$ 510,71$ & $\mathrm{R} \$ 510,71$ & $\mathrm{R} \$ 510,71$ & $\mathrm{R} \$ 510,71$ & $\mathrm{R} \$ 510,71$ & $\mathrm{R} \$ 510,71$ & $\mathrm{R} \$ 510,71$ & $\mathrm{R} \$ 510,71$ & $\mathrm{R} \$ 510,71$ & $\mathrm{R} \$ 510,71$ & $\mathrm{R} \$ 510,71$ & $\mathrm{R} \$ 510,71$ & $\mathrm{R} \$ 510,71$ \\
\hline & $\mathrm{CHu}$ & $\mathrm{R} \$ 39,57$ & $\mathrm{R} \$ 39,39$ & $\mathrm{R} \$ 39,57$ & $\mathrm{R} \$ 39,57$ & $\mathrm{R} \$ 39,57$ & $\mathrm{R} \$ 39,39$ & $\mathrm{R} \$ 39,57$ & $\mathrm{R} \$ 39,57$ & $\mathrm{R} \$ 39,57$ & $\mathrm{R} \$ 39,57$ & $\mathrm{R} \$ 39,39$ & $\mathrm{R} \$ 39,57$ & $\mathrm{R} \$ 39,57$ & $\mathrm{R} \$ 39,39$ & $\mathrm{R} \$ 39,57$ \\
\hline & $\mathrm{R}$ & 0,8750 & 0,8824 & 0,8750 & 0,8750 & 0,8750 & 0,8824 & 0,8750 & 0,8750 & 0,8750 & 0,8750 & 0,8824 & 0,8750 & 0,8750 & 0,8824 & 0,8750 \\
\hline & \% Pelotões Sem_Faixa & 79,87 & 81,84 & 73,34 & 75,93 & 56,29 & 81,84 & 75,93 & 56,29 & 73,34 & 75,93 & 81,84 & 73,34 & 56,29 & 81,84 & 73,34 \\
\hline & \% Pelotões Com_Faixa & 63,06 & 52,87 & 65,41 & 61,14 & 53,03 & 51,74 & 59,6 & 49,23 & 64,67 & 58,55 & 51,42 & 65,25 & 52,78 & 52,18 & 64,48 \\
\hline & $\mathrm{rp}$ & 0,1681 & 0,2897 & 0,0793 & 0,1479 & 0,0326 & 0,301 & 0,1633 & 0,0706 & 0,0867 & 0,1738 & 0,3042 & 0,0809 & 0,0351 & 0,2966 & 0,0886 \\
\hline \multirow{6}{*}{ 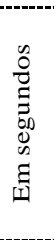 } & TVa Sem_Faixa & 1158 & 1454 & 1158 & 1158 & 1158 & 1454 & 1158 & 1158 & 1158 & 1158 & 1454 & 1158 & 1158 & 1454 & 1158 \\
\hline & TVo Sem_Faixa & 1355 & 1552 & 1355 & 1355 & 1355 & 1552 & 1355 & 1355 & 1355 & 1355 & 1552 & 1355 & 1355 & 1552 & 1355 \\
\hline & TVc Sem_Faixa & 1355 & 1552 & 1355 & 1355 & 1355 & 1552 & 1355 & 1355 & 1355 & 1355 & 1552 & 1355 & 1355 & 1552 & 1355 \\
\hline & TVa Com_Faixa & 1150 & 1371 & 1150 & 1122 & 1122 & 1355 & 1122 & 1122 & 1122 & 1141 & 1367 & 1141 & 1137 & 1367 & 1137 \\
\hline & TVo Com_Faixa & 1356 & 1531 & 1356 & 1355 & 1355 & 1531 & 1358 & 1358 & 1358 & 1359 & 1529 & 1359 & 1355 & 1532 & 1355 \\
\hline & TVc Com_Faixa & 1356 & 1531 & 1356 & 1355 & 1355 & 1531 & 1358 & 1358 & 1358 & 1359 & 1529 & 1359 & 1355 & 1532 & 1355 \\
\hline & $\sum($ tv_sf-tv_cf)*VDMi & 24298,27 & 324397,13 & 24298,27 & 124989,84 & 124989,84 & 380555,68 & 118957,92 & 118957,92 & 118957,92 & 50505,66 & 339680,87 & 50505,66 & 70815,57 & 335587,95 & 70815,57 \\
\hline & $\sum($ tv_sf-tv_cf) $*$ VHPi & 1736,81 & 23187,55 & 1736,81 & 8934,14 & 8934,14 & 27201,70 & 8502,98 & 8502,98 & 8502,98 & 3610,09 & 24280,02 & 3610,09 & 5061,82 & 23987,46 & 5061,82 \\
\hline & rtv & 0,04 & 1,20 & 0,02 & 0,22 & 0,05 & 1,43 & 0,22 & 0,09 & 0,12 & 0,09 & 1,32 & 0,04 & 0,03 & 1,26 & 0,07 \\
\hline & $\mathrm{rtv}$ & 0,74 & 17,32 & 0,35 & 3,38 & 0,74 & 21,06 & 3,52 & 1,52 & 1,87 & 1,57 & 19,06 & 0,73 & 0,45 & 18,32 & 1,15 \\
\hline & BRTV & $\mathrm{R} \$ 9.316,91$ & $\mathrm{R} \$ 219.743,34$ & $\mathrm{R} \$ 4.395,19$ & $\mathrm{R} \$ 42.686,95$ & $\mathrm{R} \$ 9.409,02$ & $\mathrm{R} \$ 267.144,89$ & $\mathrm{R} \$ 44.544,12$ & $\mathrm{R} \$ 19.257,90$ & $\mathrm{R} \$ 23.649,57$ & $\mathrm{R} \$ 19.840,79$ & $\mathrm{R} \$ 241.724,89$ & $\mathrm{R} \$ 9.235,44$ & $\mathrm{R} \$ 5.734,89$ & $\mathrm{R} \$ 232.424,34$ & $\mathrm{R} \$ 14.476,11$ \\
\hline
\end{tabular}


Tabela B.3 - Composição dos benefícios da redução dos tempos de viagem do $3^{\circ}$ ano da análise

\begin{tabular}{|c|c|c|c|c|}
\hline & $\begin{array}{l}\text { Aclive } \\
\text { i (\%) }\end{array}$ & $\begin{array}{l}5 \\
2\end{array}$ & $\begin{array}{c}11 \\
2\end{array}$ & $\begin{array}{c}14 \\
3\end{array}$ \\
\hline \multirow{21}{*}{ 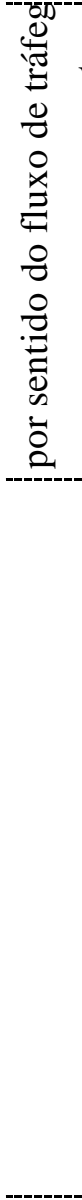 } & VHP (veic/h) & 380 & 365 & 380 \\
\hline & Veic/h (Entre_Pico) & 157 & 150 & 157 \\
\hline & VDM (p/ sent) & 5319 & 5111 & 5319 \\
\hline & VDMa & 3638 & 3751 & 3638 \\
\hline & VDMo & 85 & 82 & 85 \\
\hline & VDMc & 1596 & 1278 & 1596 \\
\hline & VHPa & 260 & 268 & 260 \\
\hline & VHPo & 6 & 6 & 6 \\
\hline & VHPc & 114 & 91 & 114 \\
\hline & $\mathrm{Pa}(\%)$ & $70,40 \%$ & $76,40 \%$ & $70,40 \%$ \\
\hline & Po $(\%)$ & $1,60 \%$ & $1,60 \%$ & $1,60 \%$ \\
\hline & $\operatorname{Pc}(\%)$ & $28,00 \%$ & $22,00 \%$ & $28,00 \%$ \\
\hline & $\operatorname{Pcv}(\%)$ & $10,00 \%$ & $10,00 \%$ & $10,00 \%$ \\
\hline & $\mathrm{Na}$ & 3 & 3 & 3 \\
\hline & No & 25 & 25 & 25 \\
\hline & SM & $\mathrm{R} \$ 535,23$ & $\mathrm{R} \$ 535,23$ & $\mathrm{R} \$ 535,23$ \\
\hline & $\mathrm{CHu}$ & $\mathrm{R} \$ 41,47$ & $\mathrm{R} \$ 41,28$ & $\mathrm{R} \$ 41,47$ \\
\hline & $\mathrm{R}$ & 0,8750 & 0,8824 & 0,8750 \\
\hline & $\begin{array}{l}\% \text { Pelotões } \\
\text { Sem_Faixa }\end{array}$ & 73,7 & 70,71 & 78,63 \\
\hline & $\begin{array}{l}\text { \% Pelotões } \\
\text { Com_Faixa }\end{array}$ & 66,01 & 40,76 & 63,09 \\
\hline & $\mathrm{rp}$ & 0,0769 & 0,2995 & 0,1554 \\
\hline \multirow{6}{*}{$\begin{array}{l}\infty \\
0 \\
0 \\
\Xi \\
0 \\
0 \\
0 \\
\infty \\
\tilde{0} \\
\tilde{0}\end{array}$} & TVa Sem_Faixa & 1151 & 1365 & 1151 \\
\hline & TVo Sem_Faixa & 1373 & 1529 & 1373 \\
\hline & TVc Sem_Faixa & 1373 & 1529 & 1373 \\
\hline & TVa Com_Faixa & 1139 & 1300 & 1130 \\
\hline & TVo Com_Faixa & 1370 & 1504 & 1374 \\
\hline & TVc Com_Faixa & 1370 & 1504 & 1374 \\
\hline & $\sum\left(t v_{-} \mathrm{sf}-\mathrm{tv} \_\mathrm{cf}\right) * \mathrm{VDM}$ & 49157,34 & 279171,02 & 75681,19 \\
\hline & $\sum\left(t v \_s f-t v \_c f\right) * V H P i$ & 3511,24 & 19940,79 & 5405,80 \\
\hline & $\mathrm{rtv}^{`}$ & 0,05 & 1,14 & 0,14 \\
\hline & $\mathrm{rtv}$ & 0,70 & 15,55 & 2,14 \\
\hline & BRTV & $\mathrm{R} \$ 9.286,34$ & $\mathrm{R} \$ 206.679,91$ & $\mathrm{R} \$ 28.376,33$ \\
\hline
\end{tabular}


Tabela B.4 - Composição dos benefícios da redução dos tempos de viagem do $4^{\circ}$ ano da análise

\begin{tabular}{|c|c|c|c|}
\hline & $\begin{array}{c}\text { Aclive } \\
\text { i }(\%)\end{array}$ & $\begin{array}{l}5 \\
2 \\
-\end{array}$ & $\begin{array}{c}13 \\
3\end{array}$ \\
\hline \multirow{21}{*}{ 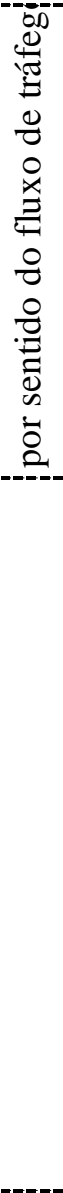 } & $\mathrm{VHP}(\mathrm{veic} / \mathrm{h})$ & 399 & 399 \\
\hline & Veic/h (Entre_Pico) & 164 & 164 \\
\hline & VDM (p/ sent) & 5586 & 5586 \\
\hline & VDMa & 3820 & 3820 \\
\hline & VDMo & 89 & 89 \\
\hline & VDMc & 1676 & 1676 \\
\hline & VHPa & 273 & 273 \\
\hline & VHPo & 6 & 6 \\
\hline & VHPc & 120 & 120 \\
\hline & $\mathrm{Pa}(\%)$ & $70,40 \%$ & $70,40 \%$ \\
\hline & Po $(\%)$ & $1,60 \%$ & $1,60 \%$ \\
\hline & $\operatorname{Pc}(\%)$ & $28,00 \%$ & $28,00 \%$ \\
\hline & $\operatorname{Pcv}(\%)$ & $10,00 \%$ & $10,00 \%$ \\
\hline & $\mathrm{Na}$ & 3 & 3 \\
\hline & No & 25 & 25 \\
\hline & SM & $\mathrm{R} \$ 560,92$ & $\mathrm{R} \$ 560,92$ \\
\hline & $\mathrm{CHu}$ & $\mathrm{R} \$ 43,46$ & $\mathrm{R} \$ 43,46$ \\
\hline & $\mathrm{R}$ & 0,8750 & 0,8750 \\
\hline & $\%$ Pelotões Sem_Faixa & 74,94 & 79,07 \\
\hline & $\%$ Pelotões Com_Faixa & 67,54 & 64,67 \\
\hline & $\mathrm{rp}$ & 0,074 & 0,144 \\
\hline \multirow{11}{*}{$\begin{array}{l}\tilde{0} \\
0 \\
0 \\
0 \\
0 \\
\infty \\
\infty \\
\tilde{D}\end{array}$} & TVa Sem_Faixa & 1170 & 1170 \\
\hline & TVo Sem_Faixa & 1384 & 1384 \\
\hline & TVc Sem_Faixa & 1384 & 1384 \\
\hline & TVa Com_Faixa & 1151 & 1151 \\
\hline & TVo Com_Faixa & 1350 & 1350 \\
\hline & TVc Com_Faixa & 1350 & 1350 \\
\hline & $?\left(t v \_s f-t v \_c f\right) * V D M i$ & 129837,57 & 129837,57 \\
\hline & ? (tv_sf-tv_cf)*VHPi & 9270,72 & 9270,72 \\
\hline & $\mathrm{rtv}^{\prime}$ & 0,18 & 0,34 \\
\hline & $\mathrm{rtv}$ & 1,88 & 3,65 \\
\hline & BRTV & $\mathrm{R} \$ 26.051,90$ & $\mathrm{R} \$ 50.695,59$ \\
\hline
\end{tabular}


Tabela B.5 - Composição dos benefícios da redução dos tempos de viagem do $6^{\circ}$ ano da análise

\begin{tabular}{|c|c|c|}
\hline & Aclive & 13 \\
\hline \multirow{22}{*}{ 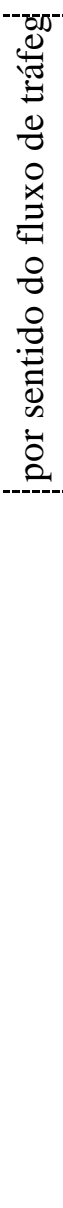 } & $\frac{1(\%)}{\mathrm{VHP}(\mathrm{vejc} / \mathrm{h})}$ & 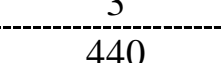 \\
\hline & Veic/h (Entre_Pico) & 181 \\
\hline & VDM (p/ sent) & 6158 \\
\hline & VDMa & 4212 \\
\hline & VDMo & 99 \\
\hline & VDMc & 1847 \\
\hline & VHPa & 301 \\
\hline & VHPo & 7 \\
\hline & VHPc & 132 \\
\hline & $\mathrm{Pa}(\%)$ & $70,40 \%$ \\
\hline & Po $(\%)$ & $1,60 \%$ \\
\hline & $\operatorname{Pc}(\%)$ & $28,00 \%$ \\
\hline & $\operatorname{Pcv}(\%)$ & $10,00 \%$ \\
\hline & $\mathrm{Na}$ & 3 \\
\hline & No & 25 \\
\hline & SM & $\mathrm{R} \$ 616,06$ \\
\hline & $\mathrm{CHu}$ & $\mathrm{R} \$ 47,73$ \\
\hline & $\mathrm{R}$ & 0,8750 \\
\hline & $\%$ Pelotões & 81,75 \\
\hline & $\%$ Pelotões & \\
\hline & Com Faixa & 66,26 \\
\hline & $\mathrm{rp}$ & 0,1549 \\
\hline \multirow{6}{*}{ 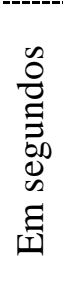 } & TVa Sem_Faixa & 1189 \\
\hline & TVo Sem_Faixa & 1395 \\
\hline & TVc Sem_Faixa & 1395 \\
\hline & TVa Com_Faixa & 1156 \\
\hline & TVo Com_Faixa & 1390 \\
\hline & TVc Com_Faixa & 1390 \\
\hline & $\sum\left(t v \_s f-t v \_c f\right) * V D M$ & 145534,73 \\
\hline & $\sum\left(t v \_s f-t v \_c f\right) * V H P i$ & 10390,17 \\
\hline & rtv & 0,29 \\
\hline & rtv & 4,15 \\
\hline & BRTV & $\mathrm{R} \$ 63.286,57$ \\
\hline
\end{tabular}




\section{APÊNDICE C - Benefícios da redução dos acidentes}

Tabela C.1 - Composição dos benefícios das reduções de acidentes (10 modo)

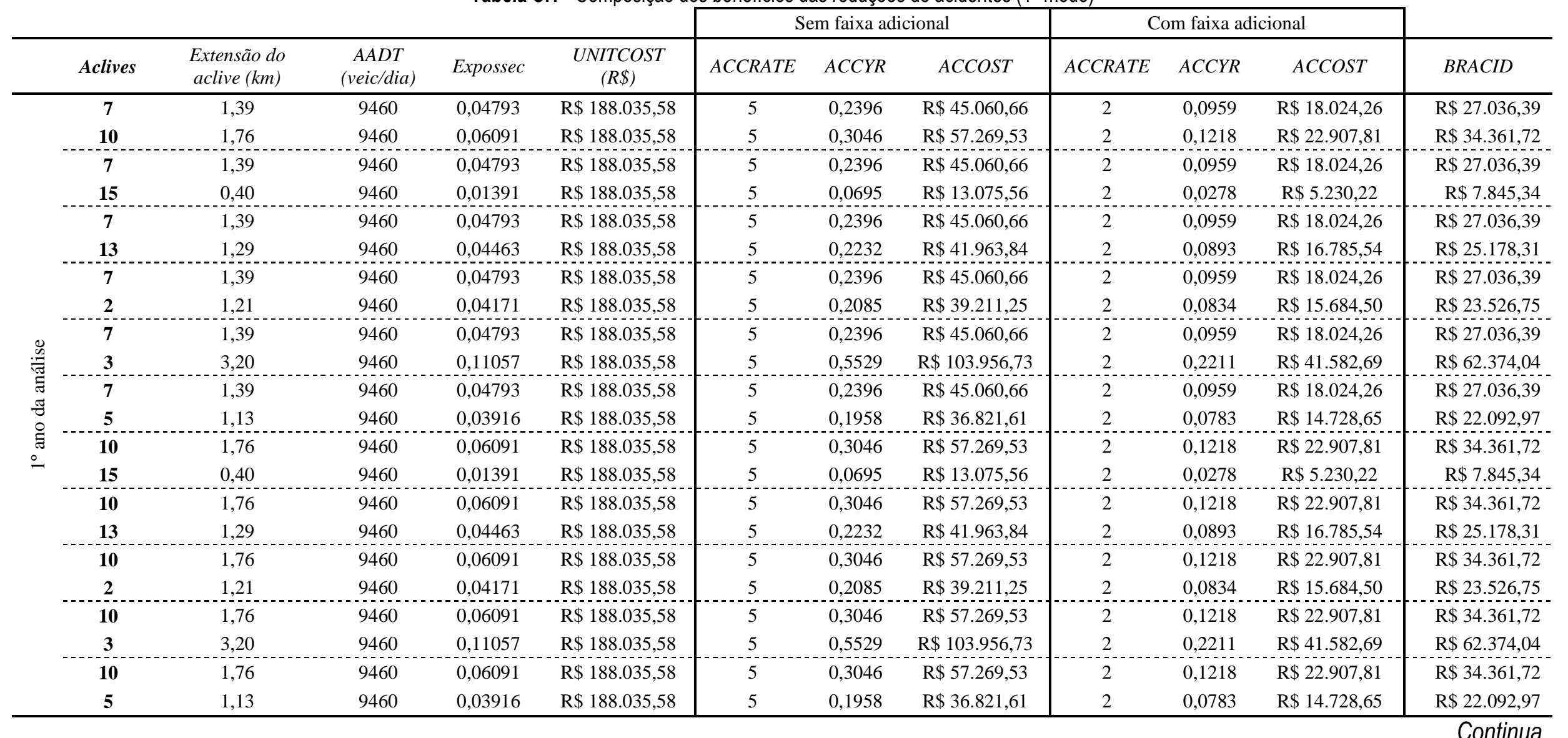


Continuação Tabela C.1

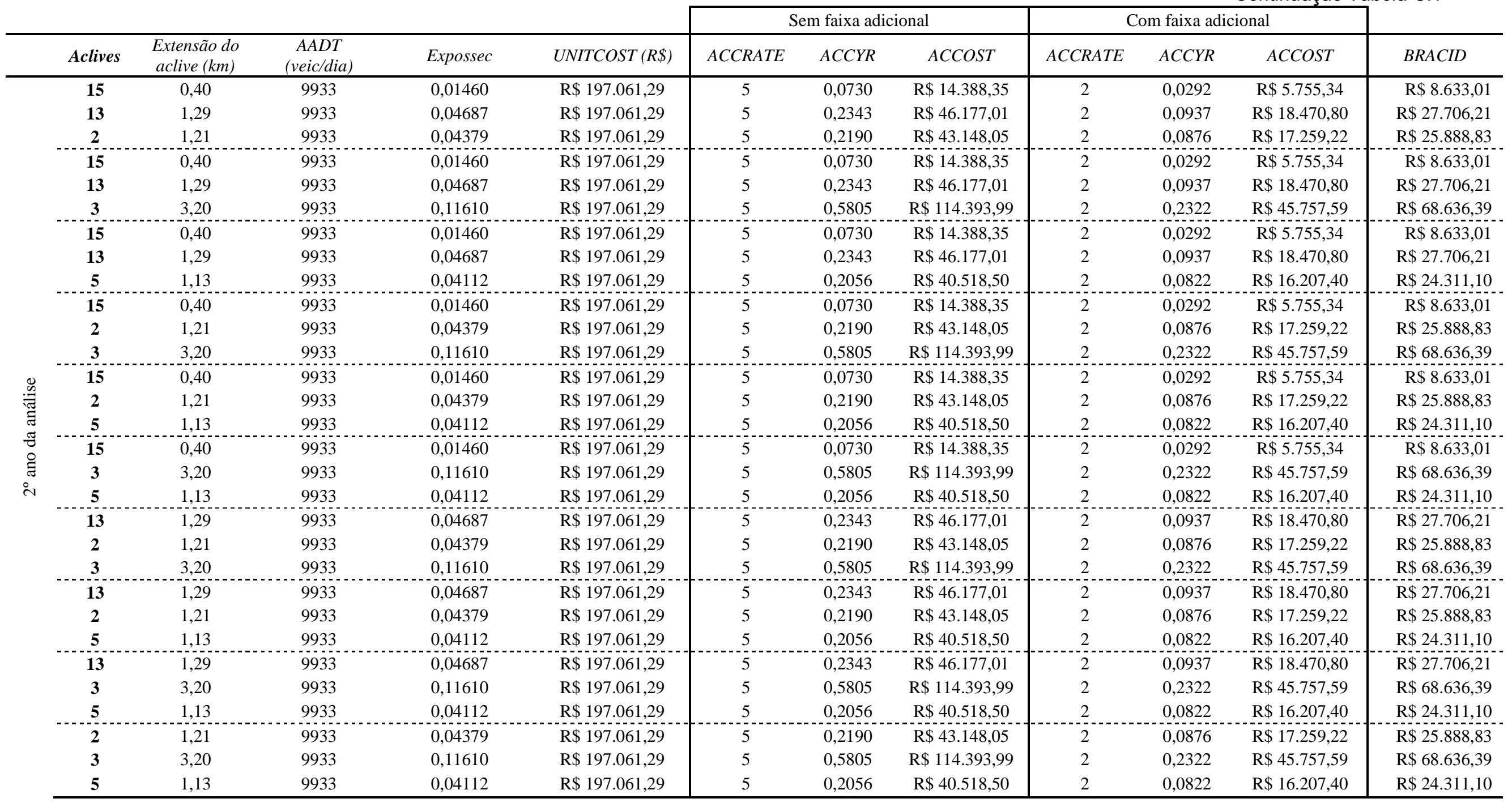


Continuação Tabela C.1

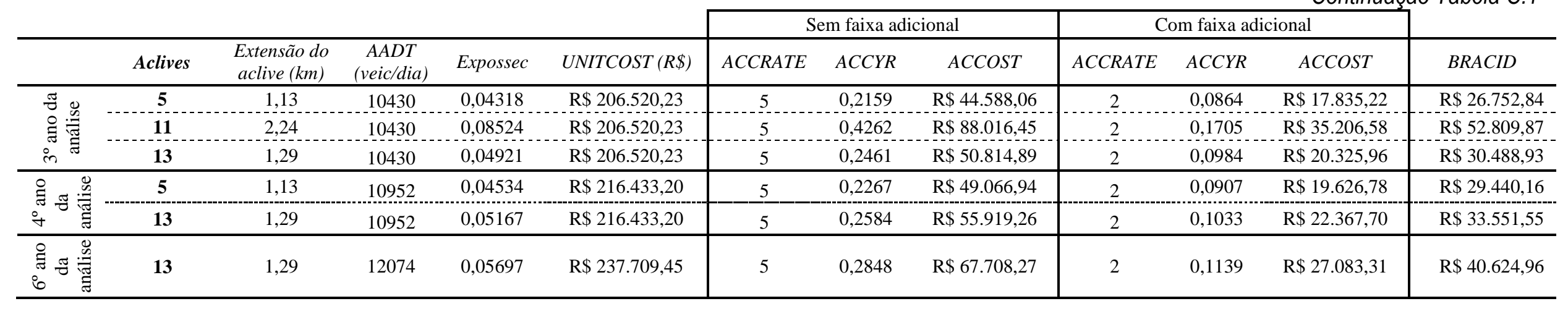


Tabela C.2 - Composição dos benefícios das reduções de acidentes ( $2^{\circ}$ modo)

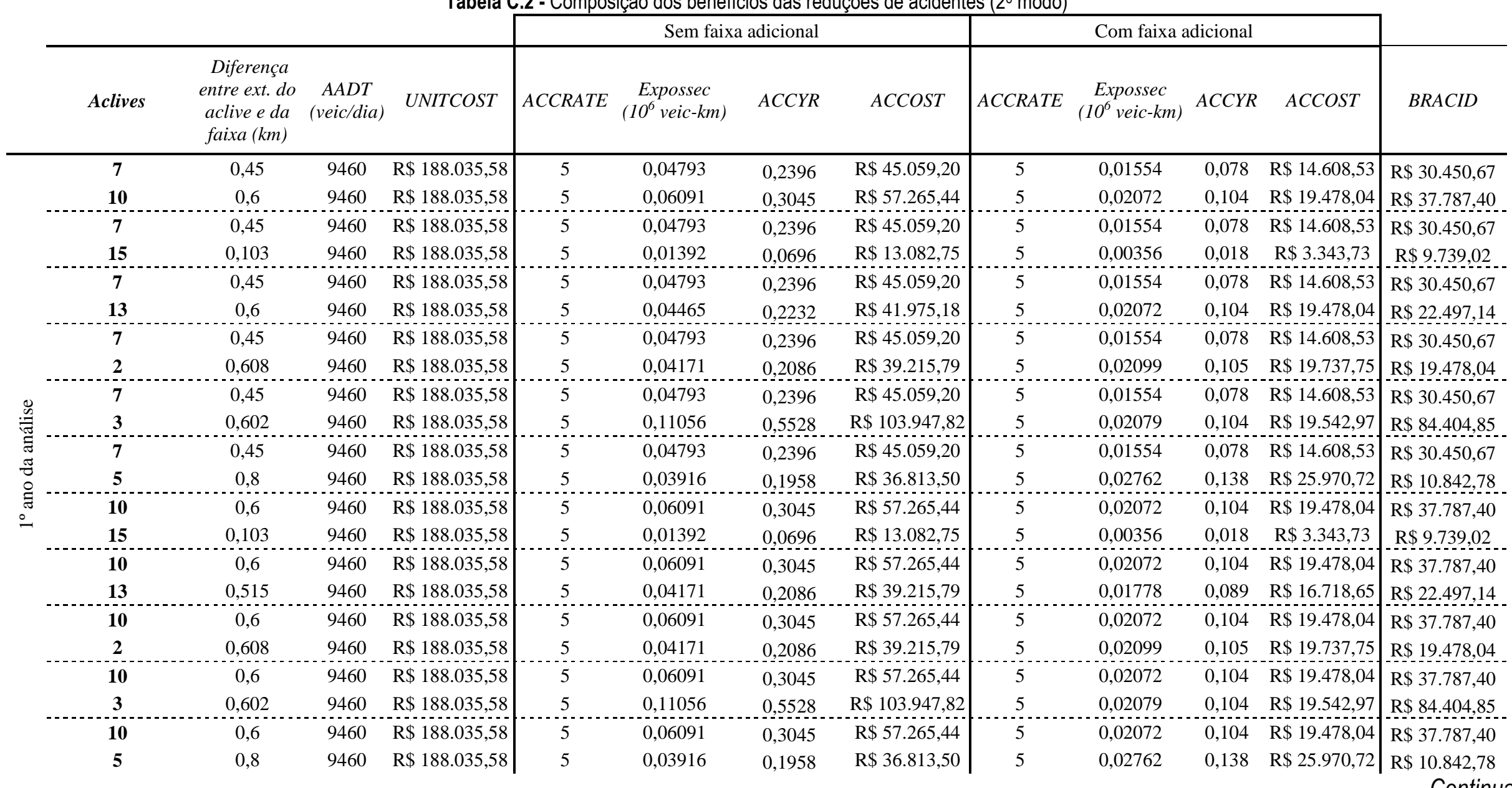

Continua 
Continuação Tabela C.2

\begin{tabular}{|c|c|c|c|c|c|c|c|c|c|c|c|c|}
\hline \multirow[b]{2}{*}{ Aclives } & \multirow[b]{2}{*}{$\begin{array}{c}\text { Diferença entre } \\
\text { ext. do aclive e } \\
\text { da faixa }(\mathrm{km})\end{array}$} & \multirow[b]{2}{*}{$\begin{array}{c}A A D T \\
\text { (veic/dia) }\end{array}$} & \multirow[b]{2}{*}{ UNITCOST } & \multicolumn{4}{|c|}{ Sem faixa adicional } & \multicolumn{4}{|c|}{ Com faixa adicional } & \multirow[b]{2}{*}{$B R A C I D$} \\
\hline & & & & ACCRATE & $\begin{array}{c}\text { Expossec } \\
\left(10^{6} \text { veic-km }\right)\end{array}$ & $A C C Y R$ & $A C C O S T$ & ACCRATE & $\begin{array}{c}\text { Expossec } \\
\left(10^{6} \text { veic-km }\right)\end{array}$ & $A C C Y R$ & $A C C O S T$ & \\
\hline 15 & 0,103 & 9933 & $\mathrm{R} \$ 197.061,29$ & 5 & 0,01461 & 0,0731 & $\mathrm{R} \$ 14.396,26$ & 5 & 0,00373 & 0,019 & $\mathrm{R} \$ 3.679,44$ & $\mathrm{R} \$ 10.716,82$ \\
\hline 13 & 0,515 & 9933 & $\mathrm{R} \$ 197.061,29$ & 5 & 0,04380 & 0,2190 & $\mathrm{R} \$ 43.153,06$ & 5 & 0,01867 & 0,093 & $\mathrm{R} \$ 18.397,21$ & $\mathrm{R} \$ 24.755,85$ \\
\hline 2 & 0,608 & 9933 & $\mathrm{R} \$ 197.061,29$ & 5 & 0,04380 & 0,2190 & $\mathrm{R} \$ 43.153,06$ & 5 & 0,02204 & 0,110 & $\mathrm{R} \$ 21.719,42$ & $\mathrm{R} \$ 21.433,64$ \\
\hline 15 & 0,103 & 9933 & $\mathrm{R} \$ 197.061,29$ & 5 & 0,01461 & 0,0731 & $\mathrm{R} \$ 14.396,26$ & 5 & 0,00373 & 0,019 & $\mathrm{R} \$ 3.679,44$ & $\mathrm{R} \$ 10.716,82$ \\
\hline 13 & 0,515 & 9933 & $\mathrm{R} \$ 197.061,29$ & 5 & 0,04380 & 0,2190 & $\mathrm{R} \$ 43.153,06$ & 5 & 0,01867 & 0,093 & $\mathrm{R} \$ 18.397,21$ & $\mathrm{R} \$ 24.755,85$ \\
\hline 3 & 0,602 & 9933 & $\mathrm{R} \$ 197.061,29$ & 5 & 0,11609 & 0,5804 & $\mathrm{R} \$ 114.384,18$ & 5 & 0,02183 & 0,109 & $\mathrm{R} \$ 21.505,08$ & $\mathrm{R} \$ 92.879,09$ \\
\hline 15 & 0,103 & 9933 & $\mathrm{R} \$ 197.061,29$ & 5 & 0,01461 & 0,0731 & $\mathrm{R} \$ 14.396,26$ & 5 & 0,00373 & 0,019 & $\mathrm{R} \$ 3.679,44$ & $\mathrm{R} \$ 10.716,82$ \\
\hline 13 & 0,515 & 9933 & $\mathrm{R} \$ 197.061,29$ & 5 & 0,04380 & 0,2190 & $\mathrm{R} \$ 43.153,06$ & 5 & 0,01867 & 0,093 & $\mathrm{R} \$ 18.397,21$ & $\mathrm{R} \$ 24.755,85$ \\
\hline 5 & 0,8 & 9933 & $\mathrm{R} \$ 197.061,29$ & 5 & 0,04111 & 0,2056 & $\mathrm{R} \$ 40.509,57$ & 5 & 0,02900 & 0,145 & $\mathrm{R} \$ 28.578,18$ & $\mathrm{R} \$ 11.931,39$ \\
\hline 15 & 0,103 & 9933 & $\mathrm{R} \$ 197.061,29$ & 5 & 0,01461 & 0,0731 & $\mathrm{R} \$ 14.396,26$ & 5 & 0,00373 & 0,019 & $\mathrm{R} \$ 3.679,44$ & $\mathrm{R} \$ 10.716,82$ \\
\hline 2 & 0,608 & 9933 & $\mathrm{R} \$ 197.061,29$ & 5 & 0,04380 & 0,2190 & $\mathrm{R} \$ 43.153,06$ & 5 & 0,02204 & 0,110 & $\mathrm{R} \$ 21.719,42$ & $\mathrm{R} \$ 21.433,64$ \\
\hline 3 & 0,602 & 9933 & $\mathrm{R} \$ 197.061,29$ & 5 & 0,11609 & 0,5804 & $\mathrm{R} \$ 114.384,18$ & 5 & 0,02183 & 0,109 & $\mathrm{R} \$ 21.505,08$ & $\mathrm{R} \$ 92.879,09$ \\
\hline 15 & 0,103 & 9933 & $\mathrm{R} \$ 197.061,29$ & 5 & 0,01461 & 0,0731 & $\mathrm{R} \$ 14.396,26$ & 5 & 0,00373 & 0,019 & $\mathrm{R} \$ 3.679,44$ & $\mathrm{R} \$ 10.716,82$ \\
\hline 2 & 0,608 & 9933 & $\mathrm{R} \$ 197.061,29$ & 5 & 0,04380 & 0,2190 & $\mathrm{R} \$ 43.153,06$ & 5 & 0,02204 & 0,110 & $\mathrm{R} \$ 21.719,42$ & $\mathrm{R} \$ 21.433,64$ \\
\hline 5 & 0,8 & 9933 & $\mathrm{R} \$ 197.061,29$ & 5 & 0,04111 & 0,2056 & $\mathrm{R} \$ 40.509,57$ & 5 & 0,02900 & 0,145 & $\mathrm{R} \$ 28.578,18$ & $\mathrm{R} \$ 11.931,39$ \\
\hline 15 & 0,103 & 9933 & $\mathrm{R} \$ 197.061,29$ & 5 & 0,01461 & 0,0731 & $\mathrm{R} \$ 14.396,26$ & 5 & 0,00373 & 0,019 & $\mathrm{R} \$ 3.679,44$ & $\mathrm{R} \$ 10.716,82$ \\
\hline 3 & 0,602 & 9933 & $\mathrm{R} \$ 197.061,29$ & 5 & 0,11609 & 0,5804 & $\mathrm{R} \$ 114.384,18$ & 5 & 0,02183 & 0,109 & $\mathrm{R} \$ 21.505,08$ & $\mathrm{R} \$ 92.879,09$ \\
\hline 5 & 0,8 & 9933 & $\mathrm{R} \$ 197.061,29$ & 5 & 0,04111 & 0,2056 & $\mathrm{R} \$ 40.509,57$ & 5 & 0,02900 & 0,145 & $\mathrm{R} \$ 28.578,18$ & $\mathrm{R} \$ 11.931,39$ \\
\hline 13 & 0,515 & 9933 & $\mathrm{R} \$ 197.061,29$ & 5 & 0,04380 & 0,2190 & $\mathrm{R} \$ 43.153,06$ & 5 & 0,01867 & 0,093 & $\mathrm{R} \$ 18.397,21$ & $\mathrm{R} \$ 24.755,85$ \\
\hline 2 & 0,608 & 9933 & $\mathrm{R} \$ 197.061,29$ & 5 & 0,04380 & 0,2190 & $\mathrm{R} \$ 43.153,06$ & 5 & 0,02204 & 0,110 & $\mathrm{R} \$ 21.719,42$ & $\mathrm{R} \$ 21.433,64$ \\
\hline 3 & 0,602 & 9933 & $\mathrm{R} \$ 197.061,29$ & 5 & 0,11609 & 0,5804 & $\mathrm{R} \$ 114.384,18$ & 5 & 0,02183 & 0,109 & $\mathrm{R} \$ 21.505,08$ & $\mathrm{R} \$ 92.879,09$ \\
\hline 13 & 0,515 & 9933 & $\mathrm{R} \$ 197.061,29$ & 5 & 0,04380 & 0,2190 & $\mathrm{R} \$ 43.153,06$ & 5 & 0,01867 & 0,093 & $\mathrm{R} \$ 18.397,21$ & $\mathrm{R} \$ 24.755,85$ \\
\hline 2 & 0,608 & 9933 & $\mathrm{R} \$ 197.061,29$ & 5 & 0,04380 & 0,2190 & $\mathrm{R} \$ 43.153,06$ & 5 & 0,02204 & 0,110 & $\mathrm{R} \$ 21.719,42$ & $\mathrm{R} \$ 21.433,64$ \\
\hline 5 & 0,8 & 9933 & $\mathrm{R} \$ 197.061,29$ & 5 & 0,04111 & 0,2056 & $\mathrm{R} \$ 40.509,57$ & 5 & 0,02900 & 0,145 & $\mathrm{R} \$ 28.578,18$ & $\mathrm{R} \$ 11.931,39$ \\
\hline 13 & 0,515 & 9933 & $\mathrm{R} \$ 197.061,29$ & 5 & 0,04380 & 0,2190 & $\mathrm{R} \$ 43.153,06$ & 5 & 0,01867 & 0,093 & $\mathrm{R} \$ 18.397,21$ & $\mathrm{R} \$ 24.755,85$ \\
\hline 3 & 0,602 & 9933 & $\mathrm{R} \$ 197.061,29$ & 5 & 0,11609 & 0,5804 & $\mathrm{R} \$ 114.384,18$ & 5 & 0,02183 & 0,109 & $\mathrm{R} \$ 21.505,08$ & $\mathrm{R} \$ 92.879,09$ \\
\hline 5 & 0,8 & 9933 & $\mathrm{R} \$ 197.061,29$ & 5 & 0,04111 & 0,2056 & $\mathrm{R} \$ 40.509,57$ & 5 & 0,02900 & 0,145 & $\mathrm{R} \$ 28.578,18$ & $\mathrm{R} \$ 11.931,39$ \\
\hline 2 & 0,608 & 9933 & $\mathrm{R} \$ 197.061,29$ & 5 & 0,04380 & 0,2190 & $\mathrm{R} \$ 43.153,06$ & 5 & 0,02204 & 0,110 & $\mathrm{R} \$ 21.719,42$ & $\mathrm{R} \$ 21.433,64$ \\
\hline 3 & 0,602 & 9933 & $\mathrm{R} \$ 197.061,29$ & 5 & 0,11609 & 0,5804 & $\mathrm{R} \$ 114.384,18$ & 5 & 0,02183 & 0,109 & $\mathrm{R} \$ 21.505,08$ & $\mathrm{R} \$ 92.879,09$ \\
\hline 5 & 0,8 & 9933 & $\mathrm{R} \$ 197.061,29$ & 5 & 0,04111 & 0,2056 & $\mathrm{R} \$ 40.509,57$ & 5 & 0,02900 & 0,145 & $\mathrm{R} \$ 28.578,18$ & $\mathrm{R} \$ 11.931,39$ \\
\hline
\end{tabular}


Continuação Tabela C.2

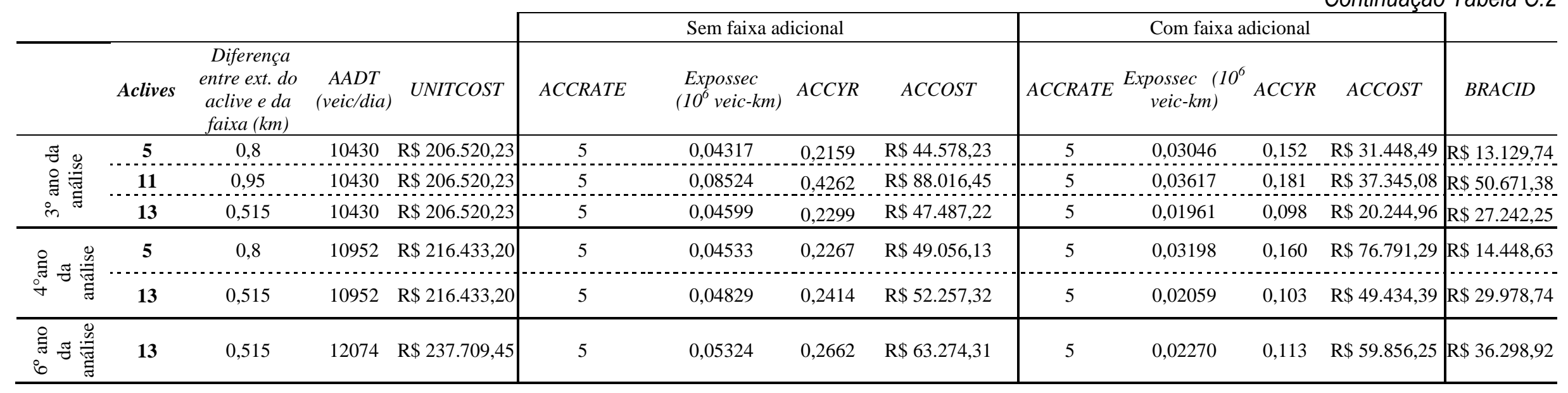




\section{ANEXO A - Números aleatórios usados na calibração do TWOPAS}

Tabela BB.1 - Conjunto de números aleatórios usados na calibração do TWOPAS

\begin{tabular}{c|c|c|c|c|c}
\hline Conjunto & NSRAND(1) & NSRAND(2) & NSRAND(3) & NSRAND(4) & NSRAND(5) \\
\hline 1 & 44601094 & 49522149 & 11209214 & 34264987 & 56444515 \\
2 & 41372736 & 30989528 & 87502611 & 25542192 & 15864685 \\
3 & 99137887 & 20832667 & 99359493 & 22004137 & 50781296 \\
4 & 51395101 & 15253062 & 60506182 & 77556215 & 75912913 \\
5 & 60971790 & 51798426 & 37752873 & 89837079 & 48319730 \\
\hline
\end{tabular}

- NSRAND(1) é a semente da sequência de números pseudo-aleatórios usadas para gerar o headway e o tipo de veículo que entra na corrente de tráfego da direção 1, isto é, no sentido crescente do marco quilométrico dentro do TWOPAS;

- NSRAND(2) tem a mesma função de $\operatorname{NSRAND(1);~porém,~na~direção~2;~}$

- NSRAND(3) é a semente de números pseudoaleatórios que seleciona as velocidades desejadas dos veículos na entrada da direção 1 e NSRAND(5), para a direção 2;

- NSRAND(4) é usada para gerar as velocidades desejadas dos veículos durante o período de warm-up. Subsequentemente, no período normal de simulação, essa mesma semente de números pseudo-aleatórios é usada nas decisões de iniciativa e execução das manobras de ultrapassagens. Cabe esclarecer que os números são pseudoaleatórios porque, apesar dos números serem gerados aleatoriamente, eles seguem a mesma sequência para cada semente de números pseudoaleatórios. Ou seja, os headways, tipo de veículo e velocidades desejadas são as mesmas para todos os cromossomos testados durante a execução do AG. 


\section{ANEXO B - Custos operacionais fixo e variável}

Tabela AA.1 - Composição de custos operacionais para carros populares (Economia e Transporte, 2007)

\begin{tabular}{|c|c|c|c|c|c|c|}
\hline & \multirow{2}{*}{ Custos } & \multicolumn{5}{|c|}{ Veículos } \\
\hline & & Gol City 1.0 & Mille Fire Flex (1.0) & Fiesta Street 1.0 & Clio Sedan Auth. 16V & Média \\
\hline \multirow{5}{*}{ 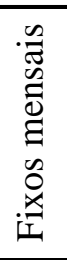 } & Depreciação & $\mathrm{R} \$ 129,14$ & $\mathrm{R} \$ 127,74$ & $\mathrm{R} \$ 155,75$ & $\mathrm{R} \$ 187,42$ & $\mathrm{R} \$ 150,01$ \\
\hline & Remuneração do capital & $\mathrm{R} \$ 71,83$ & $\mathrm{R} \$ 60,39$ & $\mathrm{R} \$ 74,35$ & $\mathrm{R} \$ 90,33$ & $\mathrm{R} \$ 74,23$ \\
\hline & Licenciamento + seguro + IPVA & $\mathrm{R} \$ 50,97$ & $\mathrm{R} \$ 42,42$ & $\mathrm{R} \$ 52,26$ & $\mathrm{R} \$ 63,53$ & $\mathrm{R} \$ 52,30$ \\
\hline & Seguro do casco & $\mathrm{R} \$ 73,62$ & $\mathrm{R} \$ 72,58$ & $\mathrm{R} \$ 67,36$ & $\mathrm{R} \$ 88,94$ & $\mathrm{R} \$ 75,63$ \\
\hline & & & & & Total & $\mathrm{R} \$ 352,16$ \\
\hline \multirow{6}{*}{ 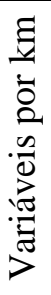 } & Manutenção & $\mathrm{R} \$ 0,0273$ & $\mathrm{R} \$ 0,0240$ & $\mathrm{R} \$ 0,0300$ & $\mathrm{R} \$ 0,0365$ & $\mathrm{R} \$ 0,0295$ \\
\hline & Pneus, câmaras e recapagens & $\mathrm{R} \$ 0,0065$ & $\mathrm{R} \$ 0,0068$ & $\mathrm{R} \$ 0,0054$ & $\mathrm{R} \$ 0,0054$ & $\mathrm{R} \$ 0,0060$ \\
\hline & Combustível & $\mathrm{R} \$ 0,1377$ & $\mathrm{R} \$ 0,1408$ & $\mathrm{R} \$ 0,1482$ & $\mathrm{R} \$ 0,1282$ & $\mathrm{R} \$ 0,1387$ \\
\hline & Óleo de carter & $\mathrm{R} \$ 0,0016$ & $\mathrm{R} \$ 0,0031$ & $\mathrm{R} \$ 0,0016$ & $\mathrm{R} \$ 0,0016$ & $\mathrm{R} \$ 0,0020$ \\
\hline & Lavagens e graxas & $\mathrm{R} \$ 0,0200$ & $\mathrm{R} \$ 0,0200$ & $\mathrm{R} \$ 0,0200$ & $\mathrm{R} \$ 0,0200$ & $\mathrm{R} \$ 0,0200$ \\
\hline & & & & & \multicolumn{2}{|r|}{ R\$ 0.1962} \\
\hline
\end{tabular}

Tabela AA.2 - Composição de custos operacionais para ônibus rodoviários (Economia e Transporte, 2007)

\begin{tabular}{|c|c|c|c|c|c|c|}
\hline & \multirow{2}{*}{ Custos } & \multicolumn{5}{|c|}{ Veículos } \\
\hline & & Micro Piccolo LO 915 & Paradiso OF $1722 \mathrm{M}$ & Alpha 17.230 EOD & Paradiso 1800 DD B-12R & Média \\
\hline \multirow{6}{*}{ 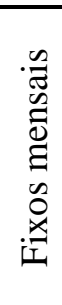 } & Depreciação & $\mathrm{R} \$ 1.255,83$ & $\mathrm{R} \$ 2.091,01$ & $\mathrm{R} \$ 2.025,83$ & $\mathrm{R} \$ 5.627,25$ & $\mathrm{R} \$ 2.749,98$ \\
\hline & Remuneração do capital & $\mathrm{R} \$ 839,13$ & $\mathrm{R} \$ 1.162,35$ & $\mathrm{R} \$ 1.126,13$ & $\mathrm{R} \$ 2.038,16$ & $\mathrm{R} \$ 1.291,44$ \\
\hline & Licenciamento + seguro + IPVA & $\mathrm{R} \$ 200,36$ & $\mathrm{R} \$ 274,91$ & $\mathrm{R} \$ 266,34$ & $\mathrm{R} \$ 467,34$ & $\mathrm{R} \$ 302,24$ \\
\hline & Salário do motorista & $\mathrm{R} \$ 1.411,27$ & $\mathrm{R} \$ 1.979,89$ & $\mathrm{R} \$ 1.979,89$ & $\mathrm{R} \$ 1.979,89$ & $\mathrm{R} \$ 1.837,74$ \\
\hline & Seguro do casco & $\mathrm{R} \$ 534,30$ & $\mathrm{R} \$ 549,81$ & $\mathrm{R} \$ 532,68$ & $\mathrm{R} \$ 934,67$ & $\mathrm{R} \$ 637,86$ \\
\hline & & & & & Total & $\mathrm{R} \$ 6.819,26$ \\
\hline \multirow{6}{*}{ 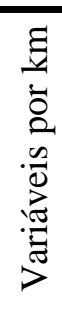 } & Manutenção & $\mathrm{R} \$ 0,36$ & $\bar{R} \$ 0,17$ & $\bar{R} \$ 0,18$ & $\mathrm{R} \$ 0,27$ & $\mathrm{R} \$ 0,24$ \\
\hline & Pneus, câmaras e recapagens & $\mathrm{R} \$ 0,03$ & $\mathrm{R} \$ 0,08$ & $\mathrm{R} \$ 0,05$ & $\mathrm{R} \$ 0,07$ & $\mathrm{R} \$ 0,06$ \\
\hline & Combustível & $\mathrm{R} \$ 0,32$ & $\mathrm{R} \$ 0,75$ & $\mathrm{R} \$ 0,70$ & $\mathrm{R} \$ 1,04$ & $\mathrm{R} \$ 0,70$ \\
\hline & Óleo de carter & $\mathrm{R} \$ 0,01$ & $\mathrm{R} \$ 0,01$ & $\mathrm{R} \$ 0,01$ & $\mathrm{R} \$ 0,02$ & $\mathrm{R} \$ 0,01$ \\
\hline & Lavagens e graxas & $\mathrm{R} \$ 0,10$ & $\mathrm{R} \$ 0,12$ & $\mathrm{R} \$ 0,10$ & $\mathrm{R} \$ 0,12$ & $\mathrm{R} \$ 0,11$ \\
\hline & & & & & Total & $\mathrm{R} \$ 1,12$ \\
\hline
\end{tabular}


Tabela AA.3 - Composição de custos operacionais para caminhões semi-pesado (Economia e Transporte, 2007)

\begin{tabular}{|c|c|c|c|c|c|c|c|}
\hline & \multirow{2}{*}{ Custos } & \multicolumn{6}{|c|}{ Veículos } \\
\hline & & 17-220 BAÚ 3E & Cargo $1722 \mathrm{CS}$ & 1725 Atego BAÚ 3E & 1718 Atego Baú & 1725 Atego CS 3E & Média \\
\hline \multirow{6}{*}{ 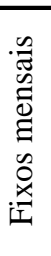 } & Depreciação & $\mathrm{R} \$ 1.161,92$ & $\mathrm{R} \$ 893,74$ & $\mathrm{R} \$ 1.026,27$ & $\mathrm{R} \$ 1.163,84$ & $\mathrm{R} \$ 986,82$ & $\mathrm{R} \$ 1.046,52$ \\
\hline & Remuneração do capital & $\mathrm{R} \$ 783,81$ & $\mathrm{R} \$ 693,73$ & $\mathrm{R} \$ 817,55$ & $\mathrm{R} \$ 728,95$ & $\mathrm{R} \$ 773,74$ & $\mathrm{R} \$ 759,56$ \\
\hline & Licenciamento + seguro + IPVA & $\mathrm{R} \$ 271,48$ & $\mathrm{R} \$ 325,73$ & $\mathrm{R} \$ 487,23$ & $\mathrm{R} \$ 258,60$ & $\mathrm{R} \$ 280,32$ & $\mathrm{R} \$ 324,67$ \\
\hline & Salário do motorista & $\mathrm{R} \$ 1.535,58$ & $\mathrm{R} \$ 1.535,58$ & $\mathrm{R} \$ 1.535,58$ & $\mathrm{R} \$ 1.535,58$ & $\mathrm{R} \$ 1.535,58$ & $\mathrm{R} \$ 1.535,58$ \\
\hline & Seguro do casco & $\mathrm{R} \$ 699,58$ & $\mathrm{R} \$ 455,85$ & $\mathrm{R} \$ 802,64$ & $\mathrm{R} \$ 567,81$ & $\mathrm{R} \$ 575,26$ & $\mathrm{R} \$ 620,23$ \\
\hline & & & & & & Total & $\mathrm{R} \$ 4.286,56$ \\
\hline \multirow{6}{*}{ 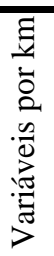 } & Manutenção & $\mathrm{R} \$ 0,17$ & $\mathrm{R} \$ 0,14$ & $\mathrm{R} \$ 0,17$ & $\mathrm{R} \$ 0,18$ & $\mathrm{R} \$ 0,22$ & $\mathrm{R} \$ 0,173$ \\
\hline & Pneus, câmaras e recapagens & $\mathrm{R} \$ 0,10$ & $\mathrm{R} \$ 0,06$ & $\mathrm{R} \$ 0,09$ & $\mathrm{R} \$ 0,09$ & $\mathrm{R} \$ 0,10$ & $\mathrm{R} \$ 0,086$ \\
\hline & Combustível & $\mathrm{R} \$ 0,49$ & $\mathrm{R} \$ 0,47$ & $\mathrm{R} \$ 0,49$ & $\mathrm{R} \$ 0,48$ & $\mathrm{R} \$ 0,50$ & $\mathrm{R} \$ 0,485$ \\
\hline & Óleo de carter & $\mathrm{R} \$ 0,01$ & $\mathrm{R} \$ 0,01$ & $\mathrm{R} \$ 0,01$ & $\mathrm{R} \$ 0,01$ & $\mathrm{R} \$ 0,01$ & $\mathrm{R} \$ 0,007$ \\
\hline & Lavagens e graxas & $\mathrm{R} \$ 0,06$ & $\mathrm{R} \$ 0,05$ & $\mathrm{R} \$ 0,07$ & $\mathrm{R} \$ 0,07$ & $\mathrm{R} \$ 0,08$ & $\mathrm{R} \$ 0,063$ \\
\hline & & & & & & Total & $\mathrm{R} \$ 0,8144$ \\
\hline
\end{tabular}

